\title{
Die
}

\section{Betricbsregulierung in den}

\section{Preussischen Staatsforsten}

$10 \pi$

\section{Michaelis}

Forstmeister und Lehrer au dex Forstakademie münden

neudamm 1906 Verlag von J. Neumann

WWVERSTY

of

TORON10

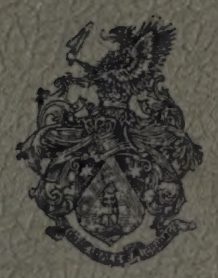

SD 553 M43 1906 


\section{Michaeliz \\ Die Betriebsregulierung in ben Preußiłachen Etaatzionjten}

\section{LIBRARY}

UNIVERSITY OF TORONTO 
- 


\section{Die \\ Betriebsregulierung in Den Preupijchen Gtaatiforiten}

nebit

einigen aus rein praftijchen Rüc(fichten fich) ergebenden

Borjchlägen zu ihrer Beiterentwicfelung

und einem 2lnbang tiber

einfache Putsanwenbungen aus ber forjtlichen

3uwachstunde

Rurz zufammengeftellt von

\section{Mridðaeliż}

Gorftmeifter unb Rebrer an ber Gorfatabemie शainben
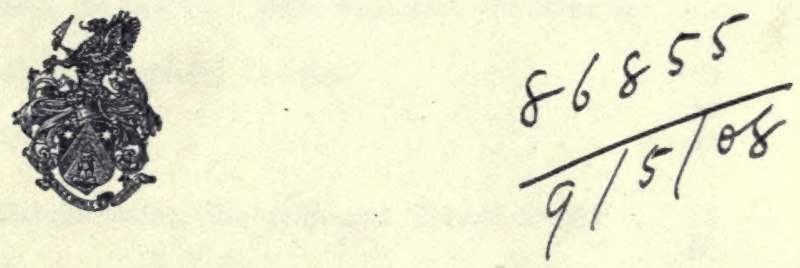

शenbamm 1906

Zerlag von 9 . Reumann

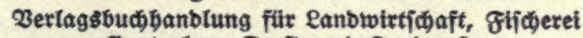

Gartenbau, Forft: und Gagbwejen 


$$
\begin{aligned}
& S D \\
& 553 \\
& M 43 \\
& 1906
\end{aligned}
$$




\section{Jnhaltż=QZerzeichnił.}

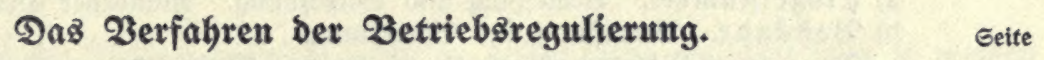

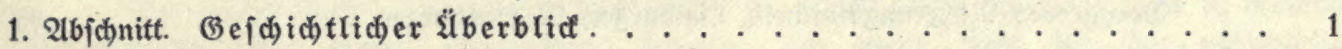

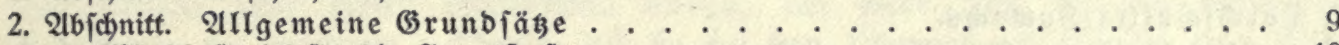

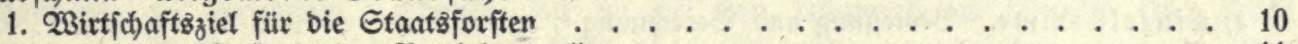

2. Inhalt und 2lufgabe Der Betriebzregulierung . . . . . . . . . . . . . 11

3. Slmtrieb. . . . . . . . . . . . . . . . . . 16

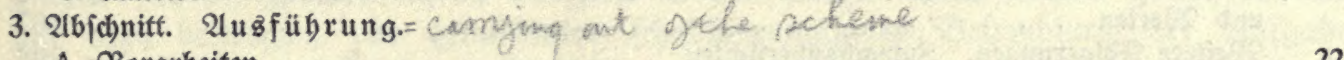

A. 3 orarbeiten . . . . . . . . . . . . . . . . 22

B. Sauptarbeiten . . . . . . . . . . . . . . . 23

I. Ffäd)enaufnahme.

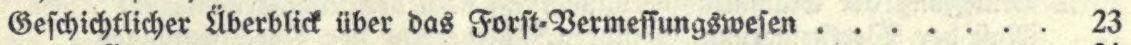

a) Grenzen . . . . . . . . . ........ 24

b) 23 irtichaftliche sinteilung . . . . . . . . . . . . 27

c) Bermeñungsiwerf.

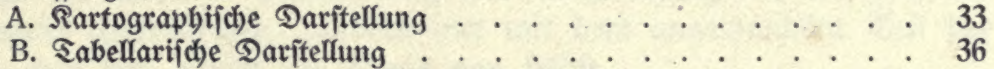

II. Bef̃andsaufnabme.

a) 2 lusführliche 3 efdidreibung . . . . . . . . . . . . . 37

b) Solzertragş-2eftimmung . . . . . . . . . . . 40

III. Betriebsplan.

a) Sodywalb.

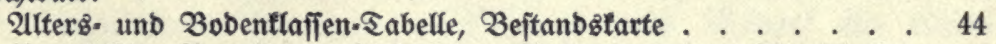

Periobifche Berteilung, Siebsfolge, Bejtandseinbeit, Wirtichaftż. farte. 44

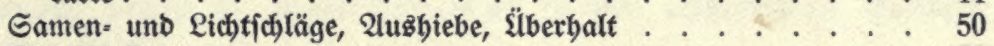

Durdfforftunggplan. . . . . . . . . . . . . . . . . 54

b) Nittel- unb Nieberwalo . . . . . . . . . . . . 54

IV. Ertrag\&bered) nung.

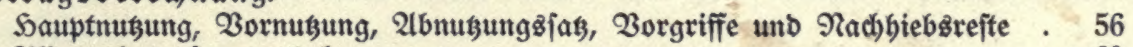

Allgemeiner Sauungsplan. . . . . . . . . . . 60

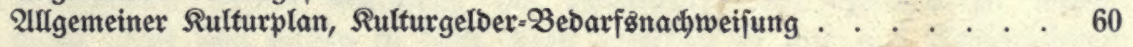

V. Darftellung bes $\mathfrak{B}$ etriebşwerfes.

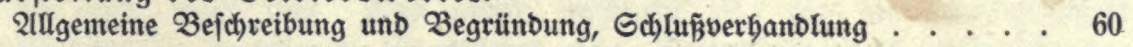

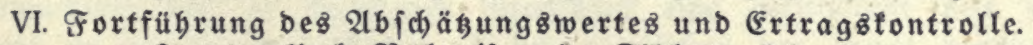

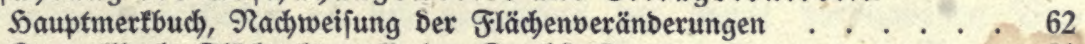

Rontrollbuch, Glächentontrolle ber Ourchforfitungen . . . . . . 64

VII. Eaxations-Revifionen. . . . . . . . . . . . 66 


\section{anbang.}

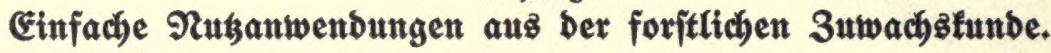

A. 2 rlgemeines

B. Laufender 3 uwad) \&.

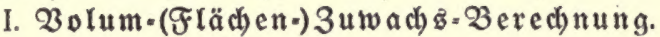

a) Einzelfämme:

I. Mefĭung am Riegenden.

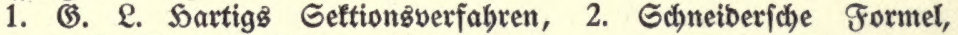

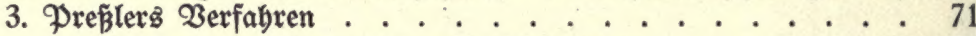

II. Neffung am Stebenben. Notwendige Berichtigungen . . . . . . . 77

b) Beftände: Borggreves Tafelmethode . . . . . . . . . . . . . . . 82

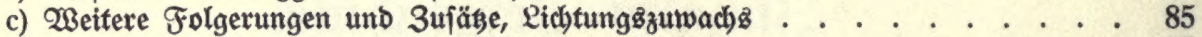

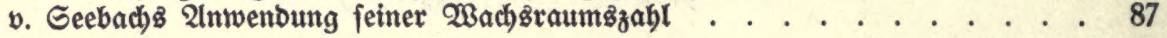

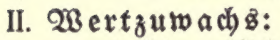

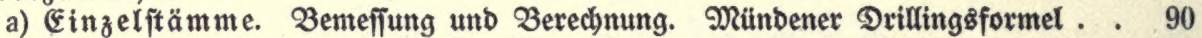

b) Beftände. Bemefîng und Bered)nung . . . . . . . . . . . . . . 93

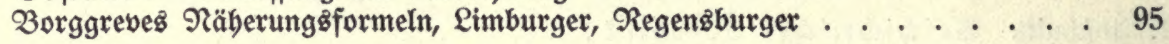

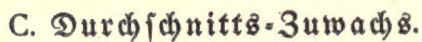

a) Ėinzelftämme. Bemefinng un๖ Bered)mung . . . . . . . . . . . . . . . 100

Borggrebes SAmtriebsformel . . . . . . . . . . . . . . . . . . . . . 101

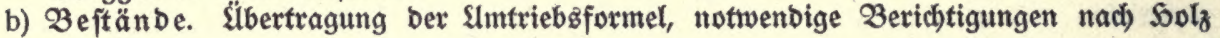

unb $\mathfrak{B}$ erten . . . . . . . . . . . . . . . . . . . . . . . . . . 102

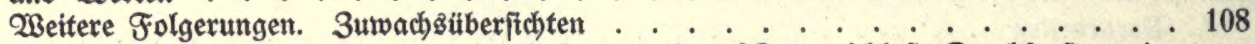

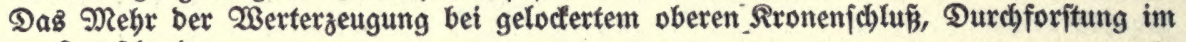

Serrjhenben . . . . . . . . . . . . . . . . . 110

Bemefing Der Gtammzahlverminderung nach Der Wachgraums̊zahl . . . . . . . 116

Må̉ Der Wertiteigerung, Befahren, Wieberfehr ber Durdjforjtungen . . . . . . 119

Unterlagen für Śmtriebsbeftimmung . . . . . . . . . . . . . . . . 126

שertzuwacbsbilber . . . . . . . . . . . . . . . . . . . 131 


\section{Qorwort.}

Die nachjtelyenbe 3 ujammenffellung foll in erfter Qinie alż Slnterlage in meinen Borlejungen über biejen Ǧegenftand bienen, um mebr 3eit für bie mündliche

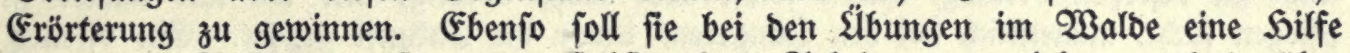

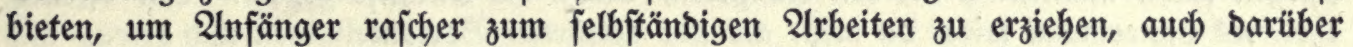

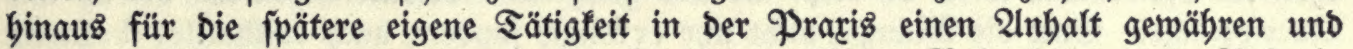
mit bazu beitragen, vor gebanfenloz fchablonenmäßiger 2 ehandlung ber 2 lufgabe ebenfo wie vor unfruchtbaren Täffteleien zu berwabren, wenn möglich aber auch zu ermiterer Betätigung auf biejem Gebiete anzuregen. Deşhalb if́t Wert barauf

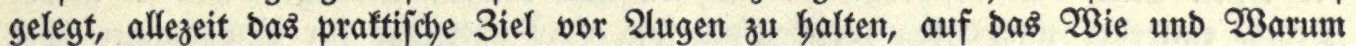
binzuweifen und wie jonft, fo auch) bier baran zut erimern, Daß́s Slnterfafien und Berfäumnis fa)merer belaf́ten, als ein Gehlgreifen in Der $\mathscr{W}$ abl ber Mittel.

Die 2lnorbnung, bie 2lrt ber Behandlung und Begrenzung beż Stoffę, ber ęs nicht mit ben alfgemein theoretifchen, fonbern nur mit bem angerwanbten Seil ber Betriebzrregulierung zu tun hat, ergibt fich Damit von felbft.

Der gejchichtliche Ṡ̉berblict ît auf bas bejchränft, was für ben gegebenen 3 weef in Frage fommt, andererfeits aber nicht wohl entbehrt werben fonnte.

Die burch beftimmte Yorjd)riften in fejte Formen gelegten 2 rbeiten find in ben betreffenben 2 bjchnitten zwar tunlich)it vollftändig, aber in thappiter Faffing

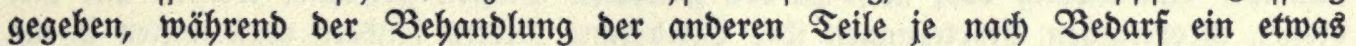
breiterer Raum zugebilligt ift, aber auch bier in ber 2 bjicd)t, furz zu fein und namentlic) WBieberbolungen befien zu vermeiben, was in Der allgemeinen Ërtragg: regelung feine Erörterung finbet.

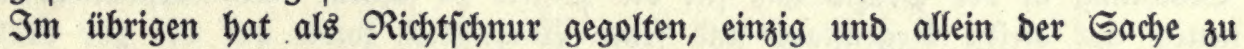
bienen, olne babei rechtz ober lint's nach) einer ber ben (Einflús beberrfchenben Ridbtungen zu fehen.

$\Im \mathfrak{m}$ Oorbergrund hatten burchweg bie Rücfficthten Der Praxis za ftehen.

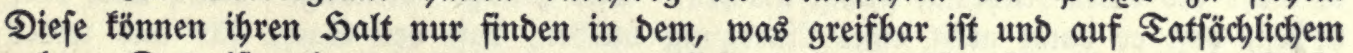

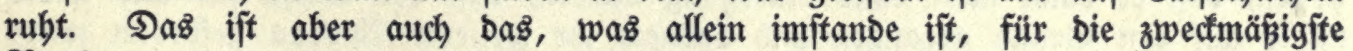
Tlusbarmachung won fo widjtigem Staatżgut eine (Grunblage von austreicjenber Sicherheit zu gerwäbren, wäbrend ę̧ fich angefichts ber bamit verbunbenen Ber- $^{2}$ antwortung ganz von félbit verbietet, irgend welche Spefulationen zum 2lużganggz=

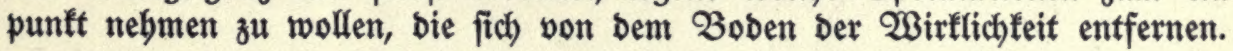


Die Wraxiiz hat ftetż gut baran getan, weniger mit ber Exrftrebung bes

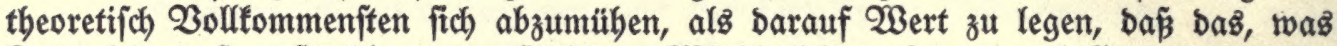

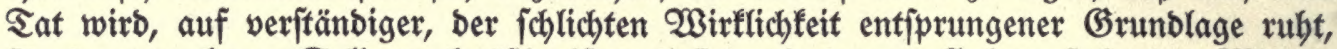

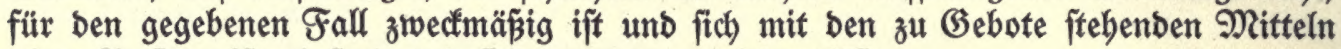
ohne $\mathfrak{S}$ mich)weife einfach und fitcher genug erreichen läp̈t.

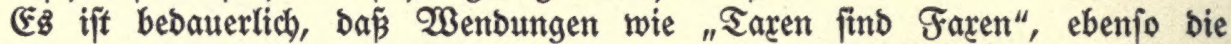
Rebenżarten von ben "papiernen Gpäßen“ u. Dergl. fo jehr baben forftlictjez Gemeingut werben fönnen. Mlögen fie entítanben fein, wie fie wollen, und nut alz finbifches Gpiel angejehen werben, fie bleiben bennoch bitterböje Worte, bie von bejonberem Bertrauten, Das weite Rreife in bie Ergebniffe folcher EElaborate jegten,

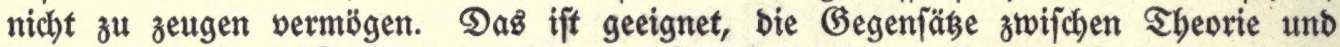
Praxis in unjerem Fach noch mebr zu verjchärfen, wäbrent faum auf einem anberen Gebiet inre ślberbrüctung erwünchter if́t und mebr Segen für Das Ganze erboffen

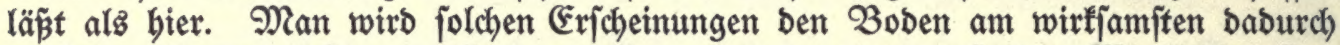

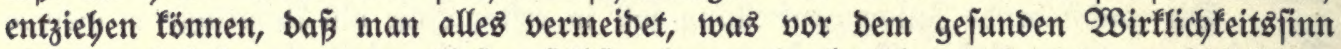
nicht zu befteben vermag, biejen felbjt aber mebr betätigt und wo nur immer zu pflegen jucht, namentlich bei Den Süngeren, Denen bie 3utunft gebört. Ein offenes,

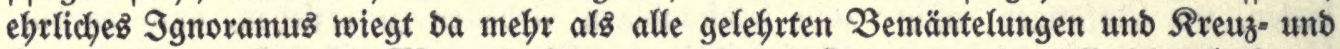
Queriprünge. Sind bie Mängel nicht mur erfannt, jonbern auch rüdthaltlos bef́annt, fo ift Damit ber erfte und einer ber widhtigften Schritte vorwärtz getan.

Der 2nbang bient im wejentlichen Der teilweijen CErgänzung unb Begrünoung

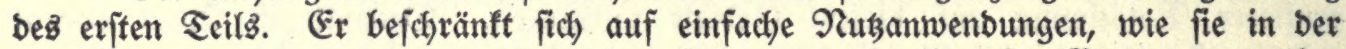
Prariz entweber unmittelbar verwertbar fins ober mittelbar für Exrwägungen über

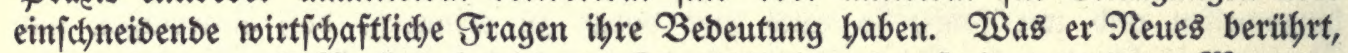
möchte ich mux als Berjuch bezeichnen, fich auch einmal auf einem anberen $\mathscr{W}$ ege an bie Gache Geranzufüblen. Zu einem nicht geringen Teile bat fich Dabei gerabe auf ben Ergebniffen von $\mathfrak{A}$ rbeiten $\mathfrak{M}$ ünbener Qebrer wie Gdüler weiterbauen laffen. Wenn bas bamit (Erreichte auch ben Gegenftand noch längft nicht zu erjechäpfen

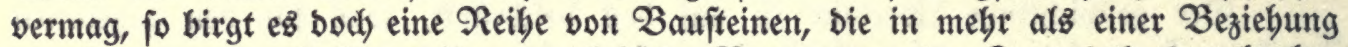

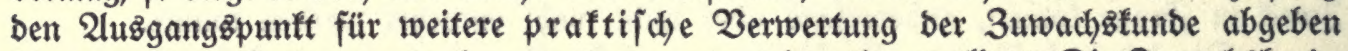
fönnen. Darauf aber gerabe fommt ez an, wenn wir weiter wollen. Die 3uwachsłunde und ihre Anwendung barf nicht zu ben gelebrten Dingen gerechnet werben und mit blopen theoretijchen Errörterungen ihre Ërlebigung finben, fonbern mup mitten in bie Praçis bineingetragen werben. Gerabe fie ift nach ibrer weitgebenden praftijchen Bebeutung mehr alz mancher andere $\mathscr{W}$ iffengzzweig bazu angetan, eine ernftere

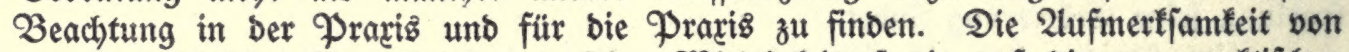
neuem auf biejen Gegenftand und feine Bithtigfeit, forwie auf bie zur praftifchen Nubbarmachung als gangbar fich erweijenben $\mathfrak{B}$ ege binzulenfen, war ber Sauptzwed

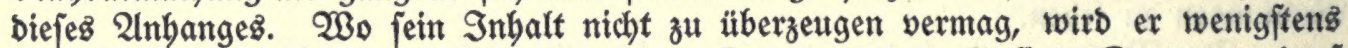
in mebr âz einer Richtung ftubig macben. Das genügt vorläufig. Denn man barf boffen, baß́ er bann nicht obne Inregung bleiben, Dä ber Eache für und wiber näber auf ben Grund gegangen und baburd ibr weiterer 2 lußbau geförbert wirb.

Soemeln b. Sann.= Mänden 1906. 
Daz Berfahren Der
Betriebsregulierung 



\section{Eriter 2 bid (bejhichtlicher s̈lberblicf.}

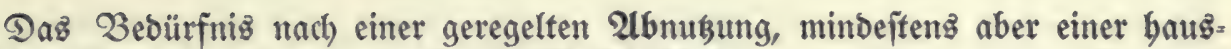

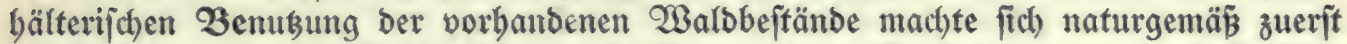

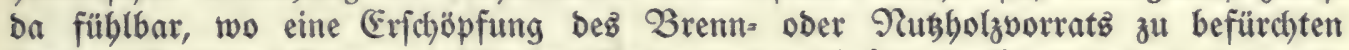
ftanb, aljo in walbarmen, Dicht bebölferten und viel $\mathbf{S o l z}$ verbrauchenden ober aus= führenden Gegenden.

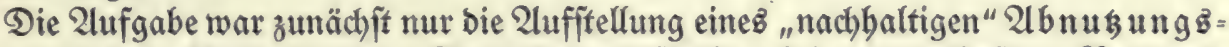

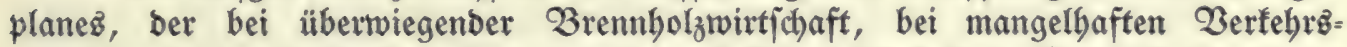
mitteln unb ber baburch aufgeztwungenen, örtlich bejchränften Bebarfabbefriebigung

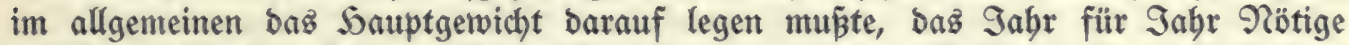
für jeben Zerbraudbsort auf örtlich eng eingegrenzten Gebieten in ausreidyenber 3utömmlichfeit zu liefern. Man rechnete Dabei obne meitgehende 3ufunftäpläne mur mit bem, wie es ber gegebene Walbzuitand Darbot.

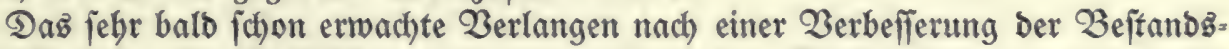

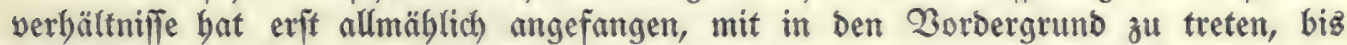
fichließslich, zuerjt pon (6. L. Sartig, bie Rücffichten auf ftete Befierung mit bem Gipfel ber Erreichung bez vorteilfafteften, jogenannten "normalen" Walbzuftandes in ben Eintichtung = uno $B$ etriebs̄plänen allem anberen vorangeftellt wurben.

3ur Gicheriftellung bes Dauernd zuläffigen und babei möglich fit gleid $=$ mäßigen jäbrlichen Solzbezugez bot von vornberein bie $\mathfrak{B a l b f l a ̈ c h e ~ b a z ~ e i n = ~}$

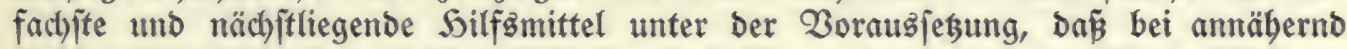

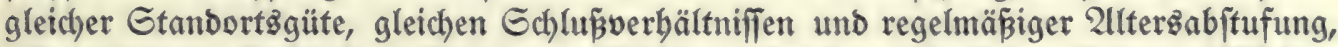

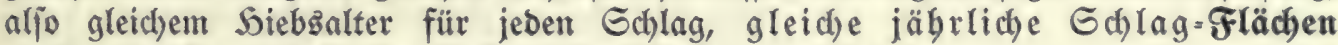
aud) annäberno gleidhe Solzerträge liefern münten.

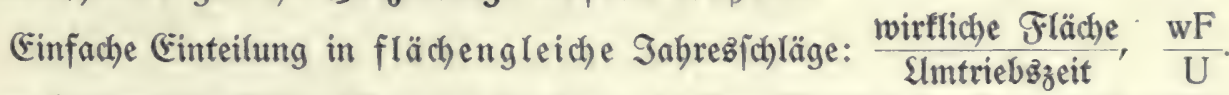
Exfurter Etadtwalo 1359. Giegener Sauberge 1447. Mähblbäujer Gtabtwald 1560. Manbfelber Waldungen 1585. Naffauifche Forftorbmung 1738. Preupijche $\mathfrak{I}_{n}=$ fruftionen unter Friebrich II. 1740, 1754, 1764.

Unter gemöbnlichen Berbältniffen war bamit für Den eriten Slmtrieb, auf ben

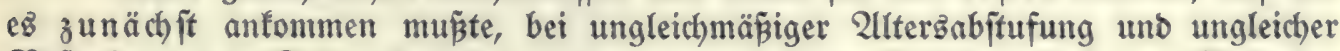
Bejtoctung bas Biel nicht obne weiterez zu erreichen, jeboch geichal) baz (Finlenfen 
um fo früber, je türzer ber Slmtrieb mar. Deşalb auch finbet fich biejez Berfabren am frübejten und allgemeiniten im Nieber $=$ und Mittelwald angewandt.

Dagegen blieb bei Berichiebenbeit ber Etandortżgüte, Der Ërtragżfähigfeit, auch für alle folgenden Slmtriebe bie Giteichmäżigfeit bez jährlichen solzbezugez

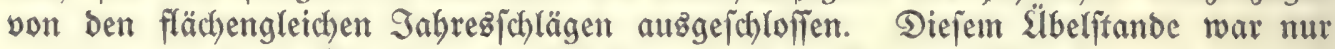
zu begegnen Durch Einteilung in Echläge gleidher Eีrtragzfähigleit, jogenannte

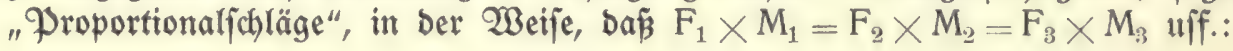

$$
\frac{\text { rebuzierte } \mathfrak{F l a ̈ c h e ~}}{\text { Untriebszzeit }}, \frac{\mathrm{rF}}{\mathrm{U}} \text {. }
$$

Rachneialich zuerít bei (Einrichtung Deż (B̈̈ttinger Gtabtwalbez ourch ben Claubthaler Oberförfiter Sacobi 1741 angewandt.

Beftehen blieb in ben meiften Fällen, zumal beim Damaligen s̈lbergang aus ber regellojen Dlenterwirtichaft, ber für bie näd) ite 3 ufunft füblbarjte Nachteil, bie Singleichbeit Der Solzerträge während bez erften Slmtriebeg. 3u ibrer bes: jeitigung wurben zum Teil weitere, für ben erfen Slmtrieb vorübergehende

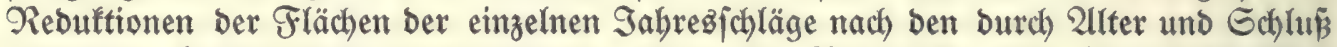
bebingten Solzerträgen vorgenommen, ober bie Borrats: uno 3 uwach żgröpen

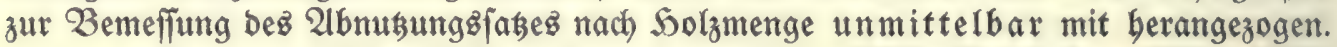

v. Eangen 1699-1776, v. 3anthier 1717-1778, B ä dhting 1729-1799, v. Bebell $1750-1799$.

Ëbenjo entitanden Berjuche einer unmittelbaren "शrafjen"= Teilung ber zu erwartenden $\mathfrak{H o l}$ erträge obne Brtliche Fejtlegung ber jäbrlich abzumugenden Flächen. Bei ben mangelhaften Silfämitteln zur Borratz= uno 3uwachgermittelung fonnten bieje Zerfabren anfänglich nur Slnoolffommenes leiften. Bejonberz feblte

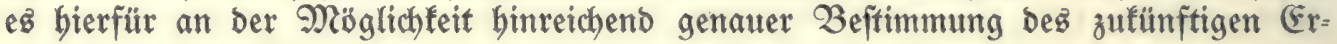
trages junger Beftände.

Diejer Gdbwierigfeit wurbe Durch Bejhränfung ber (Ërtraggberechnung auf

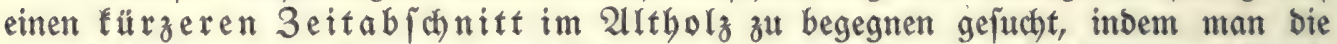

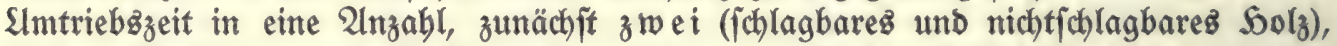

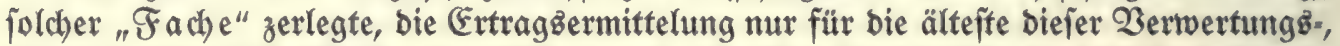
Butch in bem 2 lltholz fo lange hauen fonnte, biz bie nächjte Rlaffe in bie Siebsreife binein= gerwachjen war.

Joh. Bottlieb Bedfmann 1700-1777, oettelt 1730-1800.

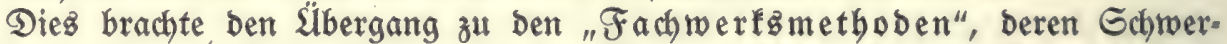

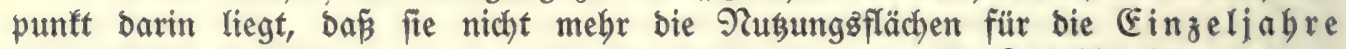
(Sabreşjhläge) fejtlegen, fonbern bie Slmtriebszzeit in gewiffe 3eitabjchnitte zerlegen und biefen 2lbnubungżzeiträumen, Fächern, Perioben beftimmte Flächen mit $\mathfrak{b o l}_{3}$ geeigneten alterz überweifen. Sie bringen Damit in ibrer weiteren Entwicfelung ein zeitlich uno B̈rtlich georonetez 3ujammenfaffen von grözeren Beftanbsigruppen zur abnubung innerbalb bejtimmter längerer 3eitabjochnitte. Dies bebeutet gegenüber Dem früberen $Z$ erfabren feine ichablonenmäp̈ige Ëinengung, ponbern eine erbeblich freiere 2hägeftaltung ber Wirtichaft. Denn je länger dieje Albjhnitte, um jo gröper ber zeitliche uno örtliche Epielraum, um fo freier Die $\mathfrak{B}$ irtichaft. 
Sluter bem Fadbwert vermod)te mummebr and bie wirtfd)aftliche Einteilung unabbängig von ber pro Inbr zu nusenben Fläche zu werben. EEz fönnen für bie Folge bei ben Einteilungen bie 3wecte ber Solzbringung, Der zroedmänigiten $216=$ grenzung von 2 irtichaftzfiguren uno bie ber 3 eftanozoronung in gropen 3 ïgen in ben Borbergruno treten. Die 2luzlegung geidbieht für bie Dauter. Einte foldse barf fich naturgemäß nicht mehr von ben wech felnben $\mathfrak{B}$ eftandsoverfchiedenbeiten abbängig machen, fondern bat fich vornebmlich ben bleibenden ftanbörtlichen unb Belänbe-

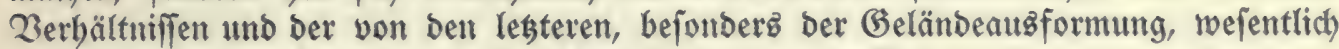

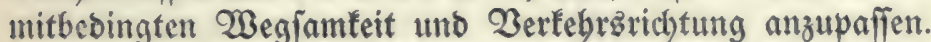

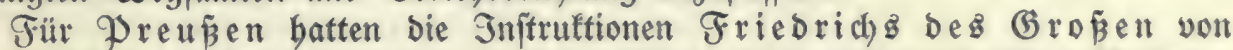
1740 unb 1754 zur Befeitigung ber regellojen Plenterbiebe eine regelmäßjige 70 jäbrige Ed) Iagwirtfdaft angeoronet, zunächfit in ber Form fchlagtweifer, lebiglich auf Ëntuahme abftänbiger uno biebsireifer Gtämme gerichteter Durchbaunngen, währeno "baz junge, wilchjige, gejchloffene Riefern=SInter $=$ unb $=$ Etangenbolz, powie alles gejunde (Eichen= uno Buchenbolz gefchont" werben follte. Eerfí bie fpäteren Injtruftionen von 1764 bis 1783 bringen Dazu Den s̈bergang zum Rahlfiebe in jomalen Gdylägen mit Ranobefamung, und bie 1787 vom Forftminifter Graf v. Arnim erlaffene bie Ein. fübrung von Breitjamenjchlägen in Riefern.

Die für Sochwalobetrieb mit Rablfchlagmirtichaft notwendige Erböbung auf

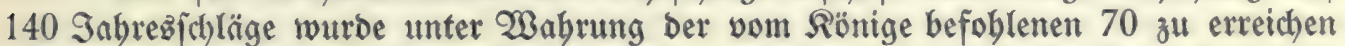
gefutcht Durch 3erlegung jeber Sauptabteilung (Blod) in zwei gleiche Teile A unb B, Einteilung ber lebteren in bie 70 Gchläge uno jäbrliche $\Re$ tugung eines ber $2 \times 70$ Ghläge in jebem 3 lod̆.

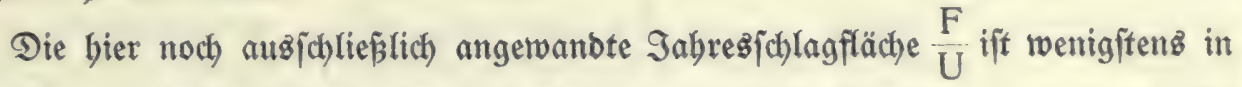

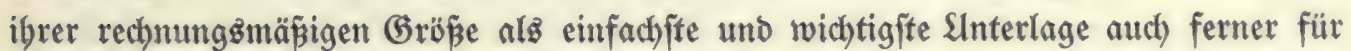
taratorifd)e 2lufgaben nicht zu entbebren gewejen.

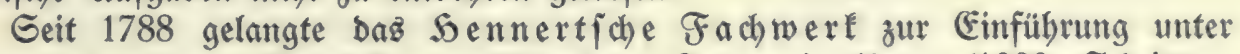
Benusung ber vom Slmtriebe unabbängigen Sageneinteilung (1000 Schritt = 200 Ruten im Quabrat), welche rajch auf weite Flächen auzgebehnt wurbe. 2lud) baß̊ Sentertfde Berfabren (Znweifung zur Taration ber Forften 1791 uno 1795) bot

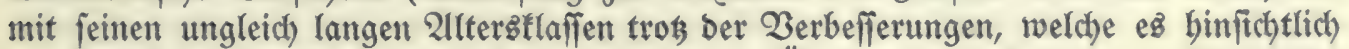
ber Flächen= und Zejtandżaufnabme mit flarer s̈lberfitcht Der Solzarten, Etandortä=

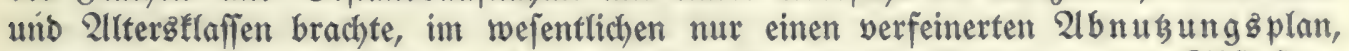

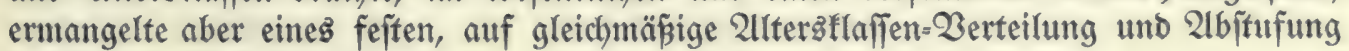
gerid)teten 3 etrieb в̊

Dieje 2 aldzuftand (5. . S Sartig 1811 an bie Epise ber Qreupifchen Forjtoerwaltung berufen war und nun bei ber von ibm inz 2 Berf gejegten Neuoronung bes gejamten Forjtwefen in Preufen auch fein Maffenfachwerf (2lmweifung zur Saxation ber Forfiten 1795, Inftruftion für Forfttaxatoren 1819) zur (Geltung brachte.

Er verlangte:

Borweg: Feftitellung ber allgemeinen Grundpäßse in bezug auf Einteilung,

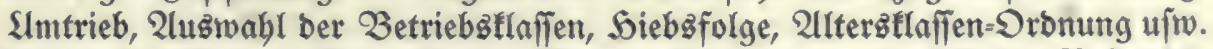

218Dann: Benaue Bermefing, Einzel=, pogenannte "ipezielle", Beftanoz= aufnabme, vorläufige 2lusftattung, fogenannte "Dotierung" Der gleich langen 


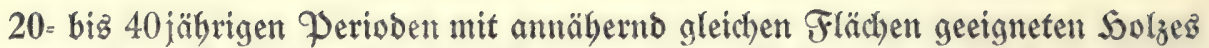

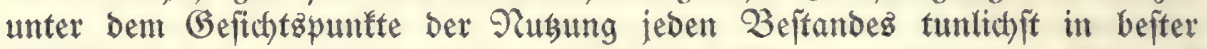
Siebsreife, bez "Yorzieheng" mangellyaft bejtocter, zuwachżarmer, jüngerer Beftandzflächen, zugleich aber aud) Der Serftellung Der "Bejtandzeinleit", D. h. Der Bejeitigung von Alterg= ujw. Berjchiebenbeiten in Demjelben Sagen, und Der Erreid)ung zwectmäpiger Siebsfolge mit möglichit engem örtlid)en 3ujammenjchlǘ Der zur gleid)en Periobe gebörigen Flächen jebes Blocées (grundiägliche Tanturveriüngung! 3u vergleichen Geite 44 uno 49).

Sierauf: 3 lockweife Ertragsberechnung (nit Gortimentżerlegung) für ben ganzen Amtrieb. Weriobenertrag $=\frac{\text { SAmtriebzertrag }}{\text { Anzabl Der Perioben }}$. Inerbalb

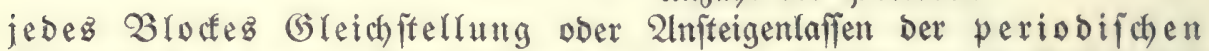
Solzerträge Dur(h) "Zerichiebung" geeigneter Beftände auf Roften ber Fläcbengleichbeit und bez vorteilbafteften Abtriebzalters. Säbrlicher

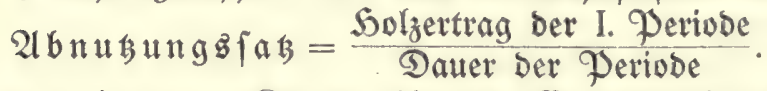

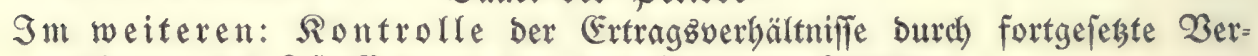
gleichung Des $\Im$ fit = E゙rtrages mit bem Eoll ber Schägung.

Die zu umfangreich angelegten $\mathfrak{S a r t i g f ( h e n ~} 21 b$ fchägungen fonnten jeboch mur Iangfam berumfommen. Deghalb wurbe bei Tleugeftaltung Des Preupifchen Finanz: wejens jenez Berfahren von 1825 ab verlaffen und auf Beranlafiung Dez Finanz= minifters v. Mog eine fummarifche Ertraggermittelung nach Dem Durchichnitts = zuwad) angewandt, um rafch einen S̈berblic über bie Qeiftungsfäbigfeit ber

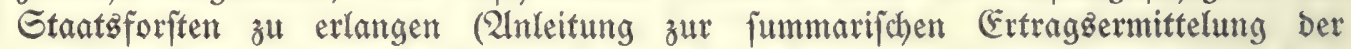
einzelnen Forfffchubbezirfe 1830). Diefe "juperfiziellen“ G(hägungen bejdränten fich leoiglich auf (ungefähre) Flächenermittelung, Boben= und Beftandsbejchreibung, Feftégung ber abnubung für bie nächjten 20 Gahre ofne eigentliche Ertragg:

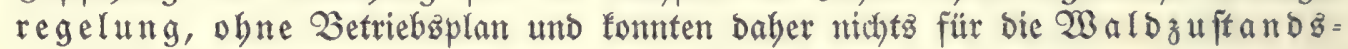
Regelung leiften.

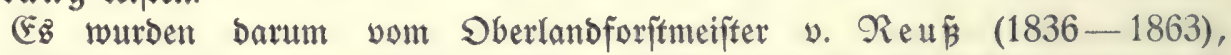

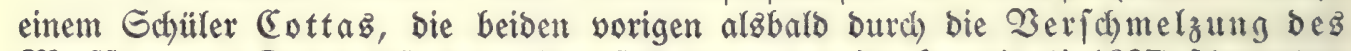

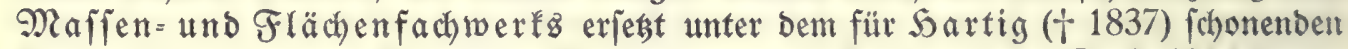

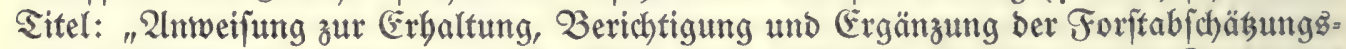
und (Einrichtungzarbeiten“ vom 24. 2lpril 1836. Diefez "Fombinierte" Fad) werk bot hinreichenben Epielraum zur 2lnpaffung an bie jerweiligen Zerbältniffe, je uach)= Dem ez alz geboten exfchien, mebr Gerwicht auf peiulicheren "פlaffen"=2lusgleid zu legen, ober alz unbebenflich, fich mebr bem Flächenfachwerf zu näbern. Qezteres

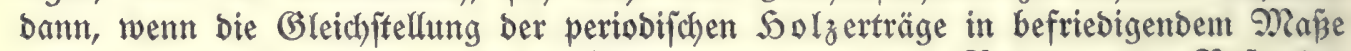
bereitz Durch annäherno gleiche Flächenverteilung ber Boben= uno Beftands= verfatebenbeiten erreichbar wurbe, waz um fo eber geidhah, je mebr baz 2llterz=

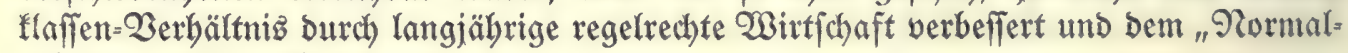
zuftand" näher gebrad)t war.

Go hat benn bie immer ftärfer werbende Sinmeigung zum Flä chenfachtwerfe, nod) ebe fie ganz in biejez hinüberführte, weitere wejentliche $Z_{\text {ereinfachungen }}$ gebrad)t. Dabin zählt bie Befchränfung Der genauen, fogenamuten "ppeziellen" (Ertragaberechnung auf bic crite, s̈berwcifung gleid)er Flächen auf bie fpäteren Derioben 
mit nur überichläglicher (Ertragsermittelung für lestere, aber mebr und mebr auch) obne biefe. Ebenip hat Den vereinfachten "MAaterial"=2lufnahmen fïr bie I. Periobe ein breiteres Felo eingeräumt werben bïrfen. Denn alfe Sdhäßung febler tönnen mit

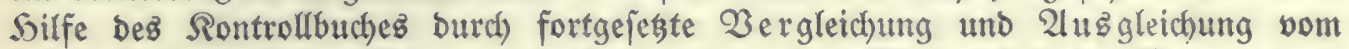

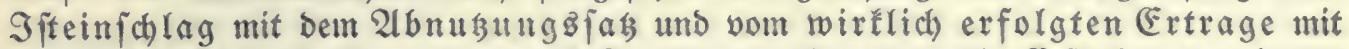
bem gefchäzten Eoll, weiter Durd) Saxationzrevifionen in bie Erfjeinung gebrad)t uno unichäblich gemacht merben, che fie erniten Echaben fififten.

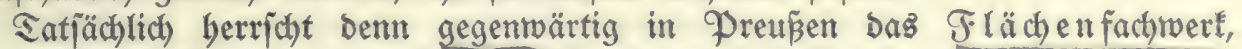
ja, man ift, bem 3uge ber 3eit folgend, bereitz jo "fuperfiziell" getworben, Daß man unter SImftänden vom Fachwert nur noch Den Namen nimmt, fich auf Das jogentunte

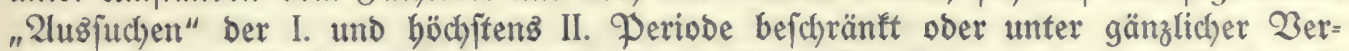
werfung Dez "Ballaftez Dez nicht auf Der Söbe ftehenden veralteten“ Fachtwerkz fïc) Damit begnïgt, lebiglich auf $\frac{F}{U}$ alz ber, wie gejagt, allezeit einfachiften (Grunto= lage aufzubauen uno banach nur bie für bie nächfte 3ufunft zur 2lbnugung heran= zuziebenden Beftände auzzumählen. Se fürzer man bieje 3eitabjchnitte rählt (man gebt in Dreuken bisher unter 20 nicht herab), befto mehr wirb bie Benegungaffreibeit

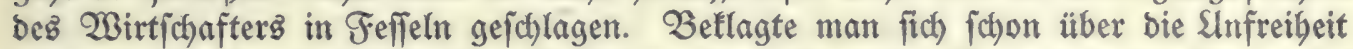
beim Fadbert mit 20 jäbrigen Perioben, fo witb biefe Beengung bei fürzer be= meffenen Setträumen von etwa zebn ober gar fünf Sabren noch viel füblbarer werben

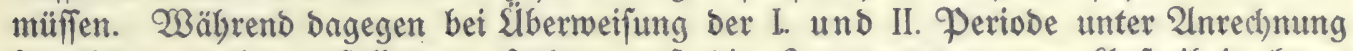

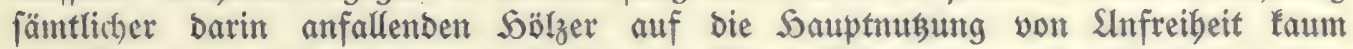
bie Rebe fein und jebem rwirtjchaftlichen Bebürfmis nads vorbereitenden Sieben und zur 3 ehebung ber meiften fich gelegentlich bei ber Etatzerfüllung einjtelfenden Echwierigkeiten am einfachfiten entiprochen werben fönnte. 3 vergleichen Eeite 56 bỉ 60 .

(Gewöbnlich unterläß̨t man bei jener "Beftandswirtichaft" Die 2lufitellung

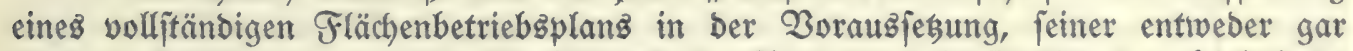

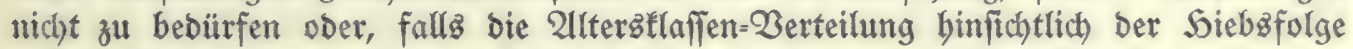
uno ähnlichem für bie fernere 3ufunft fdyon jeßst bejonbere Berüdfithtigung forbern

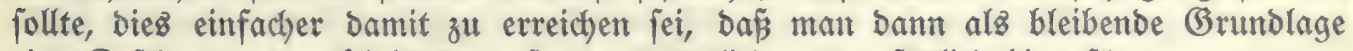
eine Feftlegung ber Siebszüge ujw. nachträglid) uno zu[äglich binzufüge.

Zsie felgr auch) beim Erteilen jeglicher Anorbmungen, infonberbeit Der forfitlichen, Dér Grumbjab zu billigen ift, teine inz einzelne gebenden Beftimmungen für 3eiten und Gerbältniffe zu treffen, die ber Inordnende nicht vorber zu überjeben vermag, to forbert boch bie auf bas Redynen mit fo langen 3eiträumen an= gemiefene Forftwirtf(haft für igre 3 ctriebsిregulierungen einen überfichtlich für bie zeitliche uno räumliche Berteilung angelegten Rabmen. Sie bebalf mindeftenz für Die 2lnbahnung guter Beftandsoromung und Siebsfolge eines weit vorgreifenden 3utunftżplaneż zur Berwirflichung ihrez Sbealbilbez, weil alle zur Eicherung jener z" ergreifenden Mapnahmen un fo wirffamer finb, je früber fie von langer Sand vorbereitet unb eingeleitet werben. Der Erreichung jedes 3ieles bat ein beftimmter Plan zu bienen, je umfaffenber und flarer biefer ijt, um fo beffer für feine Durch)= fübrung. 3war hat auch im Walde jeber Tag feine eigene Olage, aber ez fanu nicht ber fommenbe Sag, Die fünftige 3eit von felbft für bas Shre forgen, wenn nicht genügent yorgebout war. 


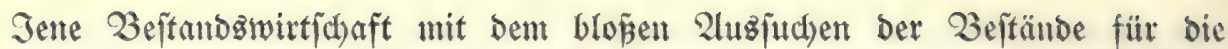

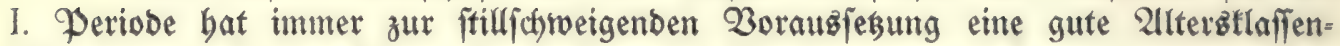
Berteilung. Dann erft fann fie in ihr vollez Recht treten unb hauptjächlich nur ber Alterbłlaffen = Sabelle folgen in Der burchaus nicht neuen, fonbern ftetz febr angebrad)t gewejenen 216 fict)t, tunlichjit jeben Bejtand in jeiner beiten Siebzreife zu nugen uno alle nicht unbedingt notwendigen $\mathfrak{B e r j}$ hiebungen und bie bamit verbundenten Opfer zu meiben. Dieje Rüiffitcten begründen an fict) feime bejondere Methode, jonbern kennzeichnen

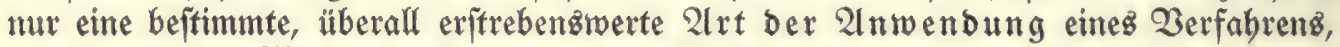
bie in gleicher Weife, z. 3. aud) beim Flächenfachwert, zum 2lugbrud gebrad)t werben fann.

Praftifch bebeutian bleibt aljo babei hauptjächlich mur baz Etreben, wo nur

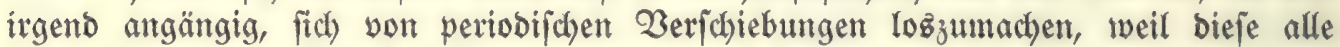

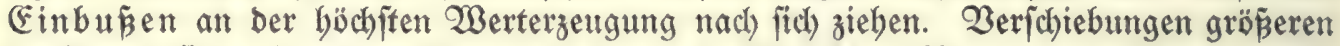
Slmfangez fint aber niemalz, wie bas bei oberflächlicher Betrachtung icheinen mag, gerabe bem Fachwert alz jolchem entiprungen oder mit ihm untrennbar verbunben, fondern lebiglich Durch bie wirtichaftlichen Berbältniffe früberer Beit bebingt gewejen. 2luch beim Fachwert, wo fie allerbings mandbmal zu einem eigenartigen Eport ausz= geartet fint, bürfen fie beute mur $b \mathfrak{a}$ als bered)tigt gelten, wo aus ibrer Nicht=

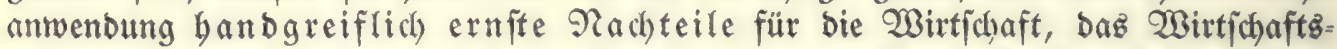
ganze, bejonbers auch bezüglich Der Siebsfolge, zu erwarten fitehent. Gonit ift, wie überall, auf bie 2lbnuzung jebes Ëinzelbeftandes in feiner beften Siebsreife Das Sauptaugenmerf zu richter.

Ticht überjeben werben Darf, Dap̃ jene Berfchiebungen in igrer friblyeren 3abl wejentlich mit veranlajat find Durch bie Rleingeit ber Bezinfe, in Denen ber block= weife 2 luggleid) zu vollziehen war, jolange überwiegende 3 rennbolz= Berwertung uno

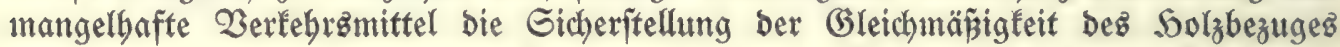
noch in örtlich eng gezogenen Grenzen für jebes Zerbrauds sebiet zwectmäß̈ig er=

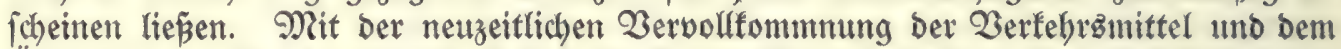

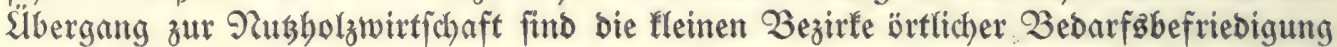

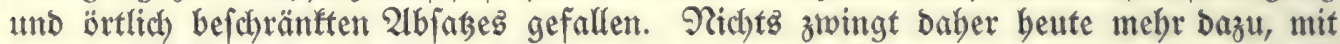

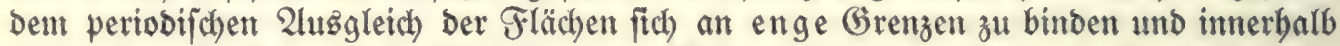

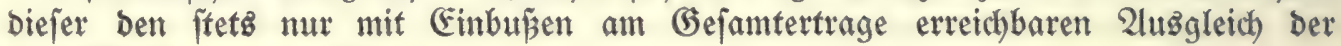
alterbłlafien burchzufübren.

Waz not tat, war aljo nicht Das Berlaffen bez Fad)werkz, jondern bas Freifommen von jenen nur zum Seil gebotenen, bäufig genug aber gewobnbeits= uno

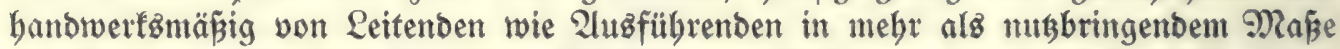

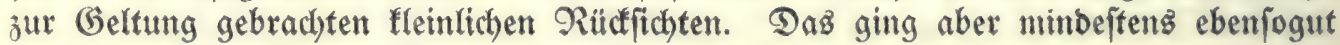
im Rabmen bez Fachwerfz wie obne biejez. 


\section{3weiter albichnitt. \\ Âtgemeine Grumbjäge.}

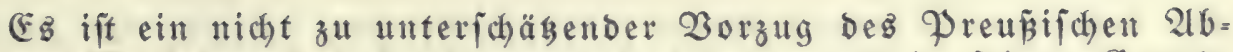

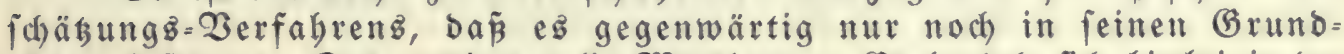
zïgen feftliegt. Das verbient volle 2 ürbigung. EE bandelt fich bierbei in ber

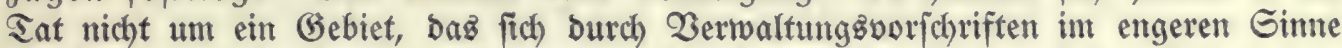
erjabopfen und in fnapper Fingrenzung bis ing fleinfte binben lieje, fonbern um ivefentlich erweiterte 2lufgaben, für roeldye eine "Direftive" beffer an Drage ift, bie mur ben 3 wed betont, auf ben ez antommt, bie Rittel zur 24uführung aber bem $\mathfrak{B}$ eauftragten überläß̨t innerbalb ber ein für allemal gegebenen fejten Formen. Darum geftattet uno forbert bas Berfabren in jebem Einzelfalle bie vorteil= Gaftefte 2lnpaffung an bie gegebenen Berbältniffe. Dagegen ift alle gebanfenloz

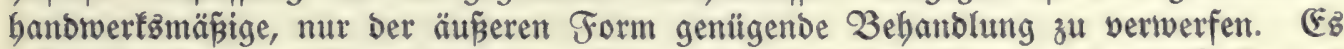
foll vielmebr unter Bermeibung Der Gdhablonenarbeit in jebem gegebenen Falle bas

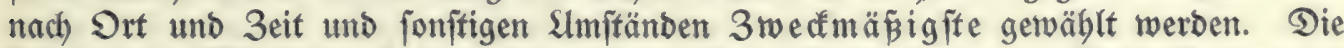
Qebre vom Möglichen fant Dabei volf zu ibrem Recht fommen. 2luch ift jebe mit 3iel uno 3wed ber Betriebsiregulterung verträgliche Bereinfachung nicht mur itatthaft, jonbern zu erftreben.

Nan fommt eben aud bier mit feftitebenben "Doftrinen" nicht burch, fonbern

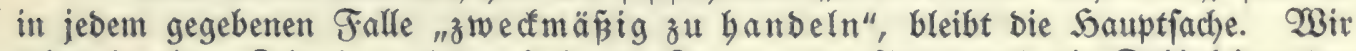
leben in einer 3eit, in weldser, frei vom 3wange Der Sdhulregel, bie Fäbigfeiten ber wiffenfchaftlich gebilbeten Forfitmänner fo weit gefïrbert fein follen, Dá biefe nach allgemeinen Weifungen im Einzelfalle Das Richtige zu treffen verifteben.

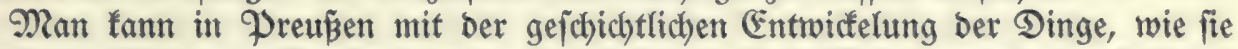

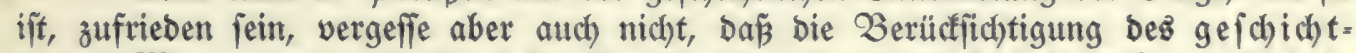
lid)en 2 erbegangez mit bie bejte Gewähr für bie Gretigfeit beg Sanbelng in Der gleichen Ridhtung bietet, welche gerabe in ber Foritwirtichaft am wenigiten zu entbebren ift. (E⿱ gefdhiebt baber ohne anzreichende imere Berechtigung, wenn, wie fo oft in unjeren Tagen, in einem nicht immer begrünbeten unb abgeflärten Berlangen nach) Neuem, für Wreupen nach einer "neuen Snftrultion" gerufen wirb, wo uns eine alte

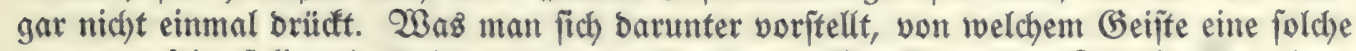
getragen fein joll, wirb nie red)t aubgejprochen. Betwip, unjere 3eit forbert einen gejunben Fortichritt auf allen bebieten. Im Ernft fönnen aber, wie bie Gachen bei

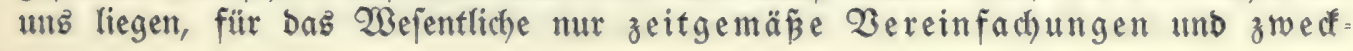


mäbige Ëinridtungen zur leidteren Befdaffung zuverläfifiger Unter = lagen in Frage fommen. Gerabe im legteren Dunft brüatt ung ber Gdoul am

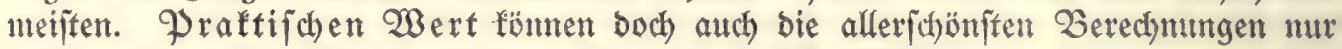
Da haben, wo die Rechnungggrundlagen auf Tatiächlichem ruhen.

Die 3eit ber für bie verichiebenften Einzelfälle Rezepte fdyreibenten und audh im Eleinen bindenden Inftruftionen im alten Ginne Darf auf biejem (Gebiete nad)= gerabe alz überwunbener Etanbpunft angejehen werben. WBo, wie in Đreußen, bie

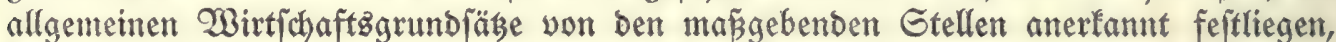

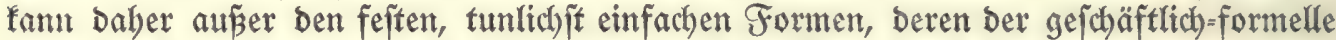
Teil wie überall fonjt zur 2 tü̈führung ber Gache bedarf, nur in Frage fommen: eine ftreng in Sinne jener Grundfäßse gebaltene weitere 2luggeftaltung für Den gegebenten 3wedx. Dazu genügen heutzutage allgemeine, bie 2lufgabe ebenjo flar wie furz und beftimmt zeichnende Direftiben, während Borjhriften, Die Daran franten, über

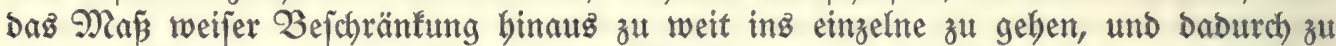

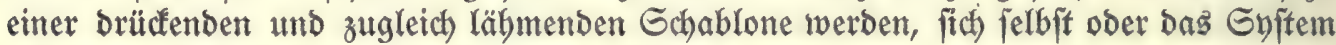
richten, nach Dem fie Gaben aufgebaut werben müffen.

\section{Wirtichaftzziel fïr bie Gtaatiforiten.}

Diefer ift am flarifen aubgeiprochen in ber $\mathfrak{v}$. Sagen=Donnerfden (Dar=

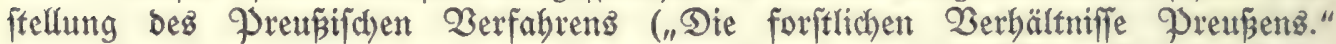
Dritte 2luf(age. 1894) und in Der Serrenbauz̧fínung vom 28. Närz 1905 Durd Den Serrn Qandwirtichaftzminifter v. Pobbieląi erneut betont, furz bahin lautend:

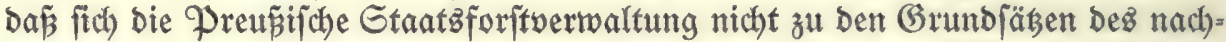

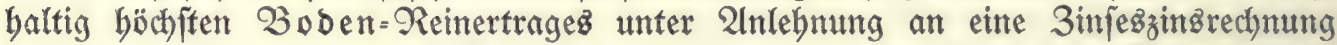
befenmen bürfe, um eine auf Rapital unb Binjengewim beredynete reine Gelbwirtichaft mit ben Gtantsforften zu treiben, fonbern fich, im Gegenjał zur Pribatforitroirtichaft, für verpflichtet halten müfie, nur bem Gejamtwohl ber Ëinwohner bez Gtaatez zu bienen burch Befriedigung bez Bebürfniffez an $\mathfrak{S o l}_{z}$ von ber begebrten 3 efchaffengeit,

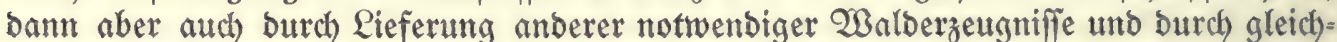

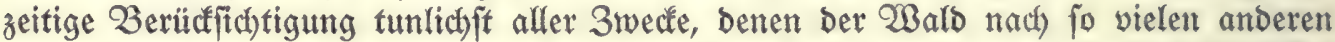
Richtungen hin bienftbar ift und für bie nädbfte 3ufunft nach menfd)lichen (Ermeffen feim wirb ober fann. Die Etantżorften find bezhalb alz ein Der Gejamtheit bez Bolfez gehörenbez Gibeifommin, alfo alz ein peiner Sreue und Obhut anvertrautez

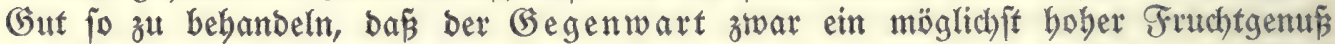
zur Befriebigung igrer Bebürfniffe zugute fommt, ber 3 utunft aber ein minbeftens gleich boher, tunlichfit aber in Rüctifcht auf Das fteigende Bedürfnis böberer Frucht= genü von gleicher 2 art gefichert wirb.

Nur infofern baz Gelo ben $\mathscr{B}$ ertmeffer aller materiellen (büter, aljo aud) ber

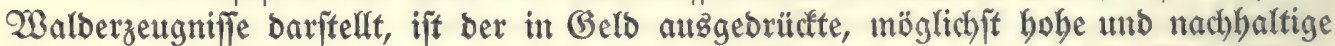

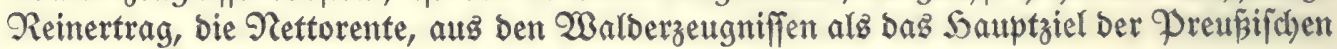
Gtataforjtwirtichaft zu bezeichnen.

Alro feine Maffenwirtichaft, fondern Bertwirtfdaft, nicht aber eine Prozentwirtfdaft! 
(Dả bebeutet bie Ėrzielung ber nachbaltig möglich)it bohen 2 albrente, Netto= rente, ober nachbaltig möglidjit Gohen Gefamtwerterzeugung von ber gegebenen

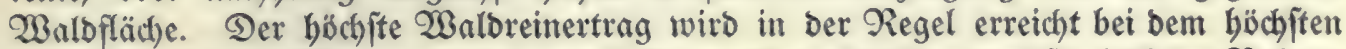

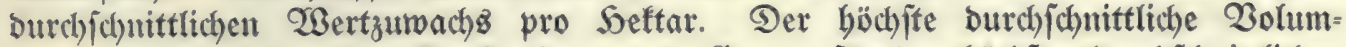
zumachs bilbet aber überall erje bie untere Grenze für ben böchiten burchíchnittlichen Wertzutuaclys.

Allo nidht bei ber bolzerzeugung nad) bloper Feftmeterzahl, nidht bei ben 3uwachşprojenten, bie man befanntlich weber verarbeiten noch verfaufen kann, bürfen wir fteben bleiben. Tas bietet zu wentg von Dem, worauf es in Wirtlic) feit autommt. Der böchften (bebraud) grwert= (rzeugung müffen wir auf ben Gruno geben, fie allein gibt Den geeigneten Taßjitab ab für bie ricltige Beurteilung bez Erfolgez Der verfchiebenen für bie Berwirtichaftung offen frehenden 2 ege.

\section{Snhalt und 2uf́gabe Der Betriebregulierung.}

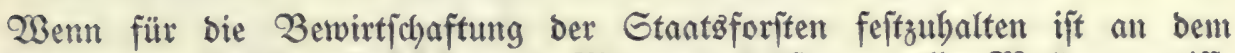

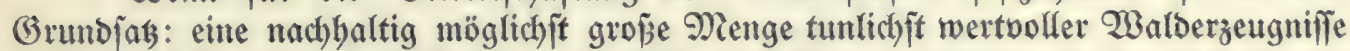
mit möglichift geringent 2lufwand von Geld unb 3eit zu erzielen, fo hat Inbalt unto Zufgabe ber Betriebzregulierung zu befteben in:

I. Feftitellung (Ermittelung, 2lbfchäßung) und Darftellung beg 2 alb= zuftandes, aljo Deffen, was ift. Diefe umfä̧t bie Flächen= nut Beftands = aufnabme binfitctlich ber

vorbandenen (Zorrat) uno

zu erwartenden (3mwadb) (5ebrauch gawerte - Saration -

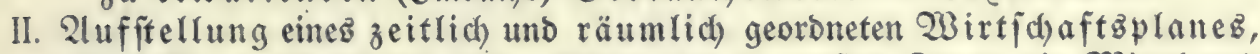
aljo beffen, wag werben foll. Diejer hat in gropen 3ügen bie Mittel uno $\mathscr{B}_{\text {ege }}$ zu zeigen und für bie nähere uno weitere 3 ufunft einen allgemeinen Rabmen feitzulegen zur $B e f(h)$ ffung beg

1. Göchft möglichen,

2. Dauernben, "machbaltigen", $(2 .+3$. fogenaunte "fitrengfte" Pach)=

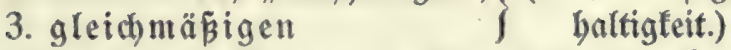

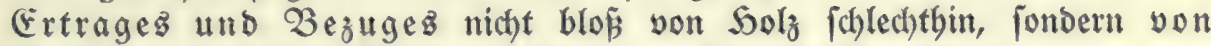
Solz vou böd) fitem (Gebraudbarwert - Ertragzregelung -

unter

III. Serbeiführung Des vorteilbafteften, fogenannten "normalen" $\mathfrak{B a l b}=$ zuftandes Durch 2lmwenoung Der

1. vorteilgafteften Solzart,

2. " Betriebsart,

3. " $\quad$ Imtriebżeit (21btriebgalter),

4. " " Berteilung ber 2lltergłlafjen nach:

a) räumlicher 2 usbebnung (Flächengröß̄e, "quantitativ"),

b) gegenfeitiger Lage (Beptanozoronung, Siebsfolge, "qualitativ").

- Betriebsregulierung, Forfeinrichtung. - 


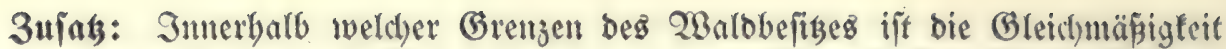
Dez Solzbezugez (II, 3) Durd) 2luzgleichungen in ben allterbflaffen (III, 4) ficherzu= fiellen? Welche Flächenabichnitte follen bafür alz in fith abgeglichene Ganze bie Einbeiten bilben?

Früber war ez Der gewöbnlich mit ben (Grenzen Dez Gchuzbezirtz zufammen= fallende "Bloct", Der, wie gejagt, alz Gebiet Der örtlict) eng eingegrenzten Bebarfz̈: befriebigung heutzutage leine Berechtigung mehr bat uno zubem für Den 2lużgleich)

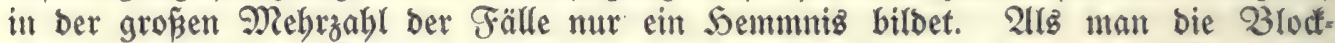
cinteilung in ihrer Rleinbeit einfübrte, war fte zumeift eine Durd) Den Drud ber

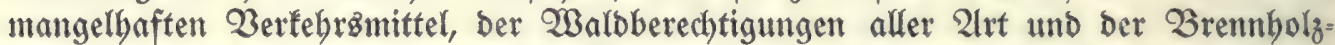
wirtfd)aft jener 3eit aufgeztwungene Notwendigkeit. 2lber f(b)on bamals galt po gut

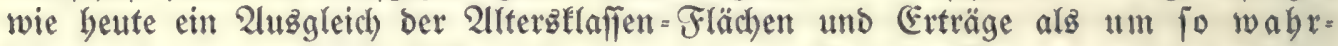
fdeinlider won jelbit fid) einfteflend, je weiter bie Grenzen gezogen werben fönnen, uno je bunter zulammengejegt baz Ganze ijt. Satjächlich) trifft biez benn auch) für Den Sochroalo der Preusitichen Gtantzforfen in feiner Gefamtheit an= näbernd zu:

attergftânen 1893 nach v. Sagen - Donner:

\begin{tabular}{|c|c|c|c|c|c|c|c|c|}
\hline & I & II & III & IV & V & VI & \multirow[b]{2}{*}{ 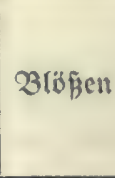 } \\
\hline & & $\begin{array}{c}\text { liber } \\
100\end{array}$ & $81 / 100$ & $\begin{array}{r}61 / 80 \\
\mathfrak{I}\end{array}$ & $\begin{array}{l}41 / 60 \\
\mathbf{r} \mathbf{e}\end{array}$ & $21 / 40$ & $\begin{array}{l}\text { big } \\
20\end{array}$ & \\
\hline Preupificace Etaat & $\cdot \cdot \cdot \cdot \cdot$ & 13 & 13 & 14 & 18 & 19 & $\begin{array}{c}19 \\
(+4)\end{array}$ & $4 \%$ \\
\hline
\end{tabular}

Dngegen für Dic cinzelnen Regienungäbezirfe fłon viel weniger, z. 23.

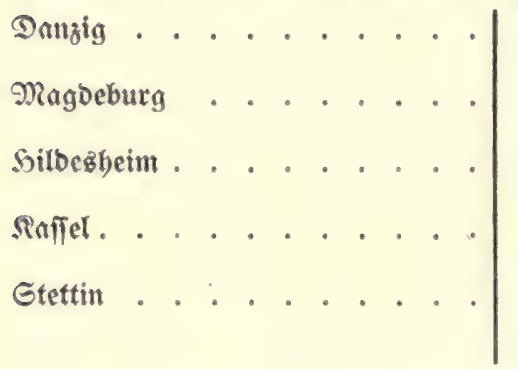

\begin{tabular}{r|r|}
8 & 13 \\
9 & 7 \\
10 & 14 \\
7 & 11 \\
23 & 12
\end{tabular}

\begin{tabular}{l|r}
14 & 19 \\
12 & 26 \\
18 & 20 \\
15 & 23 \\
11 & 18
\end{tabular}

19
26
20
23
18

\begin{tabular}{l|c|c}
21 & 18 & $7 \%$ \\
22 & $\begin{array}{c}(+7) \\
17\end{array}$ & $7 \%$ \\
21 & $\begin{array}{c}(+7) \\
14\end{array}$ & $3 \%$ \\
20 & $\begin{array}{c}(+3) \\
17\end{array}$ & $7 \%$ \\
15 & $\begin{array}{c}(+7) \\
20\end{array}$ & $1 \%$ \\
$(+1)$ &
\end{tabular}

Die 3eit ber örtlich) bej(bräntten $16 j a g g$ gebete ijt heute zumeift voriiber infolge ber bebeutend fortgejchrittenen Entwickelung unferer Berf́ebrsmittel. Daunt Sand in

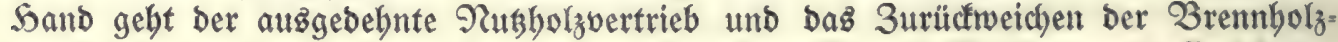

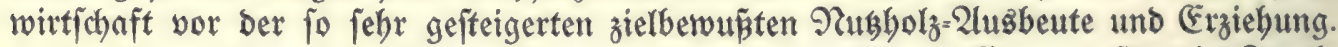

Seber 3wang zul Slnterteilungen mit eng gegriffenen Grenzen für bie 3wecke

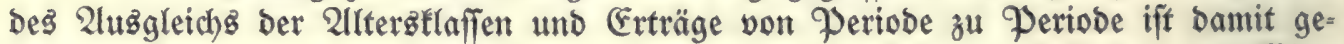
fallen. Ėg liegt baber feine Beranlaffung mebr vor, fie, bie fretz nur mit Ein= bujen am Gefamtertrage erreichbar finb, obne febr triftige Gründe, nur ber alten Gdyablone zuliebe gejucht uno fïnftlich berbeifübren ober aud nur aufrecht erhalten zu müfịen. 
WBir fönnen gegenwärtig febr viel weitere Grenzen für ben Sluggleich ziehen,

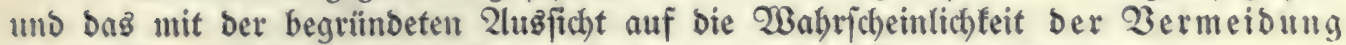
Der meiften biejem 3wect jonft zum Opfer gebrachten ËrtragseinbuËen.

Wie weit foll man barin gehen? Goll bie Oberförfferei, bie Injpeftion, baz Walogebiet, Der Regierungabezirt, Die \rovinz bie Einbeit bilben?

Die legte und allein notwentige Grenze bleibt ber bejamtwald bez betreffenden Ëigentümers, aljo bier bez Gtantez.

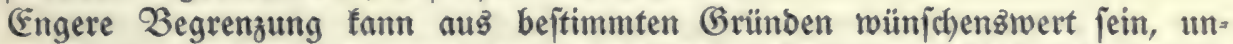
bebingt notwenbig iff fie nicht. Die obige 3 ablenüberficht zeigt, baß́ bie für (Gleich)= fitellung ber Periobenflächen zu bringenden Opfer im allgemeinen um fo fleiner werben, je mebr wir unz biejer äuß̈erifen Grenze näbern. Ënfte Sinberniffe ftellen fitc) bem unter ben beutigen Zerfebrz̈perbältniffen faum noch entgegen. Die wohl

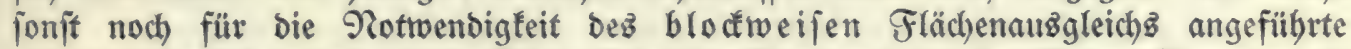
"nicht zu entbebrenbe" gleichmäp̃ige 2lrbeitżnflage auf bie beteiligten Beamten ift auch) unter ben bişherigen Zerbältniffen nur unvollfommen erreichbar gewejen, wiro

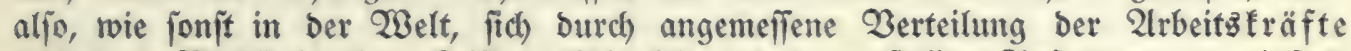

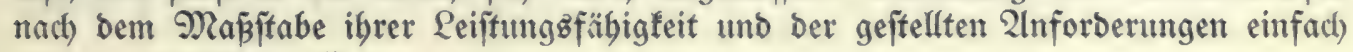
auch fo erreidsen laffen.

Für bie Gejamtbeit ber Gtantaforften zeigt bie obige S̈lberficht weiter: Ëz gibt ber binter bem (Durchjchnittzjolf nicht unerbeblich) zurüafbleibende Flächenanteil Der oberen 2lltergflafien ernfflich ju benfen, nodh aber haben fich, bant bem fonjer=

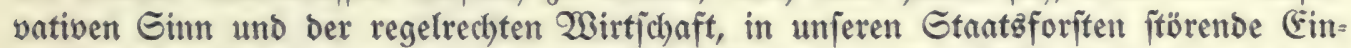

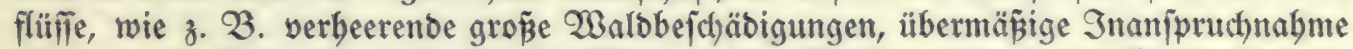
ober gar 2lbjhwendung ber wertbollitent oberen Rlafien, wie fie $z$. 2 . in Privat=

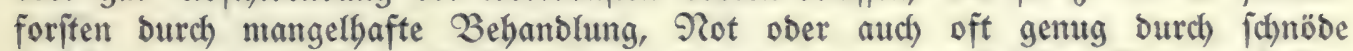

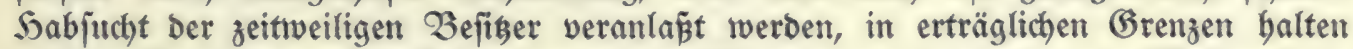

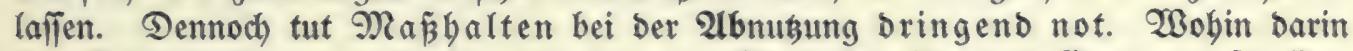
Der Gd)werpunft zu verlegen, und wie ein 2lug̈gleich für bas Ganze zu jchaffen, läß̈t noch beutlicher bie folgende s̈lberficht erfenten:

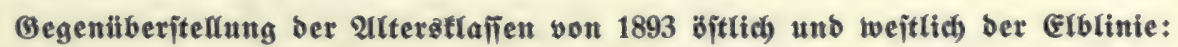

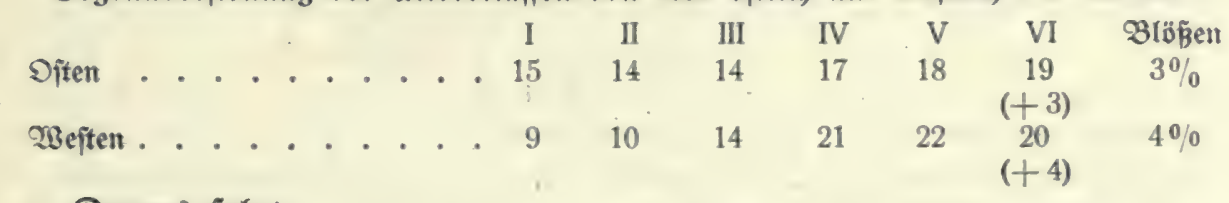

Darauв folgt:

a) Der Often bleibt mit feinen oberen Slafien mebr alb wünjchenģwert binter Dem Durchichnittzijoll zurülf, objchon er nod) eine günjtigere $\mathfrak{B e r t e i l u n g ~ z e i g t ~}$ alह bie Gejamtbeit Der Etaatbiforiften.

b) Der $\mathscr{W}$ effen fält in ben oberen Slafien febr bebentlich ab unb leibet it beunrubigendem Maß̃e Mangel an 2ltholz.

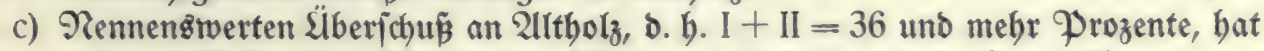
in jeiner Gejamtbeit kein einziger Regierungģbezirt aufzuweifen, wäbrend bem Goll von $33,3 \%$ nahe ftebt mit 31 bis $35 \%$ für I+ II : Narienwerber, Dotg̉bam, Franffurt a. S., Etettin, Bromberg, Brealau, Oppeln; bagegen, ebenjo wie Preußen im ganzen, bleiben zuriał mit 20 biz $30 \%$ für I + II 
Die Bezinfe: Rỏnigaberg, Gumbinnen, Danzig, Rozltn, Etraljunb, Pojen,

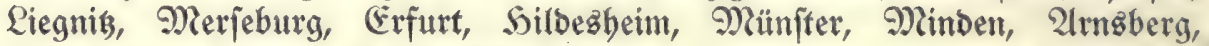
Wiezbaben, Roblenz, Düfifeloorf, Srier.

$\mathfrak{I n}_{\mathfrak{n}}$ empfindlichftem $\mathfrak{N a \tilde { \beta } e}$ arm an 2 Iltholz, b. h. unter $20 \%$ für I + II, if ber $\mathfrak{B e}$ fiten, namentlich bie Bezirfe: Magoeburg, Sannover, Püne= burg, Stabe, O\&̊nabrïaf mit 2lurid), Raffel, Röln, 2lachen, bazu biftlich ber Elblinie Edhlestwig.

d) Diejer 2ltholzmangel wirb naturgemäß in Rörperichaftz= und Privatforiten noc) füblbarer herbortreten. Dież beftätigen binreichent bie allerbingz nicht ganz fo zuverläffigen, weil teilweife mebr auf Schäßzung als genaner Feft=

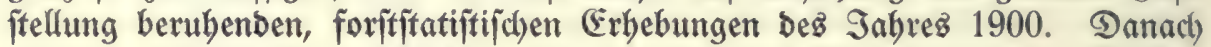

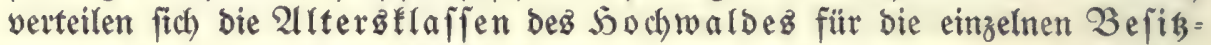

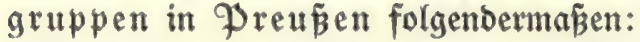

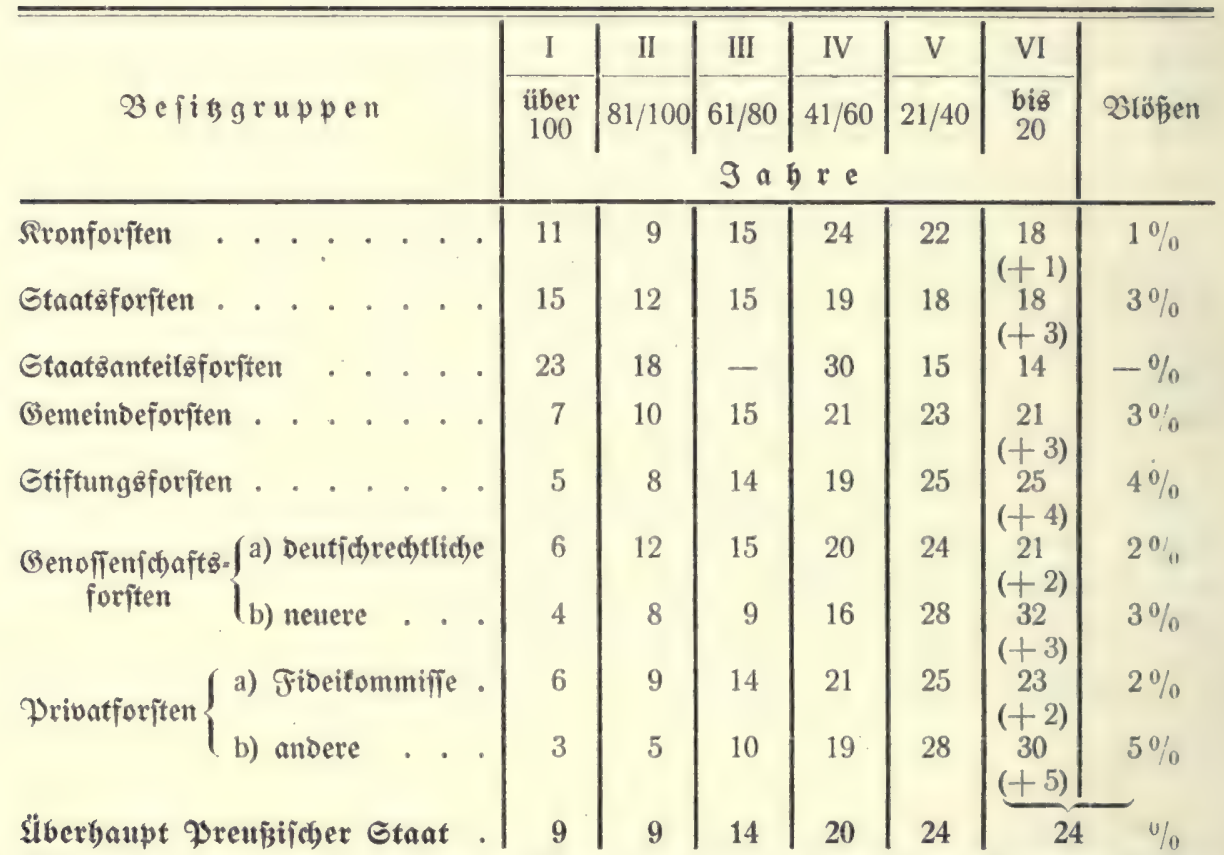

e) 2ltholz bedeutet Gtarkholz, $\mathfrak{z}_{z}$ ertholz, und bazu im allgemeinen ben Göberen Nubgolzanfall. Wenn man baher nicht Dem Banterott an biejent Gebrauch Brwerten für abjebbare 3eit entgegentreiben will, wirb eg weifen

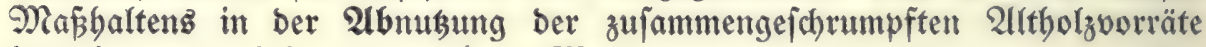
bedirffen, ganz befonders aber im $\mathfrak{B}$ eften.

f) Dagegen jteht nichtz im 2 ege, erjdheint vielmebr vom praftijchen Gtanopunfte aus erwünjcht, ben śberichū altbolzreicher (Bebiete zugunften ber Finjparungen in altholzarmen ftärfer beranzuzieben, allerbings fretz nur innerbalb Der oben Durch Den (Bejamtburchfonnitt Der Gtaatżforiten und feinen Zergleich mit bem Goll gezogenen Grenzen.

g) Weiter liegt barin ein fehr beutlicher Sinneiz, bie burch baz Gebot ber

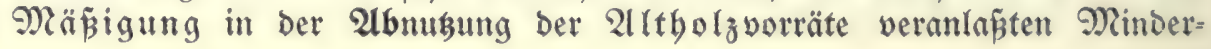


anfälle burd) zielbemüte (Ẽziebung = roieder aušzugleichen, D. h.: überhaupt mebr bon Durd)forfingen zu leben, bei biejen aber mit mäpigen Eingriffen und bäufiger Wieberfebr, in

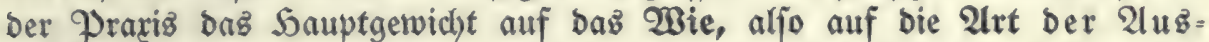
mufterung zu legen. Denn bie Forderungen Dez heutigen Solzmarttez fprechen unverfennbar bafür, ba man jowohl ben 2lnfprüchen ber bolzber= brauchenden Gewerbe wie bem eigenen Getwinn auch im faufmännifchen Einne gar nicht beffer bienen fann, alz wenn man unter Dreisggabe ber alten

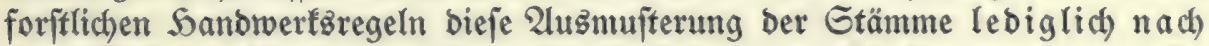
Dem (Gebrauds swert vornimmt innerbalb Der burch Die jogenannten "wald= baulichen" Rüdfichten gezogenen (brenzen, uno bie nach 21rt uno 2lus= formung wertvolleren Beftanbeg̉glieber zur Serausbiloung möglid fit hod =

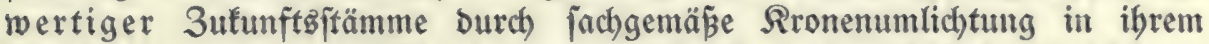

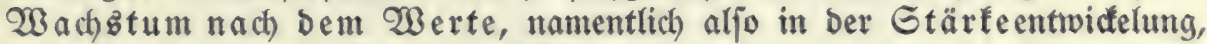
zu pflegen fucht. Gegebenenfallz werben Daber auch in ben oberen

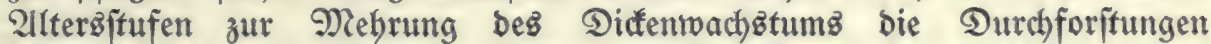
bäufiger, als bisher üblich gewejen, allmählich, aber immer nur all= mäblich, in Lichtungghiebe binüberzuleiten fein. Denn bie Patur gefällt fich eben nicht in jäben Gprüngen uno pflegt jolche im $\mathfrak{W a l b e}$ gewölynlich bitter zu rächen. Wie Denn überbaupt bie ganze forjtliche Praxiz zum Safchen nach glänzenden 2lugenblicḱserfolgen faum ein geeignetes Felo zu bieten vermag.

Bei biejer (Belegenbeit möge aud) Daรี Folgende nicht unerwäbnt bleiben.

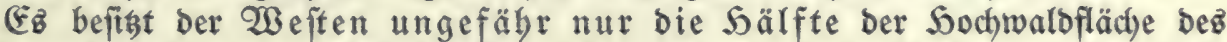
Oftens, verbraud)t aber verbältnizmäpig febr viel mebr $\mathfrak{S o l}_{z}$ als biejer. Das meijte Nusholz ziebt ber wejtliche Inoujtriebezirt auf fich, er verjd)lingt über 6 Millionen Feftuteter mebr, alz biefez (Bebiet erzengt, währenb ber Often erheblich mehr liefert,

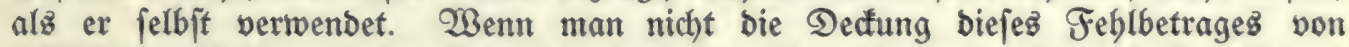
6 Pillionen Fejtmetern bem 2ülano überlafien will, wo im ganzen jo wie jo Deutfalano f(t)on 8 Nillionen Fejtmeter mebr ein= alg augführt, fo werden bier zum gejunben 2lusggleich innerbalb ber eigenen Qanbeşgrenzen entiprechende Zerfebrzerleid)terungen mit erbeblichen Frachtermäß̈̈gungen einzujezen baben, um bem beimifchen Solz ben beimif d) en Marft zu erbalten gegenüber Dem bebrohlichen, Durch mäpigen Fingang żoll

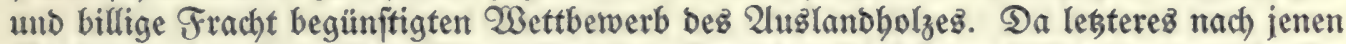
Gebietsteilen auf beutichen (Eifenbahnen im allgemeinen bö ch) ftens $500 \mathrm{~km}$ zu Durchlaufen bat, Das Solz Der Oftprovinzen aber getwöbnlic) 500 biz $1200 \mathrm{~km}$, fo würbe am ange= brachteften fein eime $\mathfrak{B}$ erbilligung ber Solzfracht erjit über $500 \mathrm{~km}$ binaus, bann aber eine nambafte. Damit bliebe baz frembe $\mathfrak{S}_{0} l_{z}$ tunlidyft an bie teuereren erifen $500 \mathrm{~km}$ gebumben, räbrenb bie über $500 \mathrm{~km}$ binaus eintretende rwejentlidue

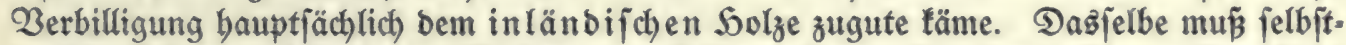
verftändlich umgefehrt vom $\mathfrak{B e j t e n ~ z u m ~ O f t e n ~ g e l t e n , ~ a l j o ~ e b e n j o ~ f u ̈ r ~ w e j t b e u t i c h e z ~}$ wie auch jübbeutiches Solz. (E⿱ twürbe bier namentlich für (Eichen=, 3 uchen= uno Fichtennusbolz von Bebeutung fein, wenngleich nach Lage ber Zerbältniffe ber 3ug

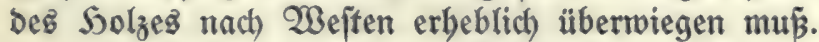

Sierzu nimmt ber "Solzmarft" 1905 aljo Gtellung: Diefer Zorjd)lag

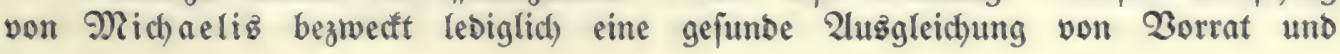


Mangel, er erjegt einen Seil ber (Ënfubr burch bab im Inlande felbjt lieferbare Material. Ër läp̈t bie Menge Der 3 ufubr zum Inoujtriegebiete, jowie alle

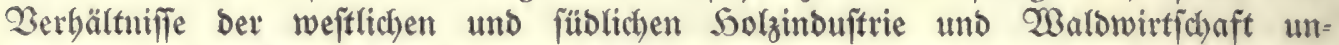

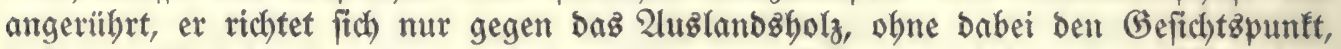

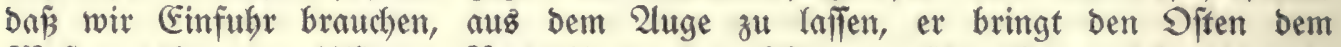
Wejten näber und bilft ben Nachteil, ber Den Oiten am f(t)werften brücfit, bie hohe Zerfehrzabgabe, mildern, ohne ben Gebanfen bez einbeitlichen Staatez und Reides ณив bem 2luge zи verfieren.

Fapet man bas vorber bejagte in jeiner praftifd)en Nukanwendung furz zu= fammen, johat ber Rern einer guten 3 etriebżegulierung bauptiächlich zu ruben auf:

a) Ġewiffengafter, möglichft genauer, fich nicht bloṕ mit unficherer, gut= achtlicher Schäbung begnügender arterşbeftimmung Durch alle Gtufen zur richtigen Einreibung in bie Alteratlanen= Sabelle.

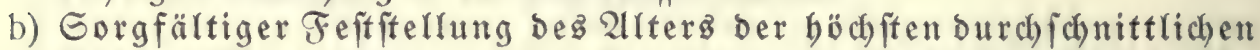
Gefamt $=\mathfrak{W}$ erterzeugung Doer furz ber vorteilhafteften Siebzreife.

c) Peinlichiter 2 bwägung bes Für uno WBiber bei ber periobifden (Ëinreigung, namentlich) ber in bie Siebsireife eintretenden uno berfelben

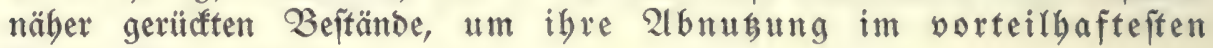
alter fitherzujterlen.

d) Sunlich fter $\mathfrak{B e r m e i b u n g}$ affer nicht unbebingt notwenbigen 21 breichungen vom Zlbtriebzalter ber befiten Siebzreife.

S̈berall aber bleibt getwiffenbafte, ehrliche, offen ftetż nur ber $\mathfrak{W a b r b e i t ~ n a c h ) = ~}$ gebende 2arbeit bie vornehmite Pflid)t jebez Taxators, fowohl an auşfübrender wie leitender Gtelle. Die Büte Der bei Betriebs̈regulierungen zu leiftenden Irbeiten

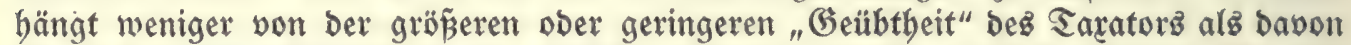
$\mathfrak{a b}$, ba von Dem überzengt bält, waz er jeben, meffen, zählen und berectinen fann.

\section{SImtrieb.}

Bizher hat man fich in Dreuß̃en gewöhnlich bamit begnügt, bie Söhe beż SImtriebes nach) allgemeinen (Errwägungen gutachtlich "anzunebmen" uno "feitzuftellen".

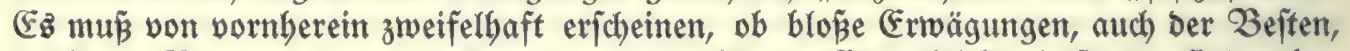

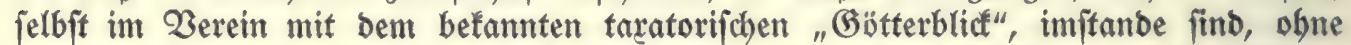
eingebende, für ben gegebenen Fall angejtellte zahlenmäpige Ërbebungen bag Richtige zu treffen. E⿺s wäre baher mindejtenz leichtfertig, für bieje wichtigfte (5) runblage Der ganzen Betriebseregullierung eine folche mur ganz ungefäbre, auf keinerlei reale Sinterlagen gejtïste Ermittelungzart ferner beibebalten zu wollen. Sinjere 3eiten forbern mit zrwingender $\Re$ otwendigteit, bei fo wichtigen grunblegenden Fragen vorweg mit aller Sorgfalt auzgiebige, einwanofreie zahlenmäpige Sinterlagen zu bejchaffen uno erfít binterher ergänzend mit allgemeinen EErtwägungen einzufeßen, um erforber=

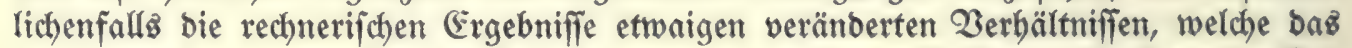
3ablenwerf nicht zum 2luzbruck zu bringen vermochte, tunlichft vorteilbaft anzupaffen. 
Sumtriebe fanm man io renig ficher einfäbäen wie Bejtandzalter. Se mebr man

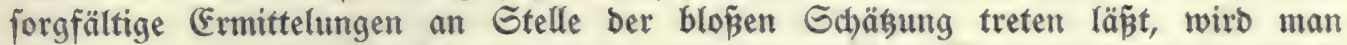
erfennen, wie weit man fich mit biejer von bem wabren $W_{\text {ert }}$ entfernt bat. Aud() bie 2lmwenbung allgemeitler Ertraggtafel=Ergebniffe allein fann Dafür alz aub= reichent nidht angejeben werben. (Das allter ber höchjten burchjichnittlichen (Bejamt= Werterzeugung if nidhts allgemein Feffitebenbes, jonbern unterliegt Edhwantungen nach) Srt und 3eit.

Slm für ben gegebenten Fall Der vorteillhafteften SImtriebşböhe auf einfachem

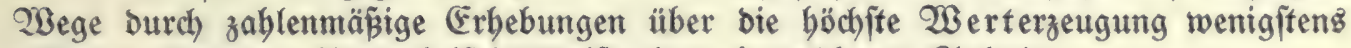
näber zu fontmen, bieten beifpieläweife einen brauchbaren 2nbalt:

a) $\mathfrak{I m}$ Rablfchlagbetrieb bie Feftitellung ber Durdyichnittlichen Werterzeugung aแร Den Gelderträgen von 2 btriebgbeftänden verichiedenen, genau befimmten Alters.

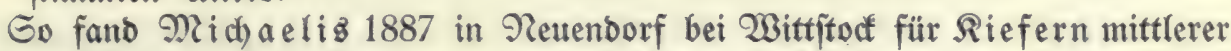

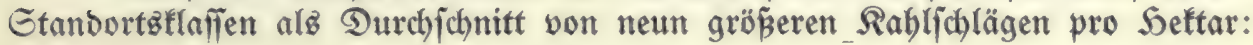

\begin{tabular}{|c|c|c|c|c|c|}
\hline \multirow{2}{*}{$\frac{\text { alter }}{\text { Sabre }}$} & \multicolumn{2}{|c|}{ Befamtertrag } & \multicolumn{2}{|c|}{ Sabresburd)idnnitt } & \multirow{2}{*}{ Bemertugen } \\
\hline & $\mathrm{fm}$ & 2x. & $\mathrm{fm}$ & MEt. & \\
\hline 90 & 324 & 2122 & 3,6 & 23,6 & \multirow{6}{*}{ 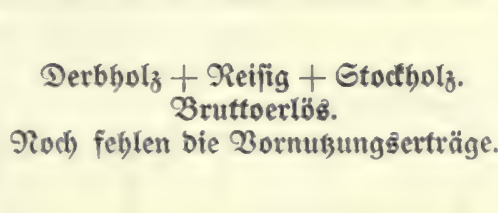 } \\
\hline 100 & 352 & 2164 & 3,5 & 21,2 & \\
\hline 120 & 370 & 2827 & 3,0 & 23,2 & \\
\hline 140 & 420 & 4177 & 3,0 & 29,6 & \\
\hline 160 & 489 & 5005 & 3,1 & 31,5 & \\
\hline 170 & 479 & 5585 & 2,8 & 32,7 & \\
\hline
\end{tabular}

b) Im Raturveriüngugzbetrieb bie Ermittelung aus ben pro Fefmeter in bejtimmten 2lttern gefundenen erntefoftenfreien Durchjobnittzerlöjen in Sieben größ̈erer Bejtandsflächen uno Den in ben nämlichen Altern pro Soeftar vor= Ganbenen oder nach EErtraggtafeln zu erwartenden 2 orräten.

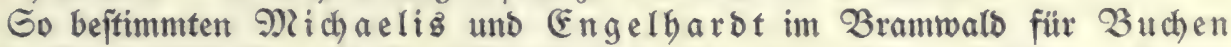

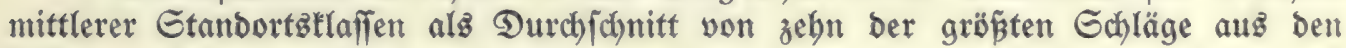
Sabren 1904 uno 1905 pro Soeftar:

\begin{tabular}{|c|c|c|c|c|c|c|}
\hline \multirow{2}{*}{\begin{tabular}{l|} 
Qliter \\
Sabre
\end{tabular}} & \multirow{2}{*}{$\begin{array}{c}\begin{array}{c}\text { Entefoiten } \\
\text { frei } \\
\text { pro fm }\end{array} \\
\text { xr. }\end{array}$} & \multirow{2}{*}{$\begin{array}{c}\begin{array}{c}\text { Ertragge } \\
\text { tafel } \\
\text { borrat }\end{array} \\
\text { fin }\end{array}$} & \multirow{2}{*}{$\begin{array}{l}\text { Geloertrag } \\
\text { erntefoiten- } \\
\text { fret } \\
\text { Drt. }\end{array}$} & \multicolumn{2}{|c|}{ Sabrezburdjid)nitt } & \multirow{2}{*}{$\mathscr{B}$ emertungen } \\
\hline & & & & $\mathrm{fm}$ & Pet. & \\
\hline $\begin{array}{c}1904: \\
110 \\
125 \\
145 \\
182 \\
1905: \\
130 \\
145 \\
149 \\
177\end{array}$ & $\begin{array}{r}5,20 \\
5,80 \\
8,32 \\
10,08 \\
\\
8,32 \\
8,96 \\
9,86 \\
10,83\end{array}$ & $\begin{array}{l}494 \\
538 \\
584 \\
645\end{array}$ & $\begin{array}{l}4584 \\
5233 \\
5837 \\
6900\end{array}$ & $\begin{array}{l}4,2 \\
4,0 \\
4,0 \\
3,6\end{array}$ & $\begin{array}{l}23,4 \\
25,0 \\
33,5 \\
35,0 \\
\\
35,3 \\
36,1 \\
39,2 \\
39,0\end{array}$ & 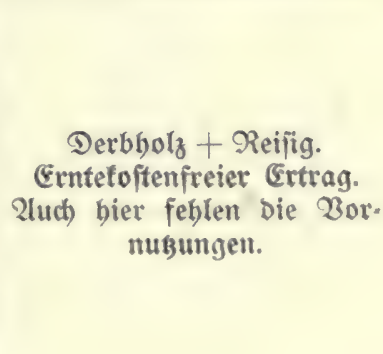 \\
\hline
\end{tabular}

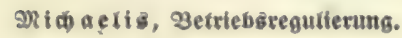


2łus unjeren Wirtjchaftäbüchern lafjen füch bie zu forchen 2lufitellungen erforberlichen 3ahlen vorläufig nicht ohne weiterez entnebmen, weil unz eine voll= ftänbige (Ertragg̈gefchichte, wie fie andere Qänder für bie einzelnen Rontrolffiguren haben, noch nicht zu (Gebote fiteht. Gie wäre unichwer zu erlangen, roenn in bem

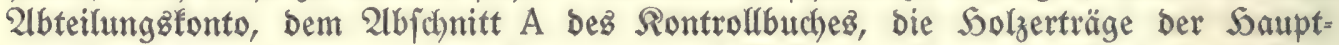
uno Bormugung in vereinfachter Form, auf volle Feftmeter abgerunbet, für bie einzelnen Sholzartengruppen gefübrt und Ginter. Der Schlupjumme auf berfelben 3eile noch in bejonberen Gpalten hinżtgefïgt würbe:

Robertrag, Werbungżoften, mithin erntefoftenfreier Ërlös.

Die Beldeintragungen rürben fïch obne erbebliche Mebrarbeit vollzieben lafien, wenn Der Förfiter gehalten wäre, unter bem Abjohlü jeber 2lbteilung im Nummer= buch einzutragen:

İ

rech $t$ bie Geldbeträge feiner (Eintragungen, nach) ben Oerabfolgezetteln auf= gerechnet.

Dieje auf ber Oberföriterei geprüfte und mit bem $3 \mathfrak{u} a \mathfrak{a}$ "auperbem Tarberlujt" ver= jebene 2lufrechnung ergibt in ber Gchlupjfumme ben Roherlös einjchließ̈lich Reifig uno

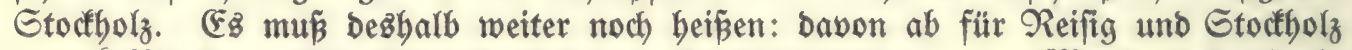
.... Marf́, mithin für nebenfifebende Derbholzfumme .... Marf, und ebenfo

3u פuiter A.

(Qinfe Geite.)

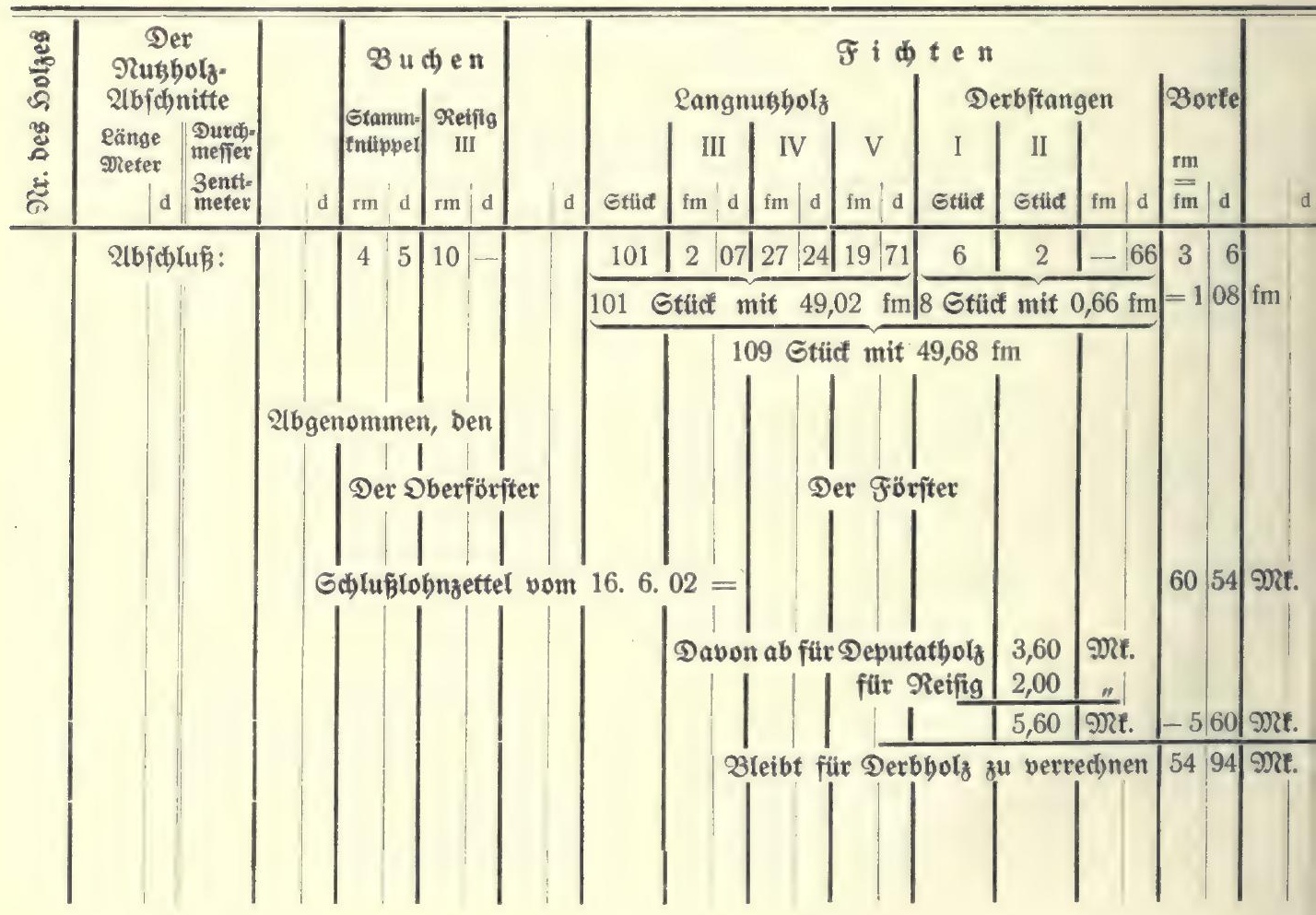


c) Die Bejtimmung Des blopent jogenannten "WBertverbältniffeğ" auz Zorrat mal mittlerem $\mathfrak{B} e$ ftandzourchmefler in $\mathfrak{B}$ rufthöbe.

Nach ben Anterjuchungen von 3 orggreve, Echumacher, (Earl, Nichaeliz, Tey, $\mathfrak{B a l t b e r}$ u. a. fteigen bie Einheitżerte (Feftmeterpreife) im allgemeinen wie bomologe Durchmeffer, alfo auch wie Brufthöhen=Durdhmeffer, waz in weiteren

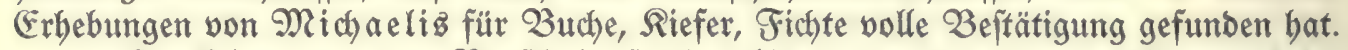

Die Obergrenze Der Brufthöbenitärten, biz zu relchen diez zutrifft, reicht bei

$$
\begin{aligned}
& \text { Eiche biz } \frac{80-90}{85} \mathrm{~cm}, \\
& \text { Buche " } \frac{60-70}{65} \mathrm{~cm}, \\
& \text { Riefer " } \frac{50-60}{55} \mathrm{~cm}, \\
& \text { Fichte " } \frac{30-35}{33} \mathrm{~cm} .
\end{aligned}
$$

\begin{tabular}{|c|c|c|c|c|c|}
\hline $\begin{array}{c}\text { Brujt } \\
\text { böbe } \\
\mathrm{cm}\end{array}$ & (Eict)e & Bucbe & Riefer & Fid)te & \\
\hline 30 & 100 & 100 & 100 & 100 & \\
\hline 40 & 100 & 100 & 100 & 90 & \\
\hline 50 & 100 & 100 & 100 & 70 & auf welchen Betrag bei ben böberen Durd)= \\
\hline 60 & 100 & 100 & 90 & 60 & mefiern bas einfache Probutt aus Borrat \\
\hline 70 & 100 & 90 & 80 & - & mat mittlerem Beftands-Durchmefler in Bruît \\
\hline 80 & 100 & 80 & 70 & - & böbe zu erniebrigen ift. \\
\hline 90 & 90 & 70 & 60 & - & \\
\hline 100 & 80 & 60 & - & - & \\
\hline
\end{tabular}

Darüber binauz finft ber $\mathfrak{W e r t}$ etwa auf bie folgenden Sundertiftel:

Man bat alfo an ber Sand realer 2 Berte ober nach) Ertraggtafel=21ngaben bie Rechnung für Den Saupt und 2 orertrag Durchzufübren uno feftzujtellen, in

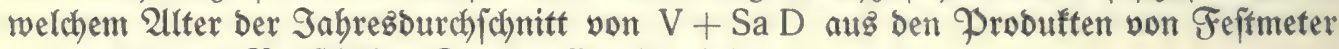
mal mittlerem Brufthöhen=Durchmefier fulminiert.

Da bie Etärteentwicfelung bei fonít gleichbleibender Büte ber 2lusformung

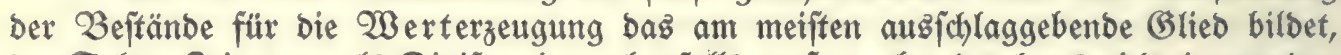
ber Faftor 3eit zwar als Divifor einen ebenfalls gropen, aber burchaus nicht immer ben

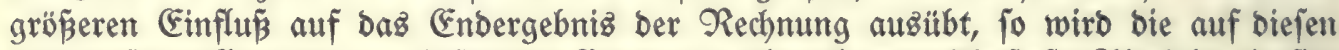

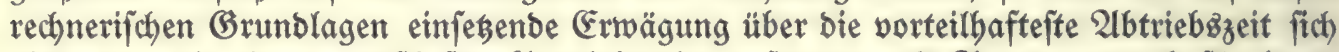

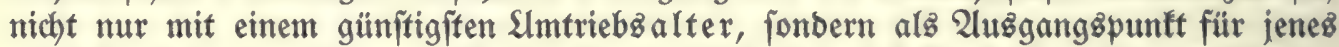

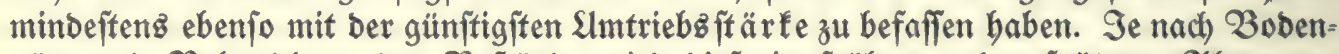
güte und Bebandlung ber Beftände wirb bieje in früheren ober fpäteren Alltern er=

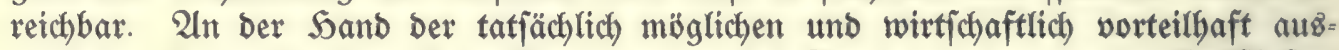

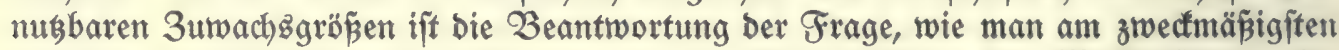
zugleich wertmehrend und zeitjparend auf bie Bejamtleiftung Der Waldbeftänbe ein= wirfen fönne, eine unjerer wichtigften 2ufgaben. Zu vergleichen ben 21nbang.

Alle bisker angefübrten 3ablen weifen auf bie Notwendigfeit von Starkbolz.

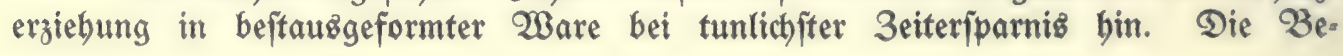


hauptungen, ber Bebarf an Gtartholz fei bei uns gar nid)t fo grof, beshalb feien bie Mittelfälzer bie relatio beftbezahlten, es genügten baher Slmtriebe, weldhe bieje lieferten, entbebren dez mit einmandfreien 3 ahlen gefübrten Beweijez. Sie finben vielleidht in einer an fich richtigen Beobachtung mit angeichloffener falf(c)er Folgerung

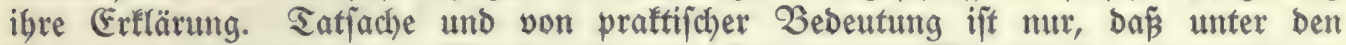

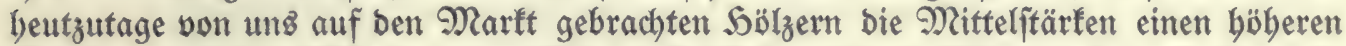
Inteil an glatter $\mathfrak{B a r e , ~ n a m e n t l i c h ~ b i n f i c h t l i c h ~ i n n e r e r ~} 2$ litreinbeit, enthalten alz bie Gtarkhölzer. Taz foll und muß bei jorgfältiger Beftanbzerziebung uno opflege für bie 3 ufunft anders werben. Im übrigen finden jene Bebauptungen aflein fdjon

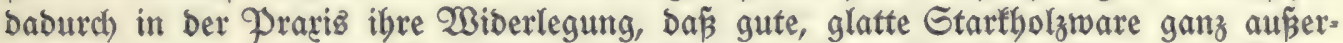
orbentlich bod) im Dreife ftebt, mit alleiniger 2 ušnabme vielleicht von Fichte. Zluserbem bringt aber auch eine Starfholzerziehung aus ibren Durchforftung: = uno Qid)tungghieben to biel an mittleren uno fdyachen Sölzern auf ben Martt uno wirb Darin won ben Durchineg mit niebrigen Slmtrieben arbeitenben Privat= unb Gemeinbe $=$ ufw. Forjten noch Derart überboten, Daß Der Bebarf Giervon Ginreichend

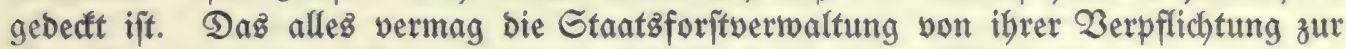
Starkholzerziebung nicht zu befreien, höchitenz um fo ernftlicher Daran zu mabuen.

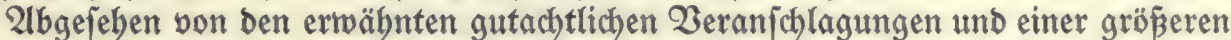
3 abl rein theoretifcher, ebenjowenig immer eimwandfreier Berechnungen und $E r=$ wägungen feblt es uns noch) jebr an praftijchen, aus tatjächlichen b̈rtlichen Wirtfchaftż= verbältniffen berauz entnommenen, Durchaus beweisłräftigen Erbebungen uno fort= laufeno gefammelten 3 ablen, welche ber Slmtriebsbeftimmung eine fichere Grundage

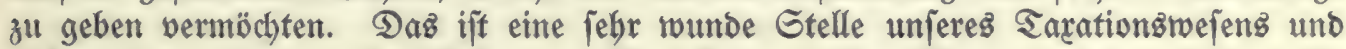
nicht minber unjerer Budbfübrung. Se offener biejer Mangel zutage tritt, befto bringlicher mabnt er zu einer grünblichen, fich ferner mit allgemeinen Rebenzarten nicht mebr begnitgenden albhilfe.

Bir buchen zwar binreichend genau ben Solzertrag, aber etwaz Bejtimmteg

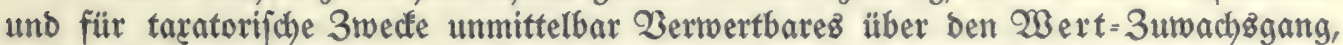
über Den Erlös ber einzelnen Arten unb Gtanbortžllaflen in ben verichiebenen 2llterz= ftufen uíw. fammeln wir in unjeren WBirtfchaftäbüchern nicht, ober gruppieren ez

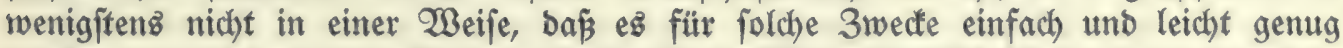
nugbar gemacht werben fönnte. 2luds bie forfftiche Statiftif iff in ibrem Geutigen

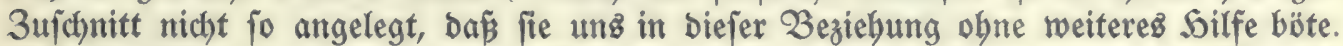
Dảs jorgfältig Darin aufgebaute 3ablenwert if zwar burchweg aus ber Praxiz gefchëpt, vermag aber in feiner jesigen Form zu wenig für bie Prariz unmittelbar wieber $\mathfrak{B}$ erwertbares gerabe für bie SAmtriebsbeftimmung zu liefern. SAnb boch Dürfte bas bierfür 3 rauchbare nicht gar zu f(d)wer fich barauf zufchneiben laffen, wenigftens bie ungefäbren Brenzwerte fef́tzulegen. Denn waz Der Yrariz barin zunächjit gute Dienite leiften fann, iff ba, wie Geite 17 biz 19 gezeigt, es braucht obne gelebrte ober gejuchte Feinbeiten mur möglichfit flar uno burchfitchtig vor 2lugen gebracht zu werben, erreichbar uno greifbar in einfachen, zruedfääpigen Formen. 2luch bier wirb ez in Göherem Mape als bisher heifen müffen: vom Flect zum 3twed!!

Im weiteren wiro auf bie 2luвffübrungen bez 2lnhangez verwiejen. 


\section{Dritter 21bichnitt.}

\section{$\mathfrak{A} \mathfrak{u} \mathfrak{B} \mathfrak{i} \mathfrak{i} \mathfrak{h} \mathfrak{x} \mathfrak{u} \mathfrak{n} \mathfrak{g}$.}

\section{A. Zorarbeiten.}

Sebe Betriebsregulierung hat in Dreußen mit Der Einleitung: $=\mathfrak{Z} e r=$ banblung zu beginmen bebufz Feffitellung ber allgemeinen (Gefrchtspunfte. Sierzu treten ber Oberforftmeifter, Der Foriftrat (gewöbnlich Tarations=-Rommifiar) und Der Oberförfter zu einer in ber Regel won Dem Minifterial=Rommiffar geleiteten $\mathfrak{B}_{e}=$ ratung zufammen. Die Ergebniffe werben in Der Dem Minifter zur Genebmigung vorzulegenden Einleitung $=$ Berbandlung niebergelegt.

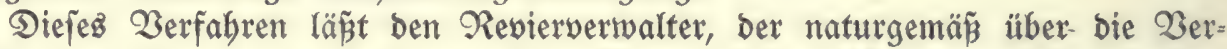
Gältniffe jeines Reviers Der beftunterrichtete Beamte fein müs ste, nur felten in bem

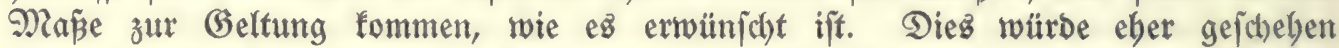

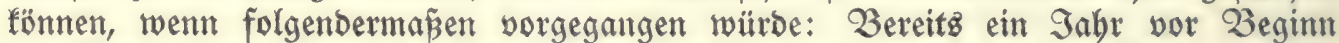

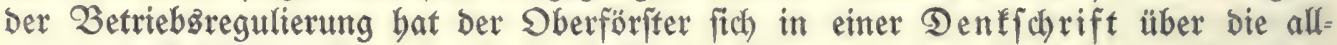

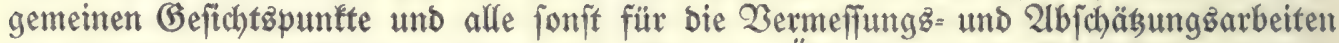

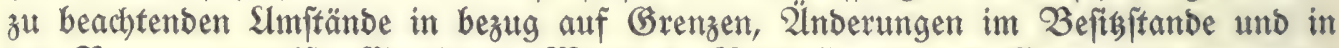
Der Bemugungäweife, Činteilung, Wegeneb, Zermeīungäwerf; Grunbzüge ber neuen

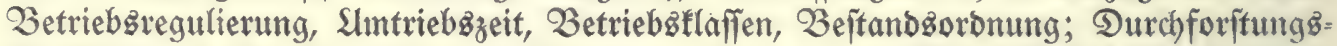

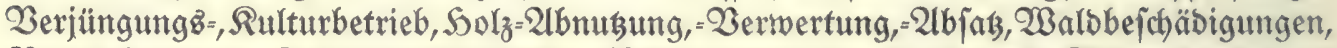
Berechtigungen, 21rbeiterverbältniffe, Nebenmukungen, Jago uno Fifcherei ufr. zu äup̃ern. Da Sauptgenicht hat er Dabei auf Die Grundzüge Der neuen Ëintichtung

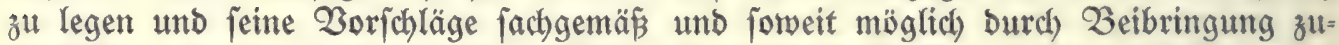

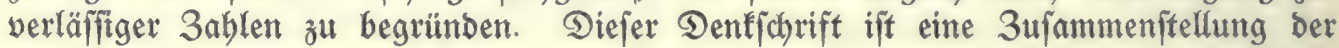
pro Softar erzielten erntefoftenfreien Ërlöje auz abtriebzerträgen ober fonítigen Siebsergebniffen von Den hauptfächlich vertretenen Bobenflaffen ber vorbandenen beftandbildenden Solzarten, und zwar aus Den für Den SAmtrieb in Frage fommenden höberen und böchfiten Altern, wie unter $\mathfrak{T r} .3$ "SAmtrieb“ angegeben, beizufügen.

Ferner ift zu ermitteln, welche noch brauchbaren Rarten und Bermeffungz: fardiften vorbanben, wann bieje zum legtenmal berichtigt, wie fie bei friberen Pad)= prüfungen beurteilt fint, und welche Entfcheibung etwa binfichtlich ber weiteren $2 \mathfrak{e}=$

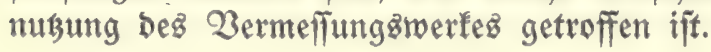


2luf Rlarbeit, 3eftimmtheit uno Rürze im 2lugbrudf ijt, wie bei allen Darftellungen in Betriebşwerf, bejonderer 2 Bert zu legen.

Tachbem bieje Denffchrift Dem Forftrat, Dem Oberforjtmeifter uno bem Tarationz=-Rommiffar zur Begutachtung vorgelegen, roiro fie Dem Minifterial=Rommiffar fur weiteren Ëntficheibung eingereid)t.

2lsbamt erfít treten bie (Genannten zu ben etwa noch erforberlichen örtlichen Prïfungen zufammen, Deren Ergebniz in Der Einleitungas: Berbanblung niebergelegt wirb, in welcher auch über bie 2lrt ber 2lubfübrung unb beren äufere Forn $\mathfrak{B} e=$ fitimmung ou treffen ifít.

Fragen, über bie eine Einigung nicht hat erzielt werben fönnen, enticheibet

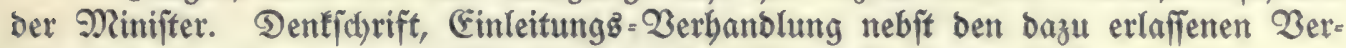

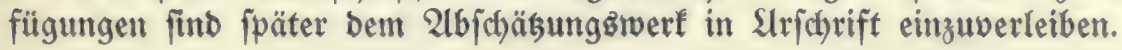

\section{B. Sauptarbeiten.}

Tie (G) runblagen ber abjdägung bilben:

1. Die $\mathfrak{B a l b f l a ̈ c b e ~ ( S o l z b o b e n ) , ~}$

2. Der Solzbeftano.

Beibe werben feftgelegt burch bie 2 ufnahme Deв 2 albzuftanbeg. Sierzu liefert zunächit bie geometrifhen Grunblagen:

\section{Die Frächenanfuabme.}

Sie umfañt bie Feftitellung bez Befífitandes uno ber Flächenverteilung (bes jogenannten "2lrealzuitanbes").

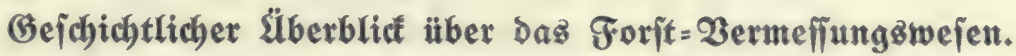

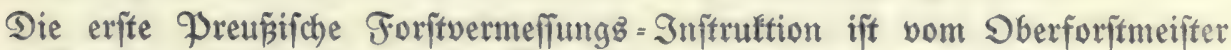
v. Webell gemeinfchaftlich mit bem Bauinjpeftor $\mathfrak{B e i z l e r ~} 1763$ benrbeitet, bann weiter ausgebaut Durch Den Oberforitmeifer v. Rropff 1783 und burch Sennert in feinem "Reglement für bie Ingenieurz zur Bermenfung Der Forf́ten" 1787. Qegterę bringt Einbeitlich)eit in bie Rartenwerfe:

"Brouillon = (SIrs) Rarten" $1: 5000$;

"Rebuzierte Rarten" 1:25000,

Darunter Beftandafarten mit Solzartenfarben und Baumfiguren; "Foritfituationşarten" $1: 100000$.

Dieje Sennertiche Grundage wurbe neu bearbeitet uno ergänzt durch (5. . Sartig zu Der "Inftruftion für bie Prenpifchen Forftgeometer" 1819.

Die Längen wurben anfänglich) Durch Echrittmeffung beftimmt, zur $23 i n f e l=$ aufnagme biente gewöhnlich bie Bufiple. Erift unter bem Einflué ber Lanbez= 
vermeffung uno ber Inftruttion für Geobäten von 1857 ifit an bie Etelle Der 3 unfole für bie Simfangåmeffungen Der Sheodolit getreten.

Das neuere, auf forgfältigiter Arbeit "wom Gropen inz Rleine“ rubenbe $B e r=$ fabren ber Forftuermefiung findet fich ausfübrlich Dargejtellt von Forftrat Defert in "Sorizontalaufnalyme bei Reumefinng ber $\mathfrak{B a ̈ l b e r " ~ 1 8 8 0 . ~ F e r n e r ~ b i e t e t ~ e i m e ~}$

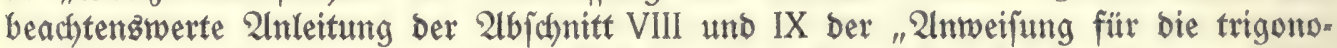
metrifchen und polygonometrifchen 2lrbeiten des Grunbjteterfatafterg" von 1881. Beibe find beriaffitchtigt in "WBalbvermeffung und 23 albeinteilung" von $\Re u n n e=$ baum 1890. Ferner ift mä̈gebend: Serrmant, "Die Wreupifichen Forftfarten" 1898.

\section{a) Grenzen.}

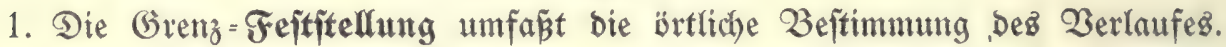
Gie hat unter 3uziebung Der 2lıgrenzer und ber nächjtbeteiligten Forjtbeamten zu gejueben.

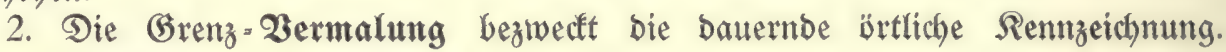
Man unterifheibet:

Natürliche, weldhe mur zugelaffen, wenn Beränderungen nicht zu befürdhten

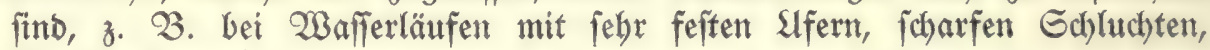
พBăllen u. Dergl. in.

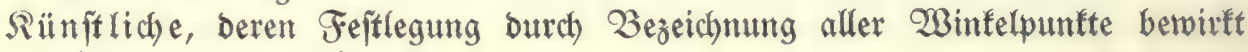
wirb, und zwar mit:

Etteinen (am ficheriften). Dieje follen genügend grop $(0,70 \mathrm{~m}$ lang, $20 \mathrm{~cm} \mathrm{im} \mathrm{Quabrat),} \mathrm{auz} \mathrm{feftem} \mathrm{Material} \mathrm{fein,} \mathrm{tief} \mathrm{eingejeßst} \mathrm{werben,} \mathrm{auf}$

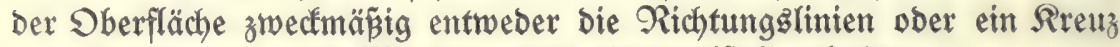
zur Beftimmung Dez Binfelpunftes eingemeipelt erbalten.

Siłgeln (ungenau und unftcher), beren Mittelpunft (Deṕpunft) unter= irbifch zu fichern iff burch pogenannte "Runben" (Eteine mit + , aufrechte Drainröbren upw.).

Pfäblen als Votbebelf auf Durchbrübigen Böben, :-Brïchern, Gee= rändern $\mathfrak{u}$ in.

In allen Fällen mur freie Überficht von Mal zu Mal möglids fein. Slm biefe zu erleichtern, find erforberlichenfalls 3wifchenmale, jogenannte "Qäufer", eimzuldualten.

Giräben alfein reichen in Der Regel zur Bezeichnung ber Brrenzícheide nicht aus, weil ihre Lage veränderlich ift. $\mathfrak{B}_{\mathrm{enn}}$ fie angetwandt werben, ift auperbem zu vermerfen, ob Mitte, Innen= ober 2lupentante bie Grenze hălt.

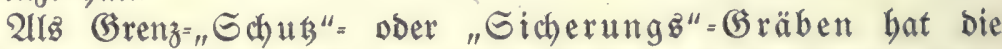
Anlage fo zu gejchehen, Daj ber ganze Graben auf Forftgrund liegt, aljo, falls nicht noch eine "Stellwanne" belaffen wirb, minbeftens bie 2lüenfante in bie Grenzlinie fällt.

3. Die Grenz= શumerierung. Sierfür gilt: jebez Grenzmal erhält eime

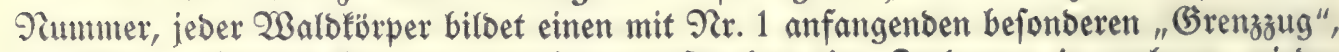
vierzifferige 3 ablen find zu vermeiben, Dafür hat eine 3erlegung in mebrere wieber mit 2 r. 1 beginnende 3üge Dlas zu greifen; Beginn Der Nummerfolge in SO., 


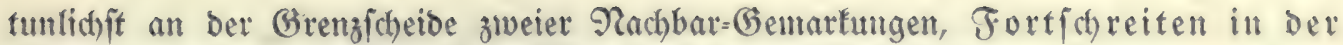

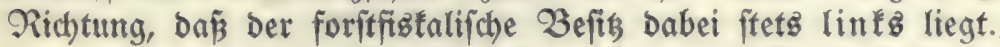

Fine örtliche Nummerbezeichnung foll möglichft überall, minbeftenz aber auf allen idharf ein= und ausfpringenden Edpunften, forwie auf bem je zebnten

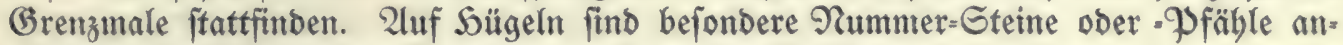
zubringen, mit jobarzen Nummern auf weišen Echilbern.

4. Die Grenz=2ufnabme befteht in:

a) unmittelbarer Reffung ber wagerechten Entfernungen unb Der 23 intel,

ß) mittelbarer Bejtimmung jebr frummliniger natürticher Gerenzläufe mittelż rechtwinfeliger s̈berjchläge von feftgelegten, am beften in ben (Eäpuntten auch) vermalten, Polygonfeiten aแษี.

5. Die Brenz=Daritellung ift eine

a) fartographifche, auf Den Epezialfarten im Mañftab 1:5000. Sie mui erfitctitich machen:

fämtlicbe Brenz $=\mathscr{2 B i n f e l p u n f t e , ~}$

fämtliche natürlichen und fünftliçen Brenz-Qinien,

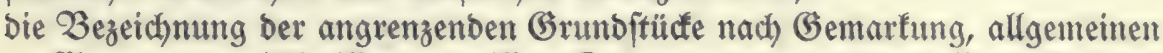

Eigentumżverbältniffen, gewiffen Rulturarten und beren Garenzicheiben.

3ur leichteren SAntericheibung wirb eine boppelte $5 \mathrm{~mm}$ breite lichtere unt $2 \mathrm{~mm}$ breite butflere farbige $\mathfrak{B a n b i e r u n g}$ auf Der 2 unenfeite ber Girenzen angebracht, uno ztwar:

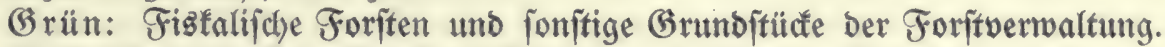

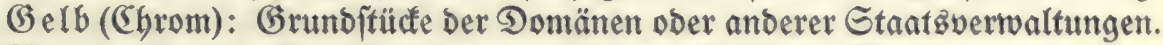

Blau: Genofienjchaftßforiten, an benen Fißłuz Miteigentum bat.

Orange (Mennige): (Benofienjd)aftäpriten ohne Miteigentum beż Fiźuz.

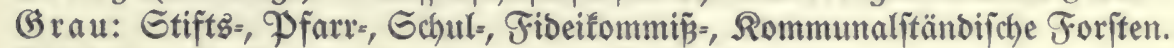

Biolett: Forifen ber hannoberichen Rlojterfammer.

Braun (Serrafiena): alle übrigen Forften.

Rarminrot: alle übrigen fremben Grunditültée.

ß) tabellarifhe, im Grenzregifter ober unter Slmftïnben in vereinfachter

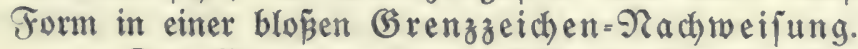

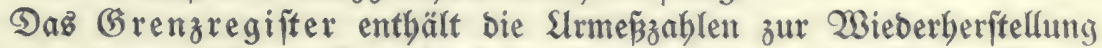
eimez etwa "yerbunfelten" Grenzlaufez. Ëz wirb bezogen auf ben Grenzs ơlufand eines beftimmten Tagez, z. 3. 1. 10.05, unb hat auf bem Titelblatt 2lngaben über bie Entitebung, bie benugten Grundlagen zu entbalten uno bie

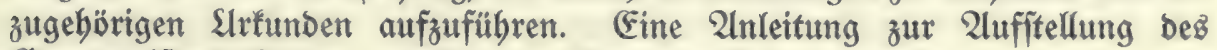
Grenzregifters ift bem zugebörigen Formular 3 vorgebructit.

In bem Grenzregifter, ebenjo in Der außbilfäweife ftatt feiner aufs geîtellten Grenzzeichen-2lachweifung, fint nacheinanber aufzufübren:

A. Die Grenzen ber zujammenbängenden Sauptteile bez Reviers,

B. Die Grenzen ber eingefchloffenen fremben (Grunditüde ("Enflaven"),

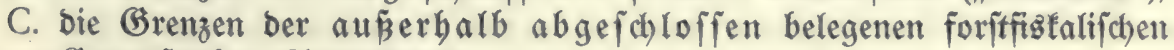
(Brunditüle ("Parzellen"),

und ztwar jebe einzelne Gemarfung in jenen unter befonberer s̈berichrift, 3. 3. 1. Grenze mit ber Ġemartung $M, 2$. uíw.

Daz̆u nachiftebend ein Mujter. 


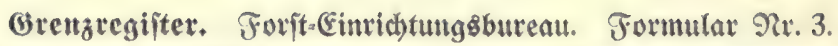

\begin{tabular}{|c|c|c|c|c|c|c|c|c|}
\hline \multirow[b]{2}{*}{ 冚 } & \multirow[b]{2}{*}{$\begin{array}{l}\text { 3cucnnung } \\
\text { Deต́ } \\
\text { Foritorts }\end{array}$} & \multirow[b]{2}{*}{ 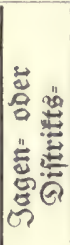 } & \multirow[b]{2}{*}{ 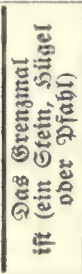 } & \multirow[b]{2}{*}{ 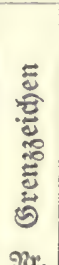 } & \multicolumn{3}{|c|}{ Grenze Des Forites } & \multirow[b]{2}{*}{ 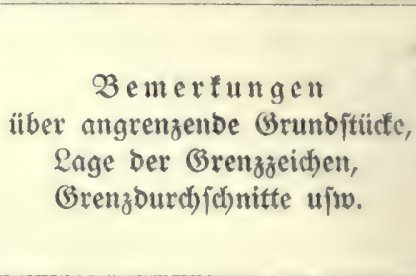 } \\
\hline & & & & & 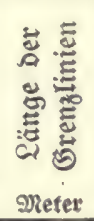 & 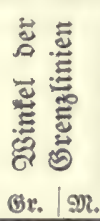 & 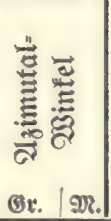 & \\
\hline
\end{tabular}

\section{A. Sauptteil Sobebetbe.}

1. Grenze mit ber Bemartung G.

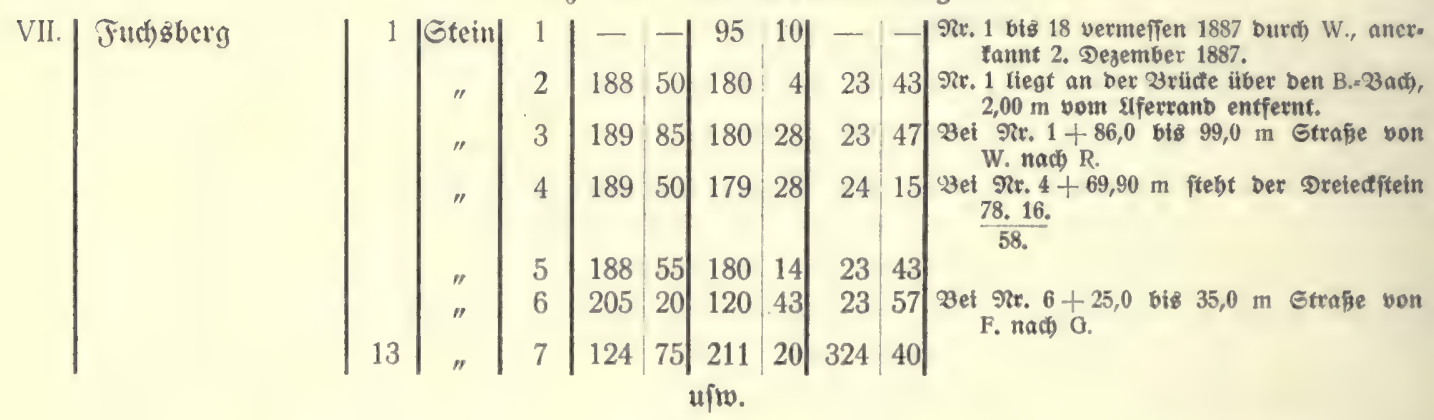

Der von feiten Dez Geometers berbeizuführenden "auß̃ergerid)tlichen" 2nerkenmung (Forjt:(Einrid)tungäbureau, Formular 26 uns 27) Der Richtigfeit Dez örtlichen Grenzzuftandez uno Dez Bermefintugg̈werfez fann burch gericht= lichen 2lft bejondere urfundliche Bebeutung verlieken werben.

Die Grenzzeidhen= Nachweifung enthält won Maß̧en nur Längen= und ungefäbre Winfelangaben, unb zwar bei ben Winteln gewöbnlich be: fchränft auf $\mathrm{A}=$ aušppringent, $\mathrm{G}=$ geftrectit, $\mathrm{E}=$ einjpringenb, ober bezogen auf bie Richtung bez Grenzuerlaufez: $R=$ rechtz, $G=$ gerabeaus, $L=$ lintz.

Aluszüge Dez Grenzregifters, eintretendenfallz ber (Brenzzeichen= ఇarbweifung, ober Rartenauzzüge, fogenannte "Grenzcouponz", mit eins gejchriebenen Rängenangaben werben zum Sandgebraudbe ber Förfíter gefertigt.

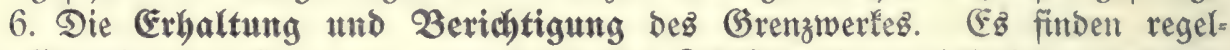
mäpige (Grenzbegänge ftatt, unb zwar burch Den Förfter eimmal jährlich, Durch ben

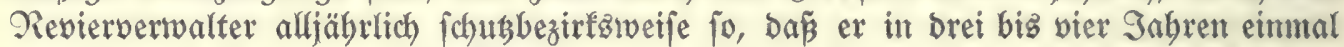
herumfommt, burch Den Injpeftionabeamten jäbrlich ein Gdubbezirf, jedeżmal in einer anberen Oberförfferei. Der Befund wirb fariftlich niebergelegt. Bei Einleitung Der 3 etriebz=Regulierungz̊arbeiten if Durch Den Taxator eine bejondere Begebung fäntlicher Grenzen Der Oberfürifterei unter 3 uziebung Dez betreffenden Förfters vorzunebmen.

Bei biejen Ģrenzbegängen ift zu prüfen, ob

bie Grenzbermalung ober fonftige Bezeichnung volfftänbig uno auzreichento ober verbefferungäbebürftig ift,

bie Grenzlinien frei und überfichtlich fint,

Überichreitungen in Der Bobenbonubung ftattfinton, 
Sarte und (B)

Bezeid)nung und Darftellung ben einfchlägigen Beftimutungen entiptid)t.

Eingetretene Beränberungen Des (brenzzultandes find alliäbrlich Durch Den Reviervervalter in Das Sauptmerfbuch und in bie Spezialfarte einzutragen, und ztwar alle Berichtigungen von Ëigentumg̈grenzen auf Der Rarte rot. 2lußserbem werben

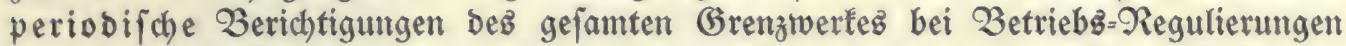

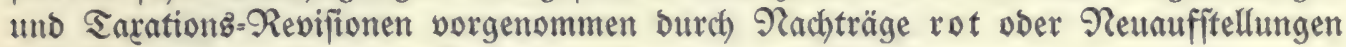
Deళ̊ Gืanzen ober einzelner Teile.

\section{b) Wirtichaftliche Cinteilung ber Oberföriterei.}

1. Cinteilung in Bröcte. Allgemeiner Brauch war biăher in Preñ̃en eine 3erlegung beg̊ räumlic) weit ausgebehnten Berwaltungäbezirfę (Oberförf́terei) in einzelne Ortabbezirfe, "Blöcfe", um in engerer Abgrenzung Hleinere Eintheiten alz felbitänbige Wirtichaftżganze mit in fich abgejchlofiener unb abgeglichener 2literg̈=

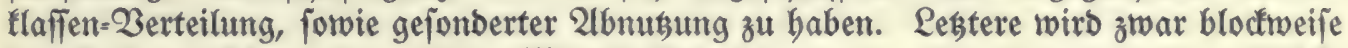
bered)net, nachber aber beim WBirtjchaftżodlzuge nur bie Gumme aller Blöfée gemeinfam im Rontrollbuch gefüfhrt. Folgerichtig wäre nur: entweder - ober!

Bei ben gegentwärtigen Berfebržverbältniffen ift, wie fchon früher erörtert, eine folche Snterteilung, "Blod́bilbung", für ben 2luşgleich zur Gicherftellung aug̈= reichender B̈rtlicher 3 ebarfäbefriebigung faum noch Erforberniz, fonbern jchabet leid)t mebr, ałB fie nübt, benn jede SAnterteilung erleichtert nicht, fonbern eríchwert

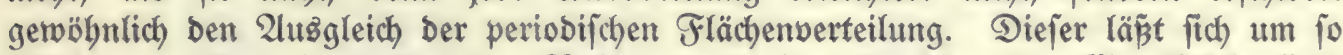
leichter erreidhen, je weiter ber Rahmen uno je zahlreicher bie Einzelf́tücfe fino, welche in ein Wirtichaftżganzes zujanmengefä́t werben.

2lrs befitimmend für bie 3erlegung in "Blöfe" bie Berfchiebenbeit ber

Abfagberhältniffe, z. B. gejchieben burch Gebirgalamm und bergleichen, alfo

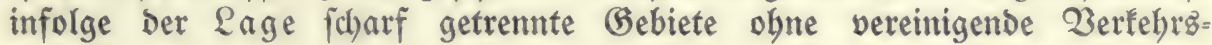
mittel,

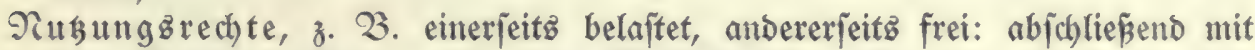
ben Pugungg̈gebieten, wie etwa 2 Beibebezirfen ujw. Der einzelnen Ort= ichaftent,

3obenverhältniffe, 3. 3. einerjeitż Söhenboben, anbererjeitz Tieberungaz= boden,

Beftanbsverbältnifje, z. $\mathcal{B}$. Solzarten febr verjchiebener Siebzreife uno Nusbarfeeit,

Betriebsart: 50 ch)=, Wlenter $=$, Mittel=, Nieberwalb.

Die Berfdiebenartigfeit alf biejer Berbältniffe fann zur Bloúfeinteilung

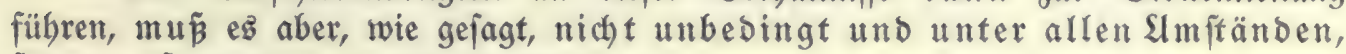

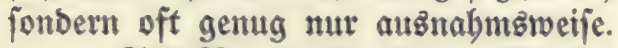

2llz Regel gilt: Seben Bloct ungetrennt in einem Grhubbezirf zufammen zu belaffen. Die Berteilung eimes Blodez auf mehrere Eduubbezirfe wird vermieden

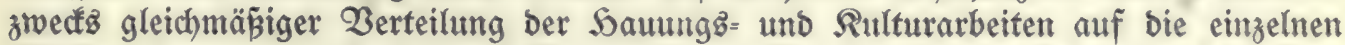
Förfter, bagegen Die 3ujammenfaffung mebrerer Bröcfe zu einem Gdułbbezirf bäufiger angewandt. 
Rartenbezeiduntug: Grenze und zugleich Schubbezintżgrenze:

fd warz im $\mathfrak{S o d}$ ) = und Plenterwald, sinnober im Mittel= und Piederwald.

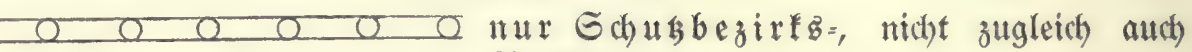
Bloctgrenze.

Tumerierung: ftehende römifbe 3iffern:

fd) warz: im Sod $)=$ und Plenterwalb,

zinnober: in Nittel= and Nieberwarto.

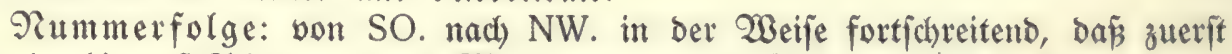
alle Sod $=$, hierauf Wlenter=, bann Mittel $=$ und zulegt Nieberwaloblöcte fommen.

Örtliche $\Re$ ummerbezeid)nung auf Gteinen und bergleidben finbet nicht itatt.

2. Einteilung in Wirtichaftzinguren (Jagen ober Diftrifte, fowie Schläge),

b. h. Fläct)enabfchnitte

mit bauernber 2lbgrenzung,

beftimmt zu gleichartiger, in erifter Sinie gleichzeitiger wirtichaftlicher $3 e^{\text {s }}$ foll: hanblung,

แnabhängig von wed) felnden 3 eftandz= Zerfchiebenbeiten,

ein ben breibenden ftandörtliden Berbältniffen fich anpaffendez,

ben Getriebszweden entipredenbes

Neţ über Daz Revier legen.

Sie birbet ben Rahmen für bie Wirtict)aftifübrung unb bietet banit bie (b) rutrolage für

Den 3 etrieb (Siebsfuibrung, 2literboronung),

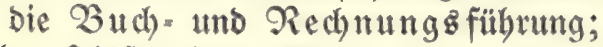

gewährt Silfsmittel für

$\mathfrak{S o l} \mathfrak{z} \mathfrak{b r i n g} \mathfrak{u n g}$,

Forfifdu,

Iagobetrieb

und bient Der Ërleid)terung Der

$\mathfrak{O r t z}=\mathfrak{B} e z$ eichnung uno =2luffindung.

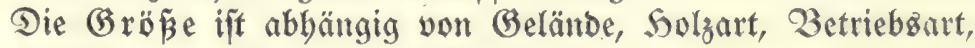
wirb fleiner im $\mathfrak{B e r g}=$ unt Shägelland,

grö̈er in Der Ëbene;

fie beträgt burd)jchnittlich für

Qaubbolz 25 bis 30 ha,

Nabelfolz 20 biz 25 ha,

bei Fichte im Berglant berab biz 15 ha und meniger,

in Den Oftprovinzen bei "aufgefpaltenen" alten Quabratjagen 22 biz 32 ha.

a) Sagen: "regelmäpige", D. h. gerablinige, fogenannte "fünftliche" Begrenzung.

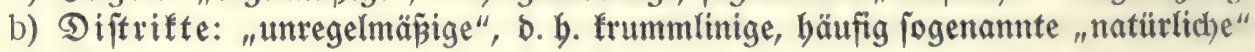
Begrenzung.

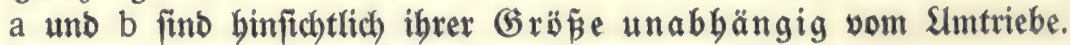

c) Echläge: regel= und unregelmäp̉ige Begrenzung. 
In bezug auf Grö̋́pe unmittelbar abbängig vom SAmtriebe alz "Iabreģ|chlag" = Flächen $\frac{\mathrm{F}}{\mathrm{U}}$.

a) Für bie Iagen=Ëinteilung, angewanot in ber Ebene, in alleitig regjamem (Gelärbe, bilbet bie Regel:

Die Rechtedform 1:2, mit ber langen Geite gegen bie herridhende Gturm= rithtung getehrt, in biefer Form unb Stellung meift bervorgegangen attg ber Teilung alter Quabratjagen.

Nǻgebend für bie Ridhtung ber Einteilungalinien ijt bie:

Form bes 2 Baldéprpers,

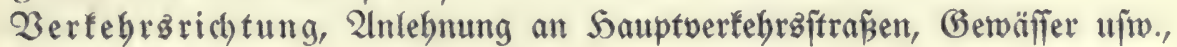
Windrichtung.

Die Grenzen ber Wirtjchaftifiguren, jowohl a wie b uno c, follen:

nict) $\mathrm{t}$ abjezen, jondern obne Sinterbrechung fortlaufen, in igren Sreffpunten feine jebr ipigen winfel bilben, tunlich fit fabrbar jein.

b) Für bie Diftriftg = Einteilung in bergigen Revieren, in befchräntt wegjamem (Gelände, wirb geforbert:

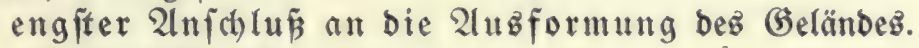

Dabei bilben bie

(brunblage:

Săler (Wafferläufe) und

Söbenrü den, powie

Gättel, Päffe als niebrigite unb leichtefte S̈bergänge über Den Ramm von einer Salfeite nach ber anberen.

Silfzmittel:

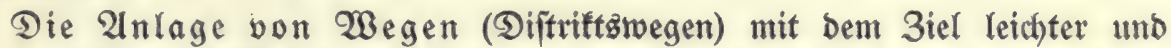
Dabei tunlich) ft furzer Fabrgelegenbeit fïr bie Solzbringung uno, jorweit bie erifteren für bie Ëinteilung nid)t ausireichen ober nicht verwenbbar find,

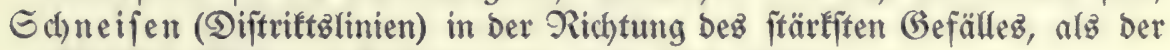
fürzeften Pinte zux Teilung won oben nach unten.

Tunlich fit regetmäß̈ige Form ber Diftrifte if anzujtreben.

Benennung: Bei Der Sageneinteilung heipen bie Teillinien "befterle". Sauptgeftelfe, OW.=Richtung, mit fitebenden grö́en lateinifchen Buchfitaben in Drudfichrift bezeichnet, yon S. nach N. aufiteigend.

Feuergeftelle: SN.= Richtung, mit ftehenben fleinen lateinifhen Suchjtaben in $\mathscr{D}$ rucfichrift, von $\mathrm{O}$. nach W. fortichreitend.

Sagen und Diftrifte:

mit arabifhen 3iffern fortlaufend burch alle Teile ber Oberföriterei,

in SO. beginnend,

in ben Reiben von O. nach W.,

bie Reigen jelbit in nörblicber Richtung auffiteigent.

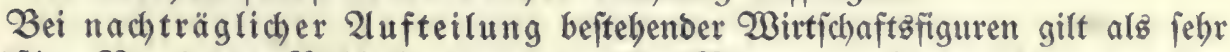

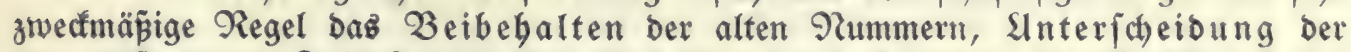
neu entftandenen Seil-Sagen ober Diftrifte burch 3 ufegen Der Buchifaben Dez grofen beutfden 21(pbabets, 子. $3.27 \mathfrak{A}, 27 \mathfrak{B}$ uff. 
Ulm bie Stetigfeit bes Wirtichaftabetriebez nicht zu ftören, empfieblt ę fich), bie beftehende wirtichaftliche Einteilung einez Revieres nach Möglich feit beizubehalten und ä̈nderungen baran nur vorzunebmen, wenn fich Davon greifbare Borteile er= warten laffen.

Örtliche Bezeichnung erfolgt burch Anbringen ber Ingen= ober Diftrif̌z: nummern und Beftellbuchfitaben (fchwarz auf weipen Gchildern) an Sagen= ober
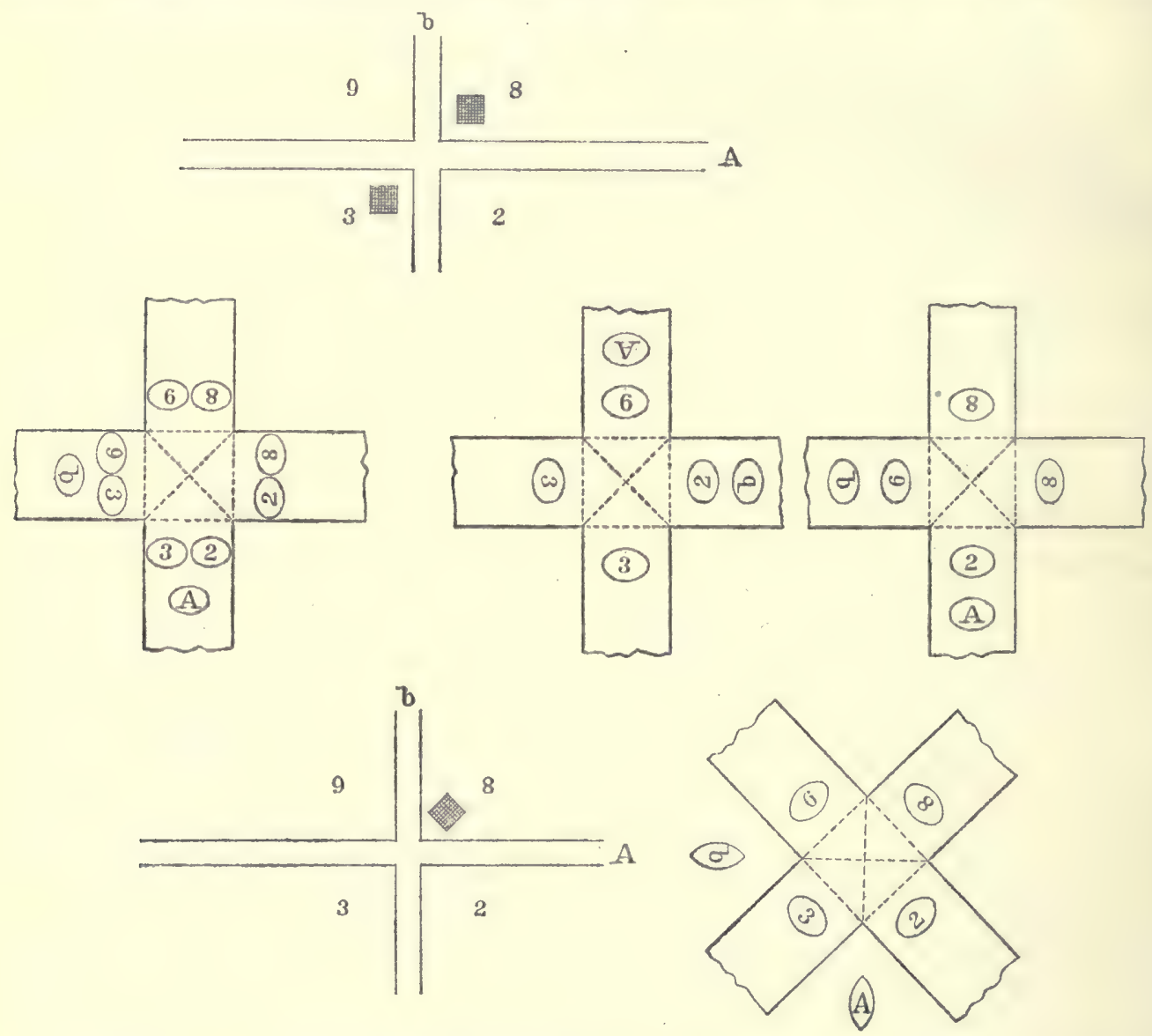

Diftriftżteinen. Shierzu werben verwendet an Den Rreuzpunften der Ingen(Diftriftza)(Brenzen:

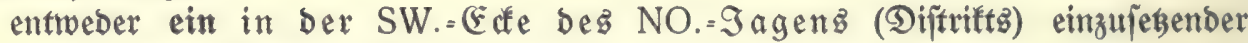
größzerer behauener Gtein,

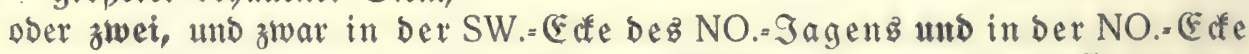

Dez SW.= Iagenz oder Diftriftz aufajtellende, bie bam Eeitenflächen von geringeren 2 bmeffungen zu haben braudien.

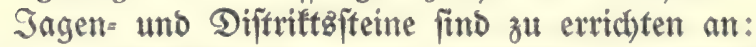

allen Treffpunften von mebreven Iagen=(Diftriftzs) (Brenzen und ba, wo restere auf bie Reviergrenze auslaufen. 


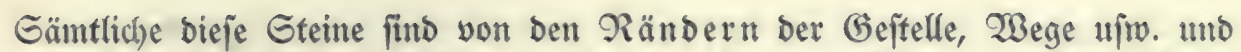
von ber Reviergrenze $2 \mathrm{~m}$ walbeinwärtz und mit ibren Eeiten gleichlaufend zu ben erfiteren zu fegen.

Trebeniftehent ifft Diez bildich) veranichaulicht. Dabei fino unten bie Geitenfläd)en Der Darüber eingezeidyneten Steine nach Dem Borgange von Edhilling, "Betriebz=

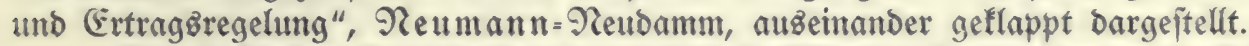

2lm leichteften finnverwirrend auf einfache Menfchentinder vermag bie Säufung ber 2lufichriften beim eriften Fall zu wirfen.

$2 \mathfrak{m}$ aflereinfachiten und zwedfmäpigften erfcheint bie (nicht offizielle) Etellung über E⿺辶, alfo mit ben Diagonalen gleidhlaufend zu Den Geftellen uin., uno

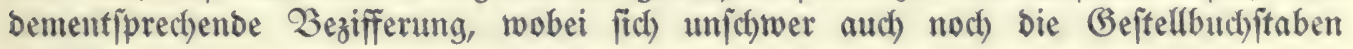

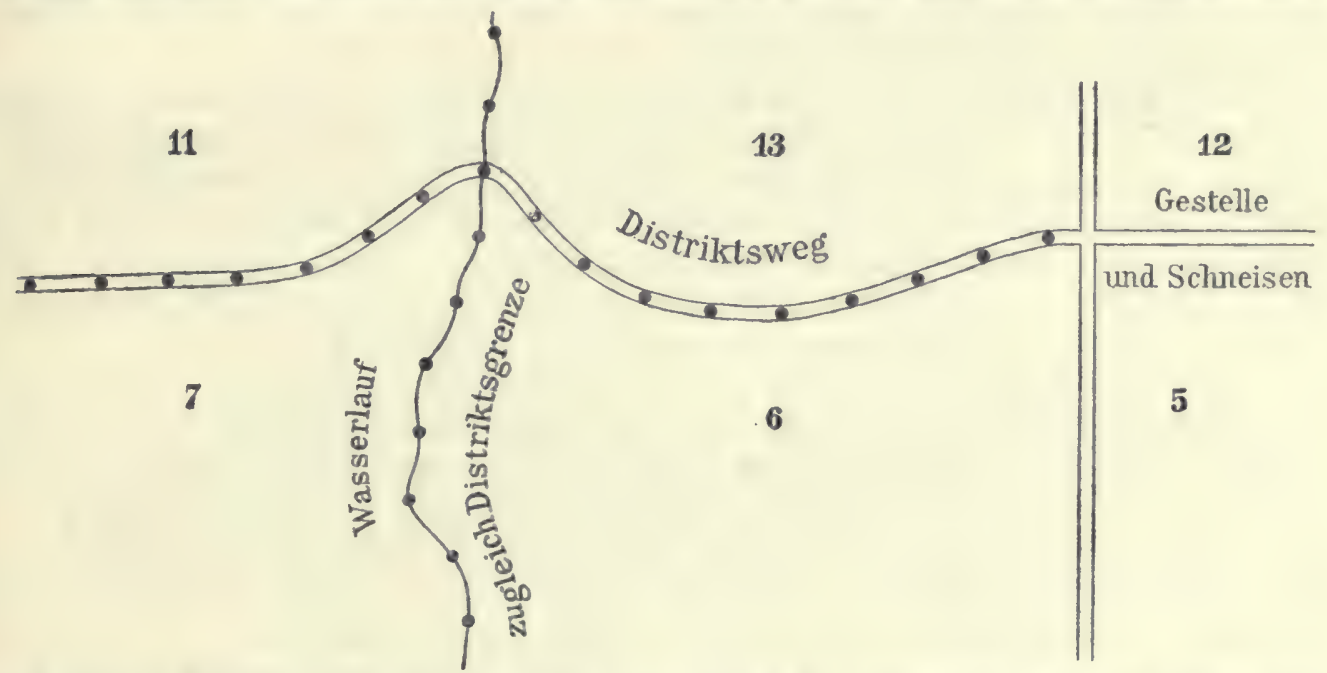

anbringen laffen, wenn man bie nach ben Geftellen weijenben Ranten bierzu auf etwa Sambgrößze verbricht.

Rartenbezeidunung:

Die Ģrenzen Der Iagen ober Diffrifte, fofern fie nicht mit Geffellen ober

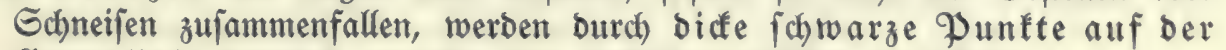
Grenzlinie fenntlich gemadt, wie vorftehend bilblich Dargejtellt.

Gefterlbudjuben: am Ende ber Beftelle, an Den Grenzen auberbalb ber WGarbfläche, itebenoe lateinifche (Dructichrift.

Sagen = und Diftriftsmumern: ftebende arabijche 3iffern, fhwarz.

c) Schlag=Einteilung: Für bie bleibenden Plenter=, Nittel- und Nieber= waldungen iff in ber Regel neben ber Sagen= ober Diffriftzeinteilung eine weitere Einteilung Durchzufübren in:

annäbernd gleid grö́e (flächengleiche) ober

nach Berhältniş ber Bobengüte ertraggigleiche

nach) ibrer 3ahl $\left(=\mathrm{U}\right.$ ober nU) uno Gröpe $\left(=\frac{\mathrm{F}}{\mathrm{U}}\right.$ ober $\left.\frac{\mathrm{F}}{\mathrm{nU}}\right)$ von ber Slmtriebżzeit abhängige Sabreżchläge.

(Ez fann jeboch aud) zur Biloung von "Partiefdylägen" burch 3ujammen"

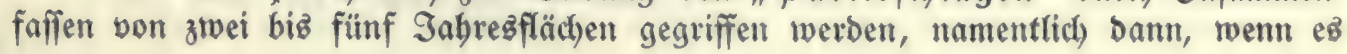


fiech um Mittel= und Nieberwalbbejtänbe handelt, bie, whne miteinander fortfaufend zujammenzuhängen, im Sobdwald zeriftreut liegen, wie 3. 3 . Ërlenbrïcher, aber gleidwobl zu einem bejonderen Betriebe vereinigt werben follen.

Die Numerierung und örtliche Bezeichnung ber Schläge gefdrebt nach ben nämlichen (Befichtapunften, wie oben bejprochen, jeodch unter Anwendung liegender römifher 3iffern.

Rartenbezeichnung: Die (Grenzen ber Gdhläge werben, foweit fie nicht mit bejtellen und $\mathfrak{B}$ egen zujammenfallen, Durch einfache zinnoberrote, in ben Slmbrucffarten allerbings zunädsft burch einfache jchrwarze Linien "Echlaglinien" bezeichnet. Die 3iffern werben ebenfallz zinnoberrot eingetragen.

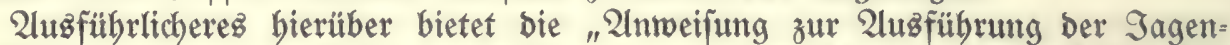

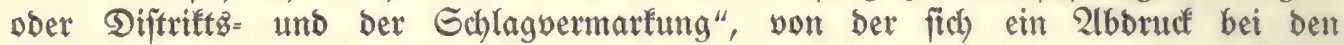
Sarationäatten ber Oberförftereien befindet.

3. Abteilungen: find nicht bauerno, fonbern nur vorübergebend zunächft

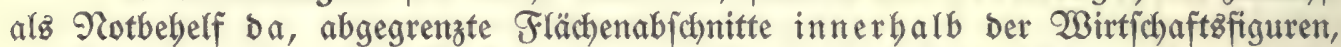

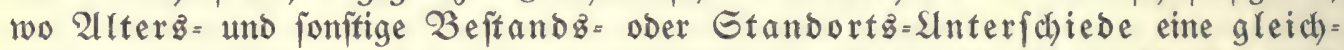
artige, wor allem gleidbzeitige wirtichaftliche Bebanblung vorläufig nod

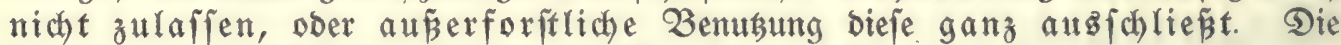
Abteilungen bilben baher für ben nächjten Sumtrieb bie wichtigften Beftandsfiguren, weil fie fichon jeßzt bie einbeitliche Berwirtfhaftung zulaffen.

Slm bas Richtige zu treffen, hat man Daber bei ihrer Ahzfcheibung nötig, alle zufammenbängenden $B$ ejtandzflächen, bie eine gleichartige (gleichzeitige) Behandhung geffatten uno fïch nach ihrer Form uno Grö̈pe zu Ferbjtändiger Bemirtichaftung eignen, zu einer 2lbteilung zujammenzufaffen, nicht aber Seilungen zu juchen.

Man unterjueibet Solzboden $=$ und Nichtbolzboben $=2$ lbteilungen.

Bährend bie erfiteren in ber Regel nicht unter 1 ha grop fein follen, fönten bie legteren ohne Radhteil in ihrer Bröze weiter Gerabgeben.

Eime Bermalung ber albteilungżgrenzen findet beim Solzboben nur auz= nahmsweife ba ftatt, wo bie Bejtanosunterichiede nicht jharf abjesen, fondern ineimanber übergehen. Sie gefdhieht bann burch fleinere Sügel mit Richtungz=

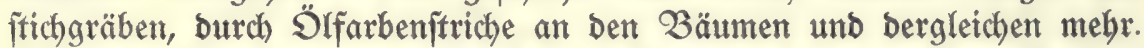

Die Benennung erfolgt Durch Buchfitaben, bie in ihrer 2 afeinanderfolge wie bei ben Sagen ujw. von O. nach W. und von S. nach N. fortichreiten, und zroar gelten für:

Holzboden fleine lateinifhe gefdriebene 3 ud ftaben,

Tichtholzboden fleine beutjdye gefdriebene 3 ud ftaben,

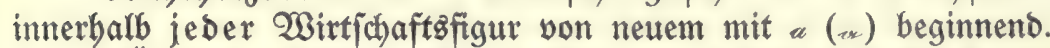

Örtliche 2 uff

Rartenbezeichnung:

Lbgrenzung: Sebe auf ber Rarte nicht mit ber Gafte Qinie gilt alz 2lbteilungzgrenze, wie biez die nebenftehende, aus Serrmann "Die Dreusifchen Forfftarten", Teumann=Teubamm, ent= nommene albbiloung baritellt.
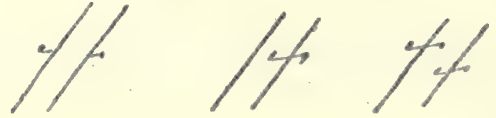


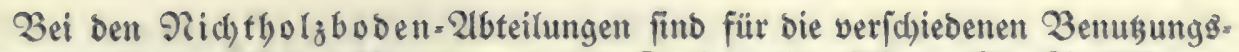
arten nod) bejonbere Ed)raffierungen uno Farben eingefübrt. Die 2luzfübrung im einzelnen ift zu erfeben aus:

Defert, "Mufterblätter zum 3eichnen unb Rolorieren ber Forfffarten", ober Sermann, "Die Preupifichen Foritfarten".

S̈ber bie mirtichaftliche Einteilung bietet nod) weitere 2luß̊funft ber

"Entwurf zum 2lbichnitt II ber Boridhriften für bie Bermefintug unb Betriebz=

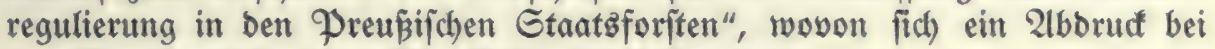
ben Taxationzaften ber Oberförfitereien befinbet.

entbält:

\section{c) Daร Bermeñuttgstwerf ber Dberförfterei}

A. eine fartographifche Darftellung bez Reviers in bezug auf topographifde Qage, bie Slmgebung, Begrenzung, wirtichaftlidge (Einteilung und aud auf bie (Beftaltung Der Oberfläche Dez (Beländes (Söbeníchichten).

1. Epezialfarten, Naj̃̄tab $1: 5000$, in Drei Exremplaren gefertigt:

a) $\mathfrak{A} r=$ (Original=, Brouillon=) Spezialfarte (ganzer Watbman obne Reinwano= unterzug) entbält nur bą̧ für längere (Dauer Bleibende (Ģrenzen, Wirt= ichaftżfiguren, Topographijchez) uno wiro im Mrinifterial= Forjteinrichtungz=Bureau aufbewabrt.

Davon fint abgezeichnet:

b) Daz Epezialfarten= Exemplar ber Regierung (ganzer $\mathfrak{B a t h m a n ~ a u f ~}$ Qein= wand gezogen), Durch Eintragung aller Einzelbeiten Der Stüdtuermeffung, insbejonbere ber abteilungen ujw. vervollftënoigt.

c) Daż Spezialfarten = Čxemplar bez Oberförfterg (halber Wathman obne Reinwanbunterzug in Mappe), Dem Inbalte nach ber vorigen gleich, wirb u. a. benugt zum alljägrlichen Fintragen ber eingetretenen Beränberungen (Grengen rot, alleg übrige grïn).

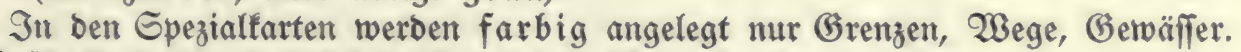
Die Bejdaffenbeit Dez Solzbeftandes wirb nicht erfidhtlid) gemacht.

Berichtigungen von a uno b periobifd bei Betrieborregulierungen, Sarationg = Revifionen. Berichtigungeెvermerf unter Dem Rartentitel rot: "Berichtigt auf ben Waldzuftand vom 1. 10. 1905 burdy N. N.".

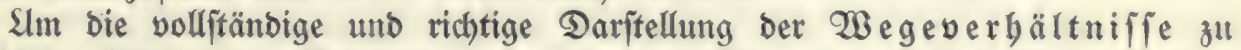
ermöglichen, fint bei ben Betriebsregulierungen bie Wege je nach ibrer $3 e j$ fhaffenbeit und Bebeutung veridiebenfarbig Darzuftellen, uno zwar auf bem Regierungz: Exemplar ber Epezialfarte:

bunfelbraun: beftebende $23 e g e$ und auggebaute Streden von Geftellen und Edyneifen;

Dunfelbraun mit zinnoberroten Querftrichen in $1 \mathrm{~mm} 2 \mathfrak{b}$ ftand: aus = gebaute und dauffierte oder gepflafterte Etrecten;

beltbraun: obne bejonderen Ausbau fabrbare Gtreden von Gejtellen und $\mathfrak{B e g e a u f b i e b e n ;}$

weiß bleiben: zwifchen ben fdhwarzen ober grünen Ranblinien alle nicht fabr $r$ baren Gtreffen von minoeftens $3 \mathrm{~m}$ breit aufgebauenen 2 egen uno von Geftellen ober Edhneifen; 


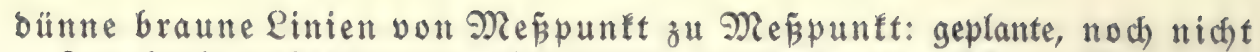
3 m breit aufgebauene, aber örtlich abgeftecte und geficherte 2 bege.

\section{$3 \mathfrak{a} a \xi$ :}

Eีrgänzungsmeffungen.

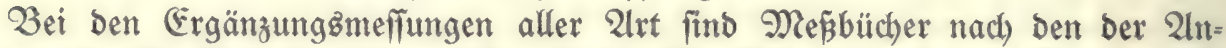
weifung vom 16. 2luguit 1901 (2llg. Werf. Tr. 20) beigegebenen Regeln uns Druftern (Forft=Cinrid)tungşbureau, Formular 30) zu fübren, in befonberen Seften für jebe Oberförfterei zu fammeln und alz Anlage Dez Zetriebşwerfez mit biefem vorzulegen.

Im einzelnen ift hervorzubeben: 3wedmäpig werben ber Yubfübrung ber

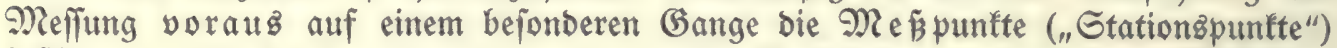
beftimmt und Durd) numerierte ober mit Buchitaben Des fleinen alpbabeţ

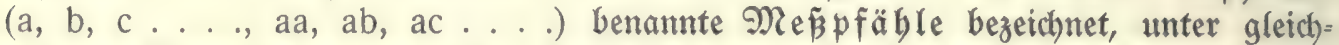
zeitigem Entwurf Der Sanbriffe. Dieje find fo zu fertigen, bấ fie ein annäbernbeg Bild ber Wirtefichteit geben. Wejentlich erleichtert twirb dieg burch ungefähre (Ëin=

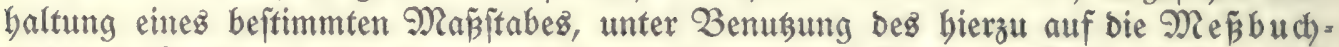
blätter (Formular 30) borgebructen Quabratnezes. 2ud empfieblt es fid), nach) Den Epezialfarten in einem angemeffen grof̧en Mapjftabe bie Sanbriffe in Blei vorzubereiten.

Jede voll ausgezogene Dinie gilt als 2lbgrenzung eines Flächenabfdynittez,

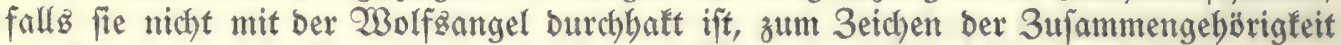
ber Durch jene als Irennlinie gefdiebenen abjhnitte. Zergleiche Seite 32. fitricbeln.

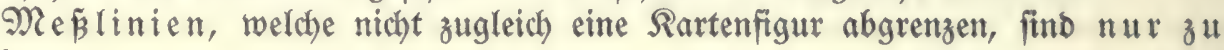

2lle 3roifdenpunte auf Mep̈linien find zur Erlangung einer Probe auf Die Richtigfeit Der Deffung und anbererjeits zu angemeffener Derteilung ber un= vermeiblichen Gebler nach beiden Enopunten Der Neṕlinie einzubinden und nicht nur bon einer Seite auв zu bef́timmen.

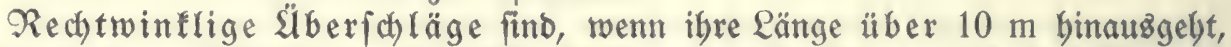
mit Silfe eines zur lbitecfung rechter Winfel dienenden Inftrumentes zu befimmen, bei längen von mebr als $40 \mathrm{~m}$ ifi bazu noch eine $5 \mathfrak{y} p$ otenufe zu meffen.

Qängenangaben (abgerundet auf ganze Dezimeter, bei Eigentumgzrenzen auf halbe Dezimeter): alle Neçzablen fins an bem Punt, auf welchen fie fich be.

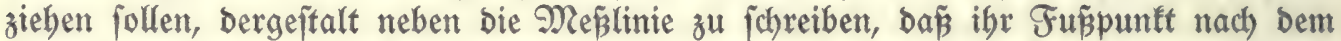

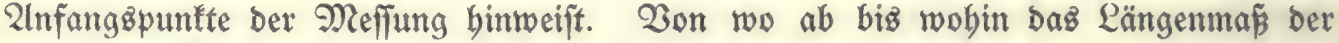
gemeffenen Qinie reichen folf, if́t burch Säfchen genau anzugeben.

Die 3ahl für die ganze Länge einer Mȩ́linie wirb doppelt, diejenige für Einbinbepunte jeitwärtz abgebender Linien einfach unterftrichen.

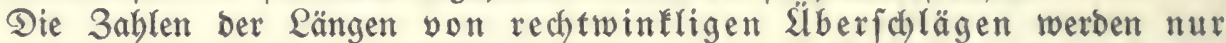
unterifrichen, wenn in Den feitlichen Ridbtungen noch 3 wifchenpunfte liegen. Winfelangaben:

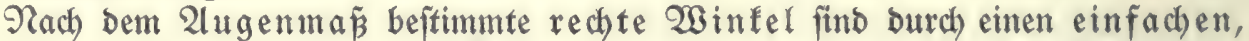
bie mit eitrem Inftrument beftimmten mit einem boppelten Rreizbogen zu bezeichnet.

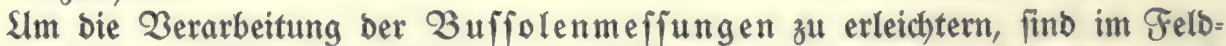
buch bie 3 uffolenwintel in ber Ridhtung ber Meffung fortforeiteno fretz über uno 
unter einen von ber Mleffungglinie aus quer zu ziebenben Strich zu fidreiben.

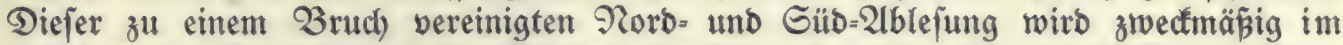

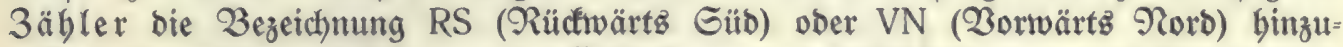

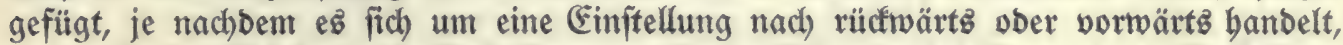

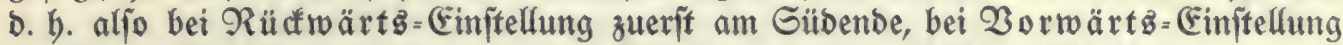
zuerit am Rorbende ablejen und bieje 2lblejung in ben $3 a ̈ h l e r$ jchreiben.

Bei einem biż auf balbe Girabe geteilten Buffolenfreife läp̃t fïc) ber Ziertelgrab, ob berjelbe mehr ober weniger yoll ift, noch genau fchäßen.

(Ẻ ergeben fîd bieraus folgenbe Gtufen ber Bewertung:

$$
\begin{aligned}
& 0+=5 \text { Minuten, }
\end{aligned}
$$

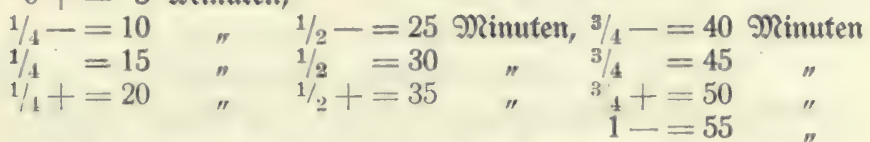

In ben bandriffen find alltäglich bie Breizablen mit Tinte fo nad)zuzieben, bá bie uriprünglichen Bleieintragungen lejerlich bleiben.

\section{Berfleinerte Rarten:}

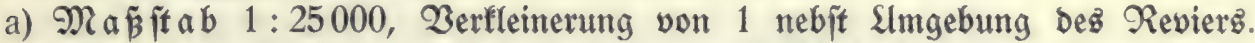

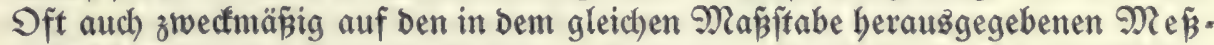
tifchblättern ber Ranbegaufnabme aufzubauen. Durch Slmbrud̆ vervielfältigt. 2luģgearbeitet zur:

a) Beftandżarte, fie entbält farbig angelegt bie berrichenden Solz= arten, mit "Baumfiguren" eingezeichnet bie Mifd)bölzer uno Einfprenglinge, foweit fie von wirtichaftlicher Bebeutung fint, uno gibt ferner burd) eine $n a d)$ Dem alter abgejtufte 2 btönung ber Holzartenfarben einen S̈berbliaf über baz vorbandene altergł laffen=

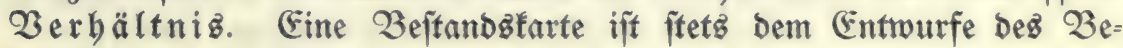
triebsplanes beizufügen.

3) Wirtfd aftgłarte, fie bringt neben Der Solzarten- Zerteilung, aber ohne 2llterbflaffen=Slnterfcheibung, lebiglich bie 3 uweifung ber $\mathfrak{B} e=$ ftänbe auf bie 21btriebzperioben burch farbige Slmränderungen

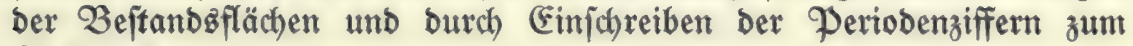
2lugbruct.

Sebr zreafmäpig werben Beftandz= und Wirtichaftźtarte miteinanber verjchmolzen und in bemjelben Bilbe zur Darjtellung gebracht.

Bon $\beta$, ober $\alpha$ mit $\beta$ vereinigt, werben gefertigt je ein Exremplar für Minifterium, Oberforit =, Injpeftions:-Beamten und Oberförfter.

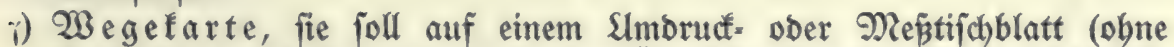
Darftellung Des Solzbeitandez) eine S̈lberfitht über bie $\mathfrak{Z B e g e v e r b a ̈ l t n i f f e ~}$ geben. 3 biejem 3 wecte fino zu fennzeichnen Durch farbige Linien: zinnoberrot: d)auffierte ober gepflafterte 2 ege und Beftelle; braun: Eromege unb alg Erowege ausgebaute Beftelle; 
blau: obne befonderen Alubau fabrbare Gtrefen und wegeanfbiebe;

blau geftrichelt: geplante, örtlich abgeftecte und gefitcherte,

aber noch nicht aufgehauene Wege.

Die gleiche Bezeichnung if aužzubehnen auf bie auperhalb

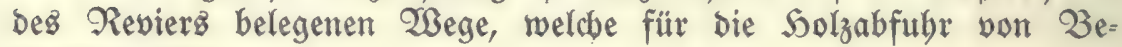
Deutung find.

Ferner if bei ben b̈ffentlichen Wegen noch burd) äunere farbige Banbierung herworzubeben, ob unterbaltungzpflichtig: gelb: Rommunalverbände,

grïn: bie Forftwerwaltung.

Die berart ausgearbeiteten $23 e g e f a r t e n ~ 1: 25000$ find in Forft=

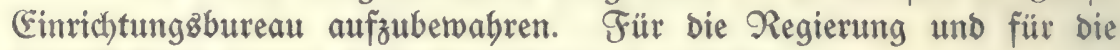
Oberfürfterei werben bort 2 bzeid)nungen gefertigt.

2lus bejonberen Beranlafiungen fönnen auß̃erdem auf Slm= bruffblättern gefertigt werben:

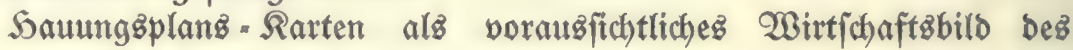
zweiten Slmtriebes,

Bobentarten nach Güiteflafien Dber nach Bobenarten,

Eervitutenfarten, Rarten Der Waldbejchäbigungen u. Dergl. m.

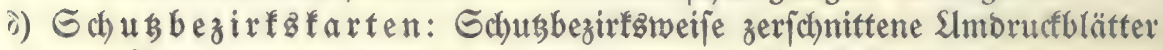
mit 2lbteilungen, aber obne Daritellung bez Solzbeftandez.

Ės if erwünjd)t, Den Förfitern etwas mebr in bie Sano zu geben, alferminbeftenz bie Sauptnukunggs= Beftände wenigitens burch) (Einfchreiben Der Deriobenziffern fenntlich zu machen, z. 3. I, I. VI, IV uff., um bie Föriter boch auch jeberzeit in ben Gtand zu jezen, baz aukerhalb

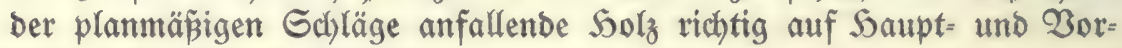
musung verteilt zu budben.

Schusbezinfzlarten exhalten fämtliche Förfrer.

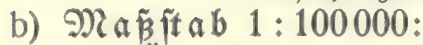

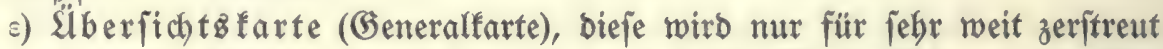
liegende Reviere hergeiftellt und Darauf bie Revierfläche gleichmäp̃ig grîn angelegt.

Eine genaue Slberficht wirb

B. in tabellarijcher Form zujammengeftellt in Dem Flächenverzeichniz, "Beneral= Bermefjungż tabelle" genant.

Die Serleitung ber Flächengrößzen, und zwar auf brei Dezimalen (Ratajter 4), gejchiebt entweber auz Den Meézzalen mit Silfe von Roorbinaten=Berechnung ober

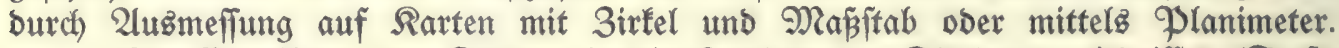

Die Einreihung Der Flächen in bie Gpalten bez Flächenverzeichniffez (Forft: (Einrichtungzbureau, Formular 4) hat nach ber Anleitung bez Titelbogenz zu gejchehen. Danach foll u. a., wenn Wafferläufe, Wege, beftelle ujw. Die Berenze zmijchen Flächenabfchnitten bilben, bie Mittellinie als (5) renze angenommen, bie unnußgbare Fläche alfo bei jeber ber beiben Abteilungen zur Sölfte bem $\mathfrak{S O l}_{\mathbf{z}}$ boben mit an= gerechnet werben. Nur fofern jene $8 \mathrm{~m}$ und barüber breit find, foll ber Alnfand: anteil befonber berechet unb vom Solzboden abgefert werben. Bei 
lanbwirtf(b)aftlich benusten Flächen pflegt man ben unnusbaren Boben im ganzen Sumfange abzuzieben, fobalo er fich mit 0,001 ha ausbrüden läṕt, alfo ab= gerunbet 10 qm auzimacht.

Abteilungzreife find alle biefe Flächenanteile in einer Pinie nebeneinander

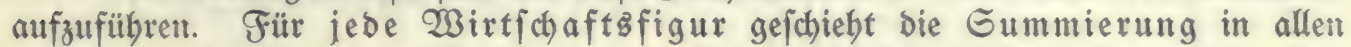
Epalten untereinanber. Die einzelnen Seiten werben nicht aufgerechnet. $2 / \mathrm{m}$

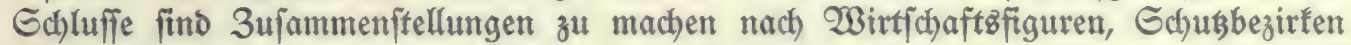
(Blöfen) uno für bag ganze Revier.

Auperbem find bie Flächen ber Dienfltänoereien in einer bejonderen Rach)= weifung, unb zrwar nach ber Reibenfolge Der Dienfiftellen im (Etat zujammenzuftellen

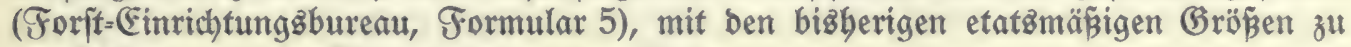
vergleichen unb bie 2lbweid)ungen zu erläutern.

EEbenjo find bie Pachtlänbereien zu bebandeln.

$2 \mathrm{~m}$ Edhluffe iff in einer 3 ufammenftellung ber auperforfflich genubten Fläd)en

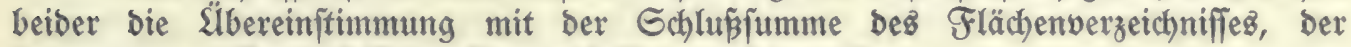
jogenannten "General= Bermefintugztabelle", nachzumeijen.

Die Fortführung und Ergänzung Des Flächennachweifez gef(bieht Durch bas "Flächenregifter". Näheres in Der 2lnteitung zu Deffen Fübrung vom 12. Suni 1857. Sierüber fpäter Seite 63 uno 64.

Periobifche Beriditigungen bez Fläd)ennachweifez geidheben bei Ertragg= regelungen und Tarations=Revifionen burch Nachträge (rot) ober burch Neuauffitellung

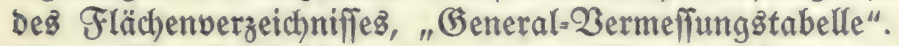

Die Serleitung ber neuen Revierfläche erfolgt in ber Beränberungs:

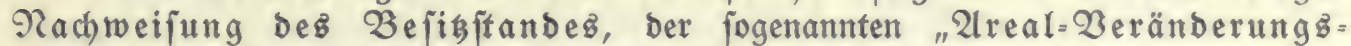

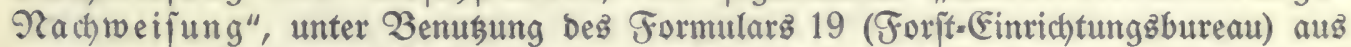

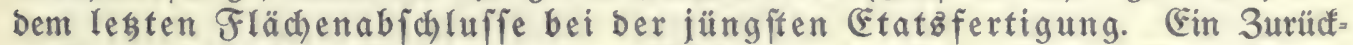

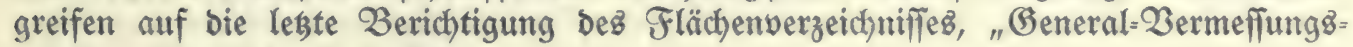
tabelle", ift nicht erforberlich.

teilt fith in bie

\section{Die Bejtandzaufnahme}

a) auвführliche, fogenannte "ipezielle", Gauptjächlich mit $\mathfrak{B g o r t e n}$ gegebene $\mathfrak{B}_{\text {eftand }}=\mathfrak{B}$ efdreibung (qualitatio),

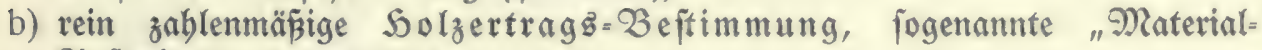
2lufnabme" (quantitativ).

$3 \mathfrak{u}$ a: Die ausfübrliche 3 efdreibung ift für jebe 2lbteilung befonders aufautellen, unter $\mathfrak{B}$ ergleichung Der 2 ngaben früberer 2 lufnabmen. Sie ift für $\mathfrak{B}$ oben

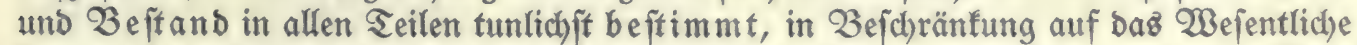

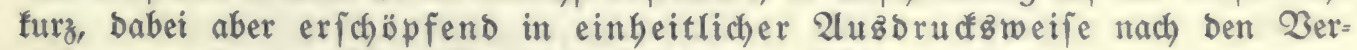
einbarungen ber Deutichen Berjuch sanjitalten von 1874 zu geben.

Dazu fei noch bemerft: Sauptjächlich fommt ez auf bie zablenmäвige Feftlegung bez $\mathfrak{B}$ efundes an. 230 es wie bier gilt, etwaz tunlichjt fnapp und beftimmt anzugeben, fennzeichnet eine einfache $3 a b l$ in ber Regel bie Eache fichärfer

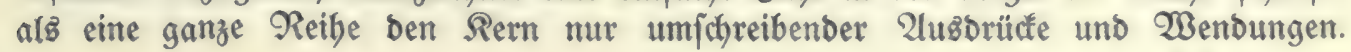


2uch laffen zahlenmääige Slnterlagen weniger 3 weifel offen uno geitatten eine flarere uno ficherere Begrünbung ber bemnächiftigen wirtichaftlichen 2ufgaben, bez vorteil=

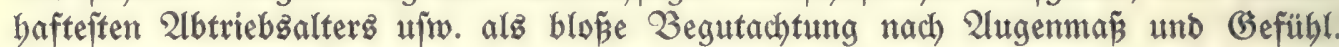
Einmal gewonnene 3ablen müffen Daber feftgehalten uno bürfen nicht Durch weniger genaue 2luzbrücke wiebergegeben werben.

Wenn man z. 3. mit einem einfachen, rajch arbeitenden (befällmeffer, wie bem

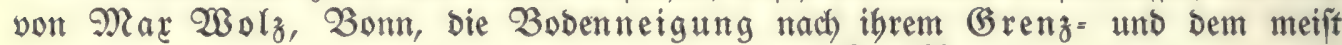

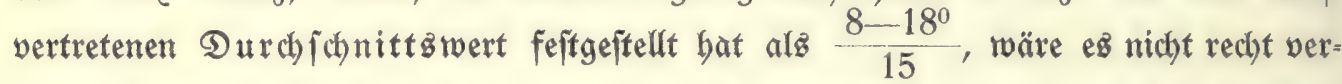
ftändlich, mun an bie Gtelle biejer ermittelten genauen 3ablengröpenen von bleibendem Bert wieber Die ungefäbren Bezeichmungen: "lebn, zum Seil fanft" ober "lehn und fanft" jesen zu wollen.

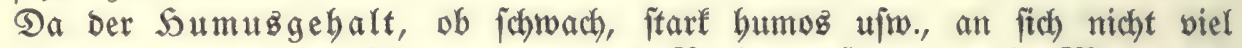
bejagt, fondern wir mebr erfahren, wenn baz Borhandenjein und die Mächtigleit einer etwaigen Rohhumuzfchicht ober ebenfo biejenige bes Mull, bez milben Sumus, doer überkaupt bes milben, burchmürbten Obergrundez angegeben wirb,

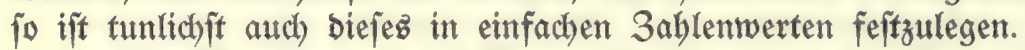

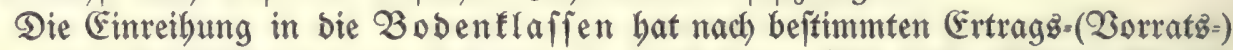

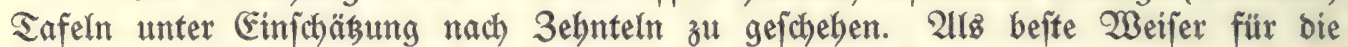
Eimichägung gelten bie Beftandzböben. Dieje fino baber zu vermerten, fallz fie ermittelt find.

Welche Iafeln Der Etandortz-2onitierung zugrunde gelegt find, ift im Ein= gange anzugeben.

Sinfichtlid Der Stärtegrenzen für Stangen $=$ und $\mathfrak{B a u m b o l z ~ i m ~ S i m m e ~ D e r ~}$ Gabungen zu Den Beftandsbefdreibungen yon 1874 und für Gtangen= uno Stammbolz im Sinne Der Einführung gleicher Gortimente für bie Solzverwertung von 1875 ift biz Geute noch immer Der Gegenfás bejtehen gebrieben, Dás die Gtangen aufbören:

Daz eine Mal bei $20 \mathrm{~cm}$ Bruithöhe,

baz andere Mal bei $14 \mathrm{~cm}$ in $1 \mathrm{~m}$ Söbe über Dem Abhieb.

Sier erjcheint bie Feftlegung einer einfeitlichen (brenze, am bejten wobl bei $20 \mathrm{~cm}$, bringeno ertuünifht.

Bei ben alterzbeftimmungen hat man fich bizher nod) gar zu febr an

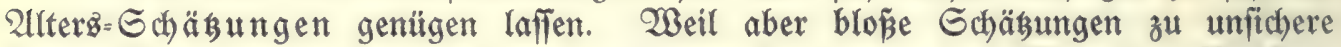
Ergebniffe liefern, wirb eв zur unabweisbaren Forberung, bas alter ber Beftänbe nicht mebr "anzupprechen", fonbern zu unterfuchen. Tangelz gejchichtlicher Nach)= weife genügen für bie meiften Fälle Allterzzählungen fduon an 20 burch ben ganzen

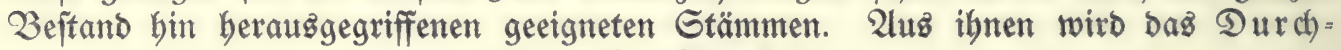

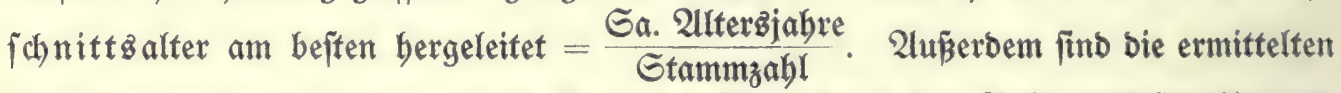
Altergagrenzen anzugeben. 2uch if in Der Alterzipalte ber Bejtanbsbejchreibungen jebezmal zu vermerfen, ob baz allter "gefchichtlich" befannt ober "gezählt" ober nur "gejchäba" ift. Faft afles bavon fönnte mit bem geringiten 2 lufwand an 3eit und 2lrbeit nach uno nach gejammelt, und bamit eime ber widhtigften (Brundlagen bem Taxator fertig in bie Sand gegeben werben, wenn bie Revierberwaltung gebalten wäre, bei Gelegenbeit jeber bierfür auzreichenden Saumng folche allerżzählungen zu 
veranlaffen unb fie unter Ingabe beళ Srteళ, Gabreళ, ber von jeber Solzart unter: fuchten Stammzahl, bes gutachtlichen 2llterg̈zujhlages, ber baraus fich ergebenden

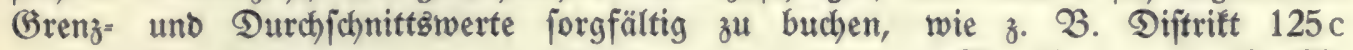

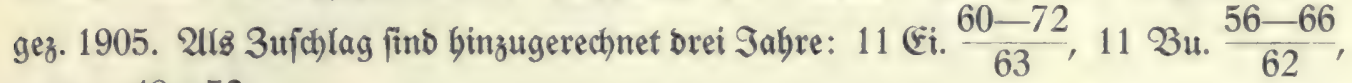
20 Fi. $\frac{48-52}{50}$.

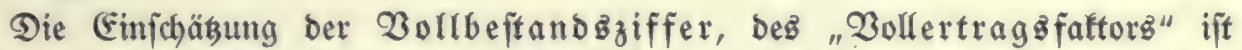
unficher, wenn man bamit fitreng genommen biejenige $3 a$ hl angeben foll, welche baz Berbältnis bez zu erwartenden Ërtrages zum Ėrtrage eineż vollen Beítandez gleichen Allters uno gleicher Rlaffe augbrüctt, leichter fchon, wenn man mit Dem Zerbältniz bez vorgefunbenen Borrates zum vollen Borrat red)net, für bie Praris aber am einfachiten uno ficheriten greifbar, wenn man fich Dabei auf bie

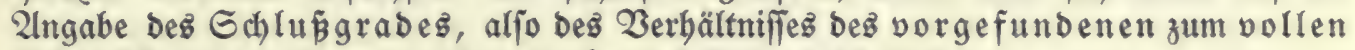
Gd)lusitande, und zwar für Den Sauptbejtand bejchränft.

Erroünjht ift aus ber Beftanosgefdichte bie 2ingabe aller Gejchebniffe,

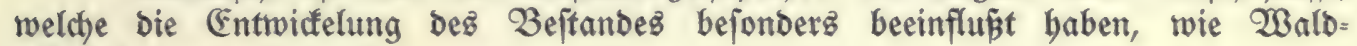
bejhäbigungen u. bergl.

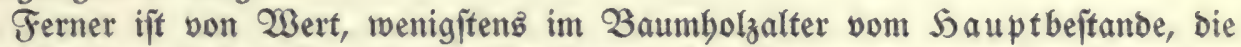
Ermittelung ber Söbe, Gtammzabl pro Seftar ober leid)ter ber zur Etammzahl in

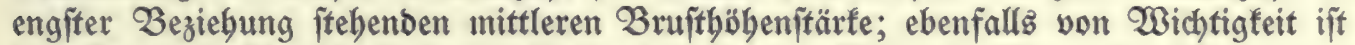
Daв Rronenverbältniz, D. h. Die Ränge ber grünen Rrone in Prozenten ber ganzen Saumböbe, z. 23. 30, 40, 45, weiter Die aftreine Schaftlänge, bie Sabrringbreite,

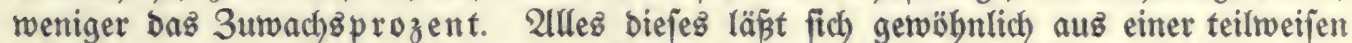
2ufnabme von Probeftreifen uno jelbít fahon aug einer befaränften 3 abl von

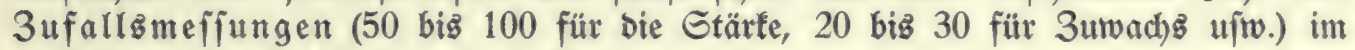
Soerrichenden hinreichend genau beítimmen.

Die Nieberfchrift ber Befchreibungen ift, jorweit fie nicht in tabellarifcher

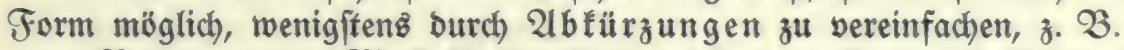

Boben, wenn 2 Rull 25 biz $30 \mathrm{~cm}$, rebmiger Sano biz $60 \mathrm{~cm}$, fanbiger Rebm biฉ̈ $90 \mathrm{~cm}$, barunter fejteg $\mathfrak{G e f t e i n , ~}$

abgefürzt: M 25-30, LS biż 60 , SL biz 90 , Darunter FG. -

3eftanb, wenn Gtammzahl 700, mittlere Bruítbäbenítärte $=\sqrt{\frac{\text { Sa. }^{2}}{\text { Stammzabl }}}=$

$24,3 \mathrm{~cm}$, Söhe $21 \mathrm{~m}$, Rronenverbältnis 30 , aftreine Gduaftlänge $11 \mathrm{~m}$, Ringbreite $1,4 \mathrm{~mm}, 3$ uwach geprozent $2,3 \%$, abgefiurzt: N 700, D 24,3, H 21, Kv 30, AS 11, Rb 1,4, p =2,3.

2lm Enve jeber Beftanosbefchreibung empfieblt fich ein nod)maliger, furzer zablenmäß̊giger s̈berblid ïber ben Solzartenanteil nach 3ebnteln, z. 3. (Ei. 0,3, 3u. 0,5 , Fi. 0,2 , Eิ fid., Ta.

Echlię̆lich bienen photographifde 2 ufnabmen, insbefondere Etereoftop: bilber, vortrefflich einer befferen Beranf(d)aulichung.

Für bie Draupenarbeit empfiehlt fich ein nach bem nachjtebenden शRujter I vorbereitetes Seft in Quartformat als Einlage in einen feften Pappumichlag,

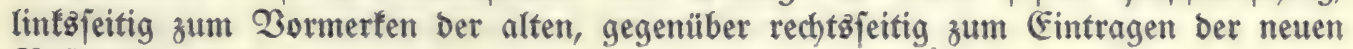
Befchreibungen. 
Beitandsbejoreibungen. Muiter I.

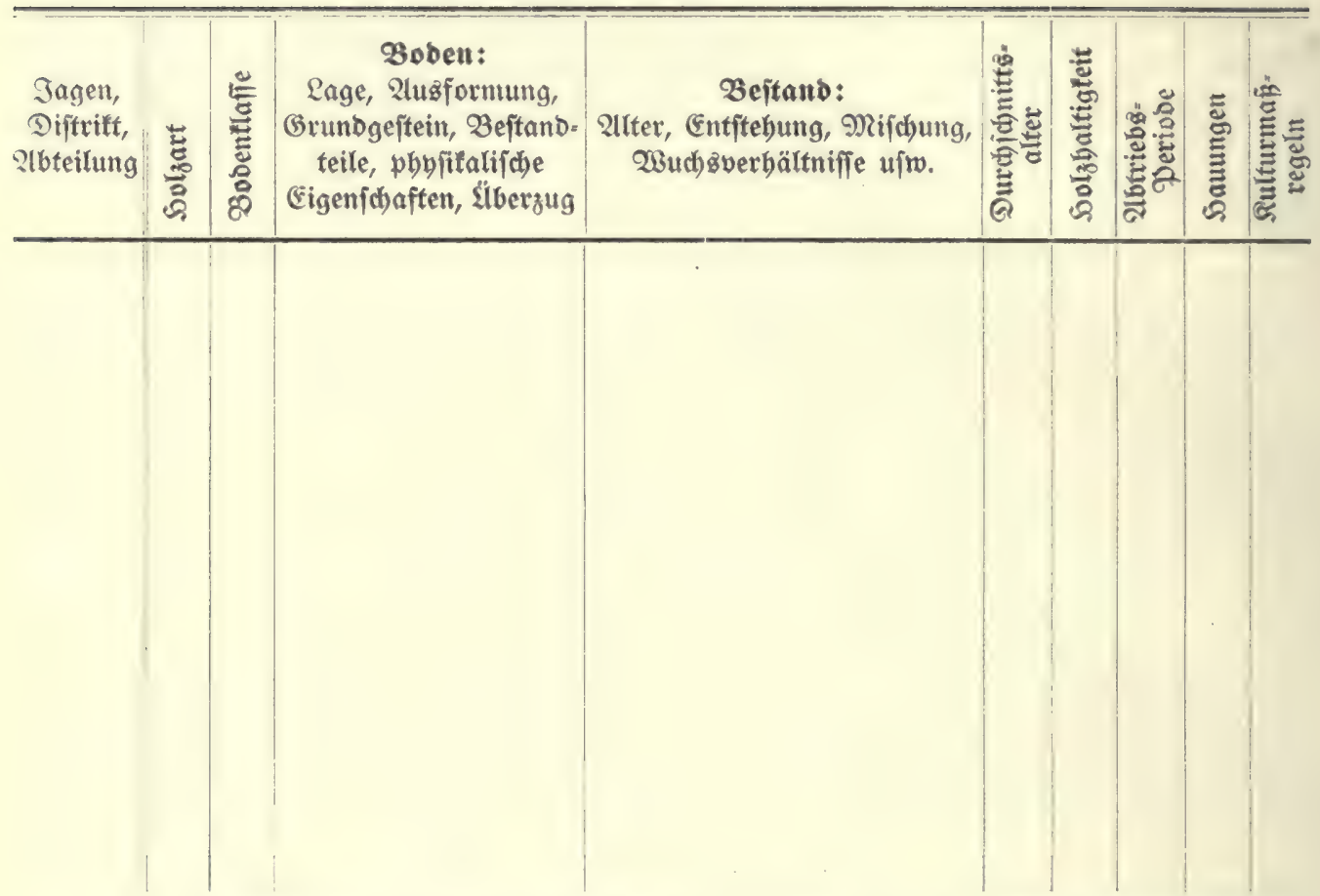

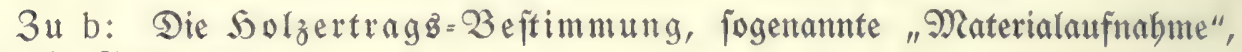
umfañ bie Gerïrumg:

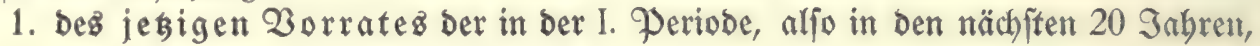
zur 2lbnubung beftimmten Beftände;

2. Dez biz zur Periobenmitte an biejem noch zu erwartenden 3 uwadję $(1+2$ Sauptertrag);

3. Dez łünftigen albtriebzertragez jüngerer, erf́t in fpäteren Derioben z̆ur 2lbnugung (Soauptnugung) fommenben Srte, ebenfallz bezogen auf Deriobenmitte. Dieje bier unter 3 erwäbnten (Exträge fommen jeboch nur

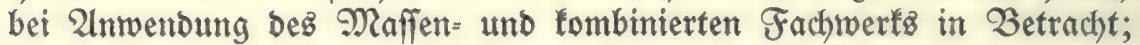

4. Der währeno ber ganzen 20 jäbrigen $\mathscr{D a u e r}$ ber I. Periobe an ben unter 3

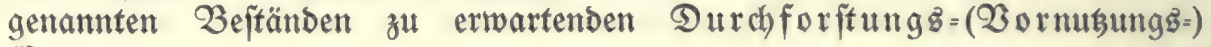
Ěrträge.

$3 \mathfrak{a}$ 1: Die Borratzermittelung, bejoraünt auf bas Derbholz, gej(bieht mittels:

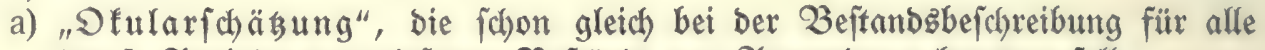
Der I. Periode zugetwiejenen $B$ eftände zur 2 Inwendung fommen foll.

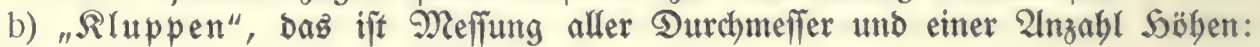

a) auf ber ganzen Gräche,

B) auf Eleineren regelmäß̈̊gen, meif́t quabratifchen Drobeflächen, im einzelnen 0,5 bis 1,0 ha gró, Dabei zufammen mindeftenz 4 biz $5 \%$ ber Gejamtfläche umfaffètro, 


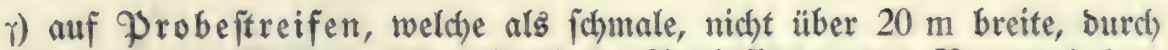
Den ganzen Beftano fid exftrecfende \robefläd)en Den Zorzug haben, ohne vielez Suchen ben Durchjh)nitt mindejtenz ebenjogut zum 2luzbruct zแ bringen als bie befonders bierfür aแżgewählten, regelmäpaig $a b=$ gegrenzten (quabratija)en) Probeflächen. (Forftl. 31.1887 G. 356 fi.)

c) "Alniprechen" nach $21 b$ triebz=, jogenannten "Realerträgen" von gleid)= gearteten $($ Nachbar $=) \mathcal{B}_{\text {ejtänben. }}$.

8) Ertrags-(Zorratasa) Safeln.

Die Regel bilbet baß 2usłluppen auf Der ganzen Fläche. Die Rruppbud)=, (", श) unter 2lmwenbung ber bierunter abgebrudten Formulare II uno III geicheben, legtere

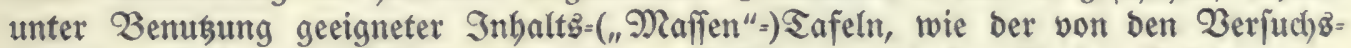
anfalten, $\mathfrak{B e b m}$ ujw. Ratjam ift vorberige Wrïfung, ob bie betreffenden Safelangaben

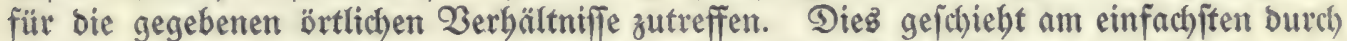
Zluafluppen und Bered)nen zum 2lbtrieb beftimmter Flächen bor bem Siebe, und nach) bem Siebe Bergleichen bes wirflichen Sïranfallz mit bem Goll.

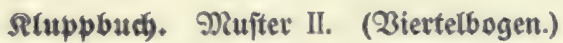

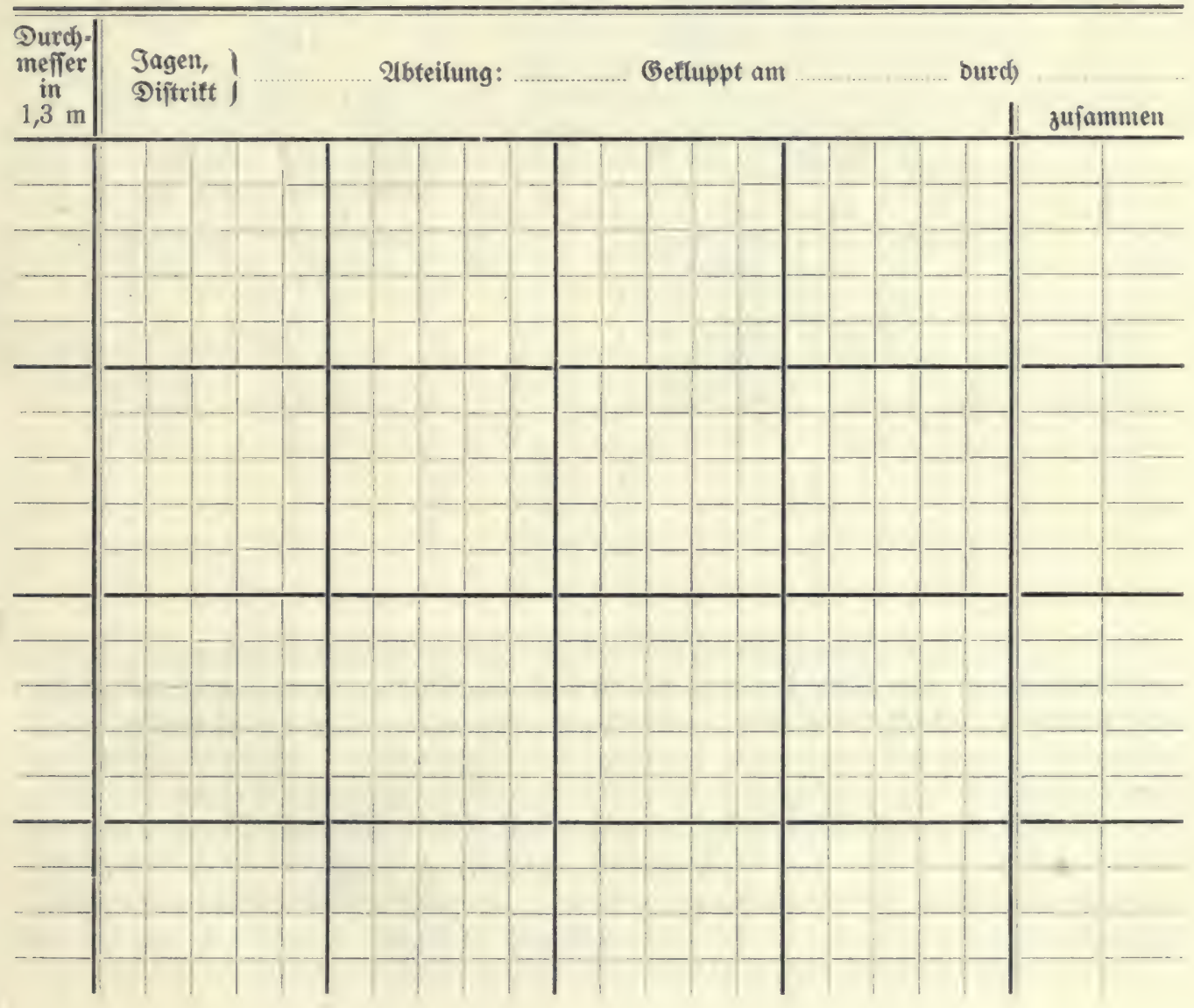




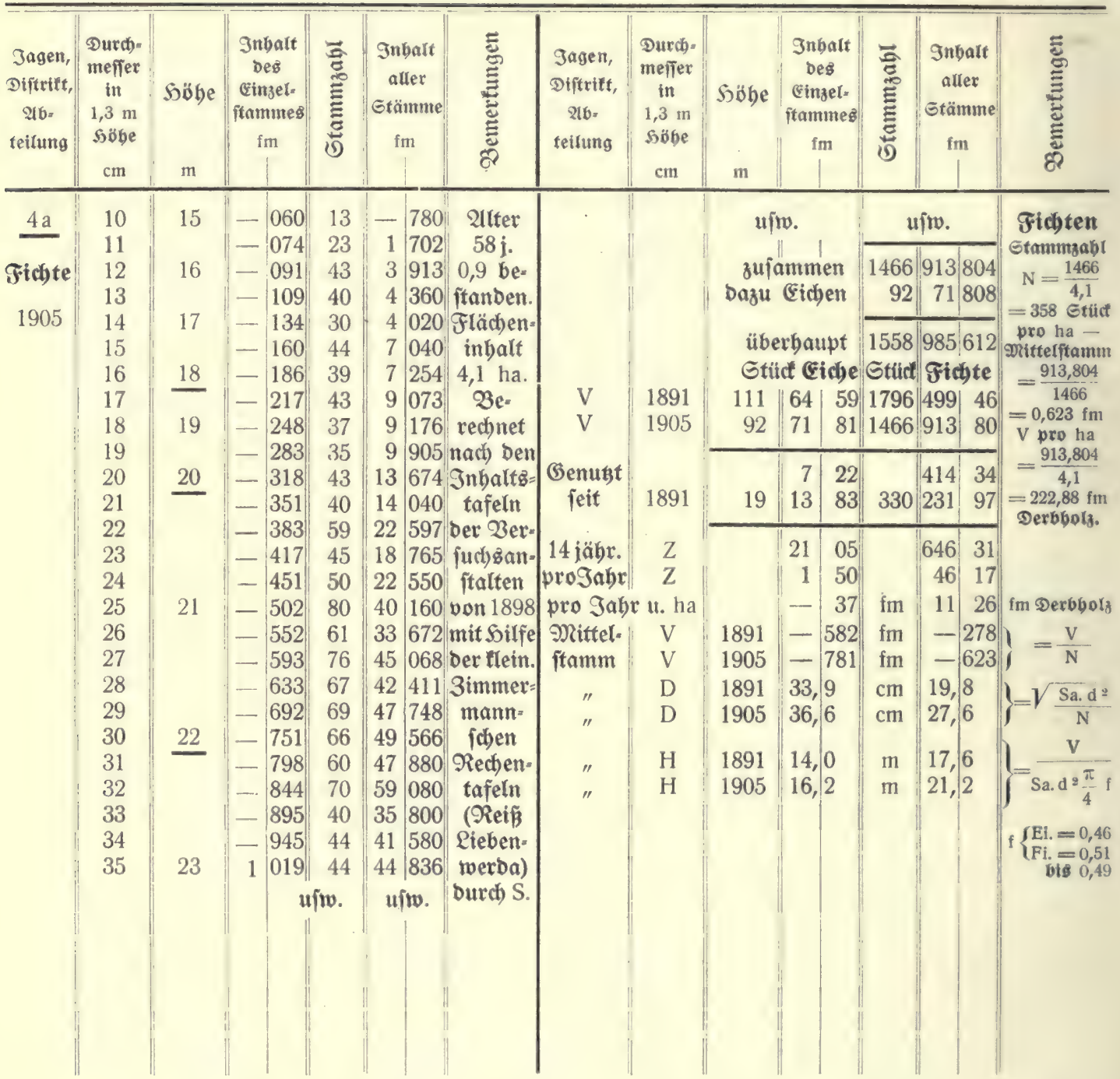

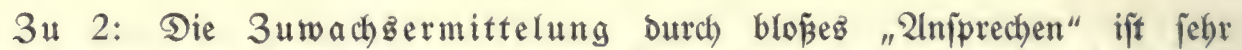

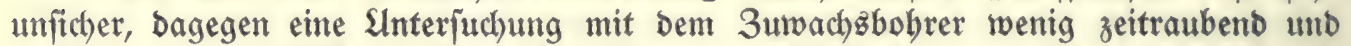

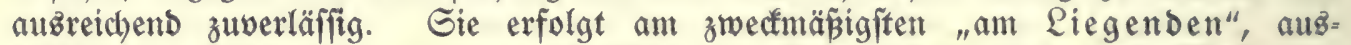

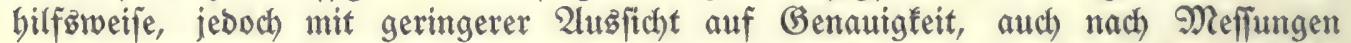
"am Stehenben". Im übrigen wirb auf bie 2lub̈rübrungen im 2lnhang verwiefen. 3u 3: Der zufünftige 2lbtriebsertrag (Souptnukungs=(Ertrag) jüngerer Beftänbe fpäterer Derioben ift nad) Ertragztafeln zu jchäben. Die Edbwierigfeit

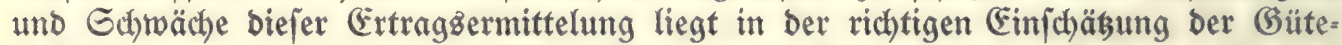
flâje, jogenannten "Bonität". Dieje Berechnung î́t jeboch), wie gejagt, nur für baß̉ "9) ใaffen" = und "fombinierte" Fachwert erforberfich, fonft burchweg entbebrlict). 


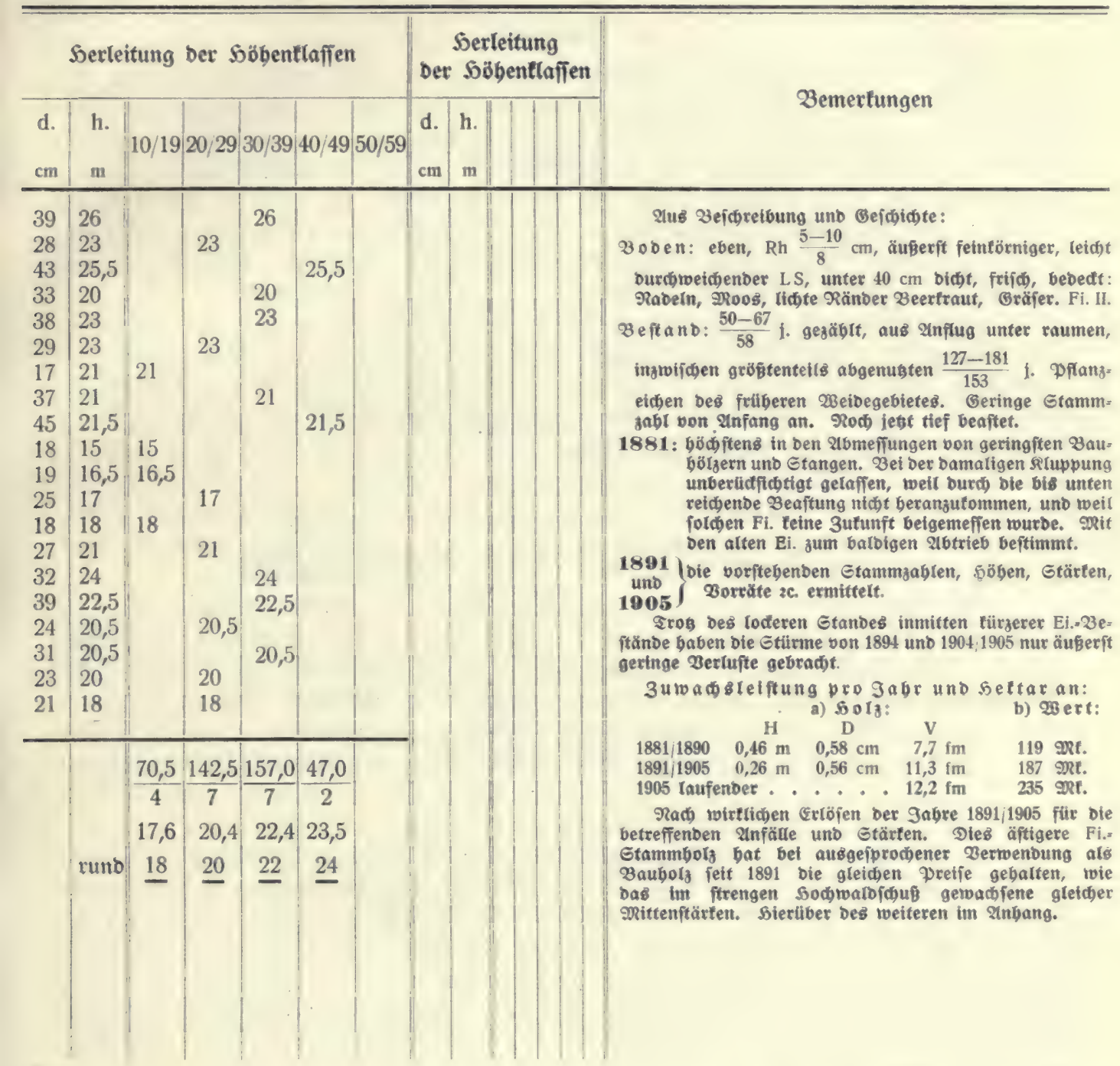

3 4: Die rährent ber 9 auer ber I. Deriode, aljo bez ganzen zwanzig=

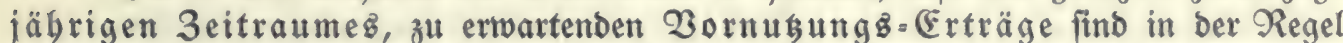

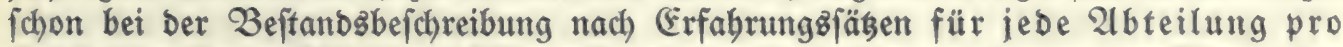
Seftar aużzuwerfen oder fpäter im ganzen nach ben bisherigen Ërgebniffen "fummarifd" in 21njag zu bringen, ober werben wobl auds), obgleich beibe in feinerlei innerer gegenjeitiger Beziebung zueinanber fteben, nach ibrem bejamtbetrage "in Prozenten ber Sauptnußung" ausgebrïtt. 


\section{Der Betriebzplan.}

a) Sodjwalb.

Nach Beendigung Der Beftandzbejchreibungen, nicht erfit am Echlué ber

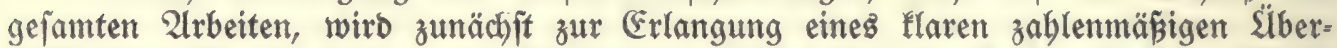

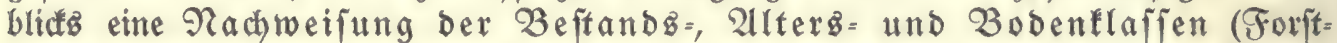
Finrichtungzbureau, Formular 16) aufgeitellt uno Dann zur überfichtlichen Zeranfchaulichung Der gegenjeitigen Lage Der Beftandofflächen auf einem Slmbructóblatt 1:25000 eine Bejtandżarte bergerid)tet. Eine Anleitung zur 2luzarbeitung berjelben ift hier beigefügt, unter Benußzung ber entiprechenden farbigen 2lbbildungen aus Serrmann: "Die Drenpifichen Foriftarten", Reumann=尺eubamm.

3um Eีntwurf bez Flächenplanes find hierauf in bie für ben Betriebs= plan beftimmten Formulare, gemöhnlich Foritt-Ëinrichtungsbureau $\Re r .7$ ober 7 a, gelegentlich audh wobl noch $\mathfrak{N}$ r. 6, Die Eintragungen aller fich auf Den tatjächlichen Waldzujtand beziebenden 2lngaben, uno zwar bie Flächengröß̄en mit einer Dezimale, zu bemirfen. Für einen vorläufigen blopen Entwurf bebarf ez babei im allgemeinen zunächit nur ber S̈bernahme aller zahlenmäß̈igen Zngaben. Die Berteilung Der Beftände auf bie Abtriebzperioben, wie fie fich in ber Beftandabeichreibung findet, uno allez, waz bamit zujammenbängt, trägt man am zmedfmäp̧igften vorläufig nur in $\mathfrak{B l e i}$ ein.

Bei ber weiteren planmäß̈igen Berteilung ber Beftanosflächen auf bie einzelmen Derioben find auper bem fteten Streben, jeben $B$ eftand in feiner beften Siebzreife zur abnusung zu ftellen, bemnächit folgende für bie Beftandsorbnung und Giruppierung maß̈gebenden befichtspunfte zu beacten:

1. Gachgemäße "Siebzfolge" Durd) Brtliches Fortidhreiten mit ben Siebz: flächen und baburch bebingte 2lneinanberreibung ber Alterzłlaffen gegen bie berrichende Winbrichtung uno Bermeibung aller wind-(weft=) feitigen Frei= ftellungen in fiturmgefäbrbeten Altern, Solzarten uno Lagen.

In Preunen ift febr bäufig angewand gewejen und noch bevorzugt bie 2llterbz= flaffenfolge mit 20 jäbrigen Eprüngen und bamit vielfach in Berbindung bie jogenannte "3erreiß̈ung ber Altergflaffen" nach ber v. Reubichen Edhablone: VI. IV. II. - V. III. I., um nicht zut grop̈e Flächen berfelben und aufeinander folgender Perioben im 3ujammentange zu haben, ba man von leģterem namentlich) im Tabel= holze eine Steigerung Der von Getter, Imjeften, Gturm ujw. Drohenben Befabren befürchtete, mandhmal aud ofne (5rund. 3u vergleichen 3 orggreve, "Forf́tab= ichä̉ung", Geite 291 bis 315.

Man jucht babei alfo jeber Periobe joviel voneinander getrennt gelegene

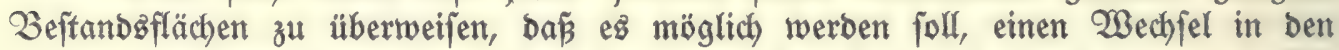
Siebzorten einzurichten uno mit ber Fortjegung bez Siebez fo lange zu warten, biz bie bier angelegten Rulturen Den Iugenogefabren entwachjen find: Cin frommer WBunfh, Der viel mit eingebilbeten Zorteilen rechnet uno biagher pollen Erfolg in WBirflichfeit faum gebracht hat. Das 3erreipen bietet wohl wirffameren Feuter=,

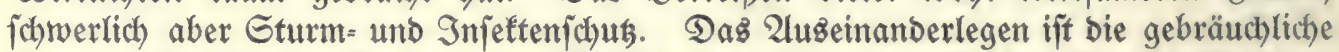
Grundform für bie Rablfdhlag=2Birtidhaft geworben, wäbrend für bie Natur= verjüngung bas 3 uammenfaffen groperer, gleiduzeitig in Betrieb zu

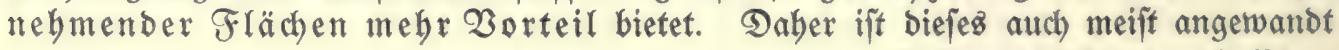




\section{Anleitung $\mathfrak{z} \mathfrak{x}$ Âuฐ̉arbeitung}

\section{von \\ Bejtands= und Wirtichaftafarten.}

Rach Den Mujterblättern zum 3eichnen und Rolorieren ber Foriftarten von Defert, unter Benugung ber Farbentafel aus Serrmann, Die Dreupijichen Forittarten. 


\section{Farben und}

Cbromgelb.

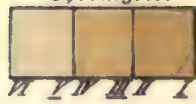

Eidben.

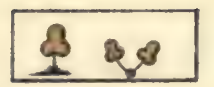

Die arweite Gigur

gilt flix

Gtodaug์ काäge.

Terraftena.

Buben unb Sainbudbe

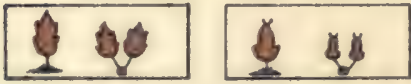

Gelbgtin.

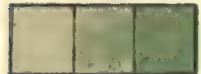

2lyorn und Eiditen.

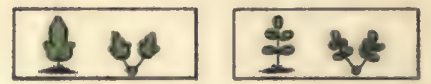

Gelbgrin.

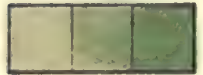

Stmen und Qfazien.

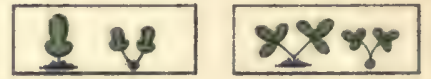

Rarmin.

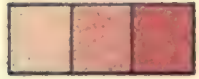

Birten.

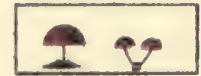

3Iaugrifin.

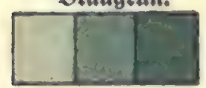

Erten.

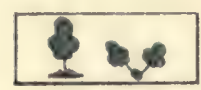

Nagenta.

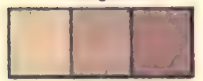

2ipen.

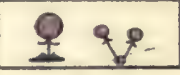

Ragenta.

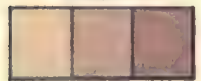

Pinden und Pappeln.

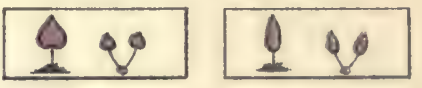

Nagenta.

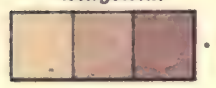

Beiben unb Sajeln.

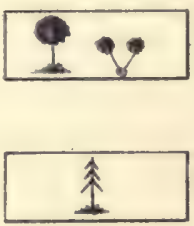

Riefern.
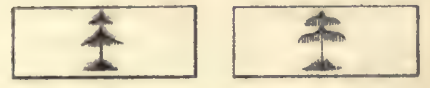

Fidbten und Sannen.

Eøwarz mit Brün.

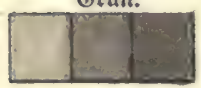

Rärchen (Wadbotber).

พือเทิ.

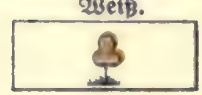

(Eid)en) Räumbe.

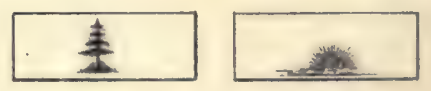

æetß.

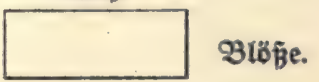




\section{Baนmกีguren.}

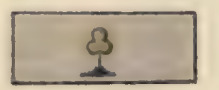

Braugrin.
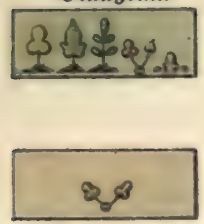

Eiđbenídbäl. walb.

Soctwalto (Riefern mit (Eid)en).

Mittelwalb (mit Eidben, 2born, Ejabenoberbolz und (Fid)en, Sinben und Sajelunterbolz).

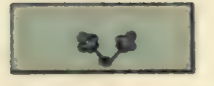

Erlenniebernalb.

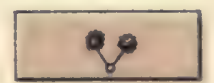

अeibenbeger.

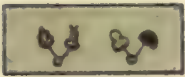

2nberer Rieberwalt.

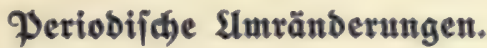
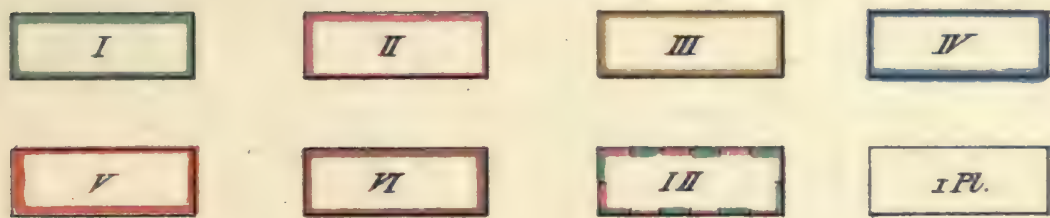

Plenterwalb.

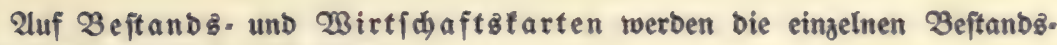
fläden farbig angelegt, unb zwar:

Fü ben Sodwald in Der Grunbfarbe ber berridaenden Solzart. Die eingefprengten Solzarten fommen, poneit fie von wirtid)aftlidber Bebeutung finb, Durdy

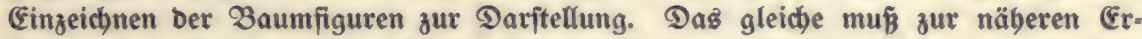
läuterung aud für bie berridbenbe Solzart in Den Fällen geideben, wo biejelbe Brundfarbe für mebrere Solzarten gilt.

Im Nittelro ald bilbet Blaugriin bie Brunbfarbe. Die im Ober- und Galag: bolz vertretenen Solzarten werben burd) bie entipredbenden Figuren beళ Baum. und Bujळbolzeв bezeidnet.

Im Rieberwalb tommt als (Brunbfarbe bie ber berridjenben Solzart zur

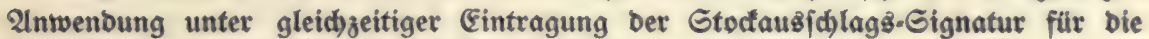
berridbende und bie fonft borfommenden widbtigeren Solzarten.

Die Beftanbsitarte entbält bie Solzartenfarben in brei Fönen abgeftuft: bell fiir 1-40 jäbrige $B$ ẹtänbe) mitter " $41-80 "$ " "

Die ältere ber zrvei unter einen Garbenton fallenben 20 jäbrigen diteraflaffen wirb burd

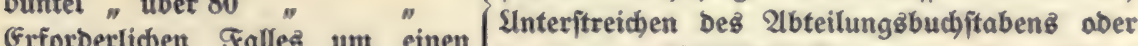
vierten Farbenton weitergefibbrt. Der Sagen=(Diftrifts-) Nummer getenmgeidonet.

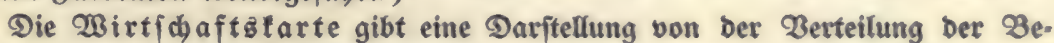
ftänbe auf bie einzelnen 2lbtriebşperioben mit Silfe farbiger SImränberungen ber einzelnen Beftanচsfläcben nebft gleichzeitiger Fintragung ber Periobenziffern. 
SImränberung für:

I. (Brïn (helf).

II. Rarminrot (Rarmin gemijht mit Dectweiß̄).

III. Chromgelb.

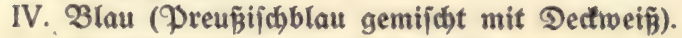

V. 3innober (ober auth Mennige).

VI. Braun (Serraftena).

Beftände, welch) während Des Imtriebes mehrmals genuat werben ("Doppelnugungen"), erbalten bie Farbe Der eriten biejer Derioben unb Die 3iffern ber. jenigen Derioben, für weld)e fie befitimmt fino, 子. 2. I. V. mit Der Slmränderung von I.

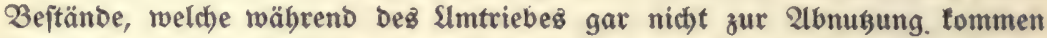
("Durd)geben"), bleiben obne farbige Slmränberung uno erbalten eingetragen bie Bezeidinung $\sim$ ober auch 2 .

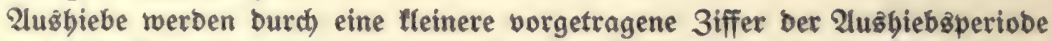
bezeichnet, alæz SImränberung bleibt biejenige ber Abtriebsperiobe in 21ntoenoung, 3. B. I. IV. mit Stmränderung von IV.

Plenterbeitänbe werben nicht umränbert, fonbern wie 2luæbiebe mit einer fleinen I. und mit PI. bezeid)net.

2uf ber Wirtichaftztarte alß joldber gej(hiebt bie Daritellung ber Solzarten

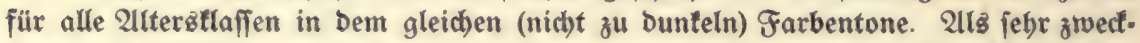

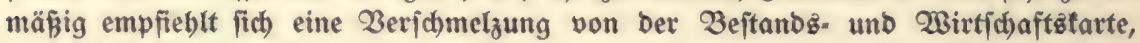
wobei bie Bejtandôtarte in Der oben angegebenen 2 (uBfübrung Die Brunolage für Die Wirtid)aftätarte abgibt und in eritere bie Perioben-SImränderung nebjt Be. zifferung eingetragen wirb. 
zu jeben, wo uno jo lange Die Paturverjüngung vorberricht. (Es wirt bei ber fitammmeifen 2lbnusung, wie fie ber Paturveriüngung eigen ift, nur burch bas 3ujaumenfaffen grö́perer Flächen möglich, mebr Solz am felben Dlás zu bereinigen,

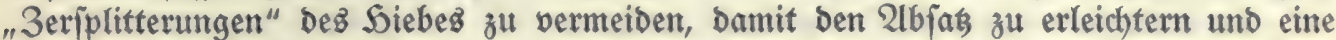
geringere 3 abl von $23 e g e z$ żgen bafür zu beanfpruchen. Dazu kommt alż ein fernerer

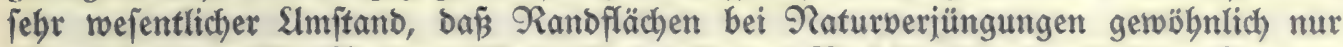

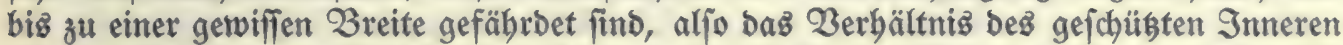
zu bem gefäbrbeten Ranbifreifen fich um fo günjtiger geftalten muß̈, je größ̈er bie ganze Fläche wirb. 3ufammenfaffen bebeutet alfo bier eine Einjchränfung ber Ingrifiz:

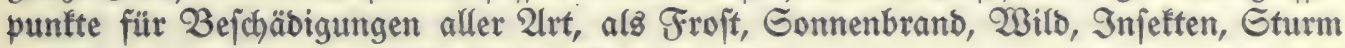
u. bergl. m., nicht aber baż Gegenteil.

Go zeigt z. 2. Nidutzerreipung: Baben, Bayern; ausgefprodenes Etreben zum 3 ufammenlegen: Franfreich, Deżleichen G. L. Sartig 1819.

W3o zur Gicherung gegen Sturmfdaben auf Einbaltung ftrenger Siebzifolge

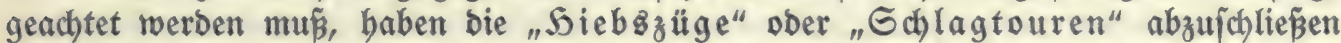

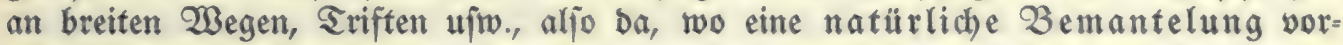
banben und erbaltbar ifít.

Wo bieje nicht gegeben if́, läpt ez fich erreichen, die (Befahren ber Frei= fifellung wenn nicht ganz aufzubeben, fo bodh wejentlich zu mildern burd):

einfacbe Belaffung einez etwa $100 \mathrm{~m}$ breiten, fch üzend vorliegenden

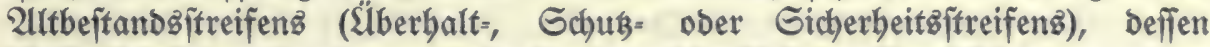
Beftandzglieber burd) voraufgebende allmähliche Durchlichtung an ben Freiftand zu gewöbnen und wiberitandsfähiger zu machen finb. (bering f̈e Opfer!

Ranbbefeftigung im $\mathfrak{B}$ ege ber Serftellung bolzleerer Gtreifen in noch nicht gefährbetem 2llter: VI, V, auch noch IV, burch minbeftenz $10 \mathrm{~m}$

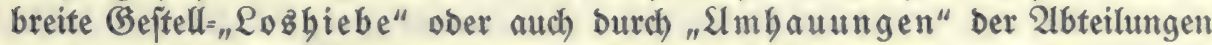
im Inneren einer $\mathfrak{B}$ irtichaftafigur. Größ̈te Opfer!

Werben biejelben in gröserer 3 reite mit Solzanbau angewand, bann ift Dauad) zu trachten, Dá̉ Damit zugleich Die Finjchiebung einez Gtreifenz Der feblenden 2litergflaffe erreidyt wirb. Mit Solzanbau verminderte Opfer!

Minbejtens ebenjo wirffam bei geringerer Einbuje wübe eine von langer Sand vorbereitete und allmäblich gefteigerte $\mathscr{D}$ urd lid)tung breiterer Streifen fid) äuß̃ern, ähnlich wie beim erfígenannten Berfabren, um bamit bie zwecfimäßjigfte

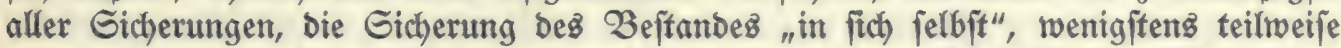
an einer ober mebreren Geiten zu erzielen, benn gelegentlich bläft ber Wino auch

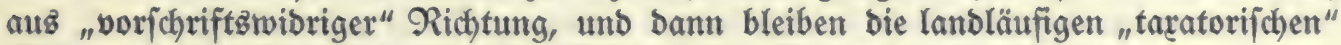
Sidherungen wirfungglog, wie daz Beifpiel won Olbernhau gezeigt hat.

2. Serfitellung beż jogenannten "normalen alterzłlaffen-Zerbältniffes"

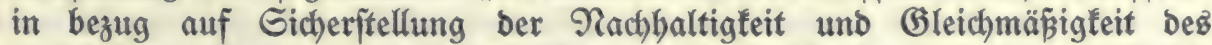
periobifchen Solzertragez burch 2luzgleich ber Flächenverteilung auf bie einzelnen 2llterzifufen uno Werioden. Diefe iff ftreng genommen not= wenbig nur für bie (Bejamtbeit eineg $\mathfrak{B a l b b e j t g e z ~ o b e r ~ f u ̈ r ~ e i n e n ~}$ anberweit feiftgelegten Wirtidhaftżuerband, entbehrlich für baв einzelne Revier, nodh mebr für ben einzelnen Blodf. 3 u vergleichen Geite 7,8 , 12 bis $13,27$. 
Ferner "foll", foweit angängig, Bebacht genommen werben auf aumäberungs= weifen 2luggleich für bie:

einzelnen Solzarten verjobiedener Pabsbarfeit (Purgwert),

verfchiebenen Bobentlaffen gleicher Solzart.

Die auperbem noch frihker mebr, jest meniger angejtrebte "Befranoseinbeit"

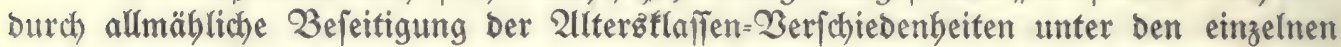

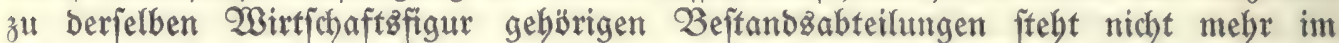
Borbergrunb. Wo beabfitchtigt, erreicht man fie Daburch, ba tunlichfit in ber gleichen ober boch in zwei zeitlich nabe aneinander liegenden Werioden zur 2 bnuzung bejtimmt und fo für bie 3ukunft eine gleichzeitige Nubung Der ganzen Wirtichaftzfigur vorbereitet. Gorveit Damit ein unnötiger 2lufwanb verbunben ift, ber ohne einen gewinnbringenden Erfolg mehr bem 2̈luserlichen, D. h. blozen Echönheitz= rǚffichten bient und Dafür unverbältnizmäßige Opfer forbert, ericheint eine gefuch te Serbeifübrung Der $B$ eftandzeinbeit nicht angebracht.

S̈berbaupt bürfen grunbjäblich alle jolche Feinbeiten uno Rünjteleien łeineg̊fallz mit unverhältnizmäß̈igen opfern, b. h. erheblicher abweichung vom vorteil= hafteiten Siebzalter, erfantf werben. Slm biez zu verbüten, find $z$. $\mathfrak{B}$. in einzelnen anderen Rändern 2lbweid)ungen um mebr alż eine Alterğtlaffe (Periobe) von 20 Jahren gerabezu unterjagt. 3u vergleichen bas Geite 8 und 16 Gejagte.

Bor allem bleibt ber zwedfmäzigften Aużahl ber Sauptnusungs.

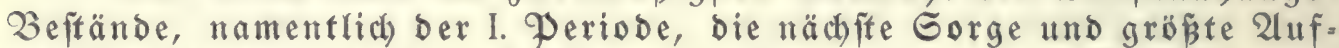
merffamfeit zuzumenden. Es fönen hierfür zunächit mur in Frage fommen: hiebsreife altbeit ände und

folche mangelbaften jüngeren Orte, won benen burch einwanbfreie Snter=

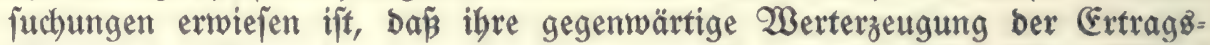
fähigfeit bes Bobens nicht entipricht uno burch andere wirtichaftlict)e Mittel nicht zu heben ift, jogenannte "biebsnotwendige", aljo in gemiffem Sinne ebenfalls biebzreife Beitänoe.

Die Flächenaug gleidung gejchieht gewöbnlich nach ben wir flichen Flächen=

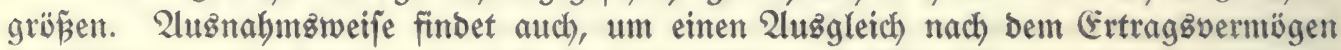
Dez Bodenz, aljo Damit audh nach Dem Solzertrage, herbeizufübren, eine Stmrechnung auf eine beftimmte, in Der Regel befte Güteflaffe 2lnwendung, gelegentlid) wohl beim Flächenfachwerf, "Flädbenrebuttion“. In ben meiften Fällen if́t fie jebodh entbehrlich.

Gamen = und Pidhtichläge rwerben zunächit mit ber yollen Fläche auf bie I. Periobe angerechnet, fofern ber auf ber Flädhe noch vorbandene Altholzyortat

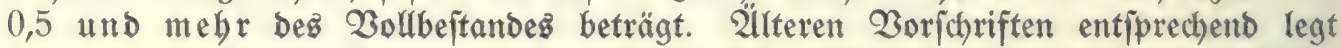
man in Preupen bie Echeibe noch meift auf 0,3 . Dieje Scheibung bei 0,3 entbebrt jeboch jeber inneren Folgerichtigfeit, enthält vielmebr eine gänglich unbegründete $21 b=$ sweichung von ber alfgemein amerfannten arifbmetijchen Seilung uno Abrutbung uno mús baher jebe rechnerifche Zerwendung erichweren.

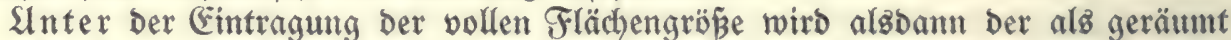
(abgenugt) zu veranjchlagende Seil rot vermerťt. Die Gumme biefer roten Inteile rwiro fohlieflich won ber Gefamtfläche Der I. Periobe in $2 b_{z} u g$ gebrad)t.

Ift weniger als 0,5 vom Mutterbeftande vorbanben, fo fommt nur ber Sungrouchs (3ufunftabejtand) für bie periobifche Flächeneinreihung in Betrad)t. 


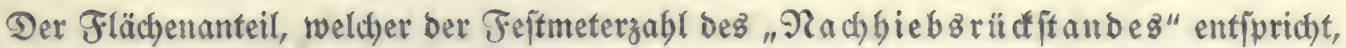

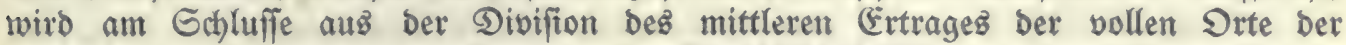
1. Periobe pro Seftar in bie Gumme aller Nachbiebsirüdfänbe nachträglich bergeleitet mo bann in einer $3 a b l$ der Fläche ber I. Deriobe binzugefét.

In gleicher Weije ift bei fogenannten "2lusbieben" uno ebenjo bei "Räumben" zu verfabren. Eg werben in ber Gläcbenpalte ber I. Periobe Feine Finzelanfäze für bie Fläche gemad)t, fondern am Ende im ganzen die anzurednenden Flächentanteile Dazugezäblt.

Rartenbezeidnung ber Zuz̧biebe: Hleine I vor ber 3iffer ber abtriebs=

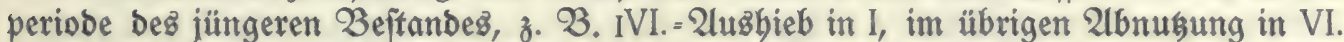

Die fonft empfoblene Schreibneife (I) VI ift bereits vergeben fuir bie $\mathfrak{B} e=$ Deutung "VI, zuläfing I" bei Den Beftanbsbefdreibungen.

Ulmgefebrt wie bei 2ubbieben ift bei "šberbaltmaffen", welche von vorn=

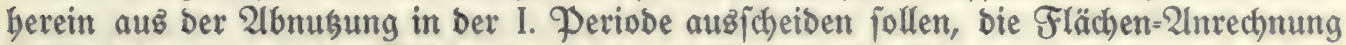

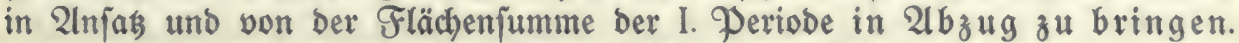

Demnach fegt fich die gejamte Fläche ber I. Periobe zufammen auz:

a) t vollen Orten,

b) + angebauenen, ourdichteten Orten von minbeftens 0,5 beв Boll=

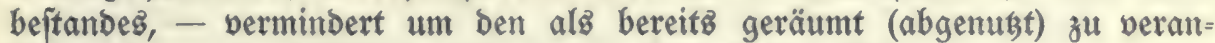

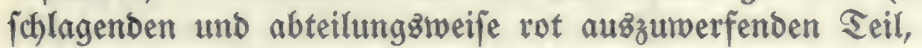

c) + Dem im ganzen berechneten Flächenanteil von päteren Perioben, ber= geleitet auв Dem Solzertrage Der 21 żhiebe, Divibiert Durch Den Durch)/chnitt= lichen Ertrag won a pro Seftar,

d) - Dem ebenjo berechneten Flächenanteil für bie zum Śb erbalt beftimmten Solzmengen.

Die betreffenden Fläcbenanteile find mit umgefebrten $\mathcal{B}_{0}$ rzeichen in $2 \mathrm{n}=$ rechmung zu bringen bei ben fpäteren, getoobnlich lebten Perioben, zu Denen fie in Beziebung fteben.

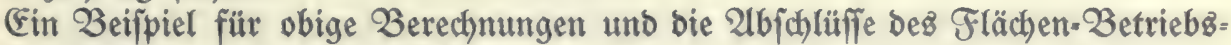
planes findet fich auf folgender Geite.

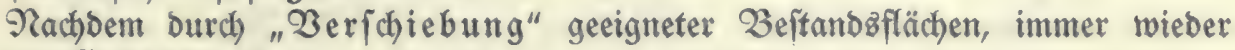
unter bem Gefichtỉpuntte:

a) Der 2 bnusung jebes 2 effandes tunlich it in befter siebreife,

b) Der Serbeifübrung angemeffener Beftandsoronung (Siebsfolge) uno

c) Der 2uftrebung erwünfdt foeinender, aber, wie gejagt, an fich nicht unbebingt erforberlicber $\mathfrak{B}$ eft anbseinbeit,

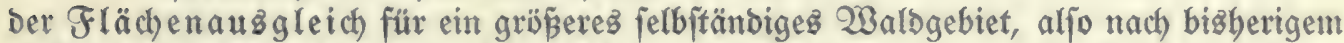
Gebrauch für bas Revier, foneit bies noch für notmendig erachtet wirb, fonft am lesten Enbe für die Gefamtheit bes betreffenben 2 Balbbefísez erreicht ift,

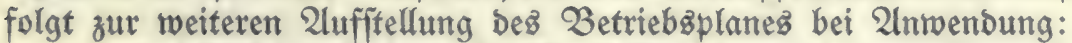

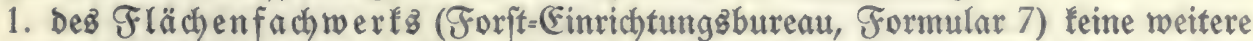

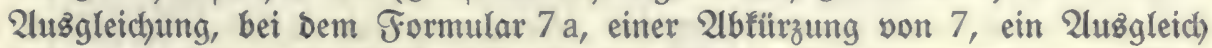
fogar mur für I unb höchftens II, für bie fpäteren Perioben nur fummarifcher

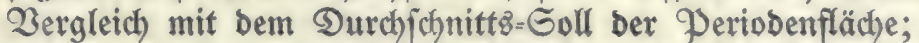

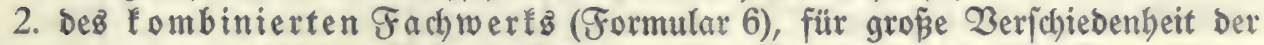
einzelnen periobifchen Beftanosflächen in ihren Ertragżverbältniffen, 3 erechnung 
Der Solzerträge Durch) alle Perioben (I. kluppen, Die übrigen nach) Eertragg= tafeln einjchäßen) und, foweit notwendig, fernere Berjchiebung ber Beftands: flächen burch 2ubztaujch an Solzertrag reicher gegen ertragzarme uno umgetebrt zuguniten periobifcher "MRaffen"=2ługgleichung.

Die fonft nod) in 2 nwenbung gewejenen Formulare $\Re r .8$ für bie fummarifche

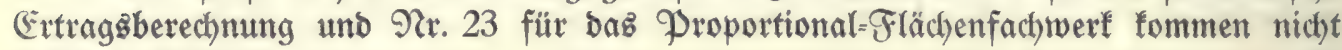
mebr in Betracht.

3ujag: $\mathscr{D a z}$ in neuerer 3eit immer.mehr, mandymal freilich auch etwaz zu einfeitig zur 2lnwendung gebrachte "blope $2(u s$ fuchen geeigneter Beftands: frächen zur 2lbnugung für bie nächften 20 Sabre" (Formular 7 a) bedeutet einen flaren S̈bergang zu einer Beftandzinirtichaft in bem Einne: unter teilweifer Sintanjegung ber Geite 44, 49 biz 50 angegebenen (Befichtżpuntte alz eigentlichez 3iel vornebmlich bie Abnugung jebez Einzelbejtandez in jeiner beften Siebz= reife anzutreben uno jene Rüdfichten nur ba gelten zulaffen, wo aub ibrer

Solzbodenfläd)e: 2755 ha,

Betriebzafläd)e $=$ Solzboben + Doppele nukungen - Durch)gehende Fläb)en:

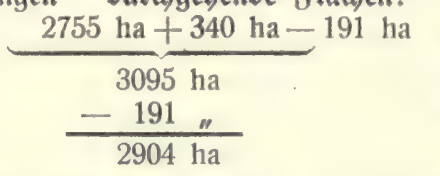

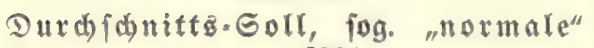
Deriobenfläde $\frac{2904}{6}=484$ ha.

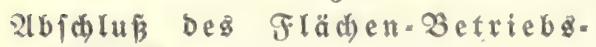
planez:

Bon ben

$140070 \mathrm{fm}$ So a $18560 \mathrm{fm}$, mithin verbleiben in volfen Orten

$121510 \mathrm{fm}$ auf 419 ha.

Der Durdidnittortrag pro settar beträgt mithin $\frac{121510}{419}=290 \mathrm{fm}$.

Fïr ben Solzertrag ber 2 usgiebe fino Demnach ber Fläh) Der I. Periobe binzu= zuésen: $\frac{18560}{290}=+64,0$ ha, Davon riegen in $\mathbf{B e f t a ̈ n}$ ben Der

$$
\begin{aligned}
& \text { V. Periode } \frac{4640}{290}=16,0 \text { ha } \\
& \text { VI. Periobe } \frac{13920}{290}=\frac{48,0 \text { " }}{64,0 \text { ha }}
\end{aligned}
$$

Terner fino zum $\mathfrak{A} b$ exhalt beftinmt: $870 \mathrm{fm}$, entipricht einer Fräcbe von $\frac{870}{290}=3,0$ ha, welde gar nicht genubt wirb.

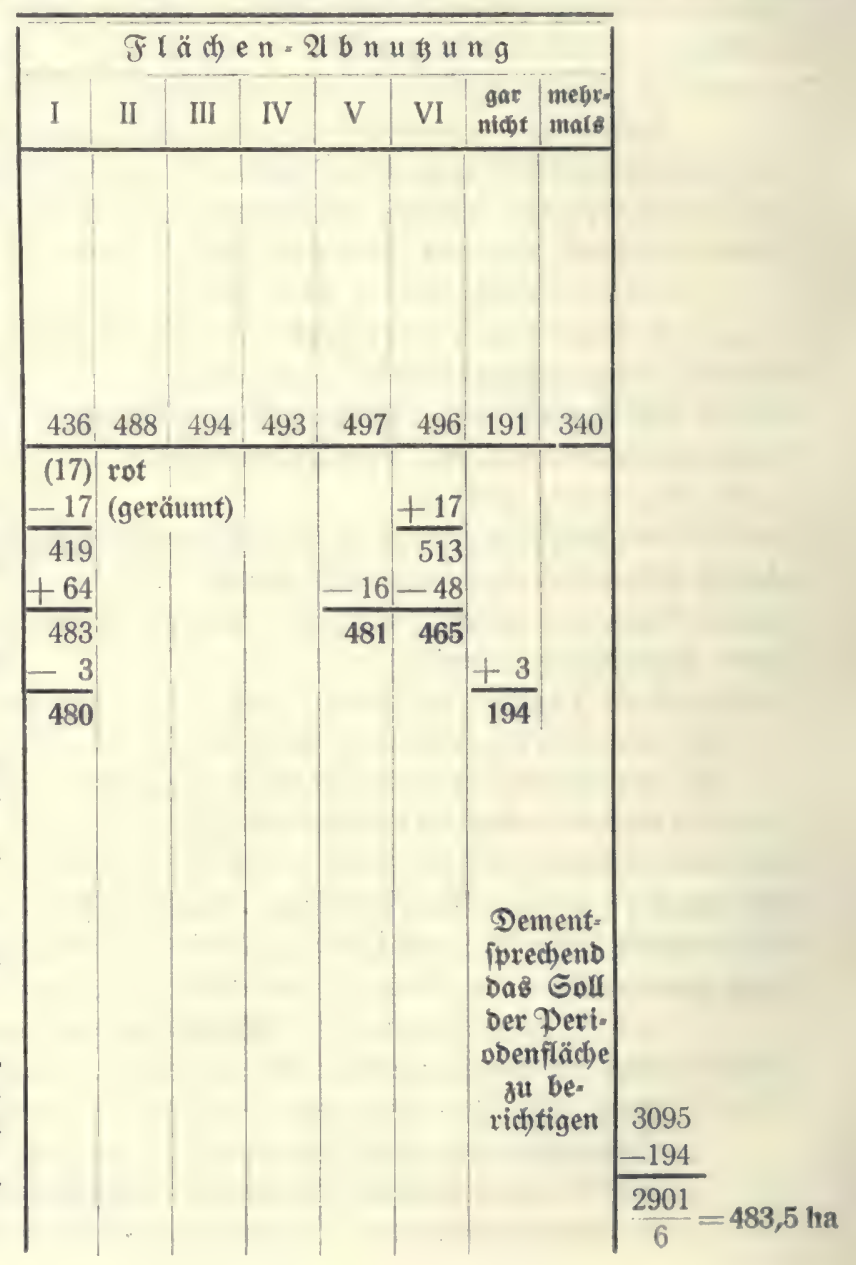




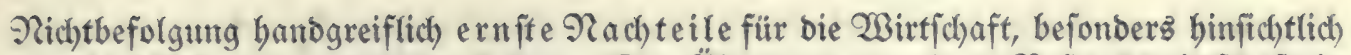
ber Siebsfolge, zu erwarten ftehen. Der S̈bergang zu eirter Beftandzinirtichaft in

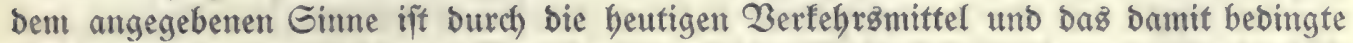
Berjatwinden von fleinen Bezirfen örtlicher Bebarfäbefriebigung uno örtlid

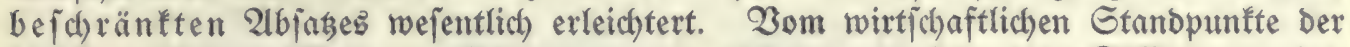
Göb)iten abjoluten SBert= unb Bätererzeugung erjcheint er in febr vielen Fällen angezeigt, minbeftens aber unbebenflich, wenn folgerichtig angewanbt und burchgeführt, ofne miederum auf Den periobifchen Flächencuछ̈gleid) im Revier vber gar im 3 lock ängfflich)

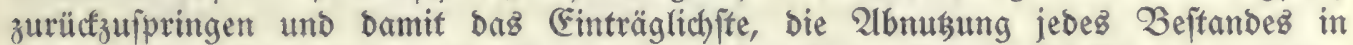
feiner beften Siebzreife, teilmeife wieber alfzugeben. Smmer bleibt zu beachten:

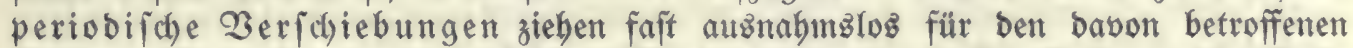
Bejtano EinbuB̃en an Der Göchiten WBerterzengung nach fict), foften alfo Geld und find beghalb in jebem Falle barauf zu prüfen, ob ber 2 ufroand für bieje Maß̃regel in Dem rechten wirtfchaftliden Berbältnis zu bem bamit erfítrebten (Gewinn iteht. Durchweg ift "Borzieben" verlujtreicher, aljo bebenflicher alz "3urüafchieben“, benn bie Werterzeugung freigt zu ihrem Söbepunft freiler an, ałs fie babinter finft.

Einen 21 hbang zum 3etriebsplan bilbet Der Durdforjtungaplan, cingeführt

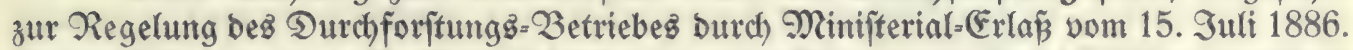

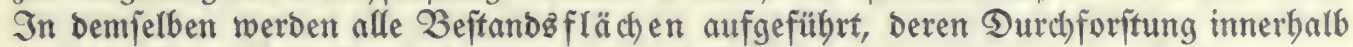
Der nächften 10 Jabre wilnjchenz̧wert erfheint, und zroar getrennt nach:

A. Durchforfungen in Beftänden ber I. Deriobe,

B. unter biejen:

ipäterer Derioben,

a) Derbholz= Durchforfungen,

b) Reiferbolz= Durdb forftungen.

Sroctnizeinfchlag, pogenannte "Sotalitätzbiebe", bleiben im Durchforitungzpplane unberiadfichtigt.

Sluż ber Gumme bez Flächeninbaltez aller 2lbteilungen, wobei für bie alle fünf Sahre wieberfehrenden Durch forjtungen bie Fläche zweimal anzurechnen ift, Divibiert burch 10 erhält man bie alljährliche Durchforftungsfläche, welche iłrerfeitz wieber mit bem Soll, ber jogenannten "normalen" Durchforftungafläche, nach ber 2literzflaffentabelle in Bergleich zu fitllen ijt.

Diefe Berteilung ber Flächen genügt für ben eigentlichen 3 wed.

Ës werben aber auch auperbem wohl noch auf ber linfen Geite im einzelnen Die zu Durchforftenben 2lbteilungen auf $z e b n$ Sabresfpalten verteilt unter an= nähernoem jäbrlichen 2usgleiche von $\mathrm{A}, \mathrm{Ba}, \mathrm{Bb}$, getrennt nod) weiter für 1 . $\mathfrak{Q} a \mathfrak{b}=$ uno 2. Nabelbolz.

Eine wohlgemeinte, aber zu weit getriebene Borauzbejtimmung. Die Ein=

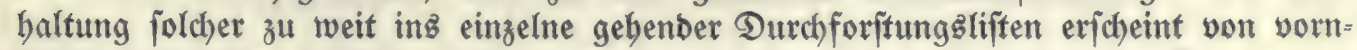
herein nicht jebr wabricheinlich.

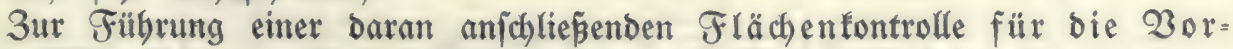
nuBung (Nin.=Erl. vom 15. Suli 1886 und vom 17. Mai 1892) fint auf ber rechten Geite ftetz zebn Jabresplpalten anzulegen, in weldse bie aubgefilbrten Durch)= 
forftungen mit ihrem Flächeninbalte und Damuter aud wobl noch rot bie Derbholz= ertråge pro Seftar eingetragen werben.

Sierzu am beften verwertbar Daz im Ropf wie untenjtebend abzuandernbe Formular 16.

\section{b) Mittel= und Rieberwald.}

Für bas Schlagholz im Mittelwald uno fïr ben Nieberwalb gilt eine flächen = weife abnubung. Nit Der Reibenfolge ber Galäge if́t zugleich baz Jahr ber abnubung feftgelegt. In Partiefdrägen, in benen bie einzelne Sabrezfläche nicht aubzerwiejen ift, bebarf eछ ber 2lngabe ber Siebsjahre.

Die Deranjchlagung ber Solzerträge vom Gablagholz gejohieht am einfachiften nach Den bizherigen lebten Siebrergebnifien.

Beim Dberforz Dez Dittelwalbez werben die SAmtriebzzeiten fo benteffen,

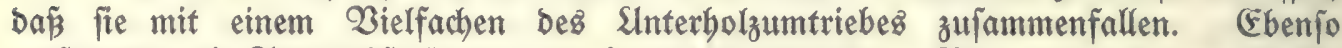

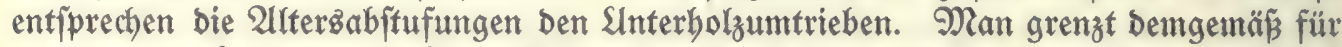
bie einzelnen Solzarten bie Altergflaffen ab und teilt babei zur Bereinfachung gewöbnlich beftimmte Gtärfeftufen ben einzelnen Slltergiflaffen zu. Für jeben Gablag mirs ein Soll bes Oberbolzes nach Dem Siebe, Der "Normal=\{̈berbalt", beftimmt, von bem Dann zufammen mit ber borbanbenen 3umachzleiftung bie Söbe ber jemeiligen

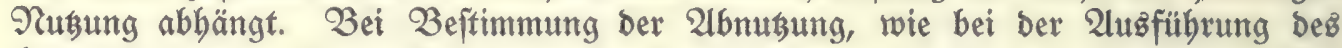
Siebes bat man es im übrigen in ber Sand, die zu Oberbolz weniger wertbollen Solzarten früber zu bejeitigen.

In ben Preupijichen Gtaatżforften fino alle nod) vorbanbenen Mittelwaloungen in ber šberfübrung zum Sochwals begriffen.

Sierfür empfiehlt eछ fith, wie alz Sauptjache zuerít von Borggreve, "Forfit= abjhäbung"1888, bervorgehoben ift, unter Unbahnung guter Siebsifolge zunäch jt

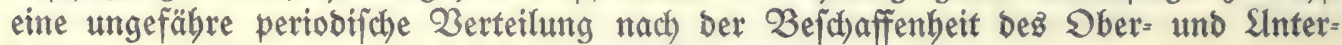
bolzes vorzunebmen und sabei im allgemeinen zuzuteilen:

Den vorberen Perioben Beftandsflächen mit bem reiffiten Dberbolz und im Sclagholz mit 2lrten, die fich zur Pachzucht oon Nubbolz weniger eignen, um to mit Silfe einer aus Dem Sberbolz und Den "Saftziebern" vom Slnterbolze gefchaffenen Gamenfchlagitelfung uno, falls exforberlich, unter woblfeiler Einbringung weiterer Nubholzarten eine im wejentlicben aub Rern:

Durd)=

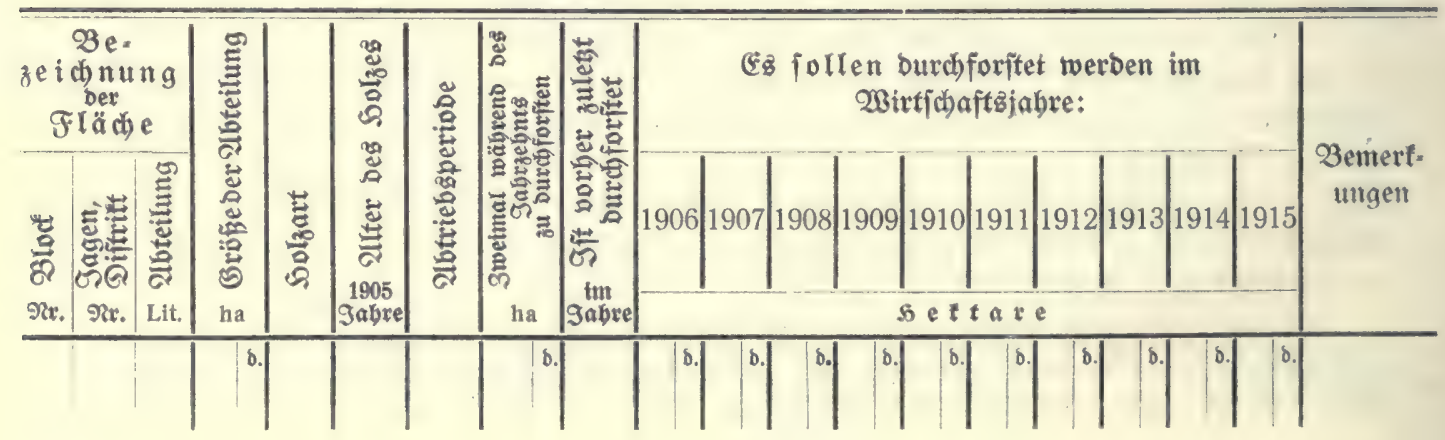




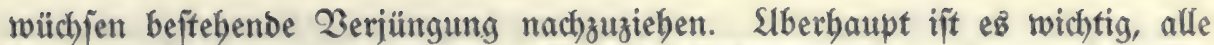
joldbe SAmwanbelungen mit einem Sinterbolzbiebe einzuleiten, Der, je nad) (Er= forberniż, auf jebem Stod ein bis brei ber bejten Loben alz Gaftzieber und aud) zur 2lufzucht ber weiter zu erbaltenden Solzarten zu fchonen bat.

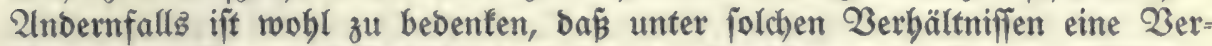

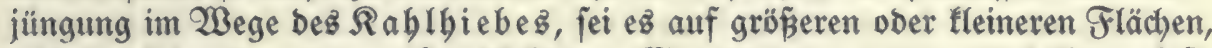
mit nachfolgenden teuren Sanbfulturen, Eingatterung uno nact)träglicher fojt

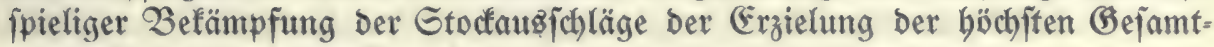
wertleiftung $a m$ wenigften bienen fann.

Den mittleren Derioben Orte mit reichlichem, aber vormiegend mittelaltem Oberbolz, um hier hauptjächlich mit Silfe von pfleglichen (Durchforftungz=

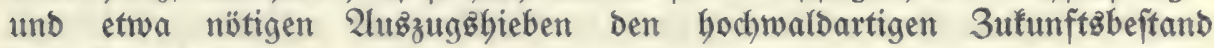
Geraufzuzieben.

Den Ginteren Perioben bie oberbolzarmen Beftände und jolche mit über= wiegend jüngften Oberbolzflafien, um aus biejem jüngften Oberbolz und Den im Sinterbolz vertretenen Nugholzarten einen geeigneten 3 ejtano heraugzubilben. Dabei ift bas vorbandene ältere Oberbolz fämtlid) zu ent= fernen und ebenjo das jüngere, forweit es nicht in abgerunbeten, leiblid) gejololofienen boriten auftritt.

Pan tut gut, in allen fpäteren Perioben von vornberein auf bie errwähnten

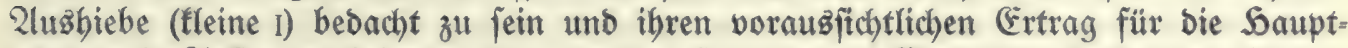

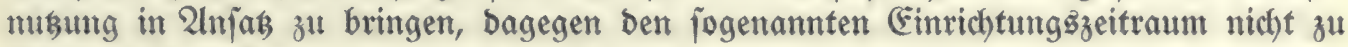
fuapp zu bemeffen.

\section{Die CErtragsbered)mung.}

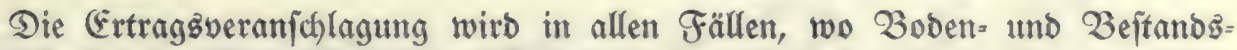

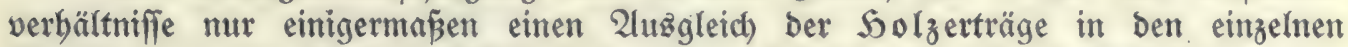
Perioben erwarten lafien (Fläd)enfact)werł́), auf bie I. Periobe bejchränte uno nur

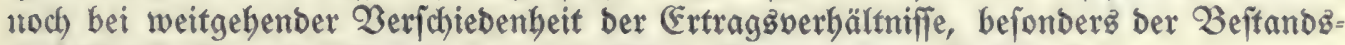
verbältniffe für alle Perioden Durchgefübrt (Rombiniertez Gachwerf).

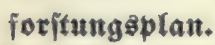

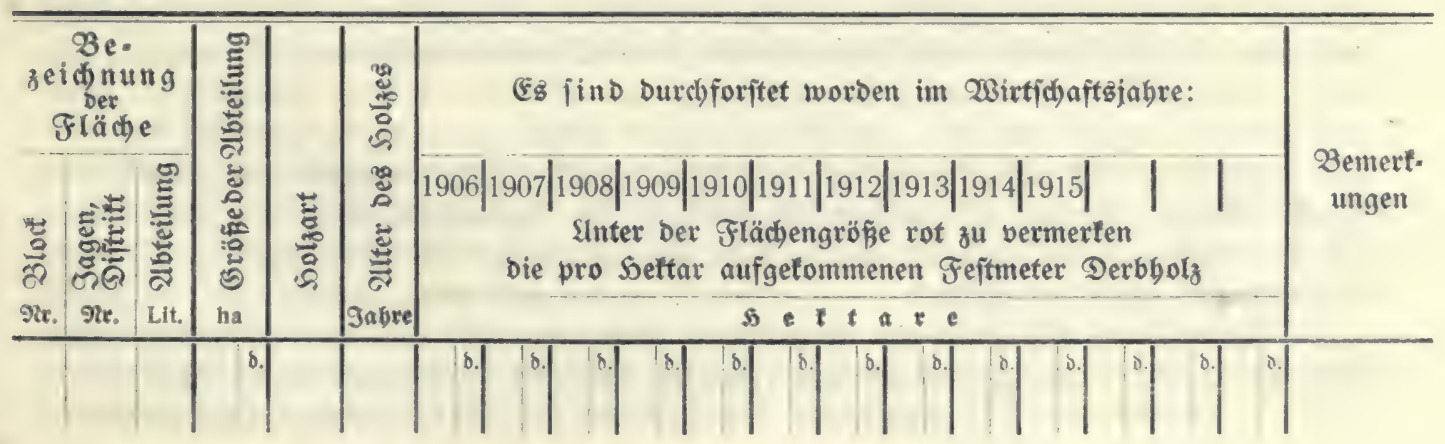


Bei Der Ërtragaberechnung, wie aud päter bei Der "Naterial"= Rontrolle,

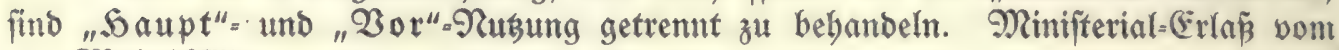
15. Mai 1875.

3ur Sauptnubung zäblen:

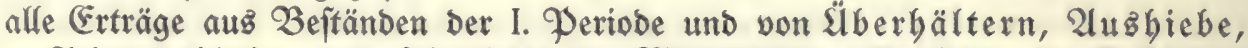
Dlenterhiebe, bas Oberbolz im Mittelwalbe, alle Siebe in Beftänden fpäterer Perioben, welche ben 2lbtrieb ober eine Beriüngung zum Biele haben ober eine $\Re u l t u r$ nötig madhen, ober aber "Den fchließ̈lichen Abtriebz= ertrag $\mathfrak{u m}$ mehr als $5 \%$ verringern". Qegteres ift jehr oft foum zu er= gründen, in 3weifeläfällten gilt $\mathfrak{S a u p t n u t b u n g . ~}$

3ur Beranjalagung bez Solzertrageg ber I. Periobe wirb dem für jebe einzelne 2lbteilung ermittelten Borrat an Derbholz Der gefunbene 3 uwach 8 , biz zur Mitte ber Periobe, $Z=\frac{z n}{2}$ binzugerechnet.

Der zufünftige Abtriebsz, Sauptmubungb=Ërtrag fpäterer Perioben, Deffen

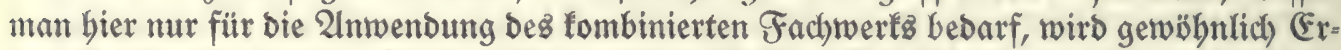
traggtafeln entnommen. 2luch) er ift in gleicher Weife auf Die Werioben mi t te zu beziehen.

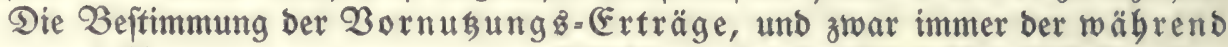
Der ganzen I. Deriobe zu erwartenden, gejchieht, wie bereitz Geite 43 zu 4 beiprochen.

Der auf bie gefamte I. Periobe entfallende Solzertrag, und zwar getrennt nach Saupt= uno Bormukung, geteilt Durch bie Periobendauer (20), ergibt ben jäbr=

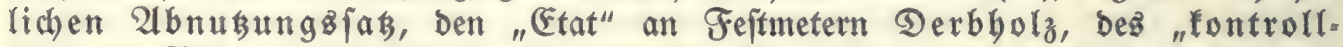
fähigen Materialg" für bie Saupt= wie Bornubung, bie Eummierung beiber ben $\mathfrak{B}$ efamt=2lbmugungbjag. Derjelbe wirb getrennt gebalten nach vier (Bruppen won Solzarten, für beren 3 uammenfafinung eigentlich nur bie annäberno gleiche

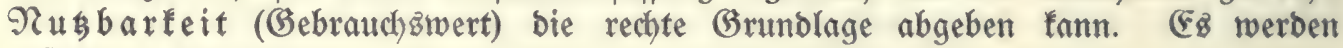
zujammen verrechnet:

1. Eichen, für fich allein,

2. Buchen, Dazu Rüjtern, 2lyorn, (Ejchen, Sainbutchen uno andere Sartbörzer,

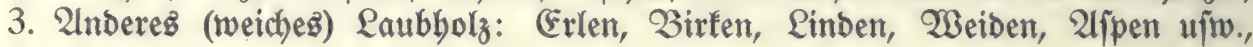

4. Nabelholz obne Sinterjichieb.

Dag von bem Derbholz vorausfichtlich im Durchjobnitt jäbrlich entfallenbe Stod" $=$ und Reiferbolz, baz "nicht zu fontrollierende Material“, wirb nad) einer Durchjchnittżberechnung aug Dem (Einjchlage ber früberen, gewöbnlich legten Sabre im ganzen veranichlagt nach Prozenten bez Derbholzes̆.

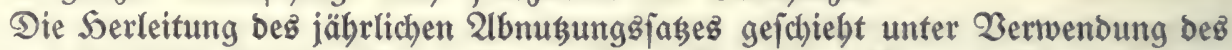

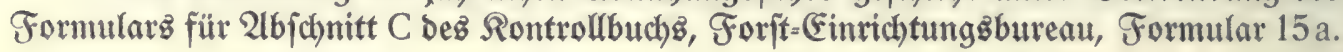

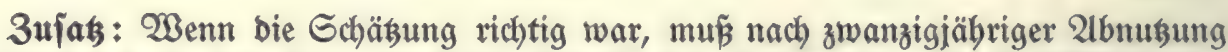
Des Siebsjakez in Der Sauptmukung fowohl ber Solzertrag wie bie Flädhe ber

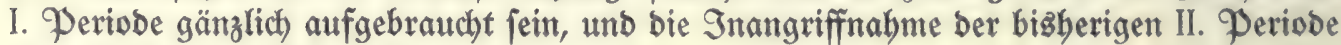
ohne weiteres geidhehen tönnen.

Alnoermittelt polfziebt fich biefer Äbergang nur bei ber Rablidslag= Wirtfchaft. Die Naturberjüngung Dagegen erforbert vorber gewiffe "Borgriffe" in bie II. Periobe, um Dą regelrechte Fortfchreiten Der Zerjüngungen ficherzuftellen, 


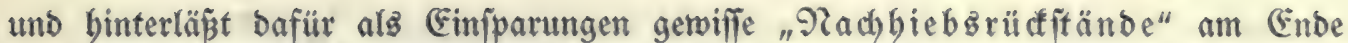
ber I. Periobe auf ben 3 ejtanogllächen biejer.

"Borgriffe" und bie bafür eingeiparten "Nachbiebzrücffänbe" mîffen einanber bie 20 age balten, auperbem aber binfichtich ibres $\mathfrak{A}$ m. fanges in einem beftimmten $\mathfrak{B}$ erhältnis zum Berjüngungszeitraum fteben. Die Beffimmung biefes lebiglich von Der Zänge ber Zerjüngungsbauer abbängigen Ulmfanges ift bie wichtigere, praftijch allein ausf(c)laggebende 2ufgabe. Eg genigt an fich nicht, wenn in Samen = und Qid)tichlägen von 0,5 und mehr bes 2 ollbeftandes

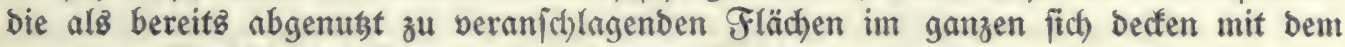

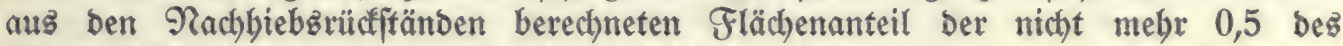

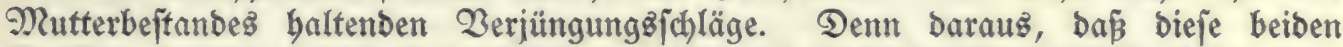
(Gröpen einanber gleich) fino, folgt noch nicht, baj̃ fie in ibrer 2lbbängigfeit von Berjüngungघzzeitraum richtig benteffen fino. Seine Finbeziebung in bie Rechnung ift zur richtigen Beftimmung ber zur regelrechten Fortfübrung Der Raturverjüngung erforberlicben Gejamtfläcbe Der Borgriffibeftänbe unentbebrlicb. Dieje mü fich bei Gejtattung Der Entuahme von einem 2 iertel Des 2 orrates rechnerifich ftellen auf:

\section{$\frac{\text { Berjüngungs̊zeitraum }}{2} \times$ Goll ber abzunusenden Sabregfläbe,}

unb zwar minbeftens auf bieje (Bröpe, weil ez fich in ber II. Periobe gemöbnlid)

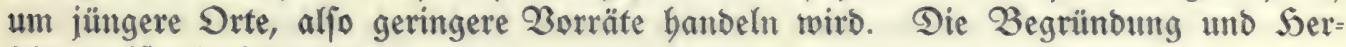
leitung ift die folgenbe:

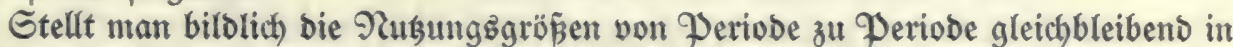

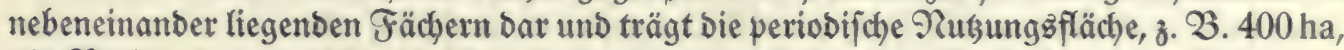
alz 2reite, Den Durchfichnittlichen Solzertrag pro Seftar, z. 3. $300 \mathrm{fm}$, als Söbe auf, fo bebentet bei ber $\Re a b l j c h l a g=2 B$ irtjchaft bie jäbrliche abnubung einen jentrechten abfitrich von je 20 ha $\times 300 \mathrm{fm}$, aljo volle abnubung ber in bem Periobenfach entbaltenen Fläcben uno Solzmengen auf biefen Fläcben uno in biefem Solz innerbalb 20 Sabren. -

Bei ber Raturverjüngung bagegen befindet fich je nach ber Qänge ber Berjüngungảbauter $\mathrm{Vz}$, eine befitimmte Fläche in Dem Sibergange vom $21 \mathrm{lt}=$ zum Sung = Beftand, bie 2lbnibung bollziebt fid) auf berfelben Fläd)e nicht mit einem Schlage, fonbern allmäblich Durch ben ganzen Deriünungछ̇zeitraum Vz. Degbalb

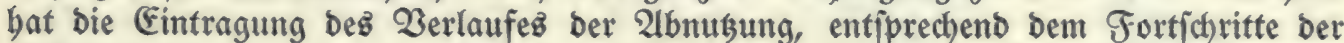
ftufentweife zunebmenten 2luglichtung, treppenförmig, ober beffer alB gleichmäßig

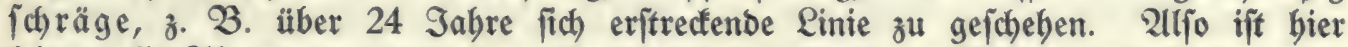
feine bolle 2lbnubung ber in bem Periobenfach entbaltenen Flächen unb Solzmengen auf biefen Fläcben unb in biejem Solz allein möglich, fonbern ein S̊bergreifen

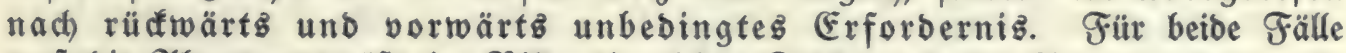

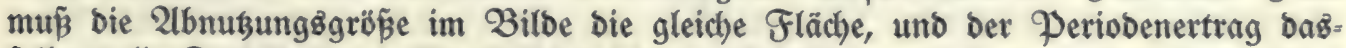
felbe volle Fach becten. (Ẻ ift bies leidht erfichtlich zu machen burch einfache $3 e r=$ wanbelung ber fdbräg liegenden Felber it bie fenfrect)t ftebenben Rechtecte, wenn bie Seilung nac) oben und unten in ber richtigen Pitte bei 0,5 (nicht 0,3 ) beह Bollbeftanbes exfolgt, und bamit die Srennungzlinie zrwifhen I uno VI fo gelegt wirb, baß̈ bei regelrechter Fübrung Der Berjüngung im Anfange ber Periobe eben: foviel alz शachbiebsirüffitand Nh auf Flächen in VI verbleibt, wie in 2inbieben bei I bereits entnommen ift. 


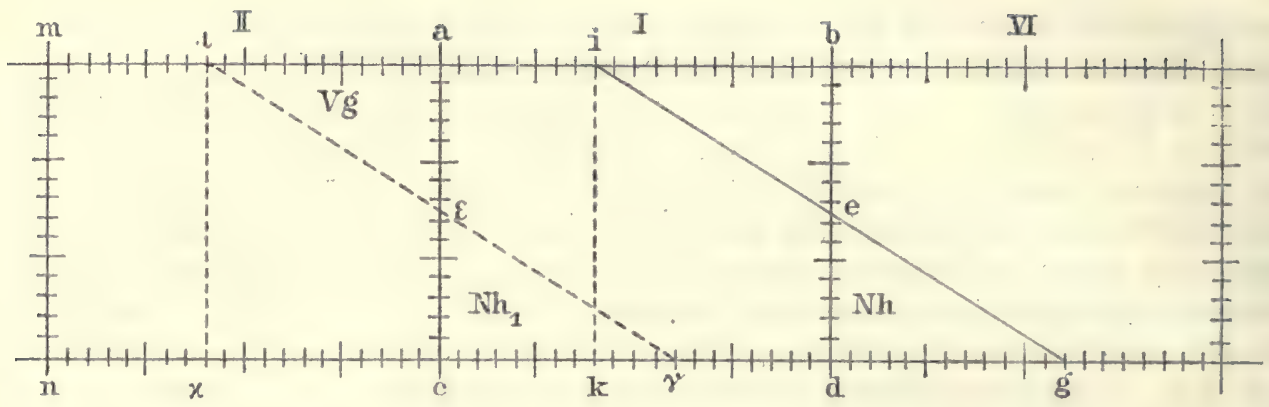

Die Flächen= unb Solzabnubung Der I. Weriobe fegt fich) zujammen auz:

a) volfen Orten acki ber obigen Daritellung,

b) + angebauenen Orten von mindejtenz 0,5 Dez Zollbejtandez ikde,

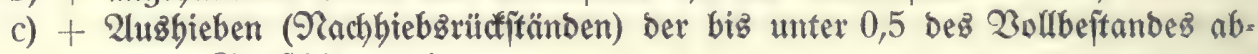
genugten Pichtichläge edg.

$\mathrm{a}+\mathrm{b}+\mathrm{c}$ bat einem volfen Fach zu entiprechen:

r.gi $=\mathrm{acdb}=$ acgi.

acki + ikde fint in bem Fach I enthalten,

edg $=$ Nh jchiepst in Fad) VI über unb entipridht in jeiner (Gröpe bem in

Fach I oben rechts fehlenben abjabnitte ebi.

acki + ikde + edg enthält alfo genau bie einem vollen Fach (voller Perioben=

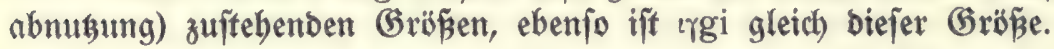

$\mathfrak{A m}$ wichtigiten jedoch ift bie ridhtige Beftimmung bes Slmfanges won $\mathrm{Vg}=\mathrm{Nh}$. Diejer wirb bebingt burch bie Länge ber Berjüngungsoauer Vz.

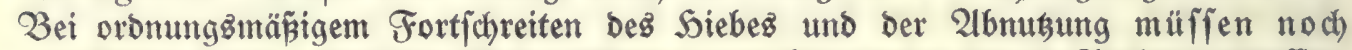
vor 2lblauf ber I. Deriobe Beftandzflächen unb Solzerträge ber II. Deriobe getroffen, alfo "Zorgriffe" Vg nötig werben, und zwar um fo früber, je länger $\mathrm{Vz}$ ober je fiirzer bei gleichem $\mathrm{Vz}$ bie Weriobentaner $\mathrm{P}$. Eo z. 3 .:

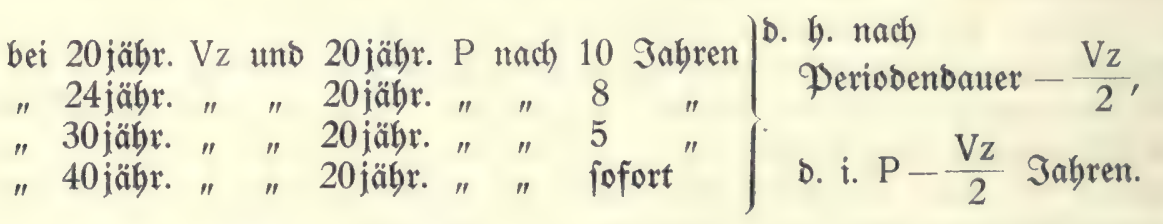

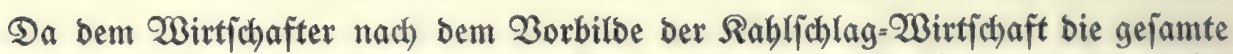
II. Periobe zunäcbit verichloffen zu Galten ifit, fo werben gewiffe Berlegenbeiten beim Serannahen jenes 3eitpunftes unvermeiblick. SAm ihnen zu begegnen, war bereitż won

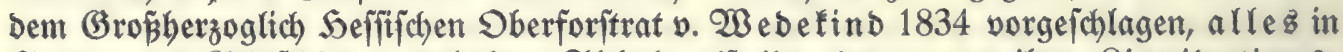

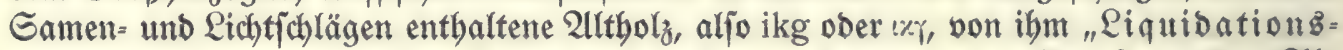
quantum" genannt, außer 2 njás zu lafjen und mur aus volfen Orten ben $216=$

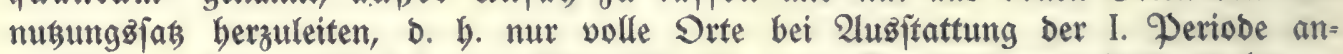
zurechnen. Dann laffe finch obne Borgriffe bie ganze Periobenbauer hinburch Gauen, unb ez würbe bei regelrechter Wirtichaft am Echluffe jeber Periobe immer wieder Das gleid)e Qiquibationżquantun übrig fein müffen. 
Der alleinige Nachteil bieję̧ Zerfahrenछ̊ bejteht barin, baß̈ ber im

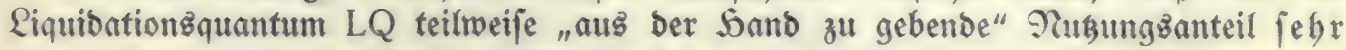
gró̉ ift. Ex beträgt: $L Q=\frac{\mathbf{V z}}{2} \times \mathbf{E}$, ober mit $\mathfrak{B}$ orten:

Berjüngungżzeitraum bivibiert Durch) 2, mal jährliche Solzabnukung (Ettat).

Sebr viel fleiner wit' biefe Größ̈e, beträgt nur ein Biertel ber eriteren und erreicht zugleich bie untere Grenze, D. G. Den Mindeftbetrag Der für 3 orgriffe in bie II. Periobe alferwenigftens zur Berfügung zu fitellenoen Nußsungżgröß̈e, wem, wie eingangz alz $\mathrm{Vg}=\mathrm{Nh} \| u x$ edg ober $\mathrm{c}_{\gamma}=$ ebi ober sa: angejehen uno in Rechnung geffellt wirb. Dann iff:

$$
\begin{aligned}
& \mathrm{Nh}=\mathrm{Nh}_{1}=\mathrm{Vg} ， \\
& \operatorname{edg}=\varepsilon c_{\Upsilon}^{\gamma}=\mathbf{a}^{\prime}, \\
& \mathrm{Vg}=\mathrm{Nh}=\frac{\frac{\mathrm{Vz}}{2} \cdot \mathrm{E}}{4}=\frac{\mathrm{Vz}}{\mathbf{8}} \cdot \mathrm{E}, \\
& \mathrm{Vz}=24, \mathrm{E}=6000 \mathrm{fm}, \\
& \mathrm{Vg}=\mathrm{Nh}_{1}=\mathrm{Nh}=\frac{24}{8} \cdot 6000=18000 \mathrm{fm} .
\end{aligned}
$$

Ebenio umgefebrt

$$
\begin{aligned}
\mathrm{Vz} & =\frac{8 \mathrm{Nh}}{\mathrm{E}} \\
& =\frac{8.18000}{6000}=24 .
\end{aligned}
$$

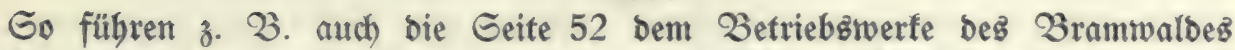
entrommenen 3ablen zu bent Erigebnis: $V z=\frac{8.18560}{7004}=\frac{148480}{7004}=21$, waร̉ ben tatfäd)lichen Zerbältnifien entipricht.

Nach bem regelrechten $\mathfrak{Z}$ erlauf würben bemnach am Ende ber I. Weriobe getwiffe Beftandsflächen Vg aแı ber II. \eriobe in gleichmäßziger 2lbftufung vom vollen Ont biz auf bie Sälfte bez Zollbeftandes burchlichtet fein müffen. Die Ermächtigung zu einer 2luslichtung bis auf bie Sälfte wirb vielleicht nicht mit Unrecht als eime zu bebrobliche Wreiggabe von Beftänben ber II. Weriobe angejeben

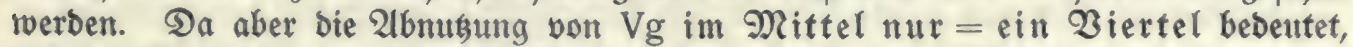
uno bie Entnabme einez gleich)mäßigen Biertelg faum eine Befabr in fich birgt, fo

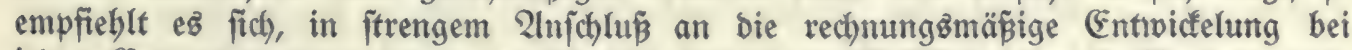
jeber Ertragzregelung von vornberein biejenigen Bejtänbe ber II. Periobe ausz= zumeifen, auz welchen im Bebarfifalle burd) vorbereitenbe Siebe bis zu je einem Biertel Des Zollbeftanbes (nach) obigem Beipiel biz zu $75 \mathrm{fm}$ pro Seftar) zu= fammen $\mathrm{Vg}$, §. i. nach) obigen 3 ablen biz zu $18000 \mathrm{fm}$, entnommen werben fant, unter $\mathfrak{B e r r e c h n u n g ~ D e ళ ~ S o l z e ß ~ a u f ~ b i e ~ S o r u p t n u ß u n g . ~}$

Die bierfür zu beftimmende Befamtfäabe ber Borgrififabejtände wirb bei Êntnahme von einem Biertel betragen müffen: $=\frac{V z}{2} \times E$, b. b. Fläd)en $=E$. 
Im vorítebenben oberen Beifpiel: Borgriffz̊fläche $=\frac{24}{2} \times 20=240$ ha.

Zergleiche "Mämbener Sefte" VII 1895 Geite 118 ர̃.

Bill man über biefe unterite red)nungżmäß̄ige b̈renze binauggeben und bem Wirtichafter von vornberein eine gröpenere Freibeit einräumen, jo viro ez für bic Draxiz noch einfacher, wenn man ibm bierz̆ bie ganze II. Periobe zur Berfügung

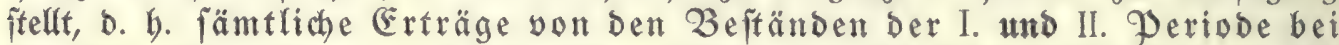

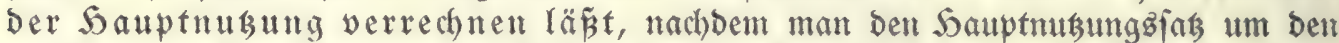
gewöbnlichen (Durd)forftungzanfall von ben Beftanosflächen Der II. Weriobe erböht hat. Tann fann bem Wirticllafter geftattet werben, im Bebarfafalle jeberzeit in ben Beftënden Der II. Deriode vorbereitende Siebe big zur Ëntnabme einez gleich)= mäßigen Biertels vom Zollbeftande zu fübren.

Damit würbe ber regelredhte Fortidritt bez Berjüngungabetriebez aud bei

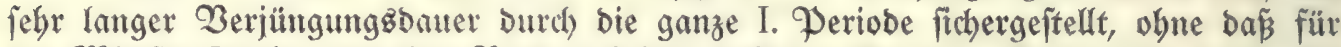

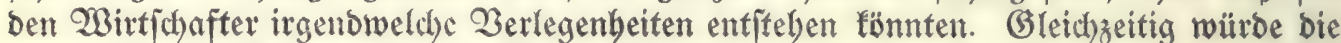
ganze 2 irtichaft beweglicher geftaltet und ez nicht mut ermöglicht, fondern gerabezu nabegelegt, bie in Den Beftänden Der II. Deriobe fo erwünfd) ten frühzeitigen, aber mäßig gehaltenen vorbereitenden Sauungen rechtzeitig zur 2 lusfübrung zu bringen,

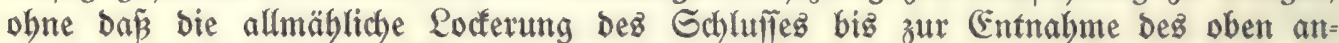

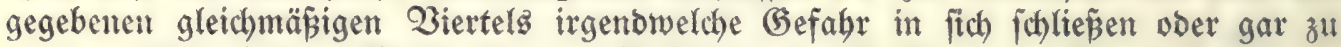
einer gefabrorobenden Dreiggabe von Beftämben ber II. Deriobe fǘtren fönnte.

Ein allgemeiner, fogenannter "genereller" Sauungzplan, D. i. eine 3 jammenftellung Der in ben erften zehn Sabren vorzugżoeije in Angriff zu

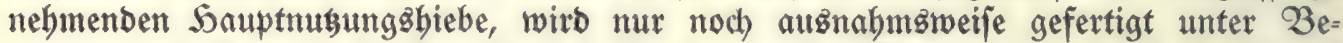
nuzung Des Formulars 10. Statt befien werben im Setriebsplan Durch farbiges

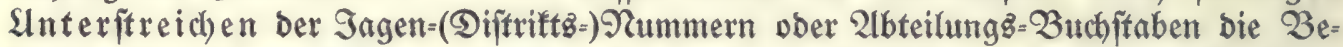
fïänbe fenntlich gemacht, in welchen bie balbige 2lusfiuthrung ber vorgefdlagenen

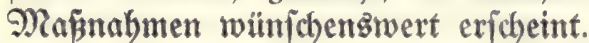

Ëbenio unterbleibt meift die 2luffitllung bez allgemeinen, fogenaunten "generellen" Rulturplanes, b. b. einer 3ujammenfafing Derjenigen Rulturen, welche in ben nächften zebn Sabren vorausfichtlich nötig werben, Formular 11 . Ex gibt bie Grundlage ab für bie Bered)nung. Dez Rulturgelder $=$ Bebarfż. Gtatt biejer 3 ujammenftellung find am Ranbe Dez Betriebšplanez unter "Bemerfungen" in bejonberen Epalten bie Fläcben Der einzelnen Rulturarten aużzuwerfen. 2lus biefen

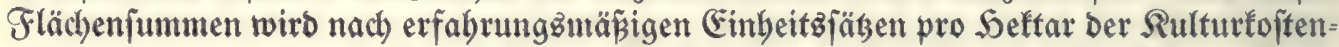
betrag im ganzen bered)net und bierzu für bie etwa nod) nicht mit inbegriffenen Nad)= befierungen ein entiprechenber 3 uchlag gemadht. Die übrigen Rulturgelder $=$ Beträge

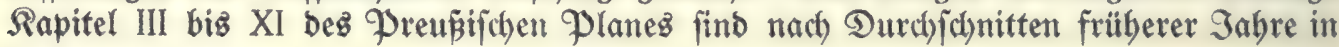
Alnjag zu bringen.

\section{Die Daritelfing Deg Betriebswerfez.}

$21 n$ Gtelle Der frïberen allgemeinen, jogenannten "generellen" Revierbejchreibung wirb in bem "Sarations $=3$ ericht" ein S̈berblicé über bie Zerbältniffe Dez Piebiereß, jowie über alle bei ber Betriebäreguliernng maß̈gebend getwejenen Slmitänbe 
geliefert uno babei für bie Betriebsిvorjaläge im ganzen und im einzelnen bie er: forberlicbe Begrübung uno (Erläuterung beigebracht.

Der Stoff wirb babei etwa folgenbermajen gegliebert:

I. Allgemeine Lage und (Befdid)te bes Revieres.

II. Dermeffungs wert:

1. Beftanoteile,

2. Zrautchbarteit,

3. Sesigez Rartenwert: a) Spezialfarte, b) vertleiterte Rarten,

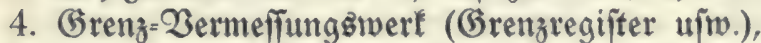

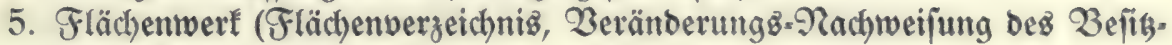
ftandes uíw.),

6. Dienftländereien,

7. Pachtlänbereien.

III. Einteilung:

1. Blöcfe und Schubbezirte,

2. Wirtiçaftg̊figuren: a) Sagen (פiftrifte), b) 2lbteilungen.

IV. $\mathfrak{W a r o z u f t a n o :}$

1. Standort (Rage, Rlima, Bobenverbältniffe),

2. Solzbeftano: a) Zorfommen uno Berbalten ber Solzarten, b) Qllterz= tlẫen= Derbältniz,

3. Walbbefchäbigungen: a) Feuer, b) $\mathscr{B a f f e r , ~ c ) ~ E t u r m , ~ d ) ~ E r b n e e , ~}$ e) Froft, f) Dürre, g) 2 ilb, h) Infeften ujw.,

4. Berechtigungen: a) 2lftivberecbtigungen, b) Gervituten,

5. 2lrbeiterverbåltniffe.

V. Betriebsregulierung:

1. Gefchidbte Der früberen Wirtjchaft, Slmtrieb, Söbe ber 2lbnußung ufiv.,

2. Grunbzüge ber gegenwärtigen Ertrags̊regelung: a) Siebżreife uno Untriebsizeit, b) Seftanbsanfnabme nach 3 efdafienbeit uno Solzmenge, c) Betriebsiplan,

3. Berfabren Der Ertragb̈berednung,

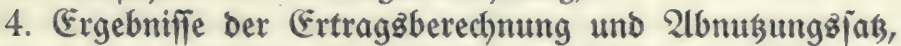

5. Sauungפ̉betrieb, Durchforftungảbetrieb, Dazu Durchforitungąplan,

6. Derjüngungb̈betrieb, Rulturen, bazu Rulturgelberbebarfb̈= શachtweifung.

VI. Bemerfengwerte

1. Materialabnubung, Nubbolzausbeute, Sortimentżverbältniffe, Preiz:= lage unb =berwegung,

2. Tebentusungen,

3. Jago uno Fifcherei,

4. Finanzielle Ergebnifie,

5. Foriftafie,

6. Forfitoientigeböfte,

7. Forfíturibruejen,

8. fommunale $\mathfrak{B}$ erbältnifie,

9. jonft BemertengెwerteB.

शach Erforbern find Dem Tarations= Bericht Padbweijungen verjdhiebenjter

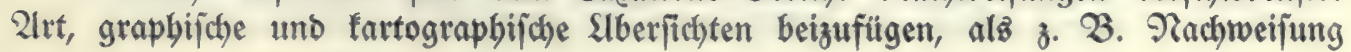




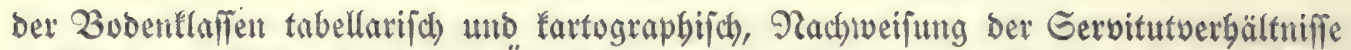

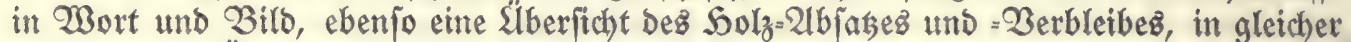
Beife eine S̈berfidyt über bie Wanlbbejdäbigungen wäbreno ber legten 50 ober 100 Sahre u. a. m. 2uch fanm bie Whotographie zur befferen Beranchaulichung vieler Dinge febr wejentliche Dienjte leiften.

Das vollendete, vber beffer Daz im Entwurf fertiggeftellte Betriebsimerf wirb

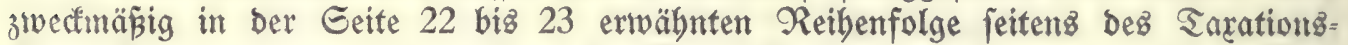

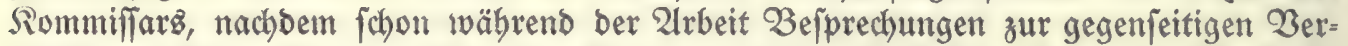
ftänbigung ftattgefunben Gaben, bem Revierverwalter, Injpeftionzbeamten, Oberforitt= meifter zur Begutachtung übergeben unD johlieplich mit beren 2luzlaffungen Dem Minifterial=Rommiffar vorgelegt. Nach einer b̈rtlichen Schlüprüfung wiro ber 3 efund in ber "Schluṕerhandlung" niebergelegt und legtere mit bem gejamten fertigen

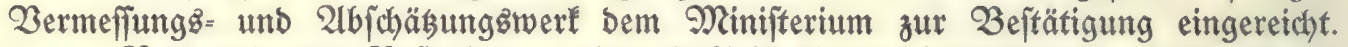

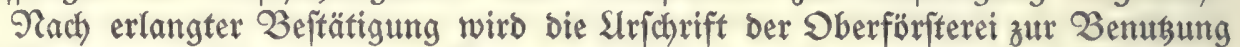
uno 2 ufberwahrung übergeben; im übrigen gejdhieht, joweit nötig, bie Serjtellung von Abjchriften uno 2luşzügen.

Bevor bie bei ber Betriebšregulierung bejchäftigten Silfzarbeiter baz Revier verlaffen, follen fie Dem Revierverwalter

1. eine Paufe von Der Wirtfchaftäarte mit Deutlicher 2 Ingabe Der Finteilung und ber Siebsflächen ber I. Weriobe,

2. einen Frächenaubzug, enthaltend mindefteng alle Solzboben=2lbteilungen,

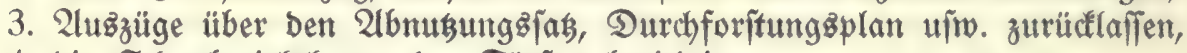

4. Die Schubbezirtałarten ber Görifter beridytigen.

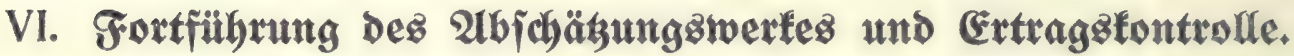
vervollitändigt:

3u biejem 3redf werben gefübrt uno alfjährlich burd) ben Revierverwalter

1. Då $\mathfrak{S a u p t m e r b u c h , ~ f r u ̈ b e r ~ " S a r a t i o n z = - N o t i z e n b u c h " ~ g e n a n n t , ~}$

2. DaB Flächenregifter,

3. Das Rontrollbuch.

1. Då Sauptmertbud Anweifung vom 6. Taa 1870 , foll alz "Revier=

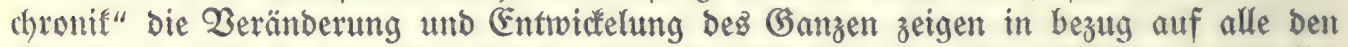

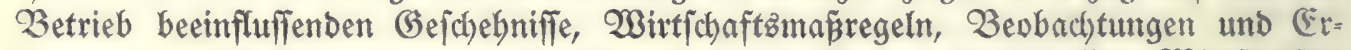
fahrungen. Die Eintragungen gefdheben alljährlich für bas abgejchlofiene Wirtfdaft jabr Durch Den Oberförfter. EE wirb in zwei Teiten geführt:

a) Der arlgemeine Seil enthält nach einzelnen Rapiteln bie auf Das Revier bezüglichen 2lufzeichnungen allgemeitter Bebeutung.

b) Der ausfübrliche, jogenannte "fpezielle" Teil bebandelt jebe einzelne abteilung, "Rontrolffigur", in bejonberem Ronto binfichtlich aller Darin

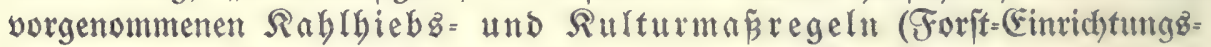
bureau, Formular 21). Er entbält:

Die Größje Der Rahlhiebsflächen, besgleichen ber Rulturflächen unter weiterer 2lngabe Der Rulturart, Der verwenbeten Samen= unto Dflanzen= menge, forwie Der Roften. 


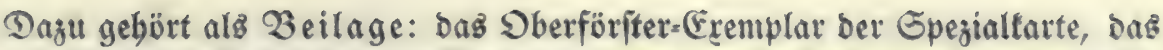

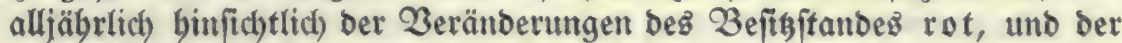
Rablhiebz= uno Rulturfläcben, forvie ber 2 ege ufw. grü zu bericbtigen ift, wie biez auf ber nachitebenden, Den "Preupijachen Forittarten" von Serrmann (PReumann= Reubamm) entnommenen 2lbbilbung veran= ichaulicht ift. Dabei fint \$iebżgrenzen mit Dunften, Rulturgrenzen mit Etrichen, beibeb zufammenfalleno mit abroechjelnoen Punften unb Etrichen zu bezeichnen, unter Beifügung Dez $\mathfrak{B}$ Birtichaftzjabres und ob $\mathrm{H}$ ober $\mathrm{K}$.

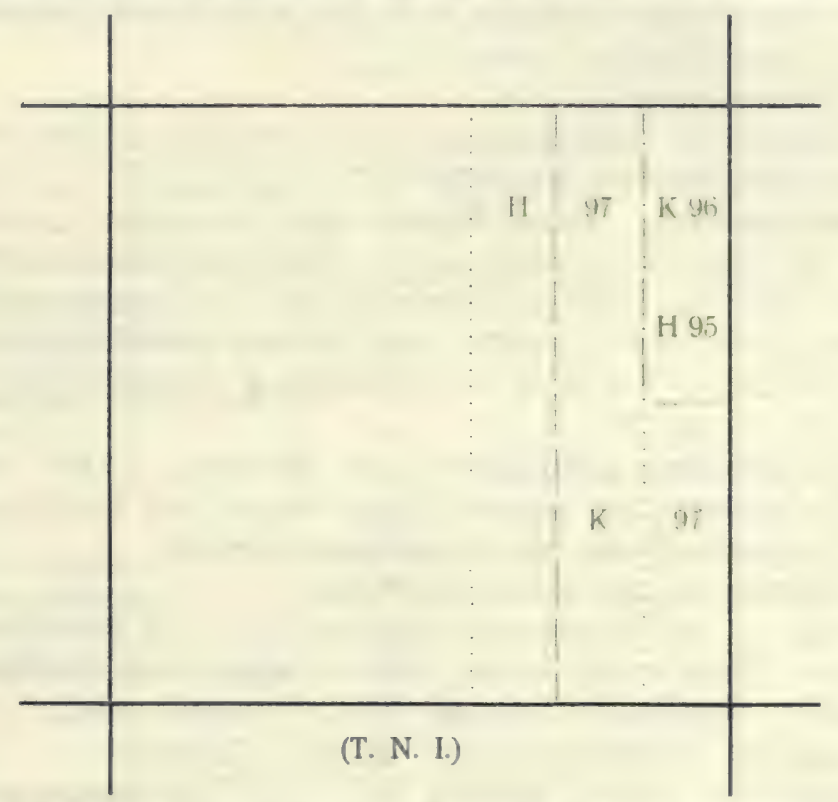

Ferner ift bie $\mathfrak{W}$ egefarte $1: 25000$ zu berid)tigen burd) Nachtragen, farbigez Anlegen ber alljäbrlich auछ̈gebauten, befejtigten u. bergl. 2 Begeftrecten.

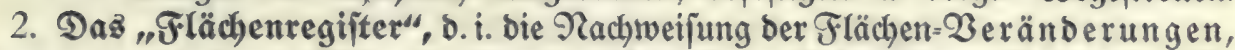

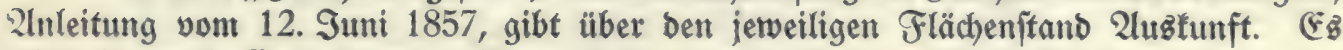
wiro in zwei Cremplaren gefübrt, und zwor auf ber Oberförffterei uno bei ber Foritfalfulatur ber Regierung.

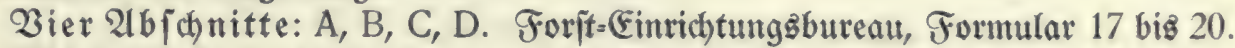

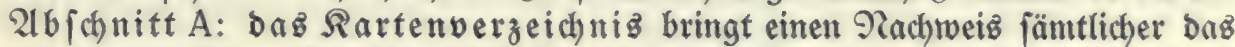

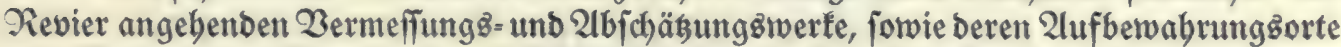
uno Inventarien $=$ Rummern. - Lbjobrift von A bei Minifterium und Regierung. Abjonitt B: Nachweifung ber eingeleiteten Flächenveränderungen. Ër bient zur Driifung ber rechtzeitigen Eintragungen in C, forvie alş 2inbalt für neu eintretente Beamte.

$21 b$ fbnitt C: Racbreiz ber eingetretenen, vollenbeten Beränberungen

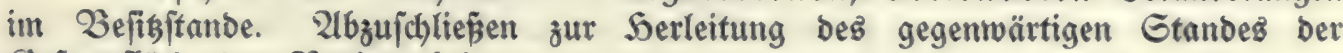
Gืefantfläche bę Reviers bei:

jeder Ëtatsfertigung, aljo alle jechs Sabre, jeber Neumeffung, Ertragßregelung ober Sarationz=Revifion. 


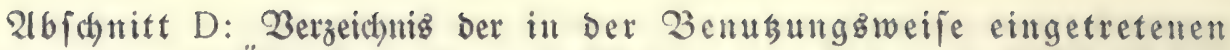

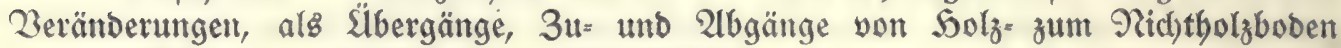
unto umgefehrt. - 3ugleid) mit $\mathrm{C} \mathfrak{a b z u}$ fdliezenen.

3. Das Rontrollbuch, 2lmweifung vom 20. Närz 1895, foll mittelṡ Dauernber Bergleidyung:

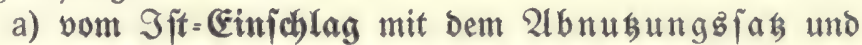

b) vom Sitt= (Extrage mit bem gefdägten Soll

bie 2lbnukung fo regeln, Dá bie ber I. Periobe zugewiefenen Beftänoe weber vor 2lblauf

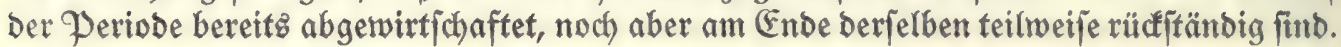

3wei Sauptabichnitte A und C,

ein Sinterabidhnitt $A_{1}$.

2lbidnitt A: 2lbteilungatonto, Ërtraģonto für jebe einzelne 2lbteilung (Forit:-Einrichtungb̆bureau, Formular 12).

Gebe abteilung, "Rontrolffigur", erbält ibre eigene Geite zur Eintragung Des alliährlich in Gumma aufgetommenen Derbholzeinfalagez. Diefe Eintragungen waren von 1886 bis 1902 mur noch für bie $\mathfrak{S} \mathfrak{a}$ atmugung gefordert, für bie Bornugung freigeftellt, werben aber feitbem erfreulicherweife wieber für beibe werlangt. Wegen Des auth Die Belberträge einbeziebenden Borfchlages zu ver= gleichen Geite 18 uno 19.

Nach erfolgtem "Endbieb" einer 2lbteilung in ber Sauptnukung gejchieht Die 2lufrechnung Der gejamten Feftneterzahl Dez Derbholzez,

bie Zergleichung mit bem Echäbungż=Soll und

bie Śbertragung Der Schlup̃abrectynung

in 2lbjchnitt $A_{1}$ zur 3ujammenftellung ber Goll= und Sfłt=Erträge, Formular 13:

Qinf: "Nach Der Sdüaung follte erfolgen“, auf berjelben Qinie

rechts: "Nach bem 2lbịhluffe in A ift wirflich erfolgt", weiter: "Mithin ijt gegen bie Gdbägung erfolgt: Mebr - 2Beniger".

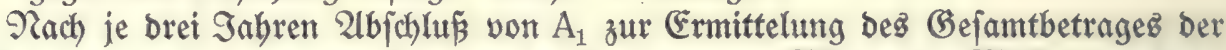
inzwifchen gegen bie 2lnjäge ber Schäßung aufgetommenen Mebr= und Mindererträge.

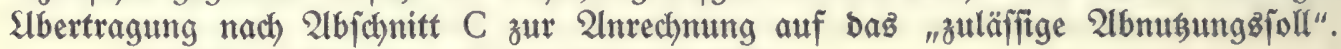

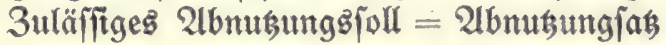

- Mebreinfdilag

+ Minbereinfablagl

+ Mebrertrag ।

- Minderertragl

Ė̉ find auseinander zu balten:

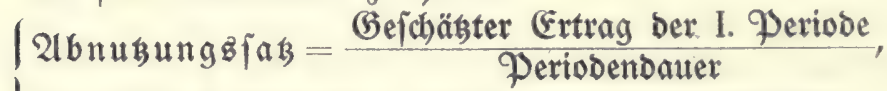

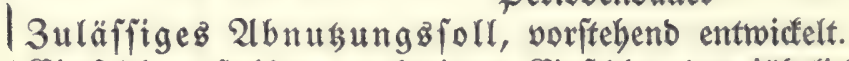

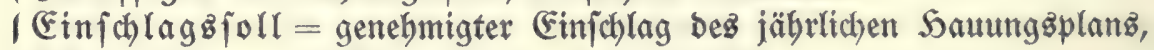

1 If teinld) $\mathfrak{l} \mathfrak{a g}=$ wirflid) erfolgter Sabrezeimichlag.

Der jeit 1886 bejeitigte 2 b f chnitt B bildete baz (Einf́chlaggfonto jedes einzelnen $\mathfrak{B}$ irtfd)aftżjahres (Formular 14).

Der abfanitt C, Formular 15a, bezwedft, getrennt nach Sauptnußsung, Bornukung uno für ben (Gejamteinjhlag, bie jäbrliche Zergleid)ung von Siteinfd)lag

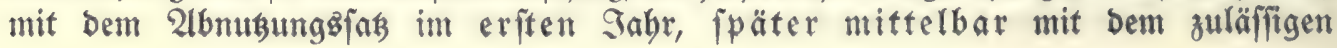




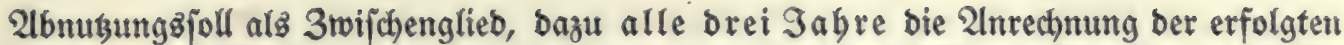

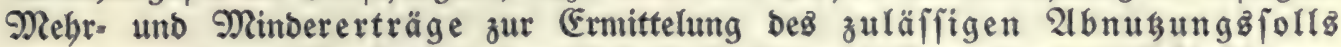

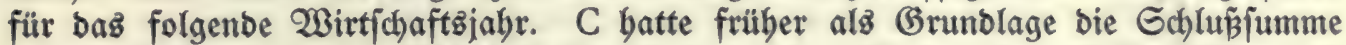

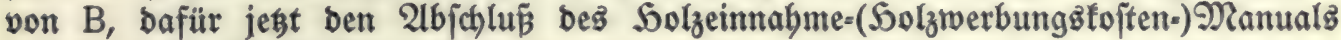
unb bazu bie 2lufrechnung von $A_{1}$.

3um 2lbfdnitt C für ben $\mathfrak{S o d}$ wald folgt bierunter ein 3 ablenbeifpiel:

abidnitt C. 1. Sodjroalo.

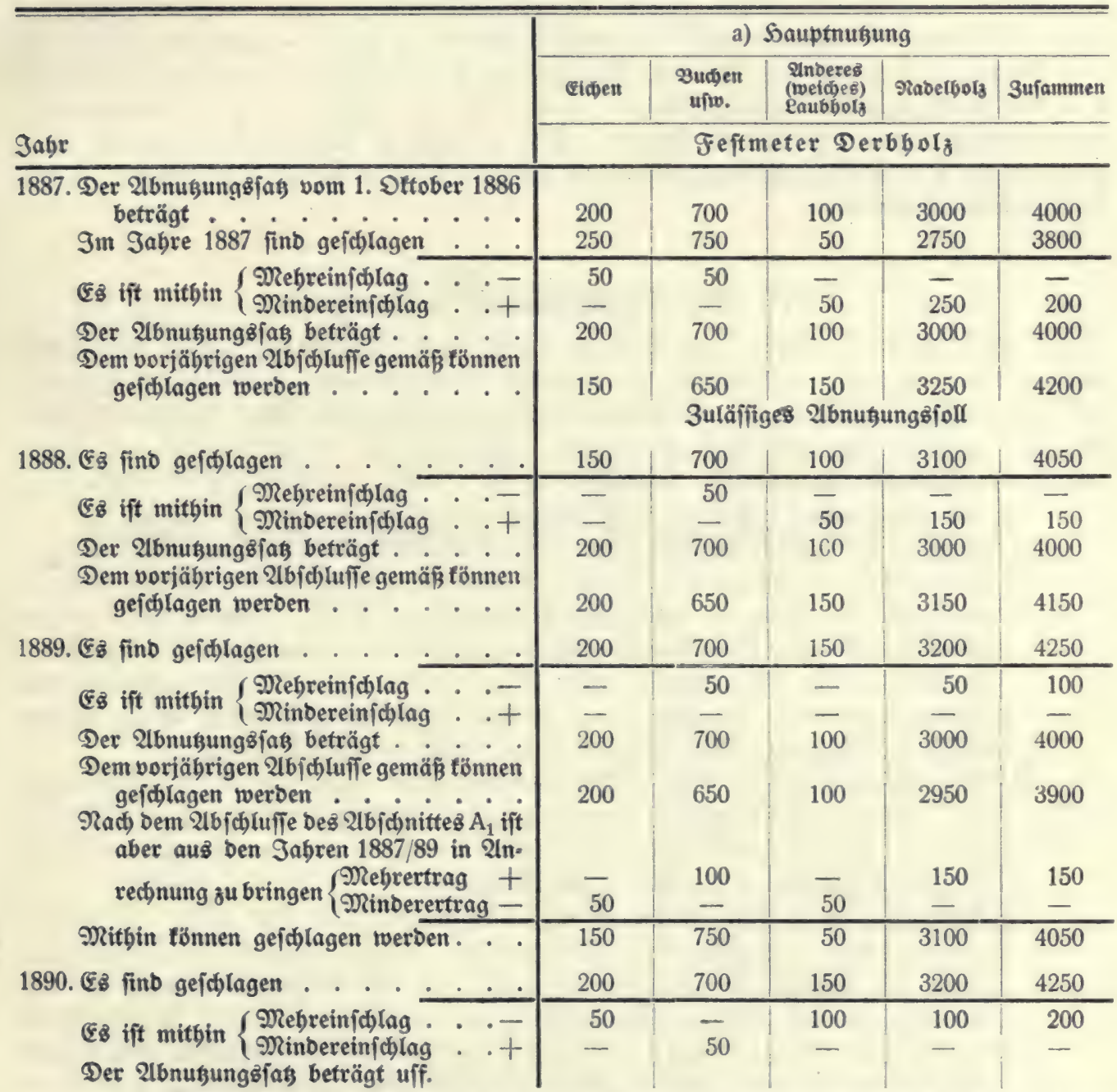

Sm Nittelwalb ift für bas Oberbolz eine Bergleichung bez Sît-Ërtragez

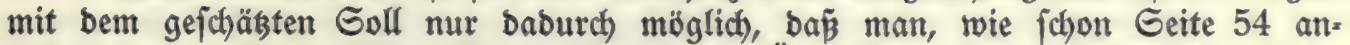
gebeutet, nach jebem Siebe idhlagweife ben Sft-S̈berbalt genau ermittelt, zum Sit: Finichlag binzuzäblt unb bann beibes gegen bie Gumme aus Soll-áberbalt und Eoll- Einfdhlag aufredhnet.

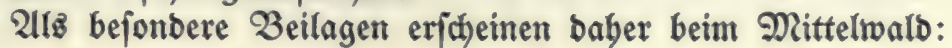

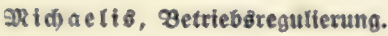


a) Die Borrats-(Ermittelung für jeben Gd)lag,

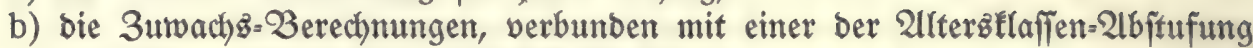
ungefähr entipprechenden Etärťeflaffenbildung,

c) eine Nachweifung ber jährlichen Oberholza (Erträge auż ben Schlägen für einen ober zwei Slnterholzumtriebe uno ibrer 2lużgleichung burch fich felbft ober bie $\mathfrak{S}$ och wald = Erträge.

Fïr bie gejamte $\mathfrak{B o r n u g u n g}$ ift feit 1886 bie Material=Rontrolle im wejentlichen aufgeboben, obwobl fie im $21 b$ jchnitt $C$ noch vergleich żweife tweitergefübrt mirb. Wichtiger ift bie jeit 1902 für Den 2 bj fhnitt A wieber eingefübrte $\mathfrak{B}$ uch ung Der Borerträge, um zur befieren Beurteilung ber Bejamtleiftung jebes Beítandes

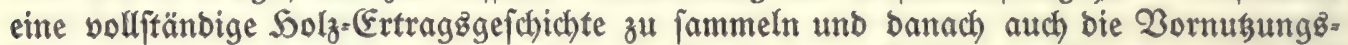

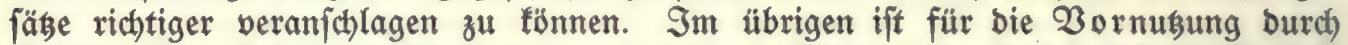

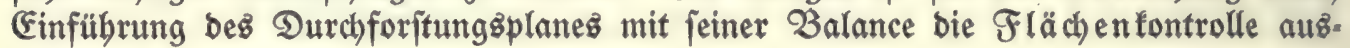
ichlaggebend geworben.

\section{Die Taxationz=Revifionen.}

Gpäteftens am Enbe einer Periobe bebarf bag Betriebżwerf einer 3ujammen= fâfung aller inzwifchen notwenbig geworbenen Berichtigungen, jowie weiterer Nach)= prüfungen uno Ėrgänzungen. Lußserbem werben polche auch wohl alle zebn Sabre

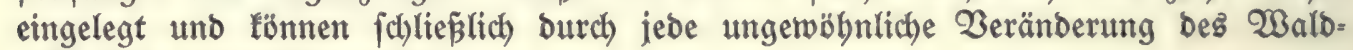
zultanbes veranlap̃t werben.

Dieje jogenannten "Sarationg=Revifionen“ fönnen führen zur:

a) Aluffitlung eines burch weg neuen Betriebsplanes nad neuer Beftandsaufnahme mit neuer Ertragsermittelung. EE ift biez ber getwöhnlicbjte, aber am wenigiten mujtergülttige Fall. Geboten wirb er nur bei einjchneibenber Slmgeftaltung ber Betriebsflächen ober Beftandšverbältnifje, alż anberweiter 2 bgrenzung burch (Figentumg̨wed)fel, Beränberungen in ber

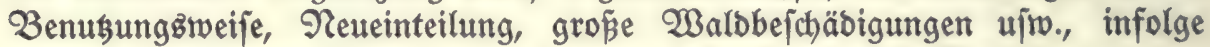
beren ber bisherige Zetriebzplan unbrauch $b a r$ geworben ift.

b) Beibehaltung bez alten Betriebsplanez, aber unter Berichtigung Der $\mathfrak{B e f t a n d s a u f n a b m e ~ u n d ~ m i t ~ n e u e r ~ E r t r a g z e r m i t t e l u n g ~ f u ̈ r ~ b i e ~}$ neue I., bişberige II. Periobe. Der feltenere, aber mujtergültigere Fall. Ingezeigt befonders am Enbe Der Weriode.

c) Beibehaltung Des alten Betriebsplanes und ber alten Ertragb= ermittelung. 2lbgejehen von ben nötigen Berichtigungen und Ergänzungen

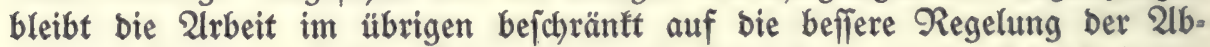
mußung für bie nächjte Folgezeit Durch Serleitung eines berichtigten

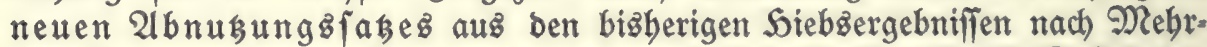
und Minder $=$ Ertrag. Eॄs ift biez Der feltenfte, aber mujtergültigfte Fall in ber Mitte einer Periobe. Ex finbet, wenn bier eine Tarationz=Revifion überbaupt

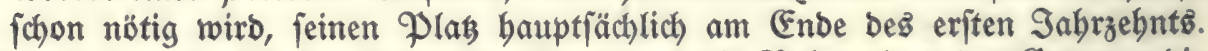

Im übrigen ift bei Den Taxationsz=Rebifinen bie Bebandlung bez Ganzen: Die

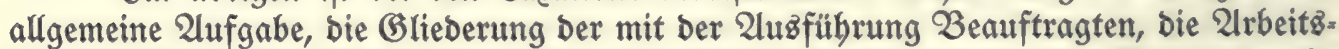
teilung und bie Arbeitżolge, bie gleiche wie bei ber 21nfertigung ganz neuer 2 etriebżwerfe. 


\section{$\mathfrak{A n \mathfrak { h a n g }}$}

(Finfache Pusanwendungen aus ber foritlichen

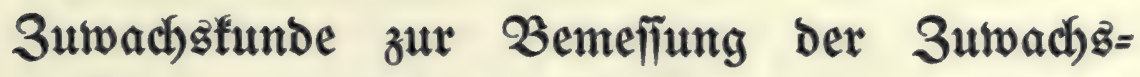

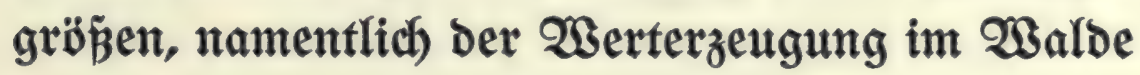




\section{A. Allgemeines.}

Die an fich fo verfdhindend winzige 3 reite bez jährlichen 3 unachbringes in ifrer gropen Bielbeit ifi uno bleibt basjenige Glieb, welches in ber Gorftwirt=

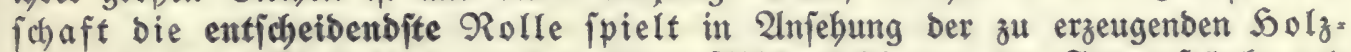
mengen, inres Einbeitzwertes in jeiner 2 bbängigheit von ber Stammftärfe und Damit beż Gefamtwerteg Der Solzbeftänbe. Seine zielbenuäte Pflege wirb baher eine ber wichtigiten $2 \mathfrak{u}$ fgaben für ben rechnenden Forfitmann werben müfifen.

Man untericheibet im alfgemeinen:
a) $\mathfrak{B o l u m}=(\mathfrak{M a f f e n}-) 3$.
b) $2 B$ ert -3 uractib
Dober nach

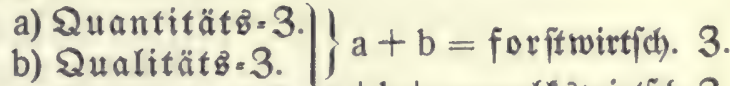
c) Seuerung:-3uwacts, Benennung (
c) Teuerung

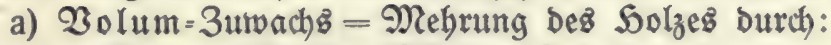

Qängen=, Gtärten-(Flächen=) 3tuabme.

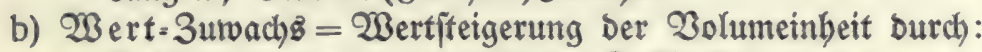

(3röß̈erwerben (mannigfaltigere Teilbarfeit nach)

Qänge unb Etärfe, weniger $\mathfrak{d b f a ̈ l l e ~ u j w . ) , ~}$ älterwerben (Rernbolzbildung, Formberbefierung, 3unabme ber aftreinen Echicht, Mitberwerden, Genilifierung u(w.),

beibes bringt vielfeitigere Gebraucbsfähigfeit, Da= mit höheren $\mathfrak{B e r t ,}$ gröpere Nachfrage.

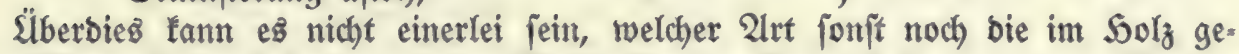

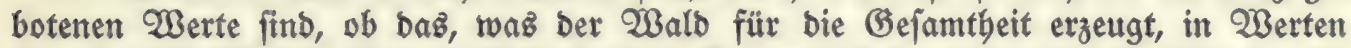
von unverwäfflicher ober borübergebender Dauer bejtebt ober mur in foldhen, bie rafthefter 2lufzebrung bienen.

Man gibt Den Wert alz im allgemeinen beftimmbar an burch ben 3 ruch $\frac{\text { Brautchbarfeit } \times \text { Seltenbeit }}{\text { Erfábbarfeit. }}$

Wie zuerif bon Borggreve bervorgeboben, tritt beim Wachżtumg̊gang b in Ericheinung in feter Beziebung zu a uno wiro burch biefez mit bebingt. Daber richtiger alz Quote beż legteren in Rechnung zu fiellen:

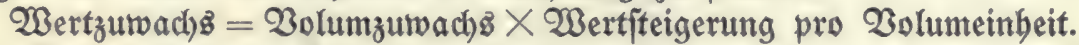

(E⿱ ermöglicht biez auch eine flarere und einfachere rechnerifche Bebandlung.

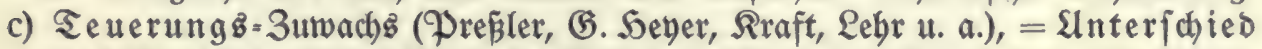

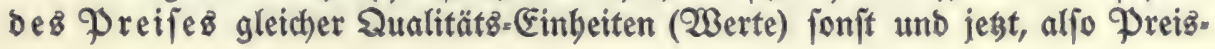


j(h)wanfungen eines vertretbaren Gtoffeв (Solz) im Zerbältniz feinez Taufch: wertes zu anberen vertretbaren Stoffen; entbehrt zu jebr ber Gejegmäß̈igfeit,

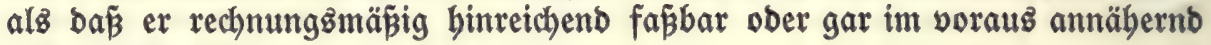
befitimmbar wäre.

Nan gibt bie 3 uwachigräß̈en an entweber alz:

2bjoluten 3uwadbz, bas if bie gefundene 3unabme in ben gebräuchlichen Maß̃en (ober Mänzen), aljo x cm, m, fm, M., - oder in

Prozenten bezogen auf:

bie frühere Menge vor $n$ Sahren, an weldje find ber 3 uwachs angelegt hat, = 100 (3ahlenaubbruá grö́per), ober

bie jegige Renge (aljo frühere +3 uwachs) $=100$,

ber gewölnnliche Gebrauch (3ahlenaugbruct fleiner). z’war alz: :

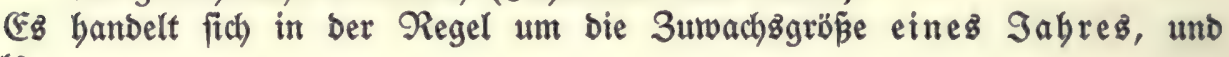

Qaufenber 3 uwach $z=3$ uwach ber (itrengen) Gegenwart $=1 z$,

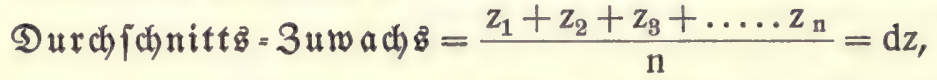

Periobifduer dz: eine befimmte Reibe von Sabren umfafienb,

Beftanbzalterz dz $=\frac{\text { Zorrat bez betr. Beftanbzalterz }}{\text { 2ltersjahre }}$

Saubarfeitz $\mathrm{dz}=\frac{\text { Borrat im Saubarfeitżalter }}{\text { Altergjabre }} \quad \mathrm{dz}=\mathbf{V d z}$

Gefamtmaffen dz $=\frac{\text { Borrat }+ \text { Ga.= Bornubungen }}{\text { 2lterbjabre }}=$ Gejamt dz $=$ Gdz.

3 wadbseredhungen an jungen Stämmen finb wegen bes erbeblichen

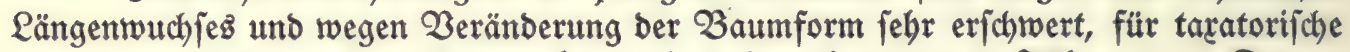
3recfe gerwöhnlich erit in älterem $\mathfrak{S o l}_{z}$ mit nabezu beendeter $\mathfrak{S b b e n}=$ und Form. zunahme erforberlich, bann aber wejentlic) vereinfacht.

Für 3uwachsunterjüchungen zu gewöbnlichen taratorifchen 3roecfen genügt bie

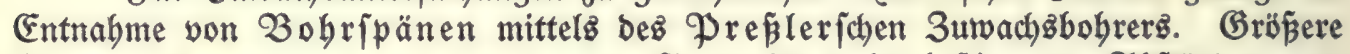
Benauigłeit gewähren aus ber ganzen Stammlänge in bejtimmten 2bjtänden entnommene Querjbeiben. Den beften uno vollftänbigften CEinblid in ben gejamten

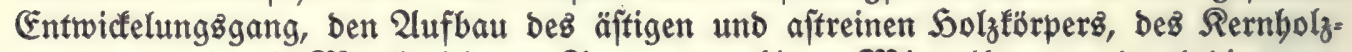
anteils uno in bie Nöglichteit ber 2lużnüung bieten Nittelbretter burch bie ganze Etammlänge. Doch lafien fïch bieje nur auf Gägewerfen berfítllen und find bann

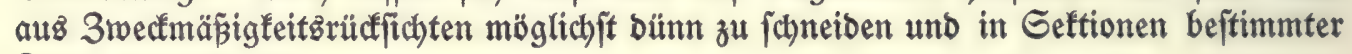
Qänge zu zerlegen.

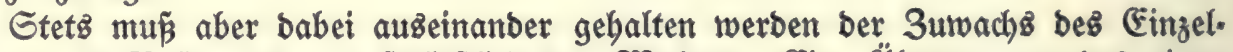

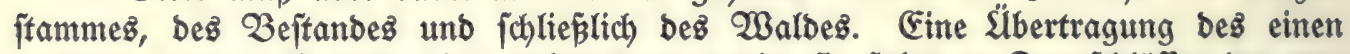
auf ben anderen iff nicht ohne weiterez angängig, fie führt zu Trugfchlüffen ber ber=

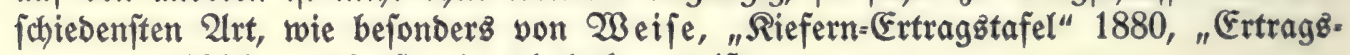
regelung" 1904 und jonft wieberbolt betont ift. 


\section{B. Qaufender $3 \mathfrak{u}$ wadt)

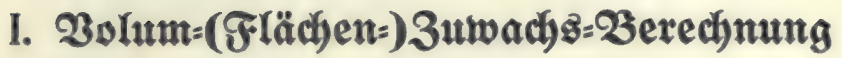 \\ an}

a) Činzelitämmen.

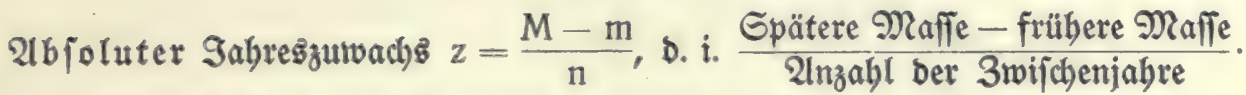

Ohne Sbäben= und Formberänberung:

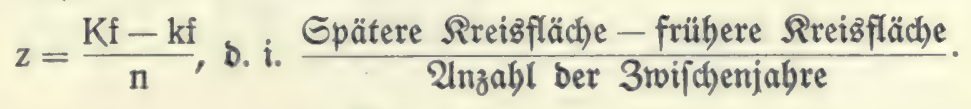

3uwadgąprozent $\mathrm{p}=\frac{z}{M} \cdot 100=\frac{\frac{M-m}{n}}{M} \cdot 100=\frac{M-m}{M \cdot n} \cdot 100$, bezogen auf bie gegen: wärtige Mafie $M$.

Ohne Sbähen- unb Formberänderung:

$$
\mathrm{p}=\frac{z}{\mathrm{Kf}} \cdot 100=\frac{\frac{\mathrm{Kf}-\mathrm{kf}}{\mathrm{n}}}{\mathrm{Kf}} \cdot 100=\frac{\mathrm{Kf}-\mathrm{kf}}{\mathrm{Kf} \cdot \mathrm{n}} \cdot 100 .
$$

\section{Mreīung am Liegenben.}

1. (5. L. Sartigz Geftionżทerfahren 1819: Fällung, Geftionzbilbung, Mefiung an allen Gdjnittfläd)en, Snbaltżberechnung:

a) Der gegenwärtigen Naffe nad) $M=\frac{D^{2}}{4} \cdot \pi \cdot 1$,

ß) Der Maffe vor 10 Sabren nach $m=\frac{\left(D-2 b_{10}\right)^{2}}{4} \cdot \pi \cdot 1$,

$$
M-m=10 z, z=\frac{M-m}{10}, p=\frac{z}{M} \cdot 100 \text {. }
$$

2. G(d)neiber|che Formel: Gegeben etwa 1850, veröffentlid)t 1853. 2̈lbnlich

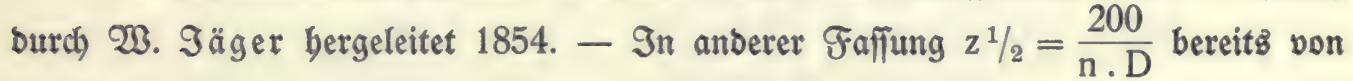
(5) Rönig 1823 entwidtelt:

$$
\text { 3uwadjaprozent } p=\frac{400}{n \cdot D} \text {. }
$$

$\mathrm{n}=2 \mathfrak{2 n z a b l}$ ber auf einen 2 luß̧en=3entimeter gebenden Sabrringe,

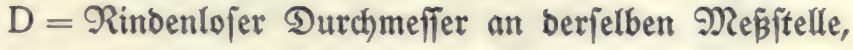

$\mathrm{p}=\frac{\mathrm{Z}}{\mathrm{M}} \cdot 100$, obne Söb̆en= und Formberänderung $\mathrm{p}=\frac{\mathrm{z}}{\mathrm{Kf}} \cdot 100$,

$z=$ Fläche bes jegrigen Sabrringez, alio $\mathrm{p}=\frac{\mathrm{Rf}}{\mathrm{Kf}} \cdot 100$. 
Einfache Serleitung nad Borggreve:

Den Sabrezring alz aufgerollteż Banb betrachtet,

Rf, baz ift Ringfläche $=\mathfrak{L}$ Imfang $\times$ Ringbreite $=u \cdot b=D \pi b$,

$$
\begin{aligned}
& \mathrm{b}=\frac{\text { Mafeinbeit }}{\mathscr{U} \mathfrak{n} z \mathfrak{a b l} \text { ber barauf gebenden Jabrringe }}=\frac{1}{\mathrm{n}}, \\
& \mathrm{Rf}=\mathrm{D} \pi \cdot \frac{1}{\mathrm{n}}=\frac{\mathrm{D} \pi}{\mathrm{n}}, \\
& \mathrm{Kf}=\frac{\mathrm{D}^{2} \pi}{4}, \\
& \mathrm{p}=\frac{\mathrm{Rf}}{\mathrm{Kf}} \cdot 100=\frac{\frac{\mathrm{D} \pi}{\mathrm{n}}}{\frac{\mathrm{D}^{2} \pi}{4}} \cdot 100=\frac{400 \mathrm{D} \pi}{\mathrm{n} \mathrm{D}^{2} \pi}=\frac{400}{\mathrm{n} \cdot \mathrm{D}} .
\end{aligned}
$$

3utreffend für bie (Gegenwart uno bie gemeffene Rreigfläche, beg̊gleichen für ben Bolumzuwadbs obne Sbbhen und Formberänberung bei Meffung in Gtammmitte.

3ujas: Die Gdueiberjac Formel wirb von mandhen alz minberwertiger Näherunggnert bezeichnet. 3u vergleichen u. a. "Zlllg. F.= u. J.=3tg." 1900, S. 414 fi.

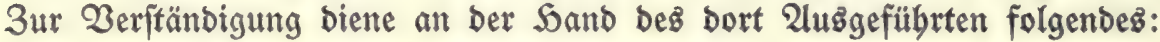

Beträgt von zwei fonzentrifchen Gdueiben

Der Salbmefler ber inneren Rreisfläche r,

ber rimbenlofe Salbmeffer ber äuferen Rreisfläche $\mathrm{R}$,

bie Differenz $R-r=\triangle R=z$ ber Gtärte,

Der Durchmeffer $\mathrm{d}=2 \mathrm{r}, \mathrm{D}=2 \mathrm{R}$, Die Differenz $\mathrm{D}-\mathrm{d}=\Delta \mathrm{D}=\mathrm{Z}=2 \mathrm{z}$,

Die 2lrzahl Der Jahrringe in bem 3 uwachggürtel $R-r=v$. (Statt $n$, zur Zer:

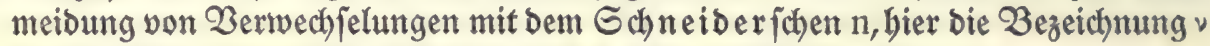
angetwandt, bent beibe bebeuten etwas fehr verichiebenes.)

Die 2lnzahl ber in biejen Gürtel auf ben 3entimeter gebenden $9 a b r r i n g e=n$,

Die Ringbreite $\mathrm{b}=\frac{1}{\mathrm{n}}=\frac{\mathrm{z}}{v}, \mathrm{n}=\frac{\nu}{\mathrm{z}}, \mathrm{z}=\frac{\nu}{\mathrm{n}}, \nu=\mathrm{z} \cdot \mathrm{n}=\frac{\mathrm{z}}{\mathrm{b}}=\mathrm{n} \frac{\triangle \mathrm{D}}{2}=\mathrm{n} \triangle \mathrm{R}$, unb in 3ahlen: $D=40, d=36, Z=D-d=2 z=4, z=2, d=D-Z$ $=36, \nu=10, \mathrm{n}=5$,

bann ftellt fich bas 3 uwadbiprozent:

a) bezogen auf bie frübere Maffe vor $>$ Sabren $=100$,

$$
\begin{aligned}
& \mathrm{p} \nu=\frac{\text { Ringfläche beв (Gärtel }}{\text { frübere Rreisfläche }} \cdot 100=\frac{\mathrm{Rf}}{\mathrm{kf}} \cdot 100, \\
& \begin{aligned}
\text { Jahres } \mathrm{p} & =\frac{\mathrm{R}^{2} \pi-\mathrm{r}^{2} \pi}{\nu \cdot \mathrm{r}^{2} \pi} \cdot 100=\frac{\mathrm{R}^{2}-\mathrm{r}^{2}}{\nu \cdot \mathrm{r}^{2}} \cdot 100=\frac{400-324}{10.324} \cdot 100 \\
& =\frac{7600}{3240}=2,345679 \% ;
\end{aligned}
\end{aligned}
$$

wäbrend bie einfache Schneiberfche Formel liefert:

$$
\mathrm{p}=\frac{400}{\mathrm{n} \cdot \mathrm{d}}=\frac{400}{5.36}=\frac{400}{180}=2,2222 \ldots \% \text {, aljo } z \text { u wenig } 0,123457 \% \text {; }
$$


b) bezogen auf bie jerige Maffe $=100$, ber gewöbnliche Fall:

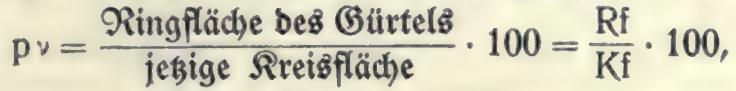

$$
\begin{aligned}
& \text { Iahrez } \mathrm{p}=\frac{\mathrm{R}^{2}-\mathrm{r}^{2}}{\mathrm{v} \cdot \mathrm{R}^{2}} \cdot 100=\frac{7600}{4000}=1,9 \% \text { ， } \\
& \text { Doer ebenjo }=\frac{D^{2}-d^{2}}{n \cdot \frac{\triangle D}{2} \cdot D^{2}} \cdot 100=\frac{30400}{16000}=1,9 \% ;
\end{aligned}
$$

währent bie einfache 5 chneiberiche Formel riefert:

$$
\mathrm{p}=\frac{400}{\mathrm{n} \cdot \mathrm{D}}=\frac{400}{5 \cdot 40}=\frac{400}{200}=2,00 \% \text {, aljo zu viel } 0,1 \% \text {. }
$$

Allgemein fann bie Bröß̨e biejer abweichung, wie folgt, bejtimmt werben:

a) Frübere $\mathfrak{N a f f e}=100$ :

$$
\begin{aligned}
& \text { Tahres } \mathrm{p}=\frac{\mathrm{R}^{2}-\mathrm{r}^{2}}{\nu \cdot \mathrm{r}^{2}} \cdot 100, \mathrm{R}=\mathrm{r}+\Delta \mathrm{R}, \mathrm{r}=\mathrm{R}-\Delta \mathrm{R}, \\
& \text { alfo } R^{2}=r^{2}+2 r \Delta R+\triangle R^{2} \\
& p=\frac{r^{2}+2 r \Delta R+\Delta R^{2}-r^{2}}{\nu \cdot r^{2}} \cdot 100=\frac{2 r \Delta R}{\nu \cdot r^{2}} \cdot 100+\frac{\Delta R^{2}}{\nu \cdot r^{2}} \cdot 100 \\
& =\frac{200 \Delta R}{\nu \cdot r}+\frac{100 \Delta R^{2}}{\nu \cdot T^{2}} \text {. }
\end{aligned}
$$

Evenjo $\mathrm{p}=\frac{200 \Delta \mathrm{D}}{\nu \cdot d}+\frac{100 \Delta \mathrm{D}^{2}}{\nu \cdot \mathrm{d}^{2}} ; \nu=\mathrm{n} \frac{\triangle \mathrm{D}}{2}$,

$$
\begin{gathered}
=\frac{200 \triangle D}{n \cdot \frac{\Delta D}{2} \cdot d}+\frac{100 \triangle D^{2}}{n \cdot \frac{\Delta D}{2} \cdot d^{2}}=\frac{400 \triangle D}{n \cdot \Delta D \cdot d}+\frac{200 \triangle D^{2}}{n \cdot \Delta D \cdot d^{2}} \\
=\frac{400}{n \cdot d}+\frac{200 \triangle D}{n \cdot d^{2}} .
\end{gathered}
$$

Ober mit obigen 3 ablenwerten:

$$
\begin{gathered}
\mathrm{p}=\frac{400}{5.36}+\frac{200 \cdot 4}{5.1296}=2,22222222+\frac{800}{6480} \text {, b. i. } 0,12345679, \\
\frac{+0,12345679}{2,34567901 \%} \text { wie oben. }
\end{gathered}
$$

Die Gchneiberfue Formel gibt aljo zu wenig $\frac{200 \triangle D}{n \cdot d^{2}}$.

Slmgelebrt ift beim gewöbnliden Fall ber 2lnwenbung ber Schneiberiften Formel

b) Sesige Maffe $=100$ :

$$
\begin{aligned}
\mathrm{p} & =\frac{200 \triangle \mathrm{D}}{\nu \cdot \mathrm{D}}-\frac{100 \triangle \mathrm{D}}{\nu \cdot \mathrm{D}^{2}} ; \nu=\mathrm{n} \cdot \frac{\Delta \mathrm{D}}{2}, \\
& =\frac{200 \triangle \mathrm{D}}{\mathrm{n} \cdot \frac{\Delta \mathrm{D}}{2} \cdot \mathrm{D}}-\frac{100 \Delta \mathrm{D}}{\mathrm{n} \cdot \frac{\Delta \mathrm{D}}{2} \cdot \mathrm{D}^{2}}=\frac{400}{\mathrm{n} \cdot \mathrm{D}}-\frac{200 \triangle \mathrm{D}}{\mathrm{n} \cdot \mathrm{D}^{2}} .
\end{aligned}
$$


Ober mit obigen 3ablenwerten:

$$
\begin{aligned}
\mathrm{p}=\frac{400}{5 \cdot 40}-\frac{200 \cdot 4}{5 \cdot 1600} & =2,0-\frac{800}{8000}, \text { o. i. } 0,1, \\
& \frac{-0,1}{1,9 \%} \text { wie oben. }
\end{aligned}
$$

Die Gdhneiberiche Formel gibt aljo zu viel $\frac{200 \triangle D}{n \cdot D^{2}}$.

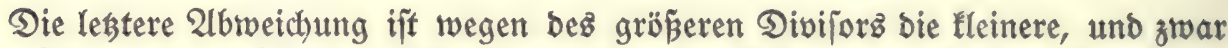
für Den Fall: ję̧ige Maffe $=100$, für welchen bie Schneideriche Frormel gegeben ift uno gewöbnlich zur 2lnwenoung tommt.

Im übrigen wirb bieje 2lbweichung um fo geringer, je ftärfer ber Durch= meffer uno je jamaler ber in bie Berechnung bineingezogene 3uwachg̈ärtel, aljo je fleiner $\triangle \mathrm{D}$ ift.

Gemöfnlich fommt bei ber Gchneiberichen Formel nur 1 2unen-3entimeter in Betracht, waz für bie Gtärfe $D=40, d=38, \triangle D=2$ aนżmachen würoe. Das wäre für Fall $\mathrm{b}$ :

$$
\mathrm{p}=\frac{\mathrm{D}^{2}-\mathrm{d}^{2}}{\mathrm{n} \cdot \frac{\triangle \mathrm{D}}{2} \cdot \mathrm{D}^{2}} \cdot 100=\frac{1600-1444}{5 \cdot \frac{2}{2} \cdot 1600} \cdot 100=\frac{15600}{8000}=1,95 \% ，
$$

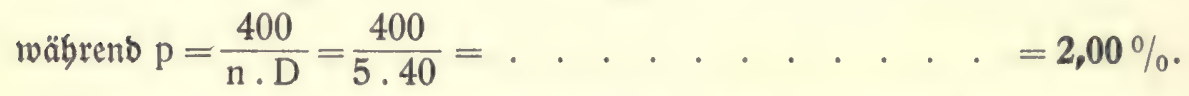

Benugt man bagegen, um tunlicbj mit ber "ftrengen Begenwart" redhnen zu fönnen, Das 2lbzäblen ber Sabrringe auf Dem 2 uken=3entimeter lebiglich bazu, um

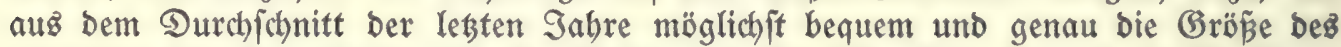
"Iaufenden“ 3 uwadhfez, aljo bie Breite bez für fid) allein hinreid)end jcharf nur

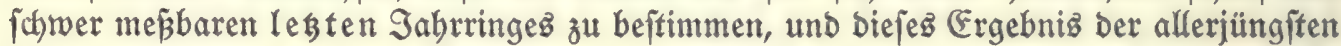
Bergangenbeit ober ber Begenwart alß̧ wahrjheinlich eintretend auf bie nächjte 3ufunft zu übertragen, rechnet alfo bei Beftimmung bez 3uwachzprozentez nur mit

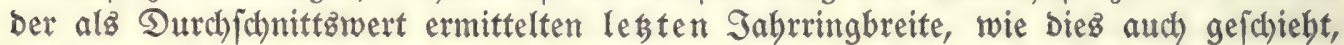
fo fhrumpft jene viel bemängelte 2lbreichung auf eine fo rinzige Größße zujammen, bá fie von vornberein für bie Prariz bedeutungzloz wirb.

3. 3. nach obigen 3ahlen $D=40, d=39,6$ :

$$
\mathrm{p}=\frac{\mathrm{D}^{2}-\mathrm{d}^{2}}{\mathrm{D}^{2}} \cdot 100=\frac{1600-1568,16}{1600} \cdot 100=\frac{3184}{1600}=1,99 \% ，
$$

rährenb $\mathrm{p}=\frac{400}{\mathrm{n} \cdot \mathrm{D}}$, oder in ber gelegentlic) angewandten $\mathfrak{A m}$ formung

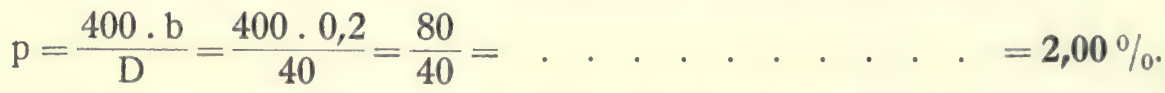

EEz Darf ferner nicht überjeben werben, Daß̃ in Der Anwendung Der Rreizlehre auf Baumformen, weldye łeinen mathematijh genauen Rreiz barftellen, für bie Borratz: $=$ und 3 urwach $b=$ Ermittelungen eine viel erbeblichere Feblerquelle liegt, als fie ber Echneiderfichen Formel zum Gorwurf gemacht werben fann.

Echließ̧lich müß̈te ber gleiche Nangel bann auch ben bei manchen als feiner angelegt unb beffer burchbacht, aljo auch als ridhtiger arbeitend geltenben Frormeln von 
Preß̈ler $\mathrm{p}=\frac{\text { Differenz }}{\text { Summe }} \cdot \frac{200}{\nu}$ für bie Gtärfe und von

Breymann $\mathrm{p}=\frac{200 \triangle \mathrm{D}}{\nu . \mathrm{D}}$ für bie Fläche anbaften,

welche, wie jogleid) zu bejprechen, nur SAmgeitaltungen ber Gdheiberichen (Brunbformel barftellen und bamit für ibre 2 nnwendung weder einfacher noch fürzer geworben find.

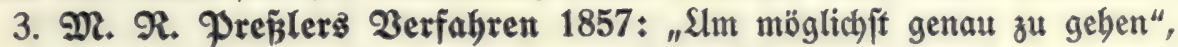
p bezogent

nidht auf bie gegenwärtige Mafie $M, p=\frac{Z}{M} \cdot 100$,

nicht auf bie frühere Naffe $\mathrm{m}, \mathrm{p}=\frac{\mathrm{z}}{\mathrm{m}} \cdot 100$,

jonbern auf ben aritgmetifden Mittelwert $\frac{M+m}{2}$,

$$
\mathrm{p}=\frac{\mathrm{z}}{\frac{\mathrm{M}+\mathrm{m}}{2}} \cdot 100 \text {. }
$$

$z=\frac{M-m}{n}, n=2 \mathfrak{n} z a b l$ ber Unterjudjungsjabre (3utwach 8 bauer).

3ur Bermeibung von Berwedhfelungen mit bem Schneiberjhen n (2lnzabl ber Sabrringe pro 3entimeter), bier im folgenden ftatt $n$ burchweg bie $\mathfrak{B}_{e}=$ zeichnung $v$ angewandt.

Bezogen auf:

gegenwärtige शaffe $\mathrm{p}=\frac{M-\mathrm{m}}{M \cdot \nu} \cdot 100$,

frübere Maffe $\mathrm{p}=\frac{M-\mathrm{m}}{\mathrm{m} \cdot \nu} \cdot 100$,

arithmetifhes Mittel $\mathrm{p}=\frac{\frac{M-m}{\nu}}{\frac{M+m}{2}} \cdot 100=\frac{M-m}{M+m} \cdot \frac{200}{\nu}$,

$$
\text { allgemein } p=\frac{\text { Differenz }}{\text { Summe }} \cdot \frac{200}{\nu} \text {. }
$$

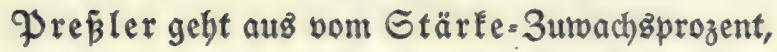

$$
\begin{gathered}
\mathrm{Z}=\mathrm{z}_{1}+\mathrm{z}_{2}=\mathrm{D}-\mathrm{d}, \mathrm{d}=\mathrm{D}-\mathrm{Z} . \\
\mathrm{p}=\frac{\text { Differenz }}{\text { Gumme }} \cdot \frac{200}{y},
\end{gathered}
$$

Gtärfe $\mathrm{p}=\frac{\mathrm{D}-\mathrm{d}}{\mathrm{D}+\mathrm{d}} \cdot \frac{200}{y}=\frac{\mathrm{Z}}{\mathrm{D}+\mathrm{D}-\mathrm{Z}} \cdot \frac{200}{\nu}$,

$$
=\frac{Z}{2 \mathrm{D}-\mathrm{Z}} \cdot \frac{200}{\nu}, \mathrm{p}_{\text {" }} \text { rü dét wärtż“ (Zergangenbeit), }
$$

ferner $\mathrm{p}=$

$$
\frac{Z}{2 \mathrm{D}+\mathrm{Z}} \cdot \frac{200}{\nu}, \mathrm{p} \text { "vorwärtă (3ufunft). }
$$

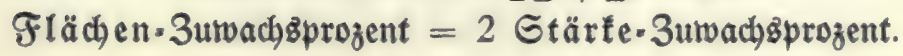


Beżehungen von Preß̧lerz Formeln zum Sdneiberíchen p ber ftrengen Gegenwart:

Preß̉ler gibt für ben Gtärfezuwadb:

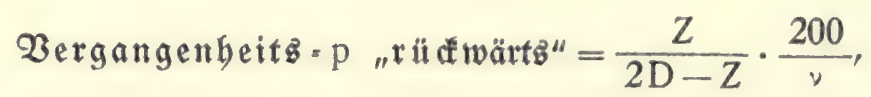

3ufunftg $\cdot \mathrm{p}$ "vorwärtż" $=\frac{Z}{2 \mathrm{D}+\mathrm{Z}} \cdot \frac{200}{\nu}$, bemnach

Begenivarts $=\mathrm{p}=\frac{Z}{2 \mathrm{D}} \cdot \frac{200}{\nu}=\frac{2 \mathrm{z} \cdot 200}{2 \mathrm{D} \cdot \nu}=\frac{200 \mathrm{z}}{\mathrm{D} \cdot \nu}$,

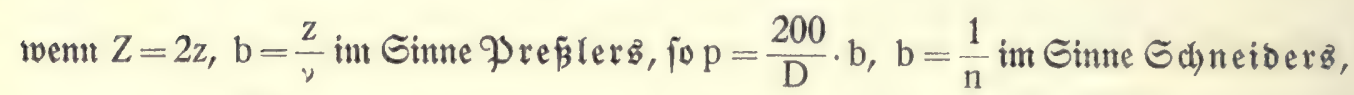

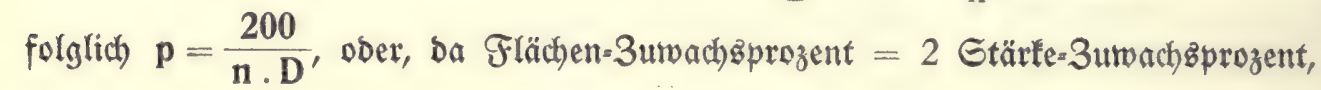

$$
\text { Flächen } \mathrm{p}=\frac{400}{\mathrm{n} \cdot \mathrm{D}} \text {. }
$$

3ablenbeifpiele: $\mathrm{D}=40, \mathrm{~d}=30$,

$$
\begin{gathered}
Z=D-d=10, \\
d=D-Z=30, \\
D_{1}=D+Z=50 \\
\nu=20 .
\end{gathered}
$$

Rad) Pref́ler $\mathrm{p}=\frac{\text { Differenz }}{\text { Summe }} \cdot \frac{200}{\nu}$.

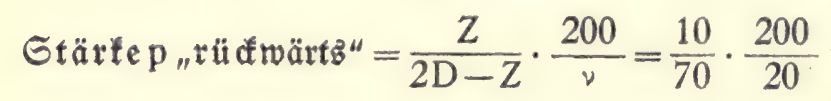

$$
=\frac{2000}{1400}=1,43 \% \text {. }
$$

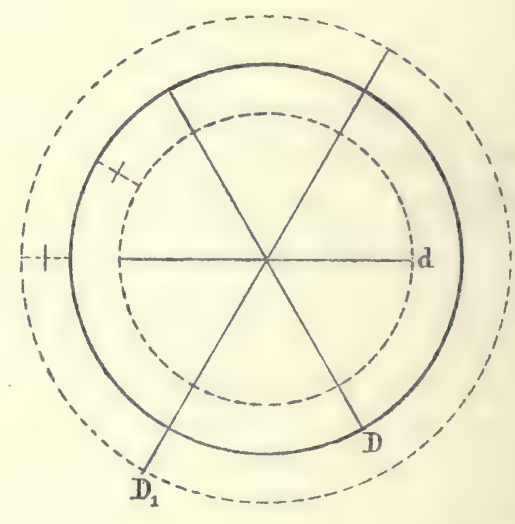

Frächen $\mathrm{p}=2 \times 1,43=2,86 \%$.

Dabfelbe nad) Gdmeiber: Für Den im Gime Pref̧lers veränberten Durd)mefier $\frac{40+30}{2}=35$ uno für $Z=2 z, b=\frac{z}{\nu}, b=\frac{1}{n}$, folglich $\frac{1}{n}=\frac{z}{\nu}, n=\frac{\nu}{z}=4$.

Tach ber Echneiberfden Formel $p=\frac{400}{n . D}$ lautet bas in ber Preflerfichen abänderung beż Durchmefiers:

$$
\begin{aligned}
& \mathrm{p}=\frac{400}{\mathrm{n} \cdot \frac{\mathrm{D}+\mathrm{d}}{2}}=\frac{400}{4.35}=\frac{400}{140}=2,86 \% \text {. } \\
& \text { Stärke } \mathrm{p} \text { "vormärţ" }=\frac{Z}{2 \mathrm{D}+\mathrm{Z}} \cdot \frac{200}{\nu}=\frac{10}{90} \cdot \frac{200}{20}=\frac{2000}{1800}=1,11 \% \text {. } \\
& \text { Flächen } \mathrm{p}=2 \times 1,11 \ldots \ldots=2,22 \% \text {. }
\end{aligned}
$$




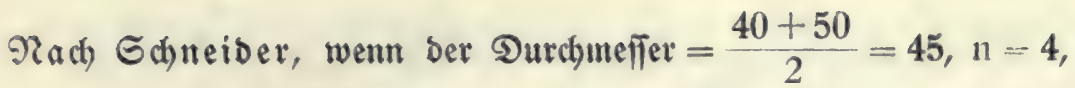

$$
\mathrm{p}=\frac{400}{\mathrm{n} \cdot \frac{\mathrm{D}_{1}+\mathrm{D}}{2}}=\frac{400}{4.45}=\frac{400}{180}=2,22 \% \text {. }
$$

Uljo, wie jhon von Borggreve in Feiner Forjtabjhägung 1888 betont, Preß̈ler gleich Schneiber, Preß̈ler nach Schneiber, übrigens beibe auf ben Gdultern von $\mathfrak{G}$. Rönig fitebend.

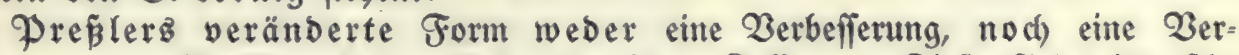
einfachung ober Berfürzung ber Gdhneiberichen Fantung. Dieje Gdneiberiche Faffung einfach und immer zutreffend für bie Rreisfläch) bes gemeffenen (Durch)= meffers und $\frac{1}{n}$ für bie Begenwart. Ferner zutreffend für jeben anberen an= gewandten Durchmeffer, alfo auch für eimen Mittelwert ober für bie Zergangenbeit "rüđtrwärtż" Doer bie 3ufunft "vortvärtg" entipprechend zu veränbernben פurd)= meffer.

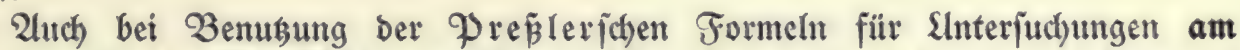
Gtehenben ift bie 3 rufthöhenmeffung nidht ohne weiteres anzuwenben auf Den 3 utwach se Der Mittenfläd)e ober bez ganzen Echaftez ober Baumtez, fondern eż bleibt z̆ prüfen, wieweit bie nachftehend bejprodbenen näberungşweifen Berichtigungen erforberlich, weil minbeftens immer ber $\mathscr{D}$ urchmeffer in $\mathcal{B}$ ruftğb $>$ berjenige ber Mittenfläd)e if́t.

Die für 3uwadbsermittelungen mit ben einfachjten uno lleinjten 3ablen

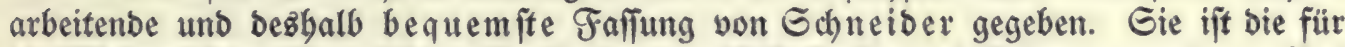

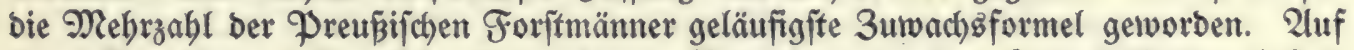
ibrer (Grunolage lafien fid) alle weiteren Betrad)tungen ber 3uwad)gfunbe einfach uno (eic)t aufbauen. Man barf nur nicht vergeffen, Daß́ fie zunäcbit einzig uno alfein für bie gemeffene Rreizfläct)e gilt.

\section{Neñung am Gtehenben.}

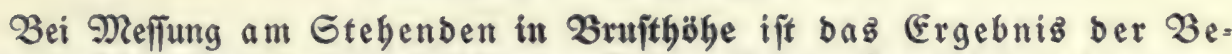
rechnung nicht obne weiteres übertragbar auf ben 3 uwach bes ganzen Stammes.

Betreffi ber 3uwachg̊ablagerung an ben einzelnen Gtammteilen gibt

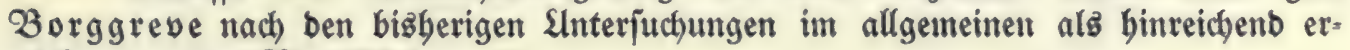
roiefen von ber Ringfläd)e $=$ Rf an:

A. Bon Bruthöhe aufwärtz bis unter bie grüne Rrone:

1. $\mathrm{rf}_{1}$ oben (Brope Reger: annäberno gleid in älteren Sodjwarb= Rf unten beftänden gewöbnlichen Edbluffes (etwa 0,9 ).

aljo $\mathrm{rb}_{1}$ oben Ringbreite oben

$V$
$\mathrm{Rb}$ unten 
2. $\mathrm{r}_{1}$ oben Geringe abnabme nad oben in gelodertem Edlú Rf unten (etwa 0,8).

Allo $\mathrm{rb}_{1}$ oben

$\|$ ober $\wedge$

$\mathrm{Rb}$ unten.

3. $\mathrm{rf}_{1}$ oben

$\wedge \wedge$

Rf unten

$2 \mathfrak{d l o} \mathrm{rb}_{1}$ oben

Rb unten.

Exabebliche 2abnabme nach oben an frei. ftehenden Gtämmen in Nachlid)tungen, Sute. bệtänben, an Nittelwald-Oberbäumen, auf Räumben $\mathfrak{u}$. Dergl. $\mathfrak{m}$. (etwa 0,7 unb weniger).

4. $\mathrm{rf}_{1}$ oben

Rf unten

(B) eringe 3unabme nach oben $(0,1$ bis 0,3$)$ in

Uljo $\mathrm{rb}_{1}$ oben ftreng gefdloffenen wublfigen Gtangen unb

VV angehend haubaren Orten (etwa 1,0).

$\mathrm{Rb}$ unten.

5. $\mathrm{rf}_{1}$ oben

$\checkmark \mathrm{V}$

Erbebliche 3 unahme nach oben an unterbrücten Stämmen. $2 \mathfrak{d} \tilde{p}_{\mathfrak{p}} \mathrm{rb}_{1}$ oben VVV

$\mathrm{Rb}$ unten (unten mitunter faum erfennbar $=0$ ).

B. Interhalb ber grünen Rrone:

6. $\mathrm{Hf}_{1}$ oben

Stetige 2lbnabme nach oben.

Rf unten

aljo $\mathrm{rb}_{1}$ oben

$\wedge \|$ Unregelmäвigfeiten von $\mathrm{Rb}$, Borficht!

$\mathrm{Rb}$ unten.

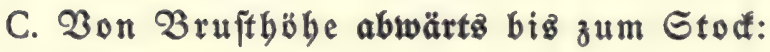

7. $\mathrm{rf}_{1}$ oben

$\wedge$ Nä́pige 3 unabme nad unten.

Rf unten

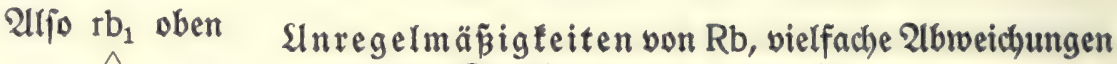

$\mathrm{Rb}$ unten von Der Rreizform nach unten hin.

Borficht! Reine 3uwadiermittelungen am Gtod!!

Slm aus ben am Gtehenden in Brujthöhe angeitellten 3uwach żmefiungen

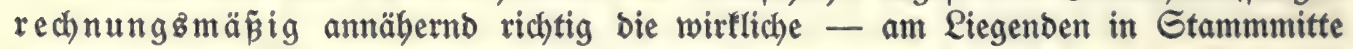

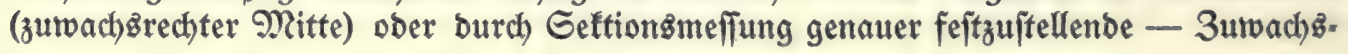




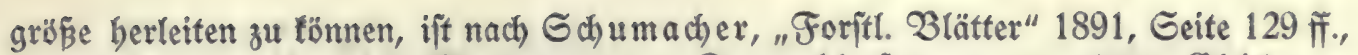
auszugeben von Der bei Rlarlegung Der Formzablgejége angerwandten (Bleid)ung: Gchaftformzabl $f=\frac{\text { Mittenquerfläche }}{\text { untere Querfläche } G}$, welche fich ergibt, wenn man fubiert nach $\mathfrak{S}$ uber: ......J J $=1 \times$ Nittenquerfläche $\mathrm{g}$, mit Silfe ber Formzabl: $J=1 \times$ untere Querfläche $G \times f$,

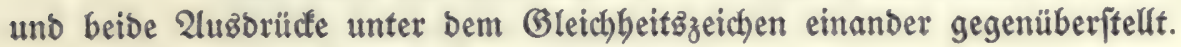

Wenn $\mathrm{D}=$ Durchmeffer unten,

$$
\begin{aligned}
& \mathrm{d}=\text { Durchmeffer in ber Mitte, fo ift } \\
& \mathrm{J}=1 \cdot \mathrm{g}=1 \cdot \frac{\mathrm{d}^{2} \pi}{4}, \\
& \mathrm{~J}=1 \cdot \mathrm{G} \cdot \mathrm{f}=1 \cdot \frac{\mathrm{D}^{2} \pi}{4} \cdot \mathrm{f}, \\
& \mathrm{f}=\frac{\mathrm{g}}{\mathrm{G}^{\prime}} \mathrm{f}=\frac{\mathrm{d}^{2}}{\mathrm{D}^{2}}, \sqrt{\mathrm{f}}=\frac{\mathrm{d}}{\mathrm{D}^{\prime}} \\
& \mathrm{g}=\mathrm{G} \cdot \mathrm{f}, \mathrm{d}^{2}=\mathrm{D}^{2} \mathrm{f}, \mathrm{d}=\mathrm{D} \sqrt{\mathrm{f} .}
\end{aligned}
$$

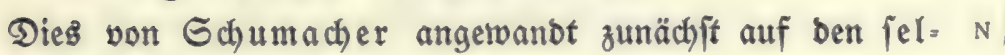
teneren Fall 2:

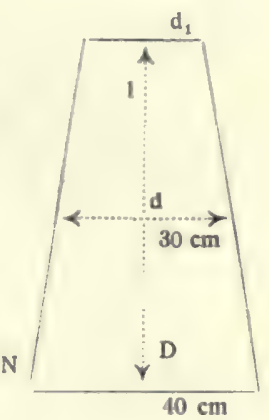

$$
\begin{aligned}
& \mathrm{rb}_{1} \text { oben } \\
& \mathrm{Rb} \text { unten }
\end{aligned}
$$

3ur Befeitigung bez aus bem größeren $D$ unten bei Mefinung in Bruftbäbe er= ruachjenden Feblers:

$$
\begin{aligned}
\text { nach } & \text { Sduneiber } p=\frac{400}{n \cdot d} ; b=B \text { und ebenjo } n=N, \\
\text { mitbin } p & =\frac{400}{N d} ; d=D \sqrt{f}, \\
\text { folglich } p & =\frac{400}{N D \sqrt{\mathrm{f}}} .
\end{aligned}
$$

Es betragen:

Die Gdaft=(und Derbholza)Formzablen:

$$
\mathrm{f}
$$

bei Baumbäben

von $15-35 \mathrm{~m}$ im $\mathfrak{N i t t e t} 25 \mathrm{~m}$

Riefer:

$$
(0,48-0,45)
$$

$$
0,45
$$

Buche: $\quad 0,50-0,48$

$(0,49-0,51)$

0,49

$(0,50)$

Fid)te: $0,55-0,49$

0,51

$(0,57-0,49)$

$(0,52)$

Tanne: $0,55-0,47$

$(0,53-0,50)$

0,52

$(0,52)$ bie Dazu gebörigen

$$
\sqrt{\mathrm{f}}
$$

bei Baumbäben von $15-35 \mathrm{~m}$ im Mittel $25 \mathrm{~m}$ für:
$0,70-0,67$
$(0,69-0,67)$
0,67
$(0,68)$
$0,71-0,69$
$(0,70-0,71)$
0,70
$(0,71)$
$0,74-0,70$
0,71
$(0,76-0,70)$
$(0,72)$
$0,74-0,69$
$(0,73-0,71)$
0,72
$(0,72)$ 
Demnad) $p=\frac{400}{\operatorname{ND} \times(0,67 \text { bis } 0,76)}$ oder mit 2̈nderung ber Romftanten

$$
\mathrm{p}=\frac{526 \text { biz } 597}{\mathrm{ND}}=\text { rund } \frac{530 \text { bis } 600}{\mathrm{ND}} \text {, im } \text { Mittel }=\frac{560}{\mathrm{ND}}
$$

bei Mefiung in 2 rufthbye und gleider Ringbreite oben und unten.

3aglenbeifpiel: $\mathrm{n}=\mathrm{N}=10, \mathrm{~d}=30, \mathrm{D}=40 \mathrm{~cm}$.

3utreffenb: bei Mefiung in Gtammmitte $\mathrm{p}=\frac{400}{\mathrm{n} \cdot \mathrm{d}}=\frac{400}{10.30}=1,33 \%$.

Ulnzutreffend: bei $\mathfrak{B r u f t g o ̈ b e n m e f f u n g ~} \mathrm{p}=\frac{400}{\mathrm{ND}}=\frac{400}{10.40}=1,00 \%$.

Etetz zu bejeitigen ber aus bem gröp̃eren D in Brujthöbe ertwachjenbe Fehler burch bie Einfügung won $\mathrm{d}=\mathrm{D} \sqrt{\mathrm{f}}$,

$$
\text { ergibt } p=\frac{400}{10.40 \cdot \frac{30}{40}}=\frac{4}{3}=1,33 \% \text { wie oben! }
$$

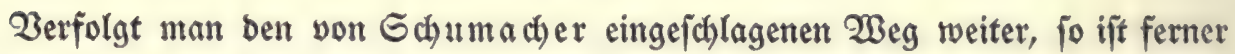
noch redunerifh greifbar ber gewöhnliche Fall 1: $\mathrm{If}_{1}$ oben,

rf in ber Mitte $=d \pi b, b=\frac{1}{n}$, aljo if $=\frac{d \pi}{n}$

$\begin{array}{ll}\mathrm{Rf}=\mathrm{D} \pi \mathrm{B}, \mathrm{B}=\frac{1}{\mathrm{~N}^{\prime}} & \text { aljo } \mathrm{Rf}=\frac{\mathrm{D} \pi}{\mathrm{N}}, \\ \mathrm{n}=\frac{\mathrm{d} \pi \mathrm{N}}{\mathrm{D} \pi}=\frac{\mathrm{dN}}{\mathrm{D}}, \frac{\mathrm{d}}{\mathrm{D}}=V \mathrm{f}, & \quad \begin{array}{l}\text { Benn im umgefebrten Werbältniz } \\ \mathrm{n}=\mathrm{N} \sqrt{\mathrm{f} .}\end{array}\end{array}$

Rach Echeiber. . . . . $\mathrm{p}=\frac{400}{\mathrm{n} \cdot \mathrm{d}}$ !

nach) voriger (Durchmefierberect)nung $p=\frac{400}{\mathrm{n} \cdot \mathrm{D} \sqrt{\mathrm{f}}}$,

im vorliegenden Falle ferner $\mathrm{n}=\mathrm{N} \sqrt{\mathrm{f}}$, folglich $\mathrm{p}=\frac{400}{\mathrm{~N} \sqrt{\mathrm{f}} \cdot \mathrm{D} \sqrt{\mathrm{f}}}=\frac{400}{\mathrm{ND} \cdot \mathrm{f}}$

๖. h. $p=\frac{400}{N \cdot D(0,45 \text { bis } 0,57)}$, ober mit 2̈nberung Der Ronftanten

$$
\mathrm{p}=\frac{700 \mathrm{biz} 889}{\mathrm{~N} . \mathrm{D}}=\mathfrak{\text { umb }} \frac{700 \mathrm{biz} 900}{\mathrm{~N} . \mathrm{D}}, \mathrm{im} \text { Nittel }=\frac{800}{\text { ND }}
$$

bei Neffung in $\mathfrak{B}$ ruftbäbe und gleicher Ringflädbe oben und unten.

3ablenbeifpiel: $\mathrm{n}=7,5 . \mathrm{N}=10, \mathrm{~d}=30, \mathrm{D}=40$.

3 utreffend bei Meffung in Gtammmitte $p=\frac{400}{n \cdot d}=\frac{400}{7,5.30}=\frac{400}{225}=1,78 \%$.

SInzutreffeno bei $\mathfrak{B r u f t h o ̈ h e n m e f i ́ n g ~} \mathrm{p}=\frac{400}{\mathrm{~N} . \mathrm{D}}=\frac{400}{10.40}=1,00 \%$. 
Es nuß vielmebr nach voriftebenb bergeleiteter Berichtigung beinen:

$$
\mathrm{p}=\frac{400}{\mathrm{NDf}}=\frac{400}{10.40 \cdot \frac{900}{1600}}=\frac{16}{9}=1,78 \% \text { wie oben. }
$$

Weiter rechnungsిmäp̃ig annäherunggึweife noch übertragbar auf ben Fall 4 bes frengen $\sigma_{\text {dhluffeg }}(1,0)$ :

$$
\begin{aligned}
& \left.\begin{array}{c}
\mathrm{rf}_{1} \text { oben } \\
\mathrm{V} \\
\mathrm{Rf} \text { unten }
\end{array}\right\} \begin{array}{c}
\text { Sngefähre 3unabme } \\
\text { von unten nach oben } \\
=0,1 \text { big } 0,3 \text {. }
\end{array}
\end{aligned}
$$

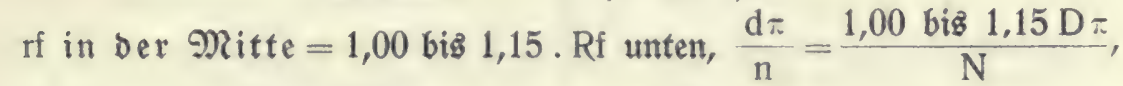

$$
\begin{aligned}
& \mathrm{n}=\frac{\mathrm{d} \pi \mathrm{N}}{1,00 \text { big } 1,15 \mathrm{D} \pi}=\frac{\mathrm{dN}}{1,00 \text { bis } 1,15 \mathrm{D}} ; \mathrm{d}=\mathrm{D} \sqrt{\mathrm{f}}, \\
& \mathrm{n}=\frac{\mathrm{ND} \sqrt{\mathrm{f}}}{1,00 \text { biz } 1,15 \mathrm{D}}=\frac{\mathrm{N} \sqrt{\mathrm{f}}}{1,00 \mathrm{big} 1,15}=\frac{100 \mathrm{~N} \sqrt{\mathrm{f}}}{100 \mathrm{biz} 115}=0,87 \text { biz } 1,00 \mathrm{~N} \sqrt{\mathrm{f}} \text {, } \\
& \text { im } \text { Rittel }=0,93 \mathrm{~N} \sqrt{\mathrm{f}} \text {. } \\
& \mathrm{p}=\frac{400}{0,87 \text { bis } 1,00 \mathrm{~N} \sqrt{\mathrm{f}} \cdot \mathrm{D} \sqrt{\mathrm{f}}}=\frac{400}{0,87 \text { bi } 1,00 \mathrm{NDf}^{\prime}} \text { im } \text { Mittel }=\frac{400}{0,93 \mathrm{NDf}^{\prime}} \\
& \text { Doer mit Q̈nderung ber Ronjtanten, } \mathrm{p}=\frac{700 \text { biz } 1000}{\mathrm{ND}} \text {, im Nittel } \frac{850}{\mathrm{ND}} \text {, }
\end{aligned}
$$

bei Neffung in 23 ruftgoble uno 3 unabme ber Ringfläde von unten nad) oben um 0,1 bis 0,3 .

3ablenbeifpiel: $\mathrm{n}=7, \mathrm{~N}=10, \mathrm{~d}=30, \mathrm{~N}=40$.

3 utreffend: bei Mefiung in Gtammmitte $p=\frac{400}{\mathrm{n} \cdot \mathrm{d}}=\frac{400}{7.30}=\frac{400}{210}=1,90 \%$.

Anzutreffeno bei 3 rufthöbenmefiung $p=\frac{400}{N D}=\frac{400}{10.40}=1,00 \%$,

vielmebr nach vorítebeno bergeleiteter Berichtigung:

$$
\mathrm{p}=\frac{400}{0,93 \mathrm{NDf}}=\frac{400}{0,93 \cdot 10 \cdot 40 \cdot \frac{900}{1600}}=\frac{16}{0,93 \cdot 9}=\frac{16}{8,37}=1,91 \% \text { wie oben! }
$$

Goweit zuberläfingere 3ablenwerte feblen, um eine treffentore Erbobung Der Ronftanten bet Meffung in 2 rufthöbe vornebmen zu fönnen, bieten obige

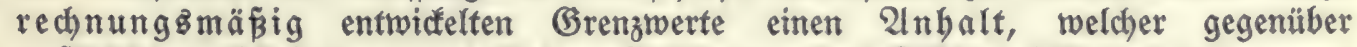

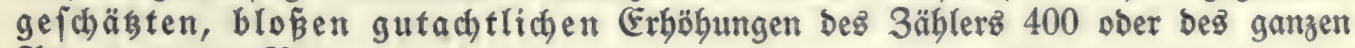
Đrozentes ben 2 orzug verbient. feptlegen:

Mit obiger Rechnungsbilfe laffen fich bie (Brenzen ungefäbr wie folgt

1. Für freiftebende Stämme (etwa 0,7 und weniger), Fall 3 , vielleicht

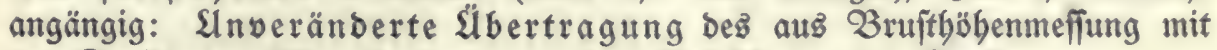
Der Romitanten 400 gefundenen p obne Erhb̈bung Der Ronjtanten.

2. Für geloferten Echlú (etra 0,8), Fall 2, geboten: Erhöhung ber Ronftanten auf 500 biz 600 , im Mittel auf $\mathbf{5 7 0}$. 
3. Für gewöbnlichen Galuz (etwa 0,9), Fall 1, geboten: EErböbung ber Ronjtanten auf 700 bis 900 , im Mittel alt 800.

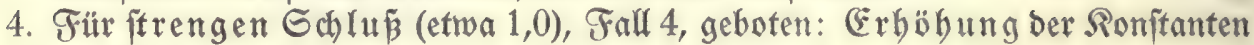
auf 700 bis 1000, im Mittel auf 850 .

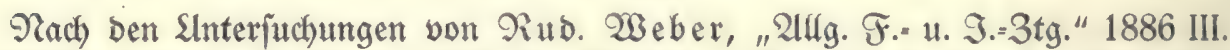
unb "Forftl. naturw. 3eitjur." $1896 \mathrm{VI}$, finbet im allgemeinen eine 3unabme von Rf nach oben nicht ftatt, fo ba pa biernach bie Erthöhung ber Romitanten mit im Mittel 800 ibre Grenzen erreichen würbe für ben Flächenzuwach obne Söben= zunabme. $\mathscr{D a}$ legtere jeboch im Baumbolz nie ganz uno in freng gefoloffenen Etangen (Fall 4) am wenigften feblt, fo ift bei ber Śbertragung auf ben $\mathfrak{B}$ olum= zuwach dez ganzen Gtammez bier noch mit reiteren Erböbungen zu rechnen.

H. Etöger gibt (, $\mathrm{Allg}$. F.: H. S.=3tg." $1896 \mathrm{IV}$ ) alg "leiblich ficher" folgenbe, wohl mit $\mathfrak{B}$ orficht zum Seil etwaz niebrig gegriffenen Durchjhnittżgröß̈en für bie Ronftante:

Stangengol
gefdloffen
bominierend
700

$\begin{array}{cc}\text { Mittelgolz } \\ \text { gefchlofien freiftebend } \\ \text { bominierend } & \text { bominierend } \\ 600 & 500\end{array}$
$\mathfrak{A l t h o l z}$
gefichlofien licht $450 \quad 400$

\section{3u wieberbolen:}

3uwachzermittelungen am Stehenden find zwar zu jeber 3eit leidht und

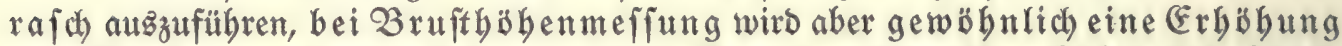
ber Ronftanten in ber Schneiberichen Formel erforberlich. Oaber find Sinter-

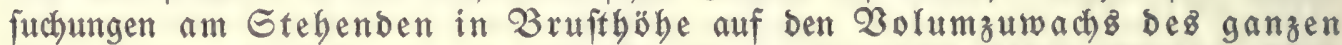
Stammer nur bebingt uno mit Slmrechnung innerbalb obiger Brenzen übertragbar.

Biel zuverläfiger und beshalb ftetz zu bevorzugen find 3uwachzermittelungen

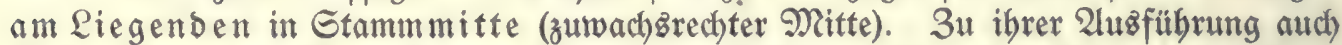
in ber Draris, z. 3. währenb taratorifher 2lrbeiten, if meifit jebr aubgiebige Gelegenbeit geboten in Schlägen, Rachlidhtungen, Räumungen, Rinienaufhieben uím., ohne dás ez bierzu immer befonderer Fällung von Probefämmen bebarf. Dezhalb mués man ftetz Darauf bebacht fein, jebe fich bazu bietende Gelegenbeit rechtzeitig auszunusen!

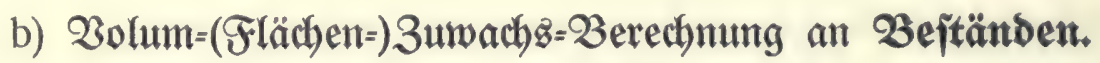

3orggreve, "Forjtl. $\mathfrak{B l}$." 1884 Geite 313, 1885 Geite 362, 1889 Geite 227. Foritabjchägung 1888 .

Für Den Einzelftamm: $p=\frac{R f}{K f} \cdot 100, \frac{p}{100}=\frac{R f}{K f}$.

$\mathrm{Rf}=\mathrm{p} \cdot \frac{\mathrm{Kf}}{100}=\frac{400}{\mathrm{n} \cdot \mathrm{d}} \cdot \frac{\frac{\mathrm{d}^{2} \pi}{4}}{100}$.

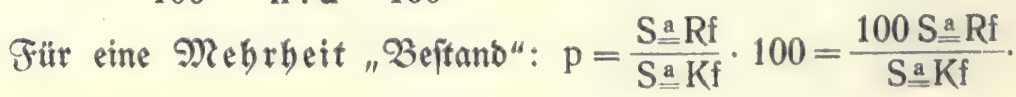


Ės ift $R f=\frac{d \pi}{n}, K i=\frac{d^{2} \pi}{4}$, mithin $p=\frac{\frac{d \pi}{n}}{\frac{d^{2} \pi}{4}} \cdot 100=\frac{\frac{d}{n}}{\frac{d^{2}}{4}} \cdot 100$

$$
=\frac{\frac{4}{n} \cdot d}{d^{2}} \cdot 100=\frac{100 \frac{4}{n} \cdot d}{d^{2}} .
$$

2līo für cine Mebrbeit: $p=\frac{100 \mathrm{~S} \frac{\mathrm{a}}{\mathrm{n}} \mathrm{d}}{\mathrm{S} \underline{\underline{a}} \mathrm{~d}^{2}}$,

Dabei wie oben ber शenner erforberlichenfallz zu multiplizieren mit $\sqrt{\mathrm{f}}$ ober mit $\mathrm{f}$ ujw., wenn 3 rufthöben= Mefiung.

Sierfür eine einfacbe unb bequeme 2 ufrechnung, jowie Durchj(d)nittæermittelung bargeboten in ber Borggrebejchen jogenannten "Safelmethobe". Begeben 1883.

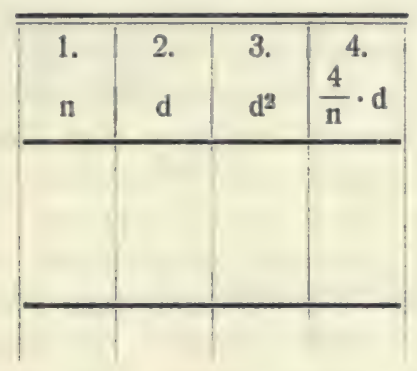

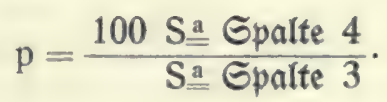

\begin{tabular}{|c|c|c|c|c|c|c|c|c|c|}
\hline शir. & 1. & 2. & nd & $\frac{400}{n d}$ & 3. & $\begin{array}{c}4 . \\
\frac{4}{n} \cdot d\end{array}$ & $\begin{array}{c}\text { I. } \\
\mathbf{K f}=\frac{\mathrm{d}^{2} \pi}{4}\end{array}$ & $\begin{array}{c}\text { II. } \\
\mathrm{Rf}=\mathrm{p} \cdot \frac{\mathrm{Kf}}{100} \\
=\frac{400}{\mathrm{nd}} \cdot \frac{\frac{\mathrm{d}^{2} \pi}{100}}{\mathrm{~d}} \\
\mathrm{Rf}=\frac{\mathrm{d} \pi}{\mathrm{n}}\end{array}$ & 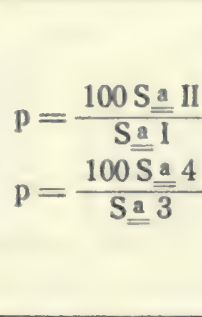 \\
\hline 1 & 5 & 20 & 100 & 4 & 400 & 16 & 314,16 & 12,57 & \\
\hline 2 & 10 & 40 & 400 & 1 & 1600 & 16 & 1256,64 & 12,57 & \\
\hline 3 & 4 & 10 & 40 & 10 & 100 & 10 & 78,54 & 7,85 & \\
\hline $\mathrm{G}_{\mathfrak{a}}$. & 19 & 70 & 540 & 15 & 2100 & 42 & 1649,34 & 32,99 & \\
\hline
\end{tabular}

Erräuternbeß 3ahlenbeipiel:

1. 3 utreffend $p=\frac{100 \mathrm{~S}=4}{\mathrm{~S}^{a} 3}=\frac{4200}{2100}=2 \%$. (Einfach) und bequem!

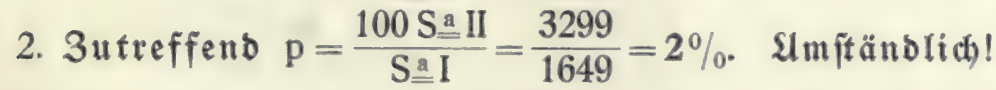

3. $\mathfrak{A}$ «utreffend $\mathrm{p}=\frac{\mathrm{p}_{1}+\mathrm{p}_{2}+\mathrm{p}_{3}}{\mathrm{stz}}=\frac{\mathrm{S} \underline{\mathrm{a}} \mathrm{b}}{\mathrm{stz}}=\frac{15}{3}=\mathbf{5} \%$. 
4. Unzutreffend $\mathrm{p}=\frac{400}{\frac{\mathrm{S} a \mathrm{a}}{\mathrm{stz}}}=\frac{1200}{540}=\frac{400}{180}=2,2 \%$.

5. Ulnzutreffend $\mathrm{p}=\frac{400}{\frac{\mathrm{S} \frac{\mathrm{a}}{\mathrm{stz}}}{\mathrm{stz}} \times \frac{\mathrm{Sa} 2}{\mathrm{stz}}}=\frac{400}{\frac{19}{3} \times \frac{70}{3}}=\frac{9.400}{1330}=2,7 \%$.

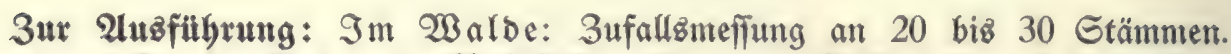

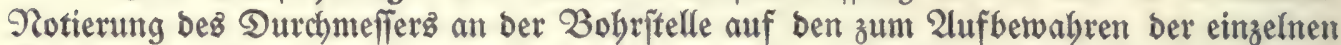
Bohripäne beftimmten 2pothefertütchen unter ber vorber eingetragenen 2lngabe

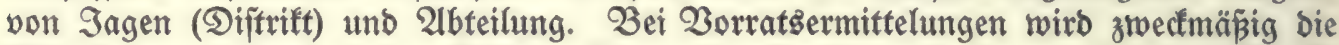
Bohripanentnabme mit ben Söbenmefiungen verbunden und bann alfo zum 3ruft= böbenourdymeffer auch noch bie gemeffene Söbe vermertit.

Sm 3 immer: Berechnung beż nadten d burch $2 b_{z} u g$ beż boppelten Rinben=

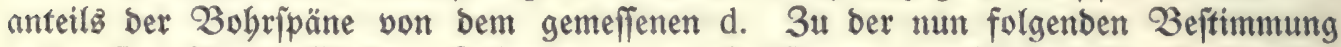
Dez $n$ find fallecht fichtbare Jabrringe am einfachjten uno rafcheften focharf erfennbar zu machen burdh Echleifen ber Epäne auf mittelfeinen Glazpapier mit nicht zu Garter ober zu weicher SInterlage. 2llz folche bient am beften eine zulammen= gefaltete alte 3eitung. Siterzu jei noch weiter bemerht, bá man zum Echleifen ben

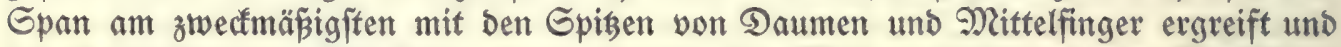
Den freigebliebenen 3eigefinger Dazu benugt, bie Mitte Dez Spanz zur Zerbütung Des (Durchbrechens zu unterftüken. Die Politur wiro am jchönften uno am Elarfiten lejerlich, wenn man ben Epan fo ftelit, baj bie Marffiftablrichtung fenfrecht zur Reibfläche zu fteben tommt. (Ë bebarf nur einez leichten Dructez, aber eineż rajchen,

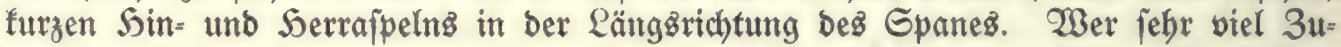
ract) zafpelt uno eine zarte Soaut hat, bem fei auserbem empfohlen, bie beiben nächjtbeteiligten Fingerippizen mit jogenannten "Däumlingen" von alten Peberbanbichulben zu ichüzen. 2ud laffen fid) einfache febernbe metallene (Breifer, wie fie zum (Fin=

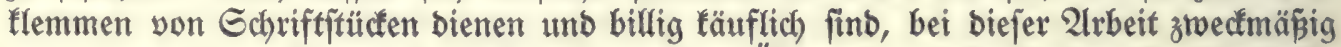

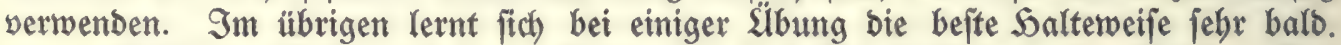

Ullbann Meffung Dez n, Ëintragung bez Ergebniffez in bie Tafel. Zor Zlufrechnung $\mathfrak{u}$. $\mathfrak{A}$. Streichen etwaiger gar zu böjer 2lug̈reißjer.

Empfeblenzwerte Rechenbilfen bieten: Die lleine 3immermannjuge Qunbrat= zahlen=Tafel, Reiś, Liebenwerba, zujammen mit ben Sennefanen Silfżtafeln, Iul. Rich, (Ehur, je 1 Nit.

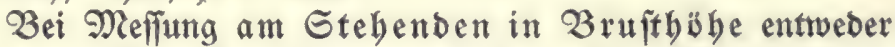

a) ungefäbre Berichtigung nach bem Geite 79 bis 82 angegebenen $\mathfrak{B}$ erfabren. Ober

b) man fann audh, um ficherer zu geben und ben 3 weifeln über bie 3 uverläjifigfeit jener allgemeinen 3 ablentwerte zu begegnen und fïch Dafür nur auf Den porliegenden Einzelfall mit jeinen etwaigen Befonderheiten zu fitüben, von Den erwähnten 20 biz 30 eine 2lnzahl Gtämme mittleren 3 uwach ġganges am Qiegenden feftionsiweife unterjuchen unb aus bem Zergleich mit bem

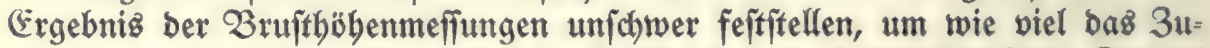
wach zprozent biefer ober aud bie Ronjtante ber Echneiberichen Formel für ben gegebenen Fall zu erböben ift. 
c) Weitere Folgerungen แno Bereinfachungen.

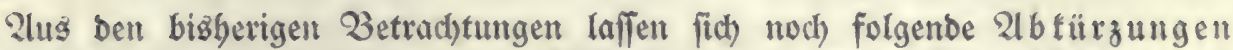

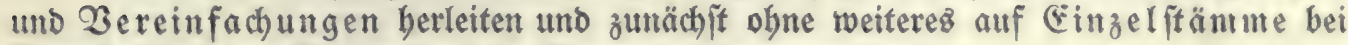
SInterfuchung ain Liegenden it Gtammmitte amwenden:

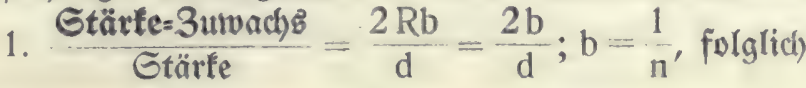

$$
=\frac{\mathrm{n}}{\mathrm{d}}=\frac{2}{\mathrm{n} \cdot \mathrm{d}}=\frac{2}{\mathrm{n} \cdot 2 \mathrm{r}}=
$$

2. Gtärfe $=3$ umbach B̊prozent $p=\frac{2 R b}{d} \cdot 100=\frac{200}{n \cdot d}=$

$$
\frac{1}{n \cdot r} \text {. }
$$

$$
\underline{4}
$$

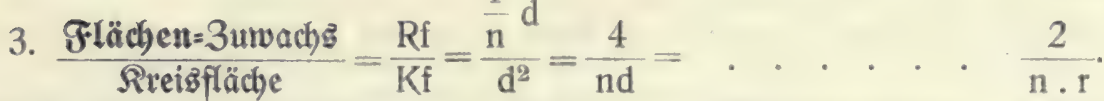

4. Fläc)en $=3$ utwact) Bpprozent $p=\frac{\mathrm{Rf}}{\mathrm{Kf}} \cdot 100=\frac{400}{\mathrm{n} \cdot \mathrm{d}}=. \quad . \quad \frac{200}{\mathrm{n} \cdot \mathrm{r}}$

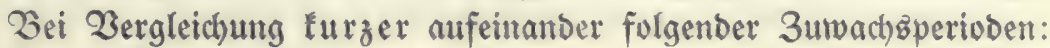

$$
\begin{aligned}
\frac{z_{2}}{z_{1}}= & \frac{\mathrm{Rf}_{2}}{\mathrm{Rf}_{1}}=\frac{\mathrm{d}_{2} \pi \mathrm{b}_{2}}{\mathrm{~d}_{1} \pi \mathrm{b}_{1}} ; \mathrm{b}=\frac{1}{\mathrm{n}} \text {, aljo } \\
= & \frac{\frac{\mathrm{d}_{2}}{\mathrm{n}_{2}}}{\mathrm{~d}_{1}} ; \text { oa aber } \mathrm{d}_{2} \text { nabezu }=\mathrm{d}_{1} \text {, fo ift fermer } \\
& \frac{1}{\mathrm{n}_{1}} \\
= & \frac{\mathrm{n}_{2}}{\frac{1}{\mathrm{n}_{1}}}=\frac{\mathrm{b}_{2}}{\mathrm{~b}_{1}}=\frac{\mathrm{n}_{1}}{\mathrm{n}_{2}} \text {, aljo umgetebrt wie } \mathrm{b} ;
\end{aligned}
$$

oder mit Worten: $\frac{\text { Gpäterer } 3 \text { uwad) } 8}{\text { Früberen 3uwad) } s}$ annäberno $=\frac{\mathrm{Rb}_{2} \text {, fpätere }}{\mathrm{Rb}_{1} \text {, frübere }}=\frac{\mathrm{n}_{1} \text {, frübere }}{\mathrm{n}_{2} \text {, fpätere }}$.

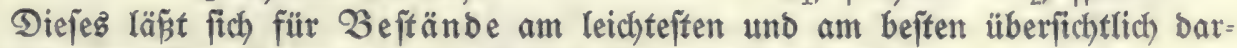
ftellen alş graphifhe Gummierung auf zwei Linien nebeneinander:

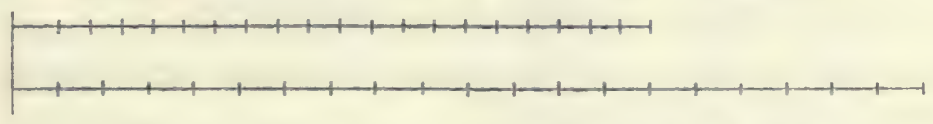

Rach Den Slnterfuchungen von $\Re$ ub. $\mathfrak{B}$ eber ("Forjtl. naturniffenfch). 3eit=

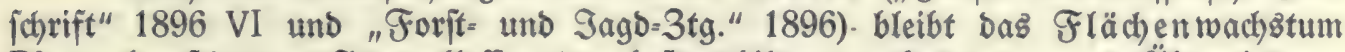
Rf ber Gerrichenten Gtammflaffen Der beftanobilbenden Solzarten nach S̈berwindung

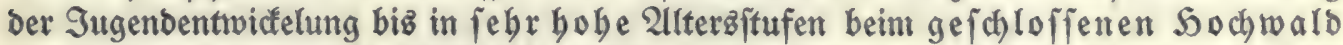
im grofen und ganzen alljäbrlich gleich. (Die Dauer ber biejem Gejés noch nicht folgenden Sugendentrvictelung fand 23 eber für: Lä. 13, Kie. 15, Wey. Kie. 17 bis

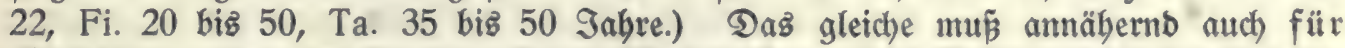
Beftände gelten, ba für bie gejamte 23 ubshleiftung eines Beftanbes bie herrfchenden

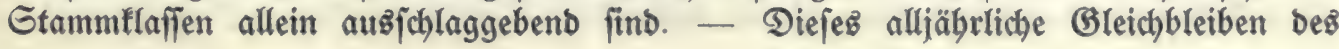




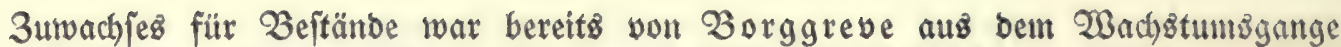

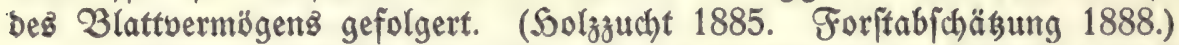

allgemein find aljo im gefchloffenen $\mathfrak{S}$ och wald bie Jabrringe alz fonzentrifche Rreife von gleichen Inbalten ber Ringflächen aufzufafjen. Der im oberen Rronen. raum gejchlofien gehaltene Sochwals vertritt aljo bie Wirtjchaft ber gleichen Ring. fläcbe, aber ftetig fallenden Ringbreite, wäbrend fortgeféste Slmlichtung ber Rronen bei ben gepflegten Sauptfä̈mmen einer in bas Serrichende eingreifenden

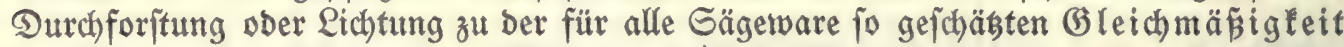
Der Ringbreite führt, wie "פlünbener Sefte" XIII nachgewiejen. Se allmäblicher bie Ślbergänge bei Der Rronenumlichtung gefchaffen werben fönnen, Dejto günftiger für bas tunlichjte Bleichbleiben Der Jahrringe, befto volffommener läß̈t fich baunit, uno zwar ebenfalls für lange (Dauer, zu ber einträglicheren Wirtichaft ber gleichen Ring= breite gelangen.

Praftifche Sauptaufgabe wiro es baher jein, Den Sahrring nicht jobmaler werben zu laffen.

2luz ben Slnterfuchungen von Dr. 21. Rönig ("Pichtungżzunachğ“ 1886) geht hervor, Dás bei Lodferung bez oberen Rronenfchluffez burd) ftärfere wie auch fchwächere

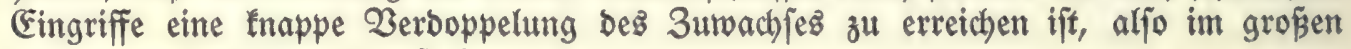
unb ganzen annäberno auf eine

$$
\begin{aligned}
& \frac{3}{2} \text { fachung bes } z \% \text {, alfo auch auf } \\
& \frac{3}{2} \text { fachung ber bizkerigen Ringfläche Rf ober auf happe } \\
& \frac{3}{2} \text { fachung ber bişberigen Ringbreite } b \text {, mithin auch annäherno auf } \\
& \frac{2}{3} \text { fachung bes bişberigen n gerechnet werben barf. }
\end{aligned}
$$

Diefe 2 irfung macht fich fo lange geltenb, als ber frübere Gdhlü nicht wieber bergeftellt ijt.

Auf bie Dauer bebeutet aber $\frac{3}{2}$ fachung ber Ringbreite aud $\frac{3}{2}$ factung

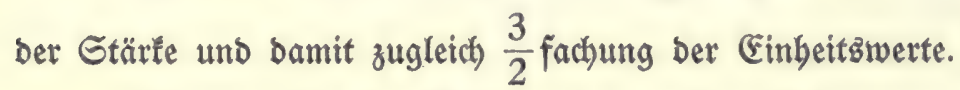

Ěz wirb aljo bie Einlegung berartiger Lid)tungen in ber gleid)en 3eit bas $\frac{3}{2}$ fache von Etärfe uno Einbeitżwert ober gleiche Gtärfe unb gleichen Einbeitżwert in $\frac{2}{3}$ ber 3eit erwarten laffen.

Bejtätigt werben bie Rönigfchen Slnterjuchungen $\mathfrak{u}$. a. Durch bie Ěrgebnifie Deż v. Geebad) fhen Betriebez, bie Dänifchen 3uwachbüberfichten, bie freie Durch)= forftung von $\mathfrak{S}$ edf.

Diefe, wie bie im 3 ramwald vorgenommenen Errbebungen lafien binfid)tlich ber Gtärkezunabme feinen 3weifel barüber, báp bie Ringbreite burch allmäbliche Locterung Des Rronenichluffes geboben wirb 
a) von fatwäd)eren Eingriffen bei $\frac{1}{10}-\frac{1}{5}$ an bisz zu eimem verbleibenden Nindeft: yorrat von $0,5 \mathrm{im}$ Mrittel bi⿱ a

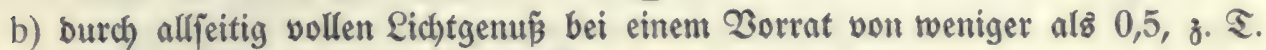
fiteigento biz auf bag volle 2 fache.

Eine genauere gejesmäß̈ige abftufung nach ben verfchiebenen Richtgraben ift vielleidht vorhanden, aber bişber nicht errviejen.

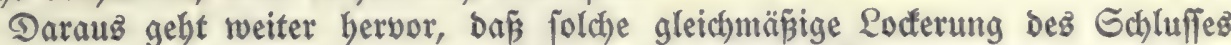

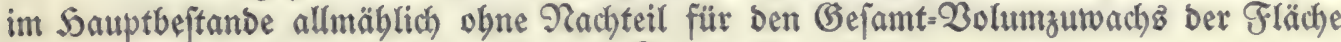
ficher biz zu einer $\mathfrak{B}$ erminberung auf $\frac{2}{3}$ gebradbt werben fann,

Denn $\frac{3}{2} \cdot \frac{2}{3}$ noch immer $=1$. 2luz bem $\mathfrak{W a l b e ~ 1 8 9 9 . ~ 2 u g u i ́ t . ~}$

Wenn bem fo ift, fann aber in Der Gamenfdlagroirtjchaft bei 20 jäbrigem Zerjüngungżeitraum uno 20 jäbriger Periobenbauer bie 3 utwach $z=2$ ufrechnung

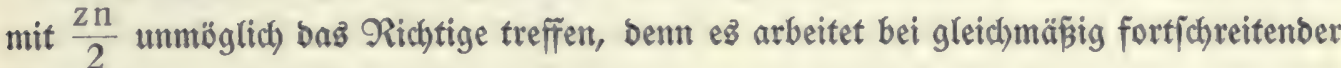
Berminberung Des Borrates

$$
\begin{aligned}
& \frac{1}{3} \mathrm{n} \text { mit } \frac{2}{2} z, \frac{2}{3} \mathrm{n} \text { mit im } \text { Mittel } \frac{1}{2} z \text {, aljo zujammen } \frac{1}{3}+\frac{1}{3}=\frac{2}{3} \mathbf{z n}, \\
& \text { anjtatt ber jonjt, z. 23. für Rabljd)lagwirtfda aft, zutreffenben } \frac{1}{2} \mathbf{z n} \text {. }
\end{aligned}
$$

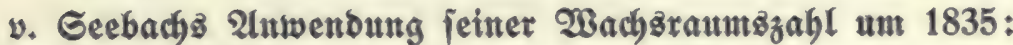

3rijchen Stammitärfe unb Rronenburd)meffer bejtebt für bie einzelnen Gtanbortg̋laffen und 2llter ein annäberno gleich bleibendez Berbältniz. Der

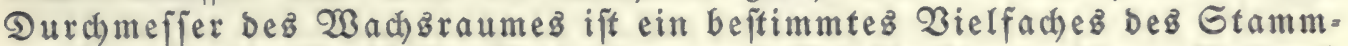
Durd)mefierz in 3ruftgöbe. Darin fommt mittelbar bie Stammabl zum 2luzbrud, unt fo entipricht jeber beftimmten Stammitärle eine beftimmte Obergrenze für bie Etammzahl. Den (Grab ber Eingriffe in ben Sauptbejtand auf biejem WBege

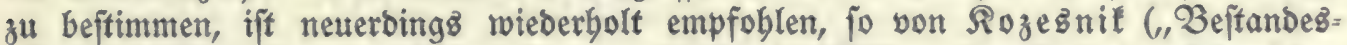

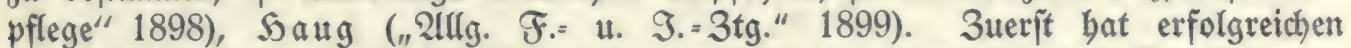
prattifchen (Bebrauch bavon v. Geebadh gemadjt in ben grunblegenden $3 e r e d) n u n g e n$ für feinen mobifizierten Buchenbocbrald (Pfeil, "Rrit. $31 . “$ XXI. 1. 1845).

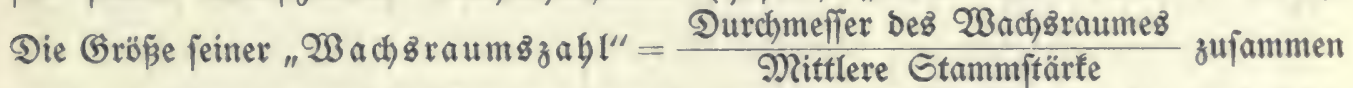
mit ber in jchon länger licht fitebenden Orten jorgfültig ermittelten Ring breite ermöglichte ihm Den Gdhluß auf bie unter gleidhen Berbältniffen nach Lichtungen zu erwartenden

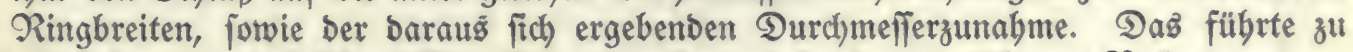
ber folgenben, auf jeben Eingriff in ben Sauptbeftand anwenbbaren Rechnung:

(5egeben: 80 jährige Buchen II mit ber mittleren Gtammftärfe $22,8 \mathrm{~cm}$, ber 23achşraumżabl 16,9, Der Stammzabl 855.

(3ejucht: bie 2 nzabl ber bei ber Rid)tung zu entnebmenten Stammzahl unter

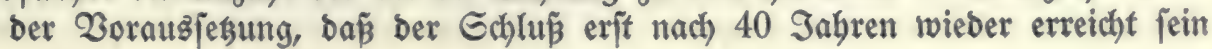


foll unb im Lichtitano nach ben angeftellten Slnterjuchungen eine jäbrliche

Durchmefferzunabme von $0,46 \mathrm{~cm}$ erwartet werben barf.

(2emmach wäre nach 40 Sabren zu rechnen auf eine mittlere Gtammftärte vou $22,8+40 \cdot 0,46=22,8+18,4=41,2 \mathrm{~cm}$, bazu nach ber Tafel bie Wachsiraumg: zahl 16,0. Sierzu bie gefucbte diefen Gröpen entiprechenbe Gtammzahl

$$
=\frac{\frac{10000}{\pi}}{(0,412 \cdot 16,0)^{2}}=\frac{12732,4}{6,592^{2}}=\frac{12732,4}{43,454}=293 .
$$

Folglich baben bei ben Richtungen zu fallen $855-293=562$ Stüd.

Die nachftebende Sabelle gibt bie nach Den Ertragsిtafeln für 10 jährige alterz: ftufen berechneten Wachiraumgzablen bes Sauptbejtanbes von 2 uche, Riefer uno Fichte, vergleichinweije auch bie "Pünbenter Sefte" IX uno XIII mitgeteilten, für

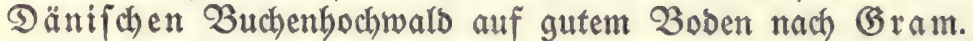

Die Dänifche Wirtjchaft zeigt Durchweg gröpere 3iffern, alfo eine niebrigere

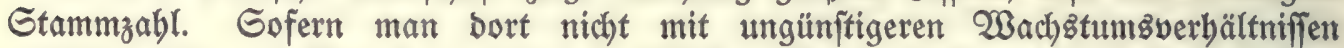
arbeitet, alfo zur Erreichung gleicher Stärfe gröp̈erer Wacbgräume bebarf, liegt,

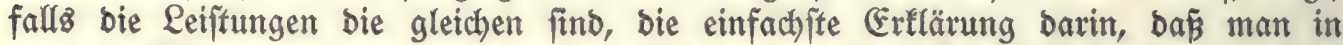

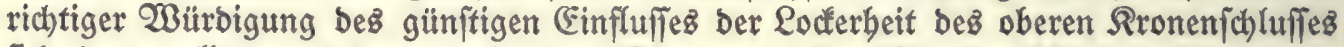
fich Dem vollen und ber zugebörigen Dbergrenze der Stamntzahl nie wieber ganz nåbert. Wir tommen barauf noch zurủd.

\begin{tabular}{|c|c|c|c|c|c|c|c|c|c|c|c|c|c|c|c|c|c|}
\hline \multirow{2}{*}{$\begin{array}{l}\text { Ze: } \\
\text { ftanbs } \\
\text { Alter } \\
\text { Sabre }\end{array}$} & \multicolumn{6}{|c|}{ Bud e } & \multicolumn{5}{|c|}{ Riefer } & \multicolumn{5}{|c|}{ Fidte } & \multirow{2}{*}{$\begin{array}{c}93 \mathrm{e}= \\
\text { itand }= \\
\text { 2lter } \\
\text { Sabre }\end{array}$} \\
\hline & I & II & II & IV & V & $\begin{array}{l}\text { ntifd, } \\
\text { gutee } \\
\text { Boben } \\
\text { (II) }\end{array}$ & I & II & III & IV & V & I & II & III & IV & V & \\
\hline 30 & 4,4 & & & & - & & & 2 & 6 & 2,5 & 25,8 & 5,0 & 18,0 & 20,4 & $1-$ & - & 30 \\
\hline 40 & 20,3 & & & & 27,7 & & & & & & & & & & 19,3 & 22,4 & 40 \\
\hline 50 & 18,2 & & & & 23 & 18 & & 16,7 & & & 21,6 & & 14,9 & 16,4 & 1 & & 50 \\
\hline 60 & 17,3 & & & & 21 & 18 & & 16,1 & & & 20,8 & & 14,2 & & 17,0 & & 60 \\
\hline 70 & 16.5 & ,3 &, 2 & & 20 & 18 & & 5,9 & 0 & 18,2 & 20,5 & & 13,9 & 15,2 & & 18 & 70 \\
\hline 8 & 0 & 9 & 17,9 & & & 17 & 14,8 & 5,7 & 9 & 18,0 & 20,3 & & 137 & 14,7 & & 17 & \\
\hline 9 & & & & & & 17 & & 5 & & & 20,1 & & & & & 16 & \\
\hline 10 & 5 & & & & & 17 & & & 4 & 7 & 20,1 & 5 & 13,2 & 1 & 2 & 6,6 & 100 \\
\hline 11 & 5,2 & 1 & & 18 & 19 & 17 & & & & & 20,1 & & 1 & & 1 & & 110 \\
\hline 120 & 0 & 16,0 & 17,1 & 18 & 19 & 17 & 1 & 15,1 & 16,2 & 17 & 20,1 & 12,2 & 12,9 & 13,7 & 14,9 & 16 & 120 \\
\hline 130 & 8 & 15,9 & 17,0 & 18,2 & 19 & 17 & 14,2 & 15,1 & 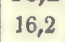 & 17 & 20,0 & 12 & 12,8 & & 4,8 & 16 , & 130 \\
\hline 14 & 14,6 & & 16,9 & 18,2 & & & & 15,0 & & & 20,0 & 12,0 & 12,7 & & 4,7 & 16 & 140 \\
\hline 15 & 14 & 15,7 & 16,9 & 18,2 & 19,2 & 16 & & & 16,2 & 17,7 & 20,0 & 12,0 & 12,7 & & 4,7 & $16, \mathrm{C}$ & 150 \\
\hline 16 & 14,3 & 15,6 & 16,8 & 18,2 & 19,2 & 16 & & 14,9 & 16,2 & 17,7 & 20,0 & 11,9 & 12,6 & & \begin{tabular}{l|l}
14,7 \\
\end{tabular} & 16,0 & 160 \\
\hline 17 & 14,2 & 15,6 & 16,8 & 18,2 & 19,2 & 16,6 & 13,9 & 14,9 & 16,2 & 17,7 & 20,0 & 11,9 & 12,6 & 13,3 & 14,7 & 16,0 & 170 \\
\hline 180 & 14,1 & 15,6 & 16,8 & 18,2 & 19,2 & 16,6 & 13,8 & 14,9 & 16,2 & 17,7 & 20,0 & 11,9 & 12,6 & 13,3 & 14,7 & 16,0 & 180 \\
\hline
\end{tabular}

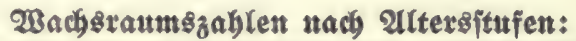

Bei Berechnung voritebenber Safel ifit bem Gtammburchmeffer ber Ourdimeflex Derjenigen Rreišfläche gegenübergeftellt, welche ber Flächeneinbeit, bivibiert burch bie Stammzahl, entppricht, auch zux abfürzung nicht mit ben Rreigfläd)en, fondern nur 
mit bem Quabrat ber Durchmeffer gearbeitet, unter Beziehung auf 12732,4 anjtatt

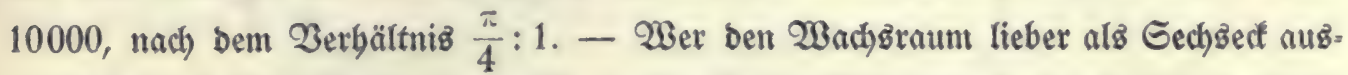

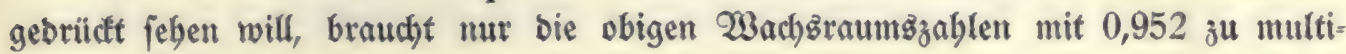

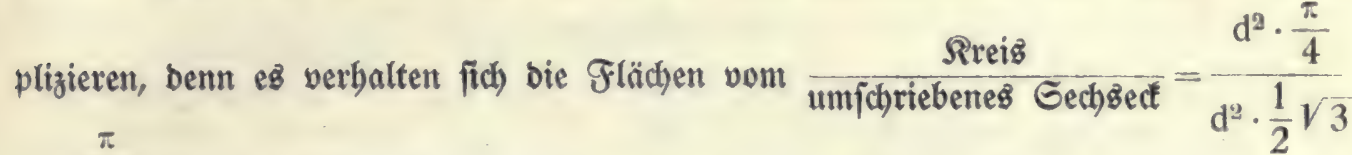

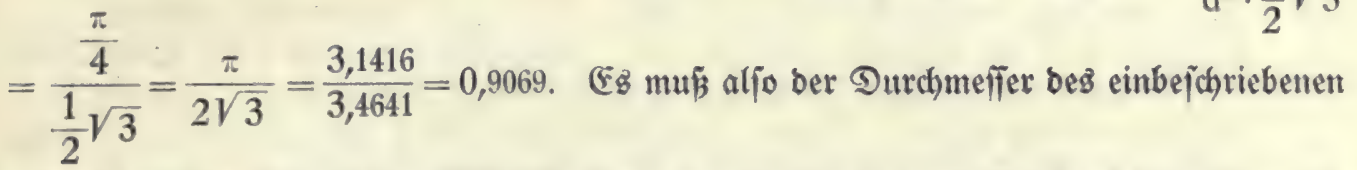

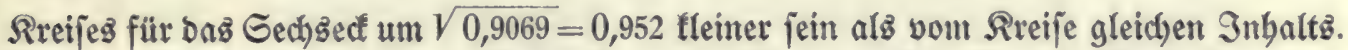
2uch v. Geebach ging vom Gectbed aus. Die von ibm für bie Buche benusten

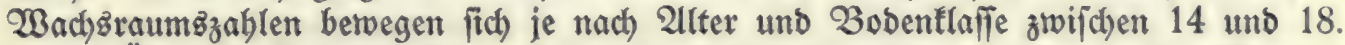
siber bie Ertragstafelangaben binaus find bie obigen 3ablen in ben Grenzen ber $23 a b r j c h e i n l i c h$ feit weitergeführt. Einen 2lnbalt boten bie Gtärte = uno Söben=

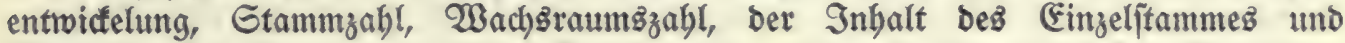

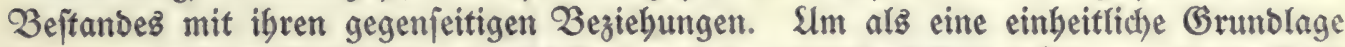

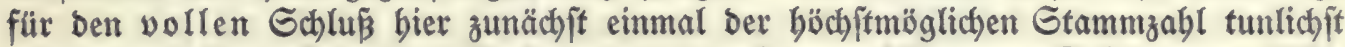
nabe zu bleiben, find für Riefer nicht bie ftammzablärmeren Safeln von 1904, fonbern bie von 1889 benugt, zumal nach $\Xi_{\text {d) }}$ appad) Die Flächen Der lesteren jämtlich) vor feinem eigenen 2luge an Ort unb Stelle bie Prüfung beitanden haben. Ëg wirb grunblegeno für jeoe weitere Zerwenoung biejer Zablen, Den oberen Grenzwert fo richtig wie möglich fejtzulegen, aljo von vornberein zu wiffen, eş tönnen im $\mathbf{S}$ aupt= beftanbe wohl weniger, niemalछ aber mebr Grämme bei beftimmter mittlerer 23 ruft Gobbenfiärfe vorbanden fein.

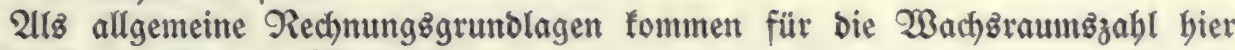
zunächit bie folgenden in Betracht:

$$
\begin{aligned}
& \text { Wacharaumżzabl }=\sqrt{\frac{12732,4}{\text { Durd)mefierquabrat } \times \text { Gtammzabl }}} \\
& \mathrm{Wrz}=\sqrt{\frac{12732,4}{\mathrm{D}^{2} \cdot \mathrm{N}}}
\end{aligned}
$$

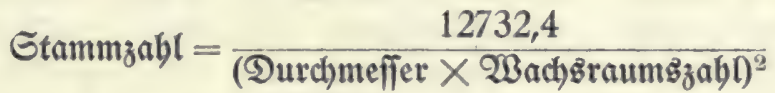

$$
\begin{aligned}
& \mathrm{N}=\frac{12732,4}{(\mathrm{D} \cdot \mathrm{Wrz})^{2}} \\
& \text { Mittlere Etammftärte }=\frac{\sqrt{\frac{12732,4}{\text { Stammzahl }}}}{\text { Wachstaumgzabl }} \\
& \mathrm{D}=\frac{\sqrt{\frac{12732,4}{\mathrm{~N}}}}{\mathrm{Wrz}} .
\end{aligned}
$$

Die weitere Ruganwendung folgt päter. 


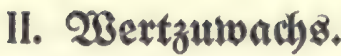

$\mathrm{Wz}=$ Volz $\times$ Bertfteigerung pro Bolumeinbeit.

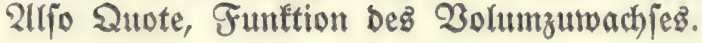

\section{a) Einzelitamm.}

Wie bereits Geite 20 erwälnt, verbalten fidc) nach ben Stnterfuchungen von: Borggreve,

Gdumad)er für $\mathfrak{B} u d$ e, "Forftl. 31 : 1889 Geite 7 fif. uno 1890 Geite 26 ff., (Carl für (Eid)e, "2lllg. F." und $\mathfrak{J}_{.=3}$ tg." 1895 Geite 60 ff.,

Michaelis für Riefer, "Forftl. $\mathfrak{B l}$." 1887 Geite 161 ff. und für Ëiche, $\mathfrak{B} u$ che,

Fichte Riefer, "Tüno. Sefte“ IX. 1896 Geite 102 fï.,

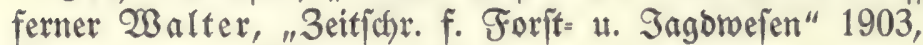

Pilz ebenba 1904 Geite 5 fi.,

im allgemeinen bie Einbeitswerte aftreiner Nubgolzabidnnitte (Echneibe= hölzer) wie ihre $\mathfrak{D} u x d$ mefjer, und zwar in ben Etärfen für:

(Eiche von 30 bis $\frac{60-70}{65} \mathrm{~cm}$ Mittendurchmeffer, wohl aud) betab bis $15 \mathrm{~cm}$,

Buche " 18 " $\frac{50-60}{55} \mathrm{~cm}$ Mittendurchmefier,

Fichte " 11 " $25 \mathrm{~cm}$, uno weiter noch biв $\frac{25-30}{28} \mathrm{~cm}$ Nittenourchmeffer, (vergl. Ney, "Neue forftl. Bl.“ 1902 Eeite 370),

Riefer " 20 " $\frac{40-50}{45} \mathrm{~cm}$ Mittenourchmefier,

bei Pängen von $3 \mathrm{~m}$ aufroärţ (bei Buche in Rollen jogar făon von $1 \mathrm{~m}$ ). Dabei

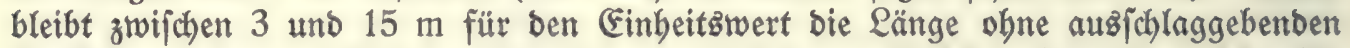
Einflup̃, ja jogar fajt belangloz, folange es fith um Stärfen bandelt, welche für

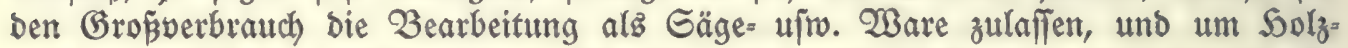
arten und Gtärfen, welche nicht in fehr überwiegendem Maß̉e ober auşj(hließ̃lich für

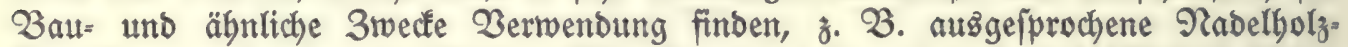
Baubölzer u. bergl., wie Fichte. Für Etangen tommt noch Das Weitere hinzu,

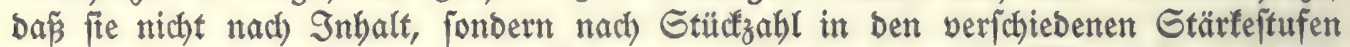
von ben Forftwerwaltungen vertauft werben. Nur eine gewiffe Minbejtlänge ift für jebe Rlaffe feitgelegt. Grö̈pere Qänge bietet aljo nicht nur Gelegenbeit zu vorteil=

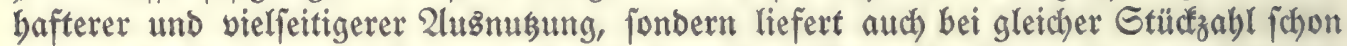
an fich mefr Solz, felbft wenn ez nur barauf antäme, bie Stangen zu verbrennen ober zu 3ellulofe zu verarbeiten.

2litreine Pugftỉcfe über $15 \mathrm{~m}$ Qänge werben mur felten verlangt.

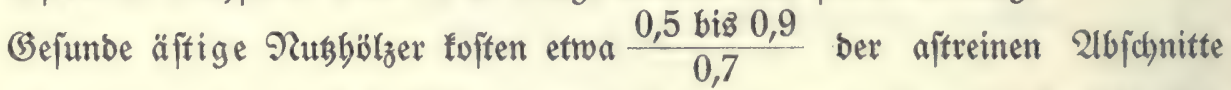
gleicher Gtärfe, verbalten fïch alfo im gropent uno ganzen ebenfallz wie ifhe Durdmeffer. Ober ganz allgemein: Einbeitsmerte wie homologe Durchmefier. Gelbłt am äftigen 3 rennholz läpt fich biez noch beutlich verfolgen, wie ein einfacher Bergleich von Preis uno Etärfe bei 2litreifig, 2iftenüppeln uno äptigen Brent= icheiten zeigt. 
Nach obigen (Erbebungen folftete ber 3 entimeter ber MRttenftärfe aft reinen $\mathfrak{S o l z}$ ez bei:

Eict): Qotbringent $\frac{80-95}{88}$ \f. 1895, 3rammalo $\frac{50-60}{55}$ Pf. 1890 biz 1894; gegentwärtig etrua $\frac{80-95}{88}$ pf.

Buche: Oberwejer $\frac{25-35}{30}$ Pf. 1889 biz 1894; gegenwärtig etwa $\frac{35-45}{40}$ Pf.

Fichte: 3 rammalo $\frac{70-80}{75}$ 叉f. 1891 biz 1896; gegentuärtig etwa $\frac{85-100}{93}$ DF.

Riefer: Neuenborf b. Wittitod $\frac{40-50}{45}$ Pf. 1886 biş 1887; gegentwärtig ent= iprectient mebr.

Siernach) Feftmeterpreiz (Einbeitżwert) aftrein = d mal 3entimeterpreiz, 3. $\mathfrak{B}$. $\mathfrak{B u c t j e}$ von $40 \mathrm{~cm}=40.40 \mathfrak{P f}$. $=16$ Mf. pro Feftmeter.

Ebenjo Feftmeterpreis äjtig $=\frac{0,5-0,9}{0,7} \cdot d \cdot$ 3entmeterpreiz, z. B. Budue von $40 \mathrm{~cm}=0,7 \cdot 16=11,20$ Mf.

Rach vorftebendem ift zur näherungşweifen Berechnung bes Wz folgenbes zu unterftellen. Egs fteigen beim Einzelftamm:

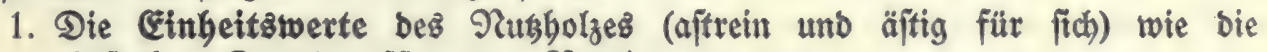
einfachen Durchmeffer ober Rabien,

2. Die Solzmengen wie bie Quabrate ber $\mathfrak{D u r d}$ meffer ober Rabien,

3. aljo bie Gefamtwerte wie bie Ruben ber $\mathscr{D}$ urdimeffer ober Rabien.

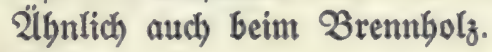

$3 \mathfrak{a h l e n b e i f p i e l e : ~}$

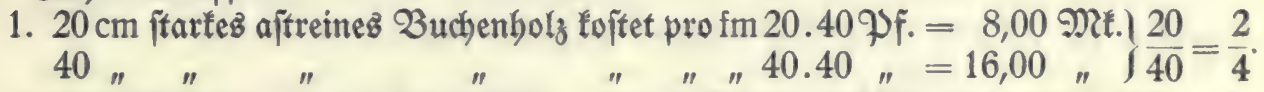

2. Ein 21 bichnitt von $10 \mathrm{~m}$ Qänge, $20 \mathrm{~cm}$ Gtärfe enthält $\left.\begin{array}{l}0,314 \mathrm{fm} \\ 1,256\end{array}\right\} \frac{20^{2}}{40^{2}}=\frac{4}{16}$

3. "Buchentabichn. " $10 \mathrm{~m} "$ " 20 " " " fojtet $0,314.8$

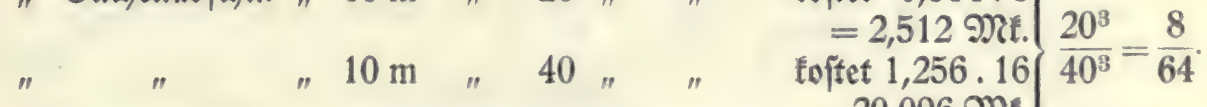

Demnach bedeutet alfo bie Gtärfezunabme eines Gtammes von 20 auf $25 \mathrm{~cm}$

$=8000$ auf 15625 ๖. i. annäberno eine 2 fachung bes (b) efamtwertez, 20 auf $29 \mathrm{~cm}$

$=8000$ auf 24389 20 auf $32 \mathrm{~cm}$

$=8000$ auf 32768

20 a uf $34 \mathrm{~cm}$

$=8000$ auf 39304

20 auf $36 \mathrm{~cm}$

$=8000$ auf 46656

3 fachung "

4 fachung "

5 fachung "

6 fachung " 
20 auf $38 \mathrm{~cm}$

$=8000$ auf 54872 D. i. amäherno eine 7 fachung Des Gefaintwertes, 20 auf $40 \mathrm{~cm}$

$=8000$ auf 64000

8 fachung ,

Wenn nach Geite 90 uno 91 als befter $\mathfrak{B e r t m e f f e r ~ b i e ~ G t a ̈ r l e ~ g e l t e n ~}$ mun, fo fann bie in Preupen unb anderen beutichen Forfterwaltungen für Lang=

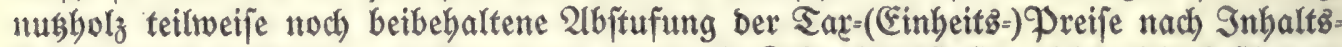

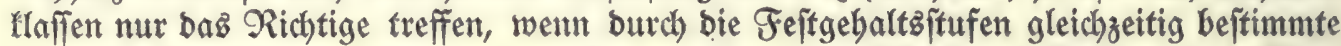

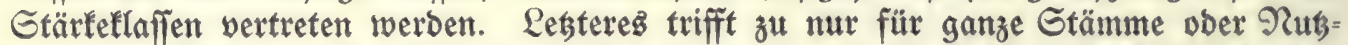
enden annäherno gleicher $\mathfrak{L a ̈ n g e}_{\text {und }}$ Form, wie fie bei ber früber üblichen robeften

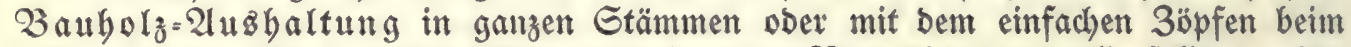
erften ftarfen 2 lit in gleichmäßig auşgeformten 2 abelbölzern allenfallz erreicht wurbe. Dagegen falließ̧t jebe forgfältigere Trenmung ber einzelnen (Gebrauchżlaffen

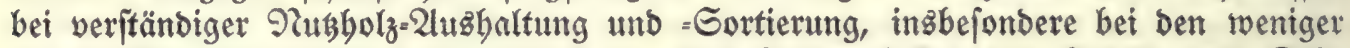

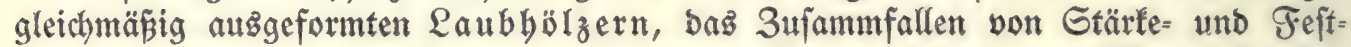

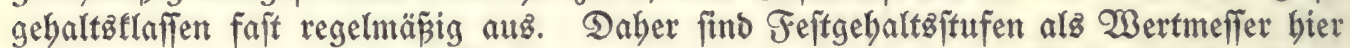
nicht ober nicht in gleichem Maje angebracht, ebenjowenig beim Nabellyolz für Säge= mübleninduftrie. Smmer zutreffend bleibt bie Srenmung nach Etärféflaffen (aftrein uno äfig für fich), wie foldhe z. 3 . nach Dezimeter=, in geringeren Gtärtent nach Galben Dezimeterftufen, wenigfteng für Laubholz, munmebr meift eingefübrt finb.

\section{3ablenbeifpiel:}

a) Ěin 216 jd)nitt von $16 \mathrm{~m}$ Qänge uno $20 \mathrm{~cm}$ Gtärfée $=0,50 \mathrm{fm}$,

b) ein $21 b$ chnitt von $4 \mathrm{~m}$ Qänge uno $40 \mathrm{~cm}$ Gtärfe ebenfalla $=0,50 \mathrm{fm}$, aber ber $\mathfrak{W e r t}$ won $\mathrm{b}$ if boppelt fo groj wie von a, wäbrend beibe nach Den

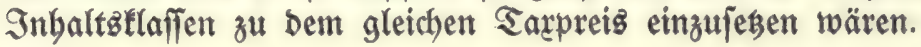

2lus bem Seite 90 bis 91 Bejprodbenen laffen fith nach Borggreve, "Forjtl. 3l." 1891 Eeite 10 fr., weiter folgende 2 lusbrïcte ableiten:

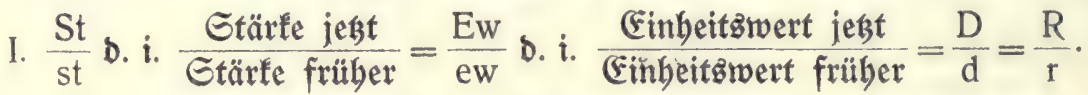

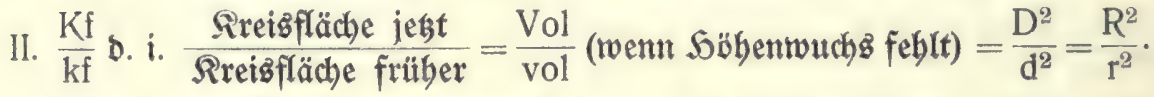
III. $\frac{\mathrm{Kf} \times \mathrm{Ew} \text { jest }}{\mathrm{kf} \times \mathrm{ew} \text { früber }}=\frac{\mathrm{Gw}}{\mathrm{gw}}$ D. i. $\frac{\text { Gejamtwert jegt }}{\text { Gejamtwert frïber }}=\frac{\mathrm{D}^{3}}{\mathrm{~d}^{3}}=\frac{\mathrm{R}^{3}}{\mathrm{r}^{3}}$.

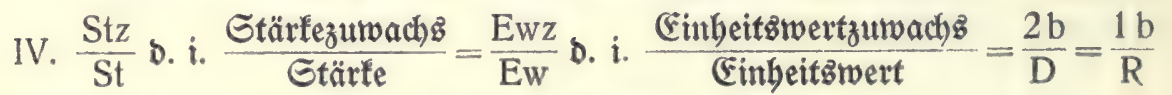
(b wie früber $=$ Ringbreite).

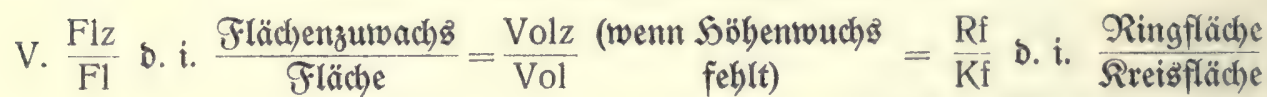 $=\frac{4 \mathrm{bD}}{\mathrm{D}^{2}}=\frac{4 \mathrm{~b}}{\mathrm{D}}=\frac{2 \mathrm{~b}}{\mathrm{R}}$.

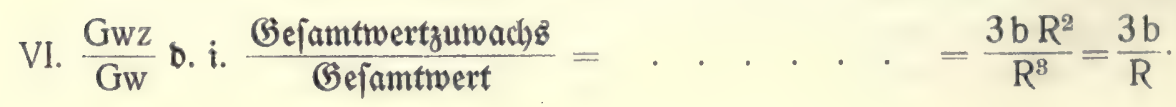


Der mafhematifche Betveis für bie Richtigfeit von VI iff erbracht burch

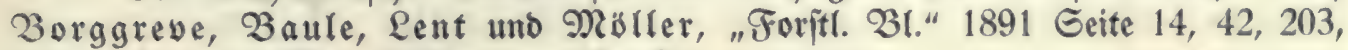
worauf bier Der Rürze Galber verwiejen fei.

2Beiter läp̃ fich baraus herleiten:

$$
\begin{aligned}
& \text { VII. Stz } \%=\frac{1}{2} \cdot \frac{400}{n D}=\frac{200}{n \cdot D}=\text {. . . . . . . } \frac{100 \cdot 1 \mathrm{~b}}{\mathrm{R}} \text {. } \\
& \text { VIII. } \mathrm{Flz} \%=\frac{2}{2} \cdot \frac{400}{\mathrm{n} \cdot \mathrm{D}}=\frac{400}{\mathrm{n} \cdot \mathrm{D}}=\ldots . . . . \cdot \frac{100 \cdot 2 \mathrm{~b}}{\mathrm{R}} \text {. } \\
& \text { IX. Gwz } \%=\frac{3}{2} \cdot \frac{400}{n \cdot D}=\frac{600}{n \cdot D}=. . . . . \frac{100 \cdot 3 b}{R} \text {. }
\end{aligned}
$$

$$
\begin{aligned}
\text { Gwz } \% \text { minbeften } & =\frac{2}{2} \cdot \text { Volz } \% \\
\text { bis } & =\frac{3}{2} \cdot \text { Volz } \% \text { nad) VIII unb IX. }
\end{aligned}
$$

Rach ber Serleitung auz ben oben angefiibrten Erhebungen wirb Wz nur

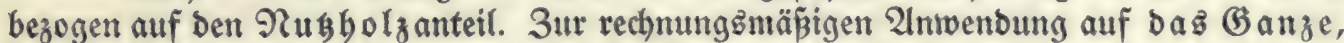
Gwz, fann baher (nach Borggreve, "Forftl. Bl." 1891 G. 16) Der Nugholzanteil, D. i. Daz jogenannte "Nugholzprozent", einfach in bie Dezimalftelle bez 3ählerz eingejert werben.

พBäre z. B. Ntugholzprozent $=60$, Daun ift

$$
\text { Gwz } \%=\frac{2,60}{2} \cdot \text { Volz } \% \text {. }
$$

Borftebende Proportionen finden fich zufammengefápt in ber fogenanntent

Dänbener Drillingşormel von 3 orggreve, "Foritl. Bl." 1891 Geite 10 fï., 42 ff., 202 ff.

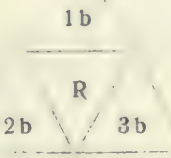

3ujag: In VII uno VIII ift obne weiterez enthalten die 3 reymannjache Formel zur Befitimmung bes 3urachiprozentes:

1. $\mathrm{Stz} \%=\frac{100 \triangle \mathrm{D}}{\mathrm{D}}$,

2. $\mathrm{Flz} \%=\frac{200 \triangle \mathrm{D}}{\mathrm{D}}$, benn $\triangle \mathrm{D}=\mathrm{D}-\mathrm{d}=2 \mathrm{~b}, \mathrm{D}=2 \mathrm{R}$.
b) Beftände.

Sier haben bie Mefinungen gewöhnlid) am Gtehenben zu gejcheben. Ëz wiro Deşhalb notwendig, möglichit alles auf Den 3 rufthöhen.Durchmeffer zu bezieben, wie bieß für Riefer bereits "פMünener Seft" IX Durchgeführt ift. 2luch für ihn gilt alz bomologez Etüđ ganz allgemein Der Eab: Einbeitżwerte wie bie Durd)=

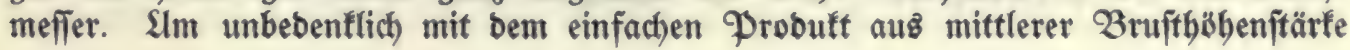




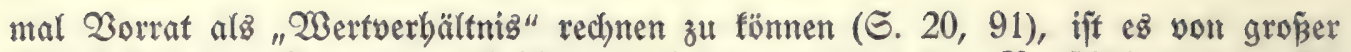
Wichtigfeit, bie Grenzen zu beftimmen, bis zu welchen ber $\mathfrak{B r u f t h o b e n o u r c h m e f l e r ~}$

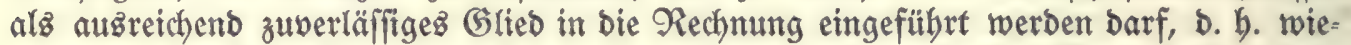
weit bas fragliche Rurvenftüc annäherno gerabe verläuft. Darauf abzielende Erbebungen baben feit 15 Sahren in einzelnen Galägen Des 3 rammaldes alljäbrlich ftattgefunben, in ben legten Sabren aber find regelmäpig bie gröpten Siebe in $\mathfrak{B} u$ chen, fowie tunlichft alle Saunngen in Fichten bierfür nubbar gemacht worben. So ergaben die Sabre $1904+1905$ zufammen für

Bude aub $8100 \mathrm{fm}$ Derbbolz + Reijg.

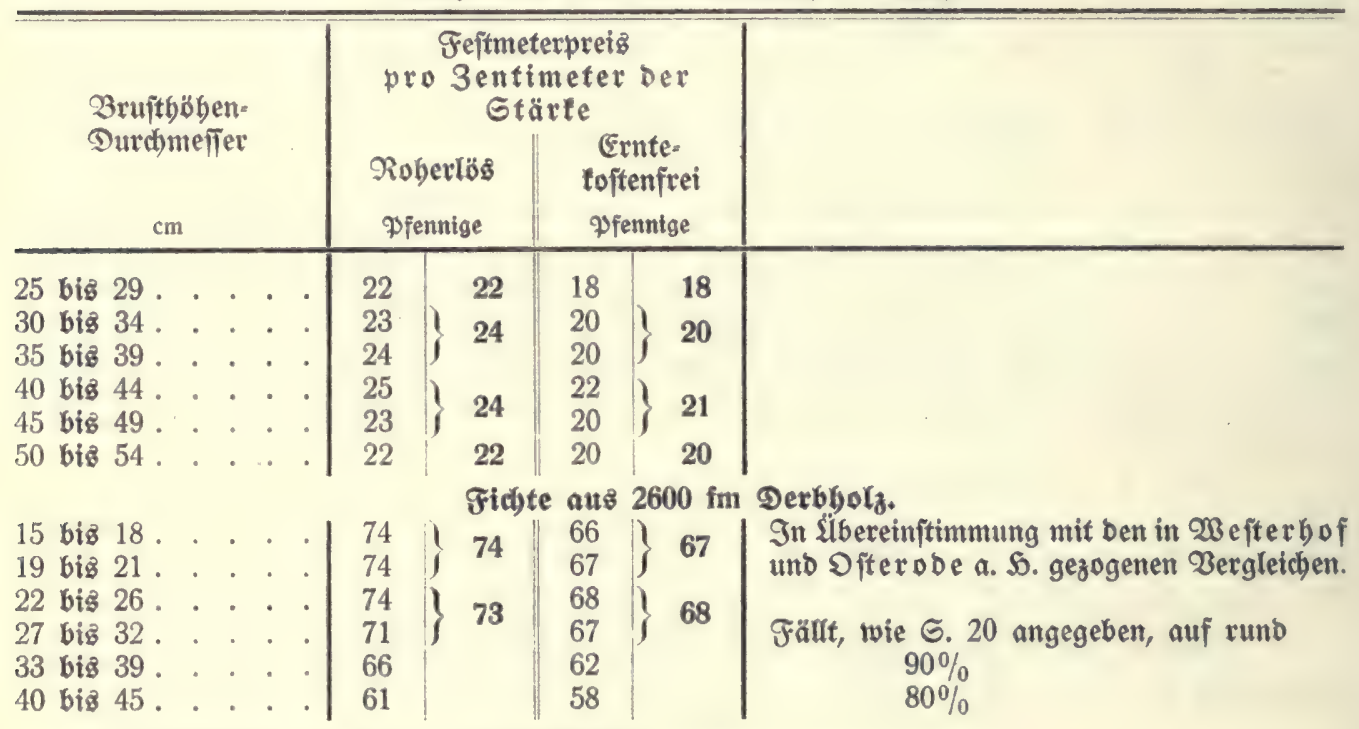

2ufferbem fei bier wieberbolt für

Riejer aus $3400 \mathrm{fm}$ शxubolz aitrein + äjtig.

$1886+1887$ Reuend orf. "Mitudener Seft" IX.

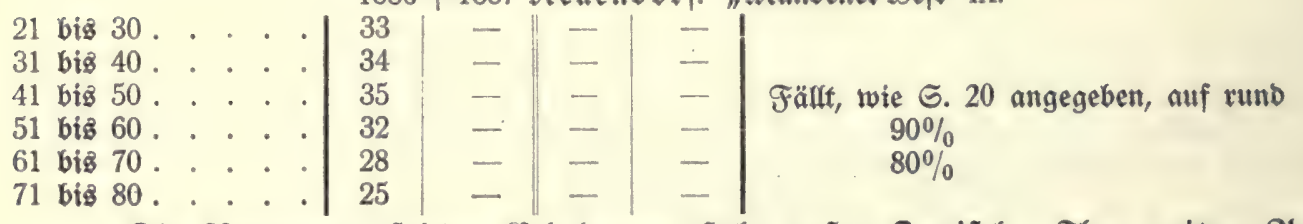

Die Bebeutung foldher Erbebungen fteht außer 3weifel. Shre weitere 2tus. bebnung ift erwiunjht.

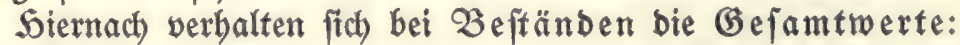

1. Bleicher Zorräte wie ihre mittleren Durchmeffer (gleiche Solzart unb gleiche prozentuelle 2lnteile Des ajtreinen Solzes voraugigefét). Wenn z. $\mathfrak{Z}$. nach হę́ger, "Dänif̧e Reifebilber", Münbener Sefte IX:

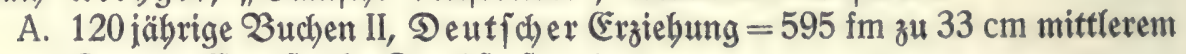
Durchmeffer (j̃arfe Durchforftung),

B. 120 jäbrige $\mathcal{B u c h e n ~ I I , ~ D a ̉ n i f c h e r ~ E ̈ r z i e b u n g ~}=595 \mathrm{fm}$ zu $51 \mathrm{~cm}$ mittlerem

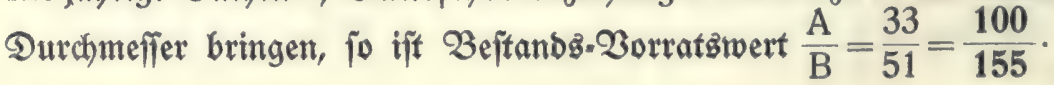


2. Sngleider Borräte wie bie \$robufte aแB Borrat mal mittlevem (2) urchmeffer, s. 3 .:

A. 120 jäbrige $\mathcal{B u c h e n ~ I I , ~ D e u t i c h e r ~ E ̈ r z i e b u n g ~}=671 \mathrm{fm}$ zu $32 \mathrm{~cm}$ mittlerem Durchmeffer (ntäpige Durchforítung),

B. 120 jäbrige Butchen II, Dänifcher Erziehung $=595 \mathrm{fm}$ zu $51 \mathrm{~cm}$ mittlerem Durdymeffer, $\mathfrak{B}$ ert $\frac{\mathrm{A}}{\mathrm{B}}=\frac{671.32}{595.51}=\frac{21472}{30345}=\frac{100}{141}$.

3. Zei Zerfdiebenheit ber a ftreinen Anteile tritt für bas gleiche Beipiel bei Anwenbung Der Geite 90 gegebenen 3ablen etwa noch folgenbe $3 e r=$ fdhiebung ein: $\mathfrak{B}$ enn z. $\mathfrak{B}$. Gătte
A. Deutface Erziebung $60 \%$ aftreine $\left\{=\frac{0,60 \cdot 100+0,40 \cdot 70}{100}=0,88\right.$,

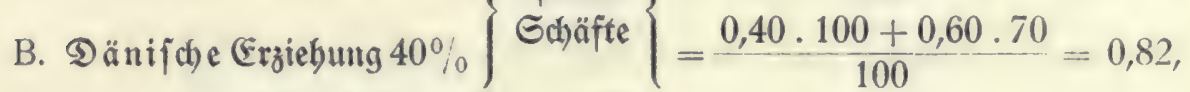 שBert $\frac{\mathrm{A}}{\mathrm{B}}=\frac{0,88 \cdot 100}{0,82 \cdot 141}=\frac{88}{116}=\frac{100}{132}$.

Siernach fpigt fich Dann alio bie rwirtichaftliche Forberung Der Bejchafïung

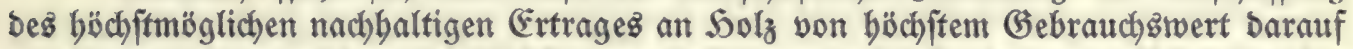
zu: in gegebener ober moglich fit turzer 3 eit möglich fit viel, möglich fi fitarfez und babei hinreidyend augiebig aftreines Solz zu erzieben. 3u vergleichen Seǻ, "Freie Durchforiftung" 1904 unb bie bierauf bezüglichen 2 rbeiten in "Mlündener Sefte" IX, XII, XVI. 2lus Dem $\mathfrak{B a l b e} 1899$, 2lıguft.

Borggreves Täberungz. Formeln zur überfdläglichen Gdäßung

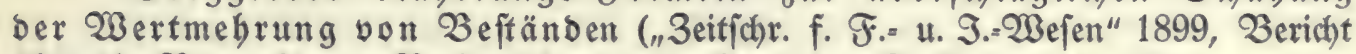
über bie Regenzburger Zerjammlung bę̇ "Deutichen Foritvereing" 1901):

Wie oben Geite 91 aubigefühtt, fteigen beim Ginzelftamm näberungşweife:

1. Die (Einbeitswerte Des शlugholzes (âftrein uno äftig jebes für fich) twie bie einfachen Durdymeffer ober Rabien,

2. Die Solzmengen wie bie Quabrate ber Durdhmeffer ober Rabien,

3. aljo bie Bejamtwerte twie bie Ruben ber Durchmeffer ober Rabien.

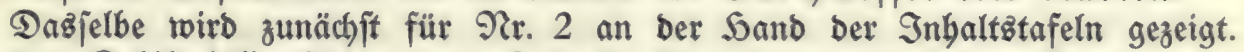
Rach ber Rubiftabelle fteigt Der Inbalt für bie nachifebenben Qängen unb

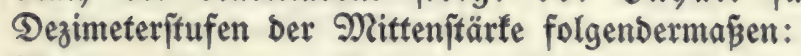
Pänge
$10 \mathrm{~cm}$
$20 \mathrm{~cm}$
$30 \mathrm{~cm}$
$40 \mathrm{~cm}$
$50 \mathrm{~cm}$
$60 \mathrm{~cm}$
$4 \mathrm{~m}$
$0,03 \mathrm{fm} \quad 0,13 \mathrm{fm}$
$0,28 \mathrm{fm}$
$0,50 \mathrm{fm}$
$0,79 \mathrm{fm}$
$1,13 \mathrm{fm}$
$6 \mathrm{~m}$
$0,05 \mathrm{fm}$
$0,19 \mathrm{fm} \quad 0,42 \mathrm{fm}$ $0,75 \mathrm{fm}$ $-4$
$8 \mathrm{~m}$ $0,06 \mathrm{fm}$

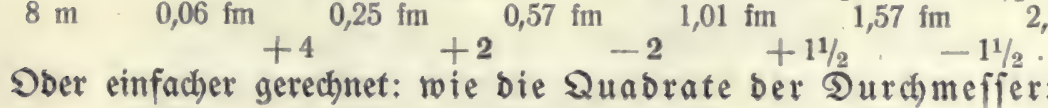 $+2$ $-2$ 100 $\pm 4$ $+2$ $-2$ 1600 $+11 / 8$ $-11 \frac{3600}{2} \cdots$ fache. weniger aโรื

Siernach erfahren Runbiftücfe zwijchen ben im älteren $\mathfrak{S o l}$ am häufigften vor: fommenben (Durd)meffern von 20 bis $50 \mathrm{~cm}$ (am zutreffendften bei ben Gtärfen 20 
biz $30 \mathrm{~cm}$ ) mit jeber $10 \mathrm{~cm}$ Stärfenzunabme eine ungeföhte 2 erboppelung ihreg Inbaltes.

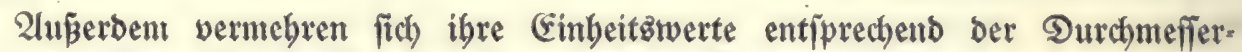
3 unabme zwijchen 20 biz $50 \mathrm{~cm}$ in Den einzelnen Dezimeterifufen

$$
\begin{aligned}
& \text { von } 20 \text { auf } 30 \mathrm{~cm} \mathrm{um} 1 / 2 \text {, } \\
& \text { " } 30 \text { " } 40 \text { " } 1 / 3 \text {, } \\
& \text { " } 40 \text { " } 50 \text { " "1/4 uff., }
\end{aligned}
$$

aljo zwifchen 20 uno $50 \mathrm{~cm}$ yon $\frac{100 \text { auf } 150 \text { biż } 100 \text { auf } 125}{100 \text { auf } 137,5}$,

Das i if burdff(c)nittlich) um je $\frac{1}{3}$, nämlic) von $\frac{3}{3}$ auf $\frac{4}{3}$ auf $\frac{16}{9}$ auf $\frac{64}{27}$, aljo von $\frac{27}{27}$ auf $\frac{64}{27}$, amftatt genau von 20 auf $50=2,5$ fach), b. i. $\frac{67,5}{27}$;

nach 3 orggreve um je $\frac{1}{4}$, nämlich von $\frac{4}{4}$ auf $\frac{5}{4}$ auf $\frac{25}{16}$ auf $\frac{125}{64}$, anjtatt genau von 20 auf $50=2,5$ fadb), b. i. $\frac{160}{64}$.

Ëbenjo fteigt nach ben Mafientafeln ber Berjuchżnjtalten baв Derbholz an einem Mittelftamm von $25 \mathrm{~m}$ böhe und nachjtebenden 3 rufthöhen=פurchmeffern wie folgt bei:

Budge îber 100 jäbrig

$20 \mathrm{~cm}=0,39 \mathrm{fm}$

$30 \mathrm{~cm}=0,89 \mathrm{fm}$

$+2$

$40 \mathrm{~cm}=1,61 \mathrm{fm}$

$50 \mathrm{~cm}=2,55 \mathrm{fm}$

$60 \mathrm{~cm}=3,71 \mathrm{fm}$,

$-2$

$+11 / 2$

$-11 / 2$
Riefer ib er 80 iäbrig

$0,34 \mathrm{fm}$

$+2$

unb zwar am zutreffendîten wieberum für bie Gtärfen 20 biิ $30 \mathrm{~cm}$.

alio ebenfallz eine ungefähre Berboppelung Deż Inhalteg.

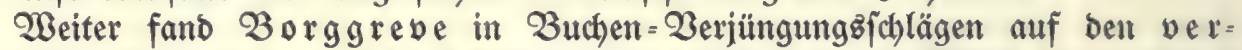
fhiebenften Gtandorten jebr häufig wieberkehrend im Nittel ein $n$ von 3 bis 4, alfo eine Etärfezunahme in brei biz vier $\Im a b r e n=2 \mathrm{~cm}$, in zehn Iabren $=6^{2} / 3$ bis $5 \mathrm{~cm}$, ober $10 \mathrm{~cm}$ in etwa 20 biz 15 Jabren.

Ferner jei hierbei baz 4 fache n ftetz annäherno gleich Der 2mzabl ber Sabre, in welcher ungefäbre Wertberboppelung bez Etammez erfolge:
a) $n=3$, ungefäbre Wertberboppelung in $4 \times 3=12$ Jabren,
b) $\mathrm{n}=4$,
$4 \times 4=16$
c) $\mathrm{n}=5$,
$4 \times 5=20$
d) $\mathrm{n}=6$,
$4 \times 6=24$
e) $\mathrm{n}=7$,
$4 \times 7=28$
f) $\mathrm{n}=8$,
$4 \times 8=32$

Fidbte über 100 jäbrig

$0,40 \mathrm{fm}$

+2 fadje -2 fache $+1 \frac{1}{2}$ factie - fade 


\section{$-97-$}

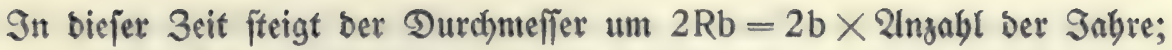

$$
\begin{aligned}
& \mathrm{b}=\frac{1}{\mathrm{n}} \text {, aljo umm } \frac{2}{\mathrm{n}} \times 2 \mathfrak{n} z \mathfrak{a b l} \text { ber Sabre, bas ifit bei: } \\
& \text { a) } \mathfrak{m} \frac{2}{3} \times 12=8 \mathrm{~cm} \text {, } \\
& \text { b) " } \frac{2}{4} \times 16=8 \text {, } \\
& \text { c) " } \frac{2}{5} \times 20=8 \text { " } \\
& \text { d) " } \frac{2}{6} \times 24=8 \text {, } \\
& \text { e) " } \frac{2}{7} \times 28=8 \text { " } \\
& \text { f) " } \frac{2}{8} \times 32=8 \text { " }
\end{aligned}
$$

Damit fteigt alfo übereinftimmend bie Gtärfe um $8 \mathrm{~cm}$, baz i î̉ für bie oben

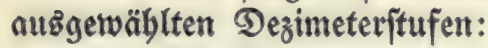

von 20 auf $28 \mathrm{~cm}$, mithin ber Gejamtwert von $20^{3}$ auf $28^{3}$ ober um bas 2,74 fache,

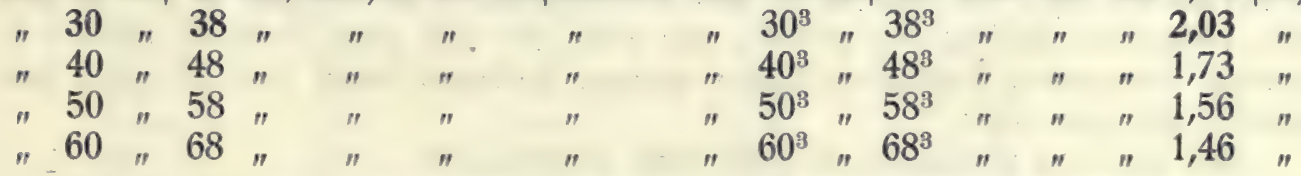

$2 \mathfrak{m}$ zutreffenditen aljo wieberum etwa bei ben Gtärten 25 biz $40 \mathrm{~cm}$.

Siernach lautet Der von Borggrebe gegebene "Limburger $\mathfrak{B e r t}$ verboppelung

Snnergalb $4 \times$ n Sagren ungefähre 2 ertwerboppelung bez Stammez.

Da fich nun ferner burch 3infez̧zinz ein Rapital verboppelt bei

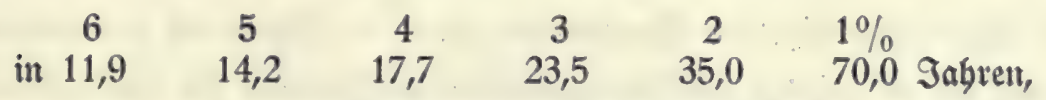

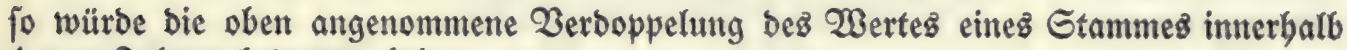
$4 \times \mathrm{n}$ Sabren bebeuten bei:

a) $\mathrm{n}=3$ fajt $6 \%$ 3injeszinjen

b) $\mathrm{n}=4$ 4 bis $5 \%$

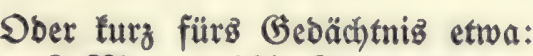

c) $\mathrm{n}=53$ biz $4 \%$

3 Ringe $=6 \%$ 3injezzinfen

d) $\mathrm{n}=6$ faft $3 \%$

e) $n=7 \quad 2$ bis $3 \%$

f) $n=8$ über $2 \%$

$4 "=5 \%$ "

$5 "=4 \%$. "

$6 "=3 \% \quad "$

Bon Borggreve "Regengburger Bemefinung Der mittleren Zeftanbz=

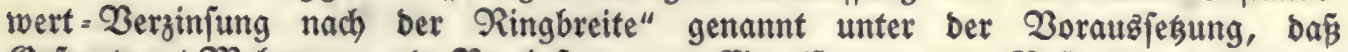
Gejamtwert-9Rebrung und Berzinjung am Einzelítamm und Beftand ben gleichen Berlauf nelgmen. 
Diejen bereinfachten शäberungg̊werten gegenüber fübrt bie gentuere Rechnung nach) Seite 97 zu folgenden Ergebniffen ber Zerzinjegzinjung, wenn freigt

bie Gtärte von 20 auf 28,30 auf 38,40 auf 48,50 auf 58,60 auf $68 \mathrm{~cm}$
a) $\mathrm{n}=3$
8,8
6,1
4,7
3,8
3,5
2,8
b) $\mathrm{n}=4$
6,5
4,6
2,8
d) $\mathrm{n}=6$
5,2
3,6
2,3
e) $\mathrm{n}=7$
4,3
3,0
3,7
2,6
f) $\mathrm{n}=8$
3,2
2,2
2,0
1,7
2,2
$3,2 \%$
$2,4 \%$
$1,9 \%$
$1,9 \quad 1,6 \%$
$1,6 \quad 1,4 \%$
1,4
$1,2 \%$

Die Näherungsformel aljo am zutreffendften etwa bei ben Gtärfen 25 bis $40 \mathrm{~cm}$ unb $\mathrm{n}=3$ b่ 6 .

Dieje Borggrevejchen Formeln find einfach in ibrer Faffung und mit igren

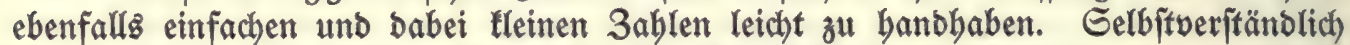

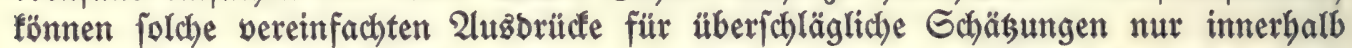

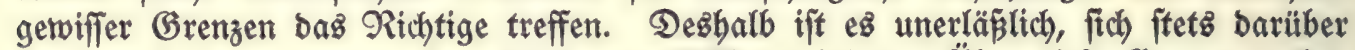
flar zu bleiben, wieweit fie leiblich zuberläfifig arbeiten. S̈ber biefe Grenzen geben obige 3ahlenzufammenjtellungen ungefähren 2lufichlü.

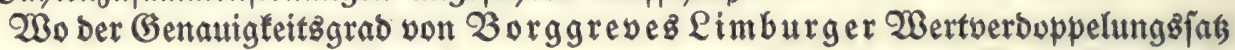

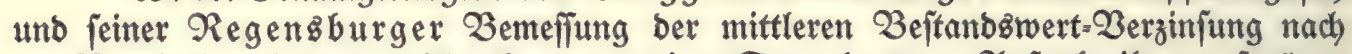
ber Ringbreite nidbt ausireid)t, fann man jene Formeln unter 2 ufgabe ibrer urjprüng lichen einfachjten Faffung für weitere, und zwar für alle nach Eeite 90 unb 94 in Betracht fommenben Durdimefferflaffen genauer fejtlegen, wenn man fie babin um= geftaltet, Daj man jagt:

Der jerweilige (Gefamtwert wirb etwa verboppelt:

bei ber Gtärfe von 20 bis $30 \mathrm{~cm}$ in je $3 \times \mathrm{n}$ Iahren,

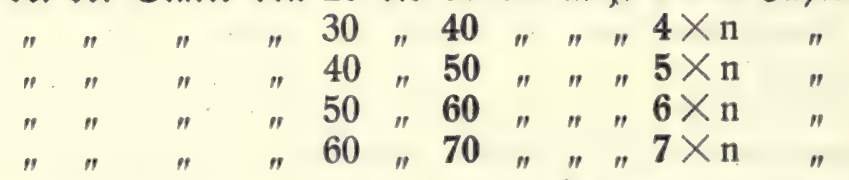

In biefer 3eit fteigt ber Durchmeffer um $\frac{2}{n} \times 2 \mathfrak{n} z \mathfrak{b l}$ ber 3 uwachgjabre, bå ift, wie Geite 96, 97 gezeigt, bei ben gewählten Etärfeftufen für bie verichiebenen $n$ itbereinjtimmend:

von 20 auf $26 \mathrm{~cm}$, mitbin ber Bbejamtwert von $20^{3}$ auf $26^{3}, 8000$ auf 17576 ober

bis 24,30

von 30 " 38

ธ่อ 32 " 40

von 40

$50 "$ " " "

um bas 2,197 fache, " $24^{3} ., 30^{3}, 13824$ auf 27000 ober unt bas 1,953 fache,

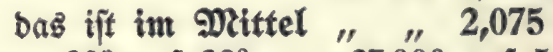
von $30^{3}$ auf $38^{3}$, von 27000 auf 54872 Dber um baż 2,032 fache, " $32^{3}, 40^{3}, 32768$ auf 64000 ober Då ift im MRittel " " 1,993 von $40^{3}$ auf $50^{3}, 64000$ auf 125000 ober นm Daร 1,953 fache, 
von 50 auf $62 \mathrm{~cm}$, mithin ber Bejamtwert von $50^{3}$ auf $62^{3}, 125000$ auf 238328 ober $\begin{array}{llll}60 & 74 & 4 & \text { um bas } 1,907 \text { fache, }\end{array}$ นต จณรี 1,876 fache.

Ober furz: unter 2 nnenbung biejer verfhiebenten 3 ablen $3 \times n, 4 \times n, 5 \times n \ldots$ fitellt jīc) Die Gejamt $=\mathscr{W e r t f i t e i g e r u n g ~ f u ̈ r ~ b i e ~ G t a ̈ r f e n ~} 20$ bis $70 \mathrm{~cm}$ innerbalb jener

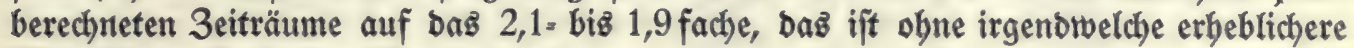
2lbweichung fitets eine Berboppelung.

2̈bnlich läp̈t fich bie Regenşburger Bemeffung ber mittleren Beftanbżwert. Berzinfung ben wabren Gröpen näber bringen, wenn man bie Stärfejtufe 30 biz $40 \mathrm{~cm}$, für weldhe bie 3 orggrevefdhen $3 a b l e n$ aun zutreffenditen fint, zum 2 lubz: gangespunft nimmt unb bazu weiter fagt:

2luf biejer Grundlage fommt man für bie übrigen Gtärfeftufen am einfad)ften zu genaueren Werten, wenn man jene für 30 biż $40 \mathrm{~cm}$ gültigen 3 ablen, wie nadjitebeno multipliziert bet:

20 biz $30 \mathrm{~cm}, 30$ biz $40 \mathrm{~cm}, 40$ bis $50 \mathrm{~cm}, 50$ biß $60 \mathrm{~cm}, 60$ biz $70 \mathrm{~cm}$ $\begin{array}{llllll}\text { mit } & \frac{4}{3} & \frac{4}{4} & \frac{4}{5} & \frac{4}{6} & \frac{4}{7}\end{array}$

จุลี gibt für:

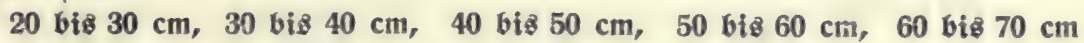
a) $\mathrm{n}=3$
b) $\mathrm{n}=4$
7,9
c) $\mathrm{n}=5$
5,9
d) $\mathrm{n}=6$
e) $\mathrm{n}=7$
f) $\mathrm{n}=8$
4,7
5,9
4,4
3,5
4,7
3,5
3,9
$2,9-2,5$
3,9
$-2,9$
2,5
2,8
2,0
2,3
1,9
1,7
1,8
1,5
3,4
2,0
1,7
2,2
1,4

Fafing:
a) $n=3$
b) $\mathrm{n}=4$
8,0
c) $\mathrm{n}=5$
d) $\mathrm{n}=6$
6,7
5,3
4,0

6,0

5,0

4,0

$-3,0$

4,8

4,0

3,2

4,0

3,3

2,7

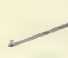

wäbrent bie wirlliche $\mathfrak{B}$ erzinfeşzinfung beträgt:

A. bet genauer 2Bertberboppelutg:
a) $n=3$
b) $\mathrm{n}=4$
8,0
c) $n=5$
d) $\mathrm{n}=6$
e) $n=7$
f) $n=8$
5,9
4,4
3,6
4,7
3,4
2,5
2,9
2,2
4,7
3,6
3,9
3,4
2,8
2,3
2,0
1,8
2,3
1,9
1,7
1,7
1,4

a) $n=3$

b) $\dot{\mathrm{n}}=4$

c) $n=5$

d) $n=6$

e) $n=7$

f) $n=8$

B. nad ber anแăbernben 2 Bertverboppelung Geite 98:

$\begin{array}{lrrrr}8,5 & \mathbf{5 , 9} & 4,6 & 3,6 & 3,0 \\ 6,3 & \mathbf{4 , 4} & 3,4 & 2,7 & 2,3 \\ 5,0 & \mathbf{3 , 5} & 2,7 & 2,2 & 1,8 \\ 4,2 & \mathbf{2 , 9} & 2,2 & 1,8 & 1,5 \\ 3,6 & \mathbf{2 , 5} & 1,9 & 1,5 & 1,3 \\ 3,1 & \mathbf{2 , 2} & 1,7 & 1,4 & 1,1\end{array}$




\section{$-100 \leftarrow$

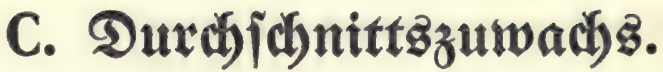

Betwöbnlich wirb barunter ber Durdjfdynitt für eine Mehrzabl von Sabren verfítanben, wäbrend man Den Mittelwert für eime Mehrzabl von 3 äumen (Beftanb) als "mittleren“ Bejtanbz̧zutwach bezeichnet.

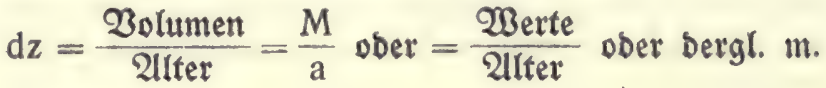

$$
\begin{aligned}
& M=1 z_{1}+1 z_{2}+1 z_{3}+\text {. . . } 1 z_{n} \text {. }
\end{aligned}
$$

พBäre $1 z_{1}=1 z_{2}=1 z_{3}=$. . $1 z_{n}$, fo wärbe einfad) fein $\mathrm{d} z=\frac{1 \mathrm{z} n}{\mathrm{n}}=1 \mathrm{z}$.

(Bewöbnlich unterfcheibet man:

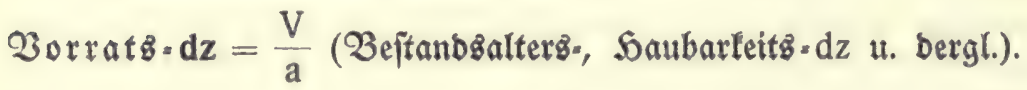

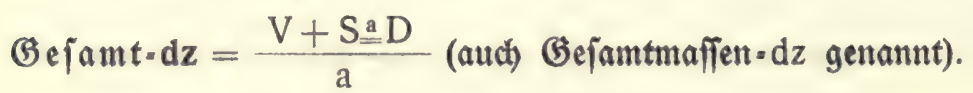

Im Prozentausbruct:

1. F ür $V d z=\frac{V}{a}$ :

$$
\begin{aligned}
\mathrm{Vdzp} & =\frac{\mathrm{Vdz}}{\mathrm{V}} \cdot 100, \mathrm{Vd} z=\frac{\mathrm{V}}{\mathrm{a}}, \text { folglich } \\
& =\frac{\frac{\mathrm{V}}{\mathrm{a}}}{\mathrm{V}} \cdot 100=\frac{100 \mathrm{~V}}{\mathrm{a} \mathrm{V}}=\frac{100}{\mathrm{a}} .
\end{aligned}
$$

3ahlenbeifpiel: $V=300 \mathrm{fm}, \mathrm{a}=60, \mathrm{~S} \underline{\underline{a}} \mathrm{D}=120 \mathrm{fm}$,

$$
\mathrm{Vd} z=\frac{300}{60}=5, \mathrm{Vdzp}=\frac{5}{300} \cdot 100=\frac{100}{60}=\frac{100}{\mathrm{a}}=1,67 \% \text {. }
$$

2. Fif $\mathbf{G d z}=\frac{V+S_{\underline{a}} D}{a}$ :

$$
\mathrm{Gdz} p=\frac{\frac{V+S_{\underline{a}} D}{a}}{V+S_{\underline{a}} D} \cdot 100=\frac{100\left(V+S_{\underline{a}} D\right)}{a(V+S \underline{\underline{a}} D)}=\frac{100}{a} .
$$

3ablenbeipier:

$$
\mathrm{Gd} z=\frac{300+120}{60}=7, \mathrm{Gd} z \mathrm{p}=\frac{7}{420} \cdot 100=\frac{100}{60}=\frac{100}{\mathrm{a}}=1,67 \% .
$$

Die betannten Gäßse über ben $1 z$ unb $\mathrm{d} z$ lauten:

1. Eteigt ber dz, fo ift $1 z$ größer, fint dz bagegen, fo ift $1 z<\mathrm{d}$.

2. Sm 3eitpunft ber "Rulmination" bes dz ift $1 z$ ibm gleich.

3. $\mathfrak{O}$ or ber Rulmination bez dz ift $1 z$ gröper, nach ber Rulmination kleiner alz $\mathrm{d} z$.

4. Der lz fann bereitz in ber Abnahme begriffen fein, wenn dz nod) fteigt. 


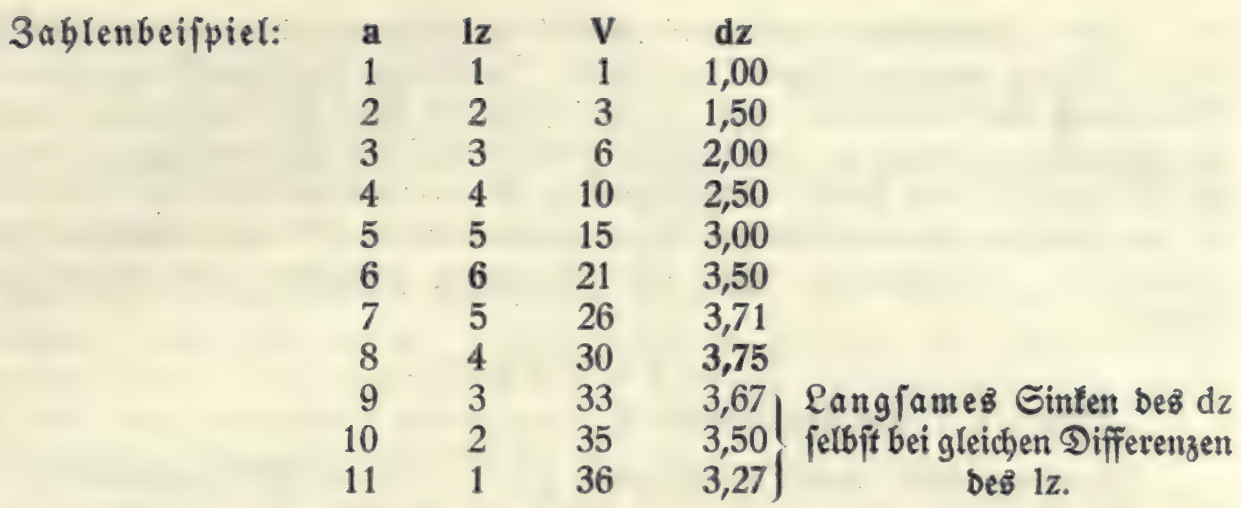

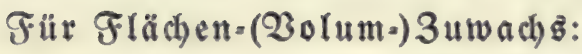

$$
\begin{aligned}
& \text { a) 2In Ėingelfämmen: } \\
& \begin{aligned}
1 z: d z & =d \pi b: \frac{\frac{d^{2} \pi}{4}}{a}=b: \frac{d}{4 a} ; b=\frac{1}{n}, \text { aljo } \\
& =\frac{4}{n} a: d .
\end{aligned}
\end{aligned}
$$

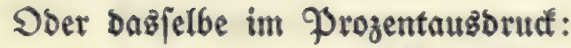

$$
1 z p: d z p=\frac{400}{n \cdot d}: \frac{100}{a}=\frac{400}{n} \cdot \frac{a}{100}: d=\frac{4}{n} a: d .
$$

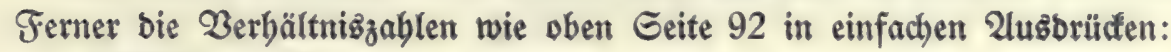

$$
\begin{aligned}
& \frac{\text { Etärfe } z}{\text { Stärte }}=\frac{2 b}{d}=\frac{2}{n \cdot d}=\ldots . . . .=\frac{b}{r}=\frac{1}{n \cdot r} \text {. } \\
& \frac{\text { Flächen } z}{\text { Fläc)e }}=\frac{\frac{4}{n} d}{d^{2}}=\frac{4}{n \cdot d}=\quad \therefore \quad=\frac{4 b}{d}=\frac{2 b}{r}=\frac{2}{n \cdot r} . \\
& \frac{\text { Fläd)en } l z}{\text { Flächen } d z}=\frac{\frac{4}{n} d}{\frac{d^{2}}{a}}=\frac{\frac{4}{n} \cdot a}{d}=\ldots . \quad . \quad=\frac{4 b}{\frac{d}{a}}=\frac{b}{\frac{r}{a}}=\frac{\frac{2}{n} \cdot a}{r} \text {. }
\end{aligned}
$$

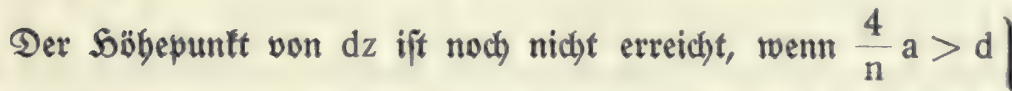

$$
\begin{aligned}
& \text { " } \mathrm{d} z \text { " erreicht, wenn ... } \frac{4}{\mathrm{n}} \mathrm{a}=\mathrm{d} \text { Schonung! } \\
& \mathrm{dz} \text { " überid)ritten, wenn . } \frac{4}{\mathrm{n}} \mathrm{a}<\mathrm{d} \text {, Ertwägung! }
\end{aligned}
$$

Borggreves "SAmtriebşformel" 1880. "Forft. Bl." 1881, G. 79 u. 197. Für Einzelftämme zutreffenb.

Die "Bobenreinertragglebre" will abmugen, wenn eine befriebigende $\mathfrak{B e r}=$ jinjung afler im Walbe angelegten 2 erte, unter Denen berjenige bez Solzoorratß voranfteht, nicht weiter zu erzielen iff. 


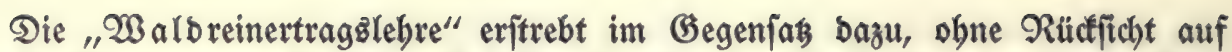
Das̊ im Walbe angelegte Rapital und beffen Berzinjung, Den böchjten burchjchnittlichen

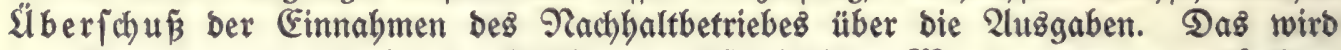
im allgemeinen erreicht bei ber bödhjten burchjdynittlichen 20 erterzeugung pro Seftar.

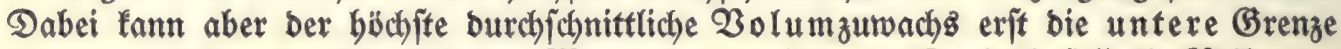
für ben böchjten burchichnittlichen $\mathfrak{B e r}_{\mathrm{t}}$ zumachs bilben. Deshalb foll bie Reibe ber vielfeitigften "Errwägungen" über bie 2lbnugung frübeftenz mit biefem 3eitpuntt einjersen.

b) $2 \mathfrak{n} \mathfrak{B}$ eftänben:

Gdyon G. L. Sartig vertritt:

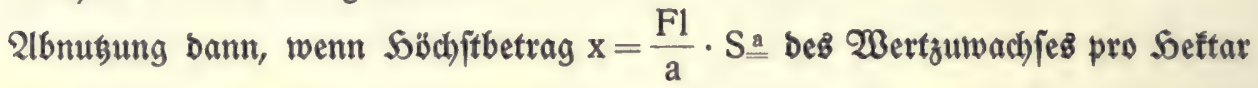
in a Sabren.

Beifpiel: Bringt ein Tiebertwald von 100 ha $\mathfrak{B a l b f l a ̈ c h e ~ b e i : ~}$

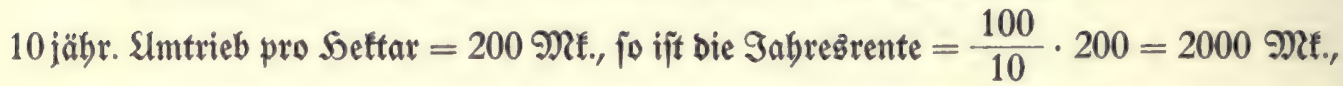
15 jäbr. 20 jähr.

Die Geite 101 befprod)ene Slmtriebsformel von Borggreve gibt, unter $\mathfrak{B e}$. nuksung bes Täfelchens Geite 83 , entiprechenb auf $\mathfrak{B}$ eftänbe übertragen:

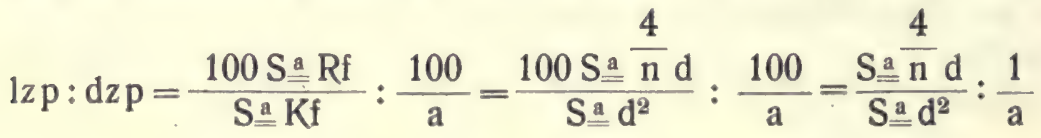

$$
\begin{aligned}
& =a \cdot S^{a} \frac{4}{n} d: S^{a} d^{2} \text {, ober unter Einjésen ber Gpaltennummer } \\
& =\mathrm{a} \cdot \mathrm{S}^{\mathrm{a}} \mathrm{Sp}_{\mathrm{p}}, 4: \mathrm{S}_{\underline{\mathrm{a}}}^{\mathrm{a}} \mathrm{Sp}_{\mathrm{p}} 3 \text {. } \\
& \begin{array}{l}
\geq \text { Echomung! } \\
<\text { Erroägung! }
\end{array}
\end{aligned}
$$

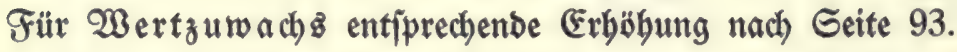

Sft bie für ben Einzelftamm zutreffende SAmtriebzformel $\frac{4}{\mathrm{a}} \mathrm{a} \gtreqless \mathrm{d}$ in ber vorftebenben Slmformung nach ber pogenannten Tafelmetbobe unbebenflich auf $\mathfrak{B}_{e}=$ ft änbe antwendbar? Dieje Frage wäre ogne weiteres zu bejaben, wenn bei Beftänden zur Simtriebabejtimmung $\mathfrak{n} \mathfrak{r}$ bie auf Den jeweiligen Borrat bezogenen 3uwad) $z=$ prozente berülffichtigt zu werben brauchten. - Die SAmtriebzbeftimmung nach bem böchiten DurdjichnittBertrage, bem jogenamnten "Walbreinertrage", forbert jeboch), Daß́

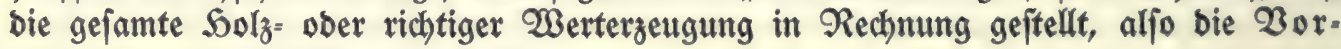
nugungen mit einbezogen werben.

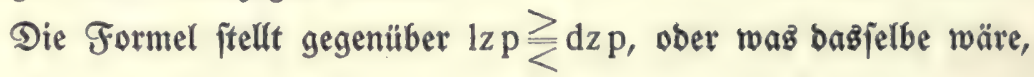
in einfachen abjoluten $\mathfrak{G} \mathfrak{r o ̈} \tilde{\beta}$ en

$$
1 \mathrm{z} \gtreqless \mathrm{dz} \text {. }
$$


Beim lzp Des (Einzelfiammes frebt nach ber (Grunbformel $p=\frac{z}{K} \cdot 100$ im शlenner alz Rapital bie gefamte bisherige Solzerzeugung beż Baumez,

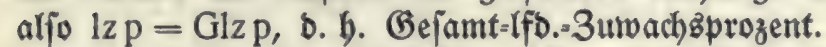

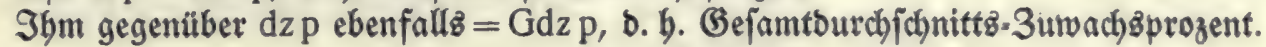
Daber ift auth bier bie Umtriebsformel $\frac{4}{\mathrm{n}} \mathrm{a} \gtreqless \mathrm{d}$ nicht anfechtbar.

Wie ftebt es bagegen mit bem gewöhnlichen lzp bes Beftanbes nach ber Tafelmetbobe? Sier fteht an ber gleichen Stelle im Renner alB Rapital nur ber gegenwärtige Zorrat $V$, aljo nur ein $\mathfrak{T}$ eil ber gejamten Solzerzeugung. Der anbere feblende Teil ift in ben bereitz entnommenen Bornubungżerträgen $S=D$ entbalten.

Beim Einzelftamm if beibes gleich, weil S a D nicht vorfommt.

Edjon läpt fich erfennen, wo bie 2 ege fich jheiben, man bebalte beghalb flar bas Folgenbe im 2luge:

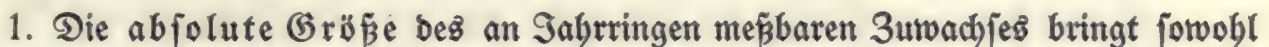
beim Einzelftamm wie beim Beftande ben gefamten gegenwärtigen

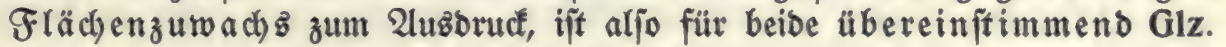

2. Die im lzp erfcheinende relative $\mathfrak{G}$ rößze wirb nach bem lanbläufigen $\mathfrak{B e}$ brauch nid)t auf gleid)geartete Rapitalgröpen bezogen, fonbern

a) beim Einzelftamm auf bie gefamte bisherige Solzerzeugung, wie fie zugleich in bem gegentwärtigen $\mathfrak{B}$ orrat entbalten ift, weil bier $\mathbf{V}=\mathbf{G z}$,

b) beim Beftand auf ben gegentwärtigen Borrat, nicht auf bie gefamte bisberige Solzerzeugung $\mathrm{Gz}=\mathrm{V}+\mathrm{S}$ 르, $\mathrm{V}<\mathbf{G z}$.

3. Ėg ift baher lzp

a) beim Cinzelftamm fowohl Vlzp wie Glzp,

b) beim 2 eftand in ber gewöbnlichen Fafiung nach bem शenner nur Vlzp, nicht aber Glzp, obgleich feine abjolute Größje ebenjo wie ber 3äbler bie (Befamtleiftung in fid fdhliept.

Die vorfommenden Berwedjelungen entifammen in ben meiften Fällen ber einfachen (Gleichftellung alles beffen, was unter ber Bezeichnung lzp auf ber einen uno dzp auf ber anberen Seite erfdceint.

Das gewöhnliche lzp beż Beftandez bebeutet aljo in jeiner relativen Beziehung

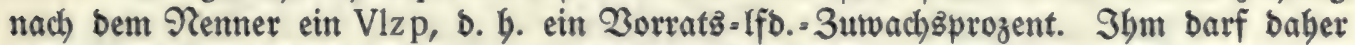
aud) nur ein ebenjoldhez Vdzp gegenubbergeftellt werben. Dieje Gegenüberiftellung ift in ber Formel nach ber Tafelmethode unanfed)tbar ridhtig geidheben.

(E⿱ fragt fich nur, ob wir mit biefer (Begenüberftellung ben 3eitpunft bes Göchiten Durdjichnittsertragez ber gejamten (Erzeugung richtig genug bejtimmen fönnen, ober ob bie Gegenüberftellung bez Vlzp und Vdzp zu anberen Errgebniffen

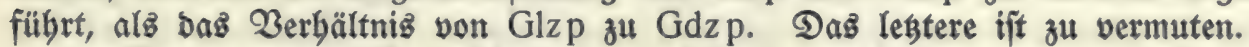

Borggreve, "Forjtabjchäsung" 1888 Geite 84 fi., vertritt ben Gtanopunft,

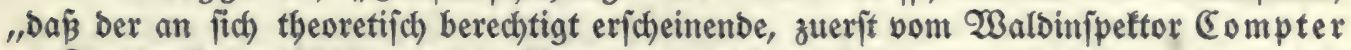
zu Freubenftabt 1881 gemachte Einwand zunächlt infofern unerbeblich fei, als bie Sinterfuctung, am bisberigen und bleibenben $\mathfrak{S}$ auptbeftanbe vorgenommen, für ben

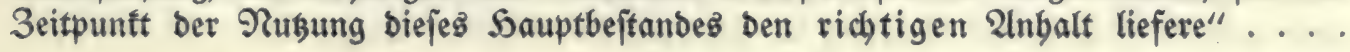


Weife, "Münbener Sefte" VII 1895 Geite 2: "Die bisher aufgejtellten Geję̧e über bas gegenjeitige Zerbältniz bez $\mathrm{dz}$ und $\mathrm{lz}$ find richtig, wenn man bie

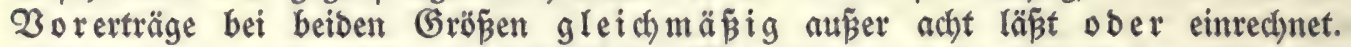
Bisher bat man fie völlig vernachläffitgt. Man fann uno barf bież aber nidyt tun, wenn man nid)t zu faljchen 2luffafjungen gelangen will."

Siernach erforbert aljo bie SImtriebšbeftimmung bie Beziebung auf Das Gdzp, um mit ber wabren (Gefamtleiffung zu rechnen. (Fin Gdzp mus aber fich gegenüber auch ein Glzp anftatt eines Vlz p haben.

Das fübrt zu ber folgenben, von ber lanbläufigen abrweidbenben 2luffafiung:

$$
\begin{aligned}
& \mathrm{Vlz}=\frac{\mathrm{V} \text { jebt }-\mathrm{V} \text { friber }}{3 \text { uwachobauer }} \\
& \mathrm{Glz}=\frac{(\mathrm{V}+\mathrm{S} \underline{\mathrm{a}} \mathrm{D}) \text { jest }-(\mathrm{V}+\mathrm{S} \stackrel{\mathrm{a}}{=} \mathrm{D}) \text { friiber }}{\text { 3uwact)gbauer }} .
\end{aligned}
$$

Dementiprechend enthält ber Glz nicht nur ben alß Nebrung beß Zorratß̊

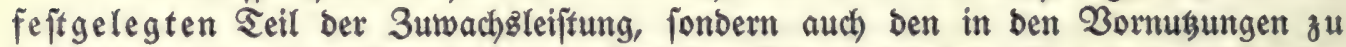
bebenben ober bereits gebobenen 2inteil. (Es wäre babei aljo nit ber gefamten Solzerzeugung auf ber Flächeneinbeit zu rechnen.

Ěz Darf baber nicht beiken: Vlzp $\gtreqless G d z p$,

$$
\text { fonbern müßste beiñen: Glzp } \gtreqless \mathrm{Gdzp} \text {, }
$$

b. h. aljo nicht $\frac{V l z}{V} \cdot 100 \geqq \frac{V+S a D}{\frac{a}{C+S a D}} \cdot 100$,

$$
\text { fonbern } \frac{G l z}{V+D} \cdot 100 \gtreqless \frac{V+S_{a} D}{\frac{a}{V+S}} \cdot 100
$$

ober in einfactien abjoluten Größ̨en

$$
\mathrm{Gl} z \stackrel{\mathrm{Gd} z}{<}
$$

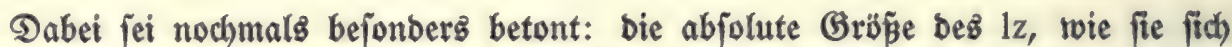
aus ben Ringbreiten am Beftande mit Silfe ber vereinfachten 3uwachb̈formeln er= mitteln läpt, zeigt ben $\mathrm{Glz}$, nicht aber Den Vlz. Ober beutlicher gejagt, man erbält

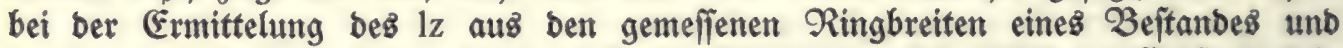
Der Daraus mit jenen Formeln bergeleiteten Berechnung ber abjoluten Größ̈e bę̧ $1 z$ nicht ben gegenwärtigen $\mathrm{Vlz}$, jonbern ben $\mathrm{Glz}$, wie er jegt uno für bie nädjite 3ufunft in bie (Erid)einung tritt.

Mit anberen Worten: ber mittlere Beftanbżumachs ber Tafelmetbobe Geite 83 ff., wie er fich aus ber Mefinung ber Ringbreiten ergibt, bringt bie gegen= wärtige Gefamtleiftung zum 2lubbrud, aber bezogen im Nenner nur auf ben Borrat.

3ahlenbeifpiel: Eేz jei bie mebrfach erwähnte Dänifche 3uwach büberfidst, "Münbener Sefte" XIII Geite 141 fĩ., gewoühlt, alB eines Bejtandes mit lichterer

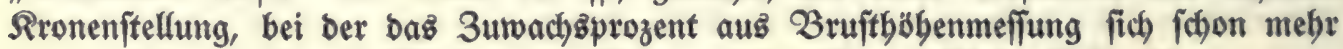
Dem กนฮื ber richtigeren Mefhung in Etammmitte näbcrt. Eiebe Ecite 81. 
Die Tafel gibt für båี 2llter

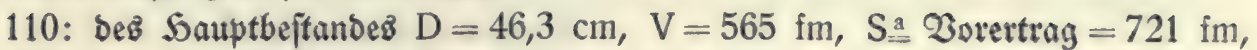

120: Deģ Sauptbeftandes $\mathrm{D}=50,8 \mathrm{~cm}, \mathrm{~V}=595 \mathrm{fm}, \mathrm{S}$ a Borertrag $=787 \mathrm{fm}$, $\mathrm{Vd} z=4,96 \mathrm{fm}, \mathrm{Gdz}=11,52 \mathrm{fm}$.

(Tanac) Iabregringbreite $=0,225 \mathrm{~cm}, \operatorname{lzp}=\frac{400 \cdot \mathrm{b}}{\mathrm{d}}=\frac{400 \cdot 0,225}{50,8}=\frac{90,0}{50,8}$ $=1,77 \% .1 \mathrm{z}=1 \mathrm{zp} \times \mathrm{V}=1,77 \times 595=10,5 \mathrm{fm}$.

Ober $\operatorname{lzp}=\frac{100 \frac{4}{\mathrm{n}} \mathrm{d}}{\mathrm{d}^{2}}=\frac{100 \cdot 4 \mathrm{bd}}{\mathrm{d}^{2}}=\frac{100 \cdot 4 \cdot 0,225 \cdot 50,8}{2580,64}=\frac{4572,00}{2580,64}=1,77 \%$,

$1 z=10,5 \mathrm{fm}$ wie oben.

(Gegenüber ben 2lngaben ber 3uwachg̈überficht ift biefez aber ber Glz, benn $\mathrm{Vlz}=\frac{\mathrm{V} \text { jegt }-V \text { früber }}{3 \text { utwact)gbater }}=\frac{595-565}{10}=\frac{30}{10}=3,0 \mathrm{fm}$,

$$
\begin{aligned}
\mathrm{Glz} & =\frac{(\mathrm{V}+\mathrm{S} \text { a } D) \text { jegt }-\left(\mathrm{V}+\mathrm{S}_{\mathrm{a}} \mathrm{D}\right) \text { früher }}{3 \text { wwachsbauter }}=\frac{(595+787)-(565+721)}{10} \\
& =\frac{1382-1286}{10}=\frac{96}{10}=9,6 \mathrm{fm} .
\end{aligned}
$$

Die 2lbweidhung 10,5 gegen 9,6 fm ertlärt fith baraus, baß bie gewählte 2lut

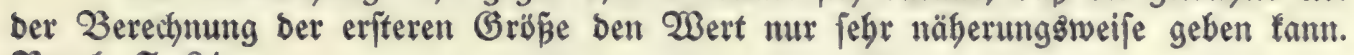
Zergl. G. 84.

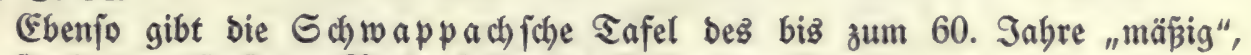
Dann "fitart" Durchforjteten $2 u c h$ enbeftanbes II für bas 2ltter

115: Deళ Sauptbeftanbez $\mathrm{D}=31,8 \mathrm{~cm}, \mathrm{~V}=581 \mathrm{fm}, \mathrm{S}$ a Borertrag $=393 \mathrm{fm}$, 120: Deళ Sauptbeftanbeß $\mathrm{D}=32,8 \mathrm{~cm}, \mathrm{~V}=595 \mathrm{fm}, \mathrm{S}$ a Oorertrag $=419 \mathrm{fm}$, $\mathrm{Vdz}=4,96 \mathrm{fm}, \mathrm{Gdz}=8,45 \mathrm{fm}$.

Sabrringbreite $=0,1 \mathrm{~cm}, 1 \mathrm{zp}=\frac{400 \cdot 0,1}{32,8}=1,22 \%, 1 \mathrm{z}=1,22 \times 595=7,26 \mathrm{fm}$, wäbrend nach ben Tafelangaben iff:

$$
\begin{aligned}
& \mathrm{Vlz}=\frac{\mathrm{V} \text { jefst }-\mathrm{V} \text { früber }}{3 \text { uwach soauer }}=\frac{595-581}{5}=\frac{14}{5}=2,8 \mathrm{fm} \text {, }
\end{aligned}
$$

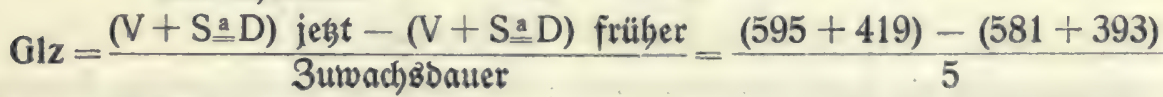

$=\frac{1014-974}{5}=\frac{40}{5}=8,0 \mathrm{fm}$. 2ljo auch bier nid)t Dem Vlz, fonbern bem

Glz am nächjiten liegent.

Da es fich mithin in bem aus ben Ringbreiten mit jenen 3uwachsformeln gefundenen WBerte um Den Glz hanbelt, fo jollte igm aud) ber Gdz gegenüber= geffellt twerben.

$\mathrm{Gd} z$ if $\mathrm{aber}=\frac{\mathrm{V}+\mathrm{S} \underline{\mathrm{a}} \mathrm{D}}{\mathrm{a}}$,

$\mathrm{Vdz}$

$$
=\frac{\mathrm{V}}{\mathrm{a}}-\text { Daraub folgt: }
$$




$$
\begin{aligned}
& \mathrm{Gdz}=\frac{\mathrm{V}}{\mathrm{a}} \cdot \frac{\mathrm{V}+\mathrm{S} \underline{\mathrm{a}} \mathrm{D}}{\mathrm{V}}=\mathrm{Vdz} \cdot \frac{\mathrm{V}+\mathrm{S} \underline{\mathrm{a}} \mathrm{D}}{\mathrm{V}}, \\
& \mathrm{Vdz}=\mathrm{Gdz} \cdot \frac{\mathrm{V}}{\mathrm{V}+\mathrm{S}=} .
\end{aligned}
$$

Das gibt mit ben 3ablen ber $\mathscr{D} a ̈ n i f \mathfrak{f}$ en 3 wwachgüberfict)t:

$$
\begin{aligned}
& \mathrm{Vdz}=4,96 \mathrm{fm}, \mathrm{Gdz}=11,52 \mathrm{fm}, \mathrm{V}=595 \mathrm{fm} \text {, } \\
& \mathrm{V}+\mathrm{S} \stackrel{\mathrm{a}}{\mathrm{D}}=595+787=1382 \mathrm{fm} \text {, } \\
& \mathrm{Gd} z=\mathrm{Vdz} \cdot \frac{\mathrm{V}+\mathrm{S} \underline{\underline{a} \mathrm{D}}}{\mathrm{V}}=4,96 \cdot \frac{1382}{595}=11,52 \mathrm{fm} \text {, } \\
& \mathrm{Vd} z=\mathrm{Gdz} \cdot \frac{\mathrm{V}}{\mathrm{V}+\mathrm{S} \stackrel{\mathrm{a}}{\mathrm{D}}}=11,52 \cdot \frac{595}{1382}=4,96 \mathrm{fm} \text {. }
\end{aligned}
$$

3ur weiteren Darlegung Der $\mathfrak{B}$ orggrevefhen Smtriebşbeftimmung an $\mathfrak{B}_{e}=$ ftänoen möge noch folgenbez 3ablenbeifpiel bienen:

(E⿱ jei $\mathrm{V}=300 \mathrm{fm}, \mathrm{S}=\mathrm{a}=120 \mathrm{fm}, \mathrm{a}=60$, lzp nach ber Tafelmethode $=2 \%$; Dann if $\mathrm{Glz}=6 \mathrm{fm}, \mathrm{Vdz}=5 \mathrm{fm}, \mathrm{Gdz}=7 \mathrm{fm}$.

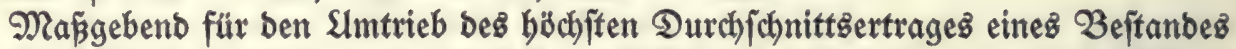

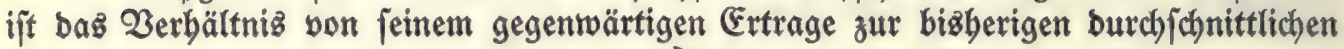
Gejamtleifrung, aljo bier: Glz: Gdz, Glz $\gtreqless \mathrm{Gdz}, 6<7$. "Ërwägung"!

Daşfelbe wirb im Prozentausbru dé ber Safelmetbobe nur richtig, wenn auch bier gleichartig bezogen auf $\mathrm{V}+\mathrm{S}$ a $\mathrm{D}, \boldsymbol{b}$. b.

$$
\begin{aligned}
& \text { Glz p }=\frac{G l z}{V+S_{\underline{a}} D} \cdot 100=\frac{6}{420} \cdot 100=1,43 \% \text {, } \\
& \mathrm{V}+\mathrm{S} \underline{\mathrm{a}} \mathrm{D} \\
& \operatorname{Gdzp}=\frac{\mathrm{a}}{\mathrm{V}+\mathrm{S}_{\mathrm{a}} \mathrm{D}} \cdot 100=\frac{7}{420} \cdot 100=1,67 \% \text {, alpo }
\end{aligned}
$$

Glzp : Gdzp, Glzp $\gtreqless G d z p=1,43<1,67$, und zwar zutreffend $6: 7=1,43: 1,67$.

Wobl nicht in gleicher $\mathfrak{B}$ eife brauchbax bürfte zu obiger Slmtriebsbejtimmung bie an fict) richtige 2 lnwenbung ber aber auf ibrer rechten Geite $\mathfrak{n} u \mathfrak{r}$ auf ben gegenwärtigen Borrat bezogenen und beşalb nur mit Vdz rechnenden Formel nach ber Tafelmethobe fein, b. h.:

Glz:Vdz, Glz $\gtreqless V d z, 6>5 ;$ Dber im Prozentaugbrut:

Glzp : Vdzp, Glzp $\gtreqless V d z p, 2>1,67$ "Gd)onung"!

Es bietet aljo bie Tafelmethode zwar ein febr einfaches 2 erfabren zur (Ermittelung

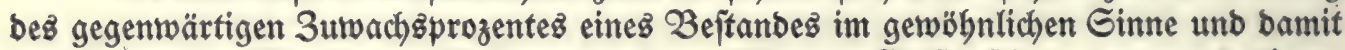
Das bequemite Mittel zur Beftimmung Der abfoluten Garb́̈e feiner gegentwärtigen Befamtleiftung, würbe aber burdh einfacbe Slmitelfung ber Gilieber in ber gegebenen

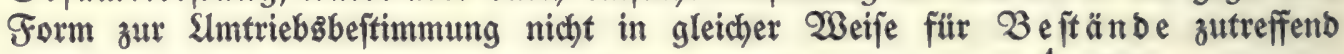
verwendbar fein, wie für ben Einzelftamm bie Slmtriebsformel $\frac{4}{\mathrm{n}} \mathrm{a} \gtreqless \mathrm{d}$.

Wie oben gezeigt, entbält bie Tafelmethobe in ibrer Slmjteflung auf ber rechten Geite ben Vdz, während bie Ermittelung Dez $1 z$ für bie linfe Geite zu bem Glz fübrt.

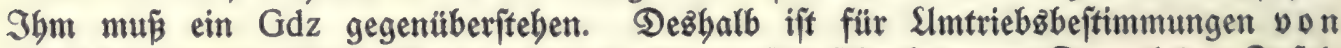
Beftänben im Gime Borggrebes bie an fich febr bequeme Formel ber Tafel- 
methobe entfprechend umzugeftalten, und zwar am einfachjêten, wenn auf ber rechten Eeite anftatt Vdz ber Gdz gejegt wirb, b. h.

$$
\mathrm{Vdz} \cdot \frac{\mathrm{V}+\mathrm{S} \stackrel{\mathrm{a}}{=} \mathrm{V}}{\mathrm{V}} \text {, weil } \mathrm{Gdz}=\mathrm{Vdz} \cdot \frac{\mathrm{V}+\mathrm{S}=\mathrm{a}}{\mathrm{V}} \text {. }
$$

Man hat alio in ber $\mathfrak{B}$ orggreveichen Formel für 3 ejtänbe entweber bie rechte Geite mit $\frac{V+S=D}{V}$ ober bie linfe Geite mit $\frac{\mathrm{V}}{\mathrm{V}+\mathrm{S} \underline{\mathrm{a}} \mathrm{D}}$ zu multiplizieren, o. b. zu jegen anftatt Deż ję̧igen Glzp $\gtreqless V d z p=a \cdot S=\frac{4}{n} d \gtreqless S^{a} d^{2}$

ธดษ วนtreffenbere: $\mathrm{Glzp} \gtreqless \mathrm{Gdzp}=\mathrm{a} \cdot \mathrm{S}=\frac{4}{\mathrm{n}} \mathrm{d} \geqq \mathrm{S}=\mathrm{d}^{2} \cdot \frac{\mathrm{V}+\mathrm{S} \underline{\mathrm{a}} \mathrm{D}}{\mathrm{V}}$

$$
\text { ober } \frac{V}{V+S^{a} D} \cdot a \cdot S_{=}^{a} \frac{4}{n} d \stackrel{<}{\gtrless}=d^{2} \text {. }
$$

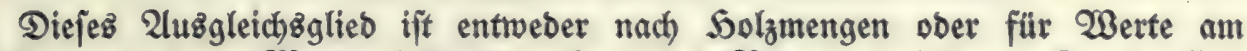

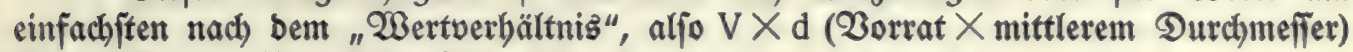
binzuzufïgen. Bergleidhe Geite 95.

3ablenbeifpiel: $\mathfrak{E}$ b fei wieber wie oben Geite 106: $\mathrm{a}=60, \mathrm{~d}=16, \mathrm{n}=12,5, \mathrm{lzp}=2 \%$; ferner:

a) im $\mathfrak{S} \circ \mathfrak{l z}: V=300 \mathrm{fm}, S \underline{a} D=120 \mathrm{fm}, 1 z=6 \mathrm{fm}, V d z=5 \mathrm{fm}, \mathrm{Gdz}=7 \mathrm{fm}$;

b) im $\mathscr{B}$ ert: $V=5000, S \underline{a} D=1000,1 z=100$,

$$
\mathrm{Vd} z=83,33, \mathrm{Gd} z=100 \text {. }
$$

Nach ber Borggrevefhen Formel: a. $S \stackrel{a}{a} \frac{4}{n} d \gtreqless S \underline{\underline{a}} \mathrm{~d}^{2}$,

$$
\begin{aligned}
& =60 \cdot \frac{4}{12,5} \cdot 16 \gtreqless 256 \\
& =307,2>256 \text { "ङ } \text { Sd)onung }^{4} !
\end{aligned}
$$

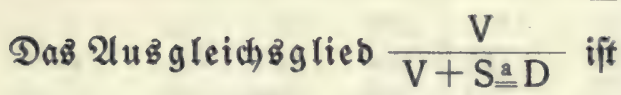

a) im Solz: $\frac{300}{420}=\frac{5}{7}$, aljo bas auf bie Befamtleifung bezogene $\mathfrak{B}$ er: לดălniż von $\frac{\mathrm{Glz}}{\mathrm{Gdz}}=\frac{5}{7} \cdot \frac{307,2}{256}=\frac{1536}{1792}=\frac{6}{7}$ wie Geite 106 .

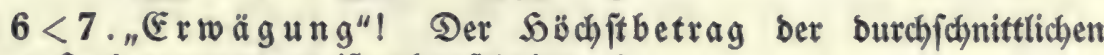
Gejamt $=$ Golzerzeugung ift überfdritten!

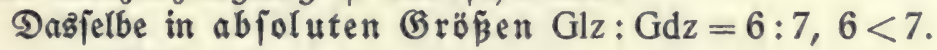

b) im $\mathfrak{B}$ ert: $\frac{5000}{6000}=\frac{5}{6}$, aljo baz auf bie Gefamtleiftung bezogene

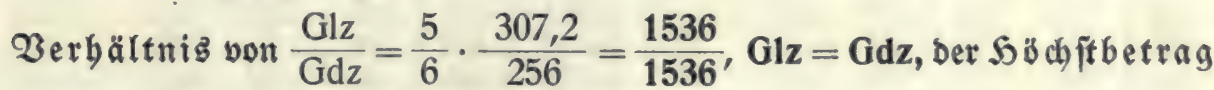

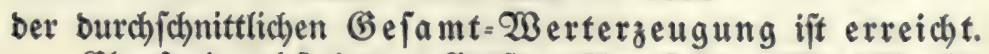

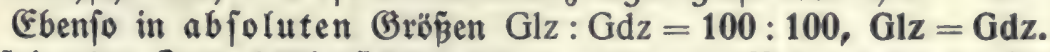

Die folgenben 3uwachsüberfidhten mögen weiter zur Beleuchtung ber berilbrten

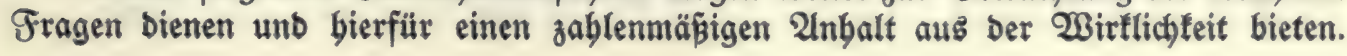


Mit biejen von befannten Ģröß̄en aus ber Wirtlichfeit abgeleiteten Beifpielen foll verfucbt werben, rechnungęmäpig vor 2 ugen zu fübren:

A) in $\mathfrak{S o l} z$,

B) im $\mathfrak{B}$ ertverbåltnis:

a) Den 3eitpunft ber Rulmination von Gdz;

b) bie Gdhrwierigfeit, von bem EFintritt ber Rulmination von Vdz mit einiger Gicherbeit auf biejenige von $\mathbf{G d z}$ zu ichlię̧en;

c) baz fpätere (Fintreten Der Rulmination bei Gdz alsె bei Vdz;

d) $\mathfrak{D a b}$ erheblich fpätere Eintreten ber Rulmination von Gdz im Wertverbältris als im Solz; anjchließend baran:

e) ben Cimflup ber Eingriffe in Den Sauptbeftand auf ben 2 ert. วนพ

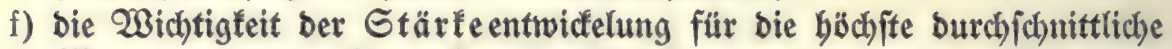
Werterzeugung. Shre Rulmination ftebt, wie bereits "Mianbener Shefte" XIII augigejprodsen, immer erfít zu erwarten, wenn biejenige Stärfe überfdritten ift, bis zu welcher bie Einbeitsmerte fteigen wie bie Durchmeffer. Damit rüaț bie Gtärte febr augenfällig in ben Borber=

S̈beriet) 1.

\begin{tabular}{|c|c|c|c|c|c|c|c|c|c|c|c|c|c|}
\hline \multirow{4}{*}{ 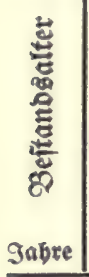 } & \multicolumn{7}{|c|}{ 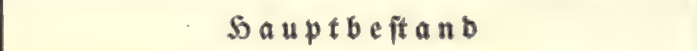 } & \multicolumn{6}{|c|}{ Entnommen } \\
\hline & \multirow{3}{*}{$\begin{array}{l}\text { Stamm: } \\
\text { zabl } \\
\text { Etild }\end{array}$} & \multirow{3}{*}{$\begin{array}{c}\text { Mrittels } \\
\text { boble } \\
\mathrm{m}\end{array}$} & \multirow{3}{*}{$\begin{array}{c}\text { Găbe } \\
\text { lidbe } \\
\text { Gtärte. } \\
\text { 3u= } \\
\text { nabme } \\
\text { mm }\end{array}$} & \multirow{3}{*}{$\begin{array}{c}\text { शitte } \\
\text { Iere } \\
\text { Gtätre } \\
\text { in } \\
\text { 3ruft } \\
\text { bobe } \\
\mathrm{cm}\end{array}$} & \multirow{3}{*}{$\begin{array}{c}\text { Cin: } \\
\text { beitg: } \\
\text { wert } \\
\text { faut von } \\
100 \text { auf }\end{array}$} & \multirow{3}{*}{$\begin{array}{c}\text { Borrat } \\
\mathrm{fm}\end{array}$} & \multirow{3}{*}{$\begin{array}{c}\text { Sm } \\
2 B e r t s \\
\text { verbăttut } \\
\text { gerteinb. }\end{array}$} & \multirow{3}{*}{$\begin{array}{l}\text { Etamm: } \\
\text { zabr } \\
\text { Etitat }\end{array}$} & \multirow{3}{*}{$\begin{array}{c}\text { sotittel- } \\
\text { böbe } \\
\text { m }\end{array}$} & \multirow{3}{*}{$\begin{array}{c}\text { פvitt- } \\
\text { lere } \\
\text { Stärte } \\
\text { in } \\
\text { Bruft- } \\
\text { bobbe } \\
\mathrm{cm} \\
\end{array}$} & \multirow{3}{*}{$\begin{array}{l}\text { Cein: } \\
\text { betts: } \\
\text { wert } \\
\text { fälft von } \\
100 \text { auf }\end{array}$} & $\begin{array}{r}\text { Bor: } \\
\text { ertrag }\end{array}$ & \multirow{2}{*}{$\begin{array}{c}\begin{array}{c}\text { Im } \\
\text { 2Bert } \\
\text { verbattnis }\end{array} \\
20 \text { 9abre }\end{array}$} \\
\hline & & & & & & & & & & & & & \\
\hline & & & & & & & & & & & & fin & $2 B \in t$ \\
\hline 40 & 3430 & 10,2 & 3,0 & 8,3 & - & 125 & 1038 & 1680 & 7,7 & 5,4 & - & 16 & 82 \\
\hline 60 & 1810 & 15,8 & 2,6 & 14,0 & -- & 266 & 3724 & 1620 & 12,4 & 9,7 & - & 49 & 396 \\
\hline 80 & 1150 & 20,4 & 2,2 & 18,6 & $\ldots$ & 378 & 7031 & 660 & 15,7 & 13,3 & - & 60 & 729 \\
\hline 100 & 800 & 24,0 & 2,2 & 23,0 & - & 460 & 10580 & 350 & 19,7 & 16,0 & - & 65 & 987 \\
\hline 120 & 598 & 26,5 & 2,0 & 27,0 & $\ldots$ & 524 & 14148 & 202 & 22,5 & 19,1 & - & 64 & 1153 \\
\hline 140 & 477 & 28,2 & 1,6 & 30,5 & - & 574 & 17507 & 121 & 24,0 & 23,1 & - & 61 & 1314 \\
\hline 160 & 397 & 29,8 & 1,6 & 33,7 & - & 603 & 20321 & 80 & 24,7 & 25,6 & - & 56 & 1382 \\
\hline \multirow[t]{3}{*}{180} & \multirow[t]{3}{*}{333} & \multirow[t]{3}{*}{31,0} & \multirow[t]{3}{*}{1,4} & \multirow[t]{3}{*}{36,8} & \multirow[t]{3}{*}{ - } & \multirow[t]{3}{*}{630} & \multirow[t]{3}{*}{23184} & 64 & \multirow[t]{3}{*}{25,1} & \multirow[t]{3}{*}{28,0} & \multirow{3}{*}{-- } & 50 & \multirow[b]{3}{*}{ exicht 2 . } \\
\hline & & & & & & & & 4777 & & & & 421 & \\
\hline & & & & & & & & & & & & Sีberficht 2 . & \\
\hline 40 & 3070 & 12,0 & 2,8 & 10,9 & $\ldots$. & 211 & 2300 & 3430 & 8,2 & 7,5 & - & 52 & 329 \\
\hline 60 & 1490 & 15,9 & 3,0 & 16,8 & 一 & 292 & 4906 & 1580 & 12,3 & 11,2 & - & 70 & 693 \\
\hline 80 & 870 & 19,1 & 2,8 & 22,8 & $\ldots$ & 354 & 8071 & 620 & 14,2 & 15,4 & - & 65 & 895 \\
\hline 100 & 638 & 21,9 & 2,1 & 27,3 & - & 400 & 10920 & 232 & 17,2 & 18,8 & - & 44 & 771 \\
\hline 120 & 512 & 24,1 & 1,6 & 30,7 & & 431 & 13232 & 126 & 17,5 & 20,9 & 一 & 32 & 641 \\
\hline 140 & 422 & 25,8 & 1,6 & 33,9 & - & 463 & 15696 & 90 & 17,8 & 23,1 & - & 28 & 624 \\
\hline 160 & 358 & 27,3 & $1, A$ & 36,8 & - & 492 & 18106 & 64 & 18,1 & 25,0 & - & 25 & 608 \\
\hline \multirow[t]{2}{*}{180} & 311 & 28,4 & 1,3 & 39,5 & 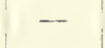 & 519 & 20501 & 47 & 18,4 & 26,9 & - & 24 & 629 \\
\hline & & & & & & & & 6189 & & & & 340 & \\
\hline
\end{tabular}


grunb. C⿺廴 liegt Daber nabe, von ber Slntergrenze einer Umtriebs.

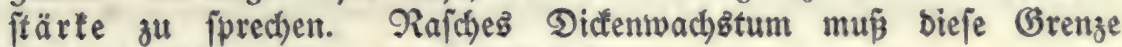
früber erreichen laffen, langfameż fpäter.

Die S̈berfichten folgen ben Gdhwappad) fhen Tafeln unb geben ben Erttag

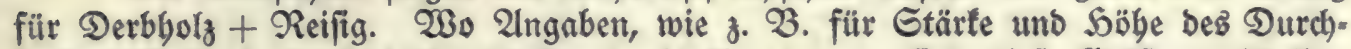
forjtungşbejtanbes, nicht obne weiteres ablešbar waren, find bieje Girößen mittelbar аแริ Den in ben Tafeln gegebenen Anterlagen bergeleitet. Fïr bie über Den Rabmen

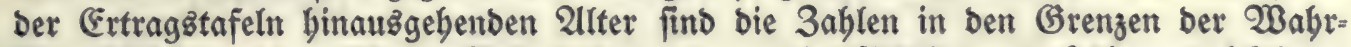
(cheinlidfeit weitergefiibrt. 2Inbalt boten bazu bie Gtärfe= unb Söbenentwiçelung,

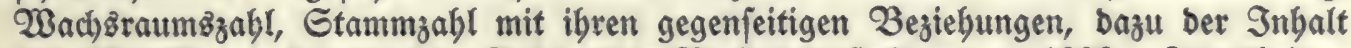

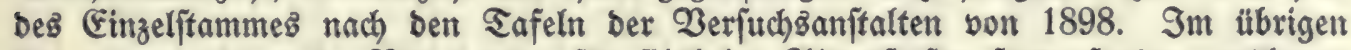
bat bie grunblegenbe $B e r e c h n u n g$ für 5 jäbrige alterg]tufen ftattgefunben, wäbrenb bier bie 3 ablen für je 20 Sabre riebergegeben finb. Daher fanm fidh $z$. $\mathfrak{B}$. ber Zorertrag im Wertverbältniß nicht genau mit bem Probult aus bem bier ftehenben Feftmeterbetrag mal Durd)mefijer becten u. Dergl. m.

Zortweg fint in Den Śberfichten 1 biż 3 für bie Mitteltafle von Budbe, Riefer und Fichte bie. Reiftungen bei mäßiger. Durdbforitung im Beberrfdeten mit bauernoer Erbaltung bes vollen Gdhluffes im oberen Rronenraum Dargeftellt,

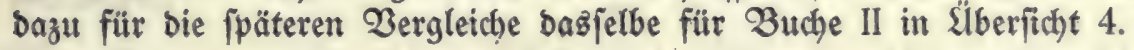

9utbe III 1893.

\begin{tabular}{|c|c|c|c|c|c|c|c|c|c|c|c|c|}
\hline \multicolumn{2}{|c|}{$\begin{array}{l}\text { Befamtertrag im } \\
\text { Wertverbältuis }\end{array}$} & \multicolumn{4}{|c|}{ In $\mathrm{Sol}_{3}$} & \multicolumn{6}{|c|}{ 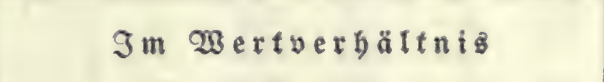 } & \multirow{3}{*}{ 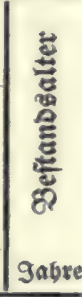 } \\
\hline $\mathrm{S} \stackrel{\mathrm{a}}{=} \mathrm{D}$ & $\mathrm{V}+\mathrm{S} \underline{\text { a }} \mathrm{D}$ & Vlz & $\mathrm{Vdz}$ & Glz & $\mathrm{Gdz}$ & Vlz & $\mathrm{Vdz}$ & Glz & Gdz & Gwz & $\begin{array}{l}\text { Davon } \\
\text { werben } \\
\text { firfitg }\end{array}$ & \\
\hline \multicolumn{2}{|c|}{ etnbetien } & \multicolumn{4}{|c|}{ Fefit et ex } & \multicolumn{4}{|c|}{ Bertetnbetten } & \multicolumn{2}{|c|}{ Prozente } & \\
\hline 82 & 1120 & 6,8 & 3,1 & 8,8 & 3,5 & 84 & 26 & 95 & 28 & 9,1 & 1,1 & 40 \\
\hline 478 & 4202 & 6,6 & 4,4 & 9,2 & 5,5 & 153 & 62 & 178 & 70 & 4,8 & 0,7 & 60 \\
\hline 1207 & 8238 & 5,0 & 4,7 & 8,2 & 6,3 & 171 & 87 & 213 & 103 & 3,0 & 0,6 & 80 \\
\hline 2194 & 12774 & 3,6 & 4,6 & 6,8 & 6,5 & 180 & 106 & 231 & 128 & 2,2 & 0,5 & 100 \\
\hline 3347 & 17495 & 3,0 & 4,4 & 6,2 & 6,5 & 183 & 118 & 244 & 146 & 1,7 & 0,4 & 120 \\
\hline 4661 & 22168 & 2,2 & 4,1 & 5,2 & 6,4 & 157 & 125 & 226 & 158 & 1,3 & 0,4 & 140 \\
\hline 6043 & 26364 & 1,6 & 3,8 & 4,2 & 6,1 & 149 & 127 & 216 & 165 & 1,1 & 0,3 & 160 \\
\hline 7397 & 30581 & 1,4 & 3,5 & 3,6 & 5,8 & 132 & $\begin{array}{l}129 \\
\gamma\end{array}$ & 199 & $\begin{array}{c}170 \\
\downarrow\end{array}$ & 0,9 & 0,3 & 180 \\
\hline \multicolumn{13}{|c|}{ Riefer III 1889.} \\
\hline 329 & 2629 & 5,0 & 5,3 & 8,0 & 6,6 & 107 & 58 & 129 & 66 & 5,6 & 1,0 & 40 \\
\hline 1022 & 5928 & 3,6 & 4,9 & 7,4 & 6,9 & 143 & 82 & 185 & 99 & 3,8 & 0,9 & 60 \\
\hline 1917 & 9988 & 2,8 & 4,4 & 5,6 & 6,8 & 159 & 101 & 202 & 125 & 2,5 & 0,5 & 80 \\
\hline 2688 & 13608 & 2,0 & 4,0 & 4,0 & 6,3 & 133 & 109 & 170 & 136 & 1,6 & 0,3 & 100 \\
\hline 3329 & 16561 & 1,7 & 3,6 & 2,8 & 5,8 & 116 & 110 & 158 & 138 & 1,2 & 0,3 & 120 \\
\hline 3953 & 19649 & 1,6 & 3,3 & 3,0 & 5,4 & 124 & 112 & 154 & 140 & 1,0 & 0,2 & 140 \\
\hline 4561 & 22667 & 1,4 & 3,1 & 2,6 & 5,1 & 117 & 113 & 151 & 142 & 0,8 & 0,2 & 160 \\
\hline 5190 & 25691 & 1,2 & 2,9 & 2,4 & 4,8 & 109 & $\begin{array}{l}114 \\
\downarrow\end{array}$ & 151 & $\begin{array}{c}143 \\
\downarrow\end{array}$ & 0,7 & 0,2 & 180 \\
\hline
\end{tabular}


İberfitct 3.

\begin{tabular}{|c|c|c|c|c|c|c|c|c|c|c|c|c|c|}
\hline \multirow{3}{*}{ 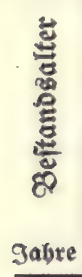 } & \multicolumn{7}{|c|}{$\mathfrak{S} a \mathfrak{u} \mathfrak{p} t \boldsymbol{b} \in$ ft $a n b$} & \multicolumn{6}{|c|}{ Entnommen } \\
\hline & \multirow{2}{*}{$\begin{array}{c}\text { Etamm } \\
z \mathfrak{a b l} \\
\text { Gtilat }\end{array}$} & \multirow{2}{*}{$\begin{array}{c}\text { פRittel- } \\
\text { bobe } \\
\text { m }\end{array}$} & \multirow{2}{*}{$\begin{array}{c}\text { Säbr. } \\
\text { Itb̧e } \\
\text { Gtärfe= } \\
\text { 3ü } \\
\text { nabme } \\
\text { mm }\end{array}$} & \multirow{2}{*}{$\begin{array}{l}\text { gottt. } \\
\text { Iere } \\
\text { Gtarte } \\
\text { in } \\
\text { 3ruit. } \\
\text { bobbe } \\
\mathrm{cm}\end{array}$} & \multirow[t]{2}{*}{$\begin{array}{c}\text { Ein: } \\
\text { better } \\
\text { wert } \\
\text { fǘut von } \\
100 \text { auf }\end{array}$} & \multirow[t]{2}{*}{ Borra } & \multirow{2}{*}{$\begin{array}{c}\text { Sm } \\
\text { wert- } \\
\text { verbättnts } \\
\text { שerteinb. }\end{array}$} & \multirow{2}{*}{$\begin{array}{c}\text { Etamm } \\
\text { zabl } \\
\text { Etila }\end{array} \mid$} & \multirow{2}{*}{$\begin{array}{c}\text { Dittel- } \\
\text { Gobe } \\
\mathrm{m}\end{array}$} & \multirow{2}{*}{$\begin{array}{c}\text { Omitts } \\
\text { Iete } \\
\text { Gtärte } \\
\text { in } \\
\text { 28ruft: } \\
\text { bobe } \\
\mathrm{cm}\end{array}$} & \multirow[t]{2}{*}{$\begin{array}{l}\text { Eint } \\
\text { beitg: } \\
\text { wert } \\
\text { fäut von } \\
100 \text { auf }\end{array}$} & \multirow[t]{2}{*}{$\begin{array}{l}\begin{array}{c}\text { 3or. } \\
\text { ertrag }\end{array} \\
\text { fite fe }\end{array}$} & $\frac{\begin{array}{c}9 \mathrm{~m} \\
\text { wert. } \\
\text { verbättnt }\end{array}}{20 \text { gabre }}$ \\
\hline & & & & & & & & & & & & & wa e \\
\hline 40 & $A S$ & 9 & 3,2 & 9,3 & - & 273 & 2539 & 3440 & 6,7 & 4,8 & - & 27 & 116 \\
\hline 60 & 0 & 15 & 3, & 15 & - & 45 & & 0 & & 9 & - & & 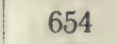 \\
\hline 80 & 1250 & 2 & 2, & 21 & - & 60 & 13 & & & 14 & - & & 7 \\
\hline 100 & 9 & 23 , & 1, & 26 & - & 72 & 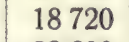 & 3 & Is & 19 & 一 & & 6 \\
\hline 120 & 800 & 25 , & 1, & 29, & - & 81 & 23 & 150 & 15 & 23,4 & - & 51 & 1102 \\
\hline 140 & 691 & 27, & 1,4 & 31 , & 98 & 87 & 27 & 109 & 15 & 25,2 & 一 & 48 & 1180 \\
\hline 160 & 605 & 28, & 1,3 & 34,5 & 95 & 91 & 088 & 86 & 15,9 & 26,8 & - & 48 & 1258 \\
\hline \multirow[t]{2}{*}{180} & \multirow[t]{2}{*}{532} & \multirow[t]{2}{*}{30,2} & \multirow[t]{2}{*}{1,1 . } & \multirow[t]{2}{*}{36,8} & \multirow[t]{2}{*}{93} & \multirow[t]{2}{*}{942} & \multirow[t]{2}{*}{32239} & 73 & \multirow[t]{2}{*}{16,3} & \multirow[t]{2}{*}{28,0} & \multirow[t]{2}{*}{ - } & 45 & \multirow[t]{2}{*}{1239} \\
\hline & & & & & & & & 7718 & & & & 454 & \\
\hline & & & & & & & & & & & & \multicolumn{2}{|c|}{ ¿lberĩtbt 4} \\
\hline 40 & 40 & 11 & 3, & 9 & - & 16 & 7 & 2980 & & 6 & - & 3 & 163 \\
\hline 60 & 1395 & 18 & 3, & 16,6 & - & 331 & 5495 & 1445 & 13 & 11,5 & - & 69 & 638 \\
\hline 80 & 855 & 23,2 & 3, & 22,8 & - & 468 & 10670 & 540 & 18,5 & 15,4 & - & 83 & 1176 \\
\hline 100 & 617 & 27,0 & 2,2 & 27,8 & - & 580 & 16124 & 238 & 22,1 & 21,9 & - & 82 & 1595 \\
\hline 120 & 492 & 29,6 & 2,0 & 31,8 & - & 671 & 21338 & 125 & 25,4 & 23,8 & - & 73 & 1706 \\
\hline 140 & 400 & 31,4 & 1,9 & 35,7 & - & 746 & 26632 & 92 & 26,1 & 27,1 & - & 68 & 1741 \\
\hline 160 & 335 & 32,8 & 1,9 & 39,5 & - & 788 & 31126 & 65 & 26,3 & 30,0 & - & 64 & 1853 \\
\hline 180 & 282 & 34,0 & 1,8 & 43,1 & - & 807 & 34782 & 53 & 26,5 & 32,8 & - & 60 & 1906 \\
\hline & & & & & & & & 5538 & & & & 529 & \\
\hline
\end{tabular}

In Marł aus̊gebrỉưt erbält man nach ber gegenwärtigen Preislage an ber Oberwejer bie Werte bier wie in ben fpäteren s̈berfichten butch) Multiplifation mit:

$$
\begin{aligned}
& \frac{0,20 \text { biz } 0,26}{0,23} \text { für } \mathfrak{B} \text { ude, } \\
& \frac{0,32 \text { biв } 0,39}{0,35} \text { für Riefer, } \\
& \frac{0,70 \text { bis } 0,76}{0,73} \text { für gicbte. }
\end{aligned}
$$

3 ugleich offenbaren bie obigen Slberfichten im 2 ergleich mit ben folgen ben bie geringe

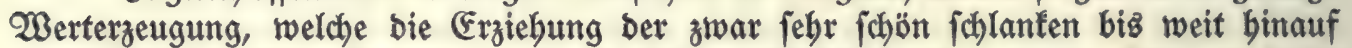
wenigften äušerlich aftreinen, Dabei aber bünnen Sölzer bietet, nach ber Qebre von Dem bauerno zu erhaltenben vollen und vollften Galluffe im oberen Rronenraum.

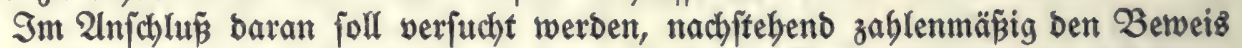

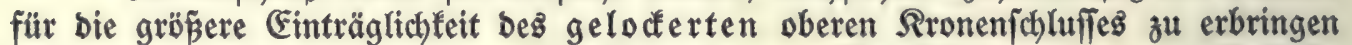
und unter ben fich bietenden Nöglichfeiten unb Nä̈blichleiten bie vorteilbaftefte aużzumitteln, uno baz tunlichjt obne prozentuelle Beziebungen, bie gar oft bazu angetan fino, ben Rern ber Gache nur zu berjhleiern. 
Fidbte III 1890.

\begin{tabular}{|c|c|c|c|c|c|c|c|c|c|c|c|c|}
\hline \multicolumn{2}{|c|}{$\begin{array}{l}\text { Befamtertrag im } \\
\text { Bertvergältuis }\end{array}$} & \multicolumn{4}{|c|}{$9 n S_{0} \circ l_{z}$} & \multicolumn{6}{|c|}{9 m Bertuerbältutb } & \multirow{3}{*}{ 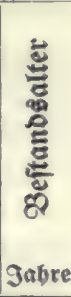 } \\
\hline $\mathrm{S} \stackrel{\text { a }}{\underline{D}}$ & $\mathrm{~V}+\mathrm{S} \underline{\underline{a}} \mathrm{D}$ & $\mathrm{Vlz}$ & $V d z$ & Glz & Gdz & Vlz & Vdz & Glz & Gdz & Gwz & $\begin{array}{l}\text { Davon } \\
\text { werben } \\
\text { fluifig }\end{array}$ & \\
\hline \multicolumn{2}{|c|}{ etnbeiten } & \multicolumn{4}{|c|}{ Fefineter } & \multicolumn{4}{|c|}{ 2bertetnbetten } & \multicolumn{2}{|c|}{ Prozente } & \\
\hline 116 & 2655 & 9,0 & 6,8 & 12,0 & 7,5 & 157 & 63 & 171 & 66 & 6,7 & 0,5 & 40 \\
\hline 770 & 7912 & 8,6 & 7,5 & 13,2 & 9,4 & 267 & 119 & 311 & 132 & 4,4 & 0,6 & 60 \\
\hline 1827 & 14934 & 6,8 & 7,6 & 10,8 & 10,0 & 307 & 164 & 363 & 187 & 2,8 & 0,4 & 80 \\
\hline 2983 & 21703 & 5,2 & 7,2 & 8,2 & 9,8 & 260 & 187 & 319 & 217 & 1,7 & 0,3 & 100 \\
\hline 4085 & 27685 & 4,2 & 6,8 & 6,6 & 9,4 & 233 & 197 & 289 & 231 & 1,2 & 0,2 & 120 \\
\hline 5265 & 32620 & 2,8 & 6,3 & 5,2 & 8,8 & 188 & 195 & 213 & 233 & 0,8 & 0,1 & 140 \\
\hline 6523 & 36611 & 1,8 & 5,7 & 4,2 & 8,3 & 137 & 188 & 165 & $\overline{226}$ & 0,5 & 0,1 & 160 \\
\hline 7762 & 40001 & 1,0 & 5,2 & 3,0 & 7,8 & 107 & 179 & 109 & 222 & 0,3 & 0,1 & 180 \\
\hline
\end{tabular}

3uche II 1893.

\begin{tabular}{r|r|r|r|r|r|r|r|r|r|r|r|r|}
163 & 1790 & 8,6 & 4,2 & 11,6 & 4,9 & 126 & 41 & 144 & $\mathbf{4 5}$ & 8,8 & 1,1 & 40 \\
801 & 6296 & 7,8 & 5,5 & 11,4 & 7,2 & 215 & 92 & 225 & 105 & 4,1 & 0,2 & 60 \\
1977 & 12647 & 6,4 & 5,9 & 10,6 & 8,1 & 259 & 133 & 318 & $\mathbf{1 5 8}$ & 3,0 & 0,6 & 80 \\
3572 & 19696 & 5,2 & 5,8 & 9,0 & $\mathbf{8 , 4}$ & 275 & 161 & 353 & $\mathbf{1 9 7}$ & 2,2 & 0,5 & 100 \\
5278 & 26616 & 4,2 & 5,6 & 7,8 & 8,3 & 261 & 178 & 346 & $\mathbf{2 2 2}$ & 1,6 & 0,4 & 120 \\
7019 & 33651 & 3,6 & 5,3 & 7,0 & 8,2 & 265 & 190 & 352 & 240 & 1,3 & 0,3 & 140 \\
8872 & 39998 & 2,1 & 4,9 & 5,3 & 7,9 & 225 & 195 & 318 & $\mathbf{2 5 0}$ & 1,0 & 0,3 & 160 \\
10778 & 45560 & 1,9 & 4,5 & 4,0 & 7,4 & 183 & 193 & 253 & $\mathbf{2 5 3}$ & 0,7 & 0,2 & 180
\end{tabular}

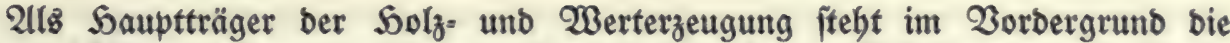
Etärfeentwicfelung. Denn ber Durchmeffer wirft auf ben Finheitşwert mit feinem einfachen Gerwicht, beim Einzelítamm auf bie Solzmenge mit Dem Quabrat, auf ben

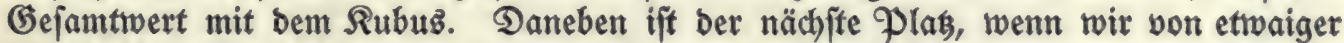
Schabhaftigteit abjehen, Der jonftigen (Güte bez Solzez, ber Gerabheit, ber aftreinen ober äftigen Bejchaffenbeit einzuräumen, welche ben Gejamtwert innerbalb ber Grenzen 100 für aftrein und ungünftigften Fallez 50 für äftig zu verjobieben vermag. Deşhalb muß́ bie Etärfeentwiçelung für bie Gejamtwerterzetgung von ber grö̈eren Bebeutung fein. Beibe zujammen baben bas Sauptziel bei allen wirtichaftlichen Map̃nbmen zu bilben.

Echließslich wirb auch bie Frage, ob unter fonf́t gleidhen Berbältniffen mebr Solz ergeugt werben fann bei gelodertem als bei vollem Gchlus, in erfiter Linie

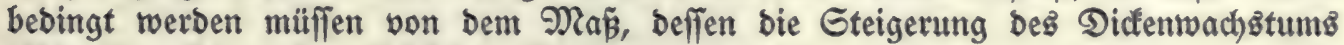
fäbig ift. Die auf tatjächlichen Grundlagen rubenbe und als zuberläfing anerfannte

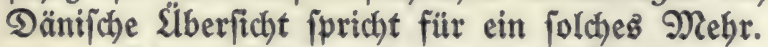

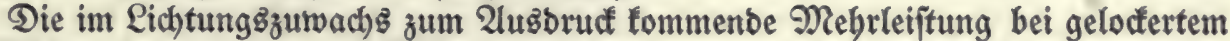

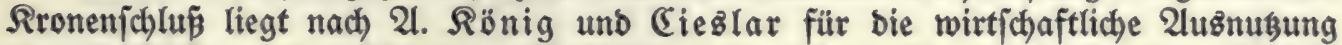
am günjtigften bei mäsigen, allmäblich uno gleichmäpig burchgefübrten Schluß́: 
unterbred)ungen, wäbrenb bei ftarlen unb zu plöglichen unb ungleid)mäpigen Eingriffen

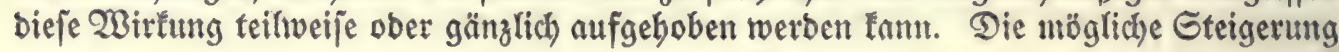
reid)t bei mäp̃igen Eingriffen bisิ zur fnappen $\frac{3}{2}$ fachung unb tann bei allmäblidber Weiterfübrung biz zur vollen Berboppelung Der Ringbreite fübren, von alter uno Solzart nur wenig beeinflupst.

Wie oben ausgeführt, zieht bie Errbaltung Deż oberen Rronenfchlufię gleiche Ringfrächen unb Damit ftetig farlenbe Ringbreiten nach fich. Dabei gebt bie Gtärfezunabme mit fteigenbent Durdhmeffer erbeblich zuriad, z. 23. Gier bei Buche II vom 60 bi 120 jährigen 2llter von 3,3 auf $2,0 \mathrm{~mm}$. Es gehören baber in böherem

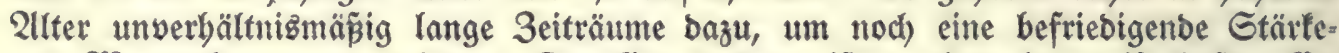

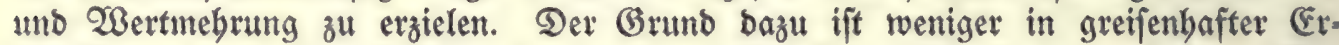
f(b)laffung als in Dem äuseren 3 wang ber nachbarlichen Slmgebung zu fuchen. Der Wald liefert bafür in allen ftammweife erfolgenden Pocterungen bes oberen Rronen-

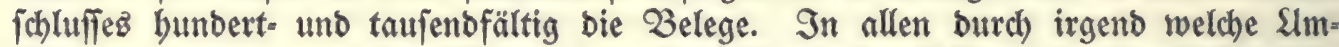
ftänbe einigermaßen gleichmäß̈ig auf ben Gchlufiftano von 0,8 und weniger gebrachten 3 eftänben finden wir augenfällig bie größ̈eren Ringbreiten fowohl bei Qaub= wie Nabelfölzern, felbit bei ber, wenigjtens in höberen altern, nach biejer Richtung bin ofter recht träg ericheintenben Riefer. So zeigten, um nur einige Beifpiele beraug= zugreifen, für Riefern bie 3uwachbunterjudhungen von 42 Altbeftänben in Reuen=

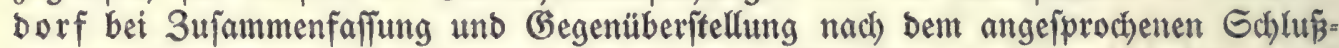
grab in ben burchjochnittlichen Pingbreiten folgende 2lbftufungen: $0,9=100,0,8=110$, $0,7=126$. v. Seebad) gibt bei feinen Slnterfuthungen an freigefitellten 150 bis 160 jäbrigen Buchen von 56 bis $73 \mathrm{~cm}$ Brufthöhenftärfe noch eine jährliche Durch.

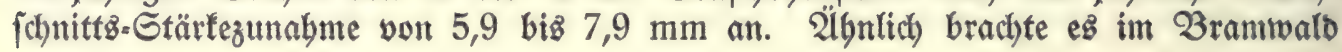

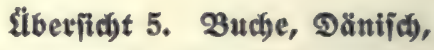

\begin{tabular}{|c|c|c|c|c|c|c|c|c|c|c|c|c|c|}
\hline \multirow{3}{*}{ 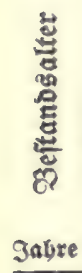 } & \multicolumn{7}{|c|}{ 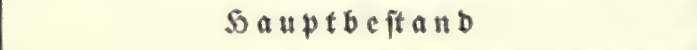 } & \multicolumn{6}{|c|}{ Entnommen } \\
\hline & \multirow{2}{*}{$\begin{array}{l}\text { Etamm } \\
\text { zabl } \\
\text { Ettit }\end{array}$} & \multirow{2}{*}{$\begin{array}{c}\text { 2rittels } \\
\text { bobe } \\
\mathrm{m}\end{array}$} & \multirow{2}{*}{$\begin{array}{c}\text { gäbr: } \\
\text { fidje } \\
\text { Stâtte: } \\
\text { 3u= } \\
\text { nabme } \\
\text { mm }\end{array}$} & \multirow{2}{*}{$\begin{array}{l}\text { Mitt" } \\
\text { Iere } \\
\text { Gtärte } \\
\text { in } \\
\text { Bruftits } \\
\text { bubbe } \\
\text { cm }\end{array}$} & \multirow[t]{2}{*}{$\begin{array}{c}\text { Ein: } \\
\text { beitses } \\
\text { wert } \\
\text { făut von } \\
100 \text { auf }\end{array}$} & \multirow{2}{*}{$\begin{array}{c}\text { Borrat } \\
\mathrm{fm}\end{array}$} & \multirow{2}{*}{$\begin{array}{c}9 m \\
2 B e r t s \\
\text { verbältnţ } \\
\text { שserteintb. }\end{array}$} & \multirow{2}{*}{$\begin{array}{c}\text { Stamm! } \\
\text { zabl } \\
\text { Gtiat }\end{array}$} & \multirow{2}{*}{$\left|\begin{array}{c}\text { Mittel } \\
\text { bobe } \\
\mathrm{m}\end{array}\right|$} & \multirow{2}{*}{$\begin{array}{c}\text { शritt } \\
\text { fere } \\
\text { Gtärte } \\
\text { in } \\
\text { 2rut: } \\
\text { bobe } \\
\mathrm{cm}\end{array}$} & \multirow[t]{2}{*}{$\begin{array}{c}\text { Cint } \\
\text { beitze } \\
\text { wert } \\
\text { fällt von } \\
100 \text { auf }\end{array}$} & \multirow{2}{*}{\begin{tabular}{|c|}
$\begin{array}{c}3 \mathrm{pos} \\
\text { crtrag }\end{array}$ \\
fitr te \\
$\mathrm{fm}$ \\
\end{tabular}} & $\begin{array}{c}\begin{array}{c}91 m \\
\text { 28ert- } \\
\text { verbăttnis }\end{array} \\
20 \text { 9abre }\end{array}$ \\
\hline & & & & & & & & & & & & & $20 \times$ \\
\hline 23 & 4628 & 7,9 & 4,7 & 7,2 & 一 & 136 & 979 & 3664 & 6,7 & 4,9 & - & 33 & 145 \\
\hline 42 & 1381 & 15,6 & 4,5 & 15,7 & - & 276 & 4333 & 3247 & 13,3 & 12,0 & 一 & 149 & 1376 \\
\hline 62 & 621 & 21,9 & 4,5 & 24,7 & - & 386 & 9534 & 760 & 20,2 & 19,5 & - & 171 & 2850 \\
\hline 82 & 353 & 26,0 & 4,3 & 33,8 & - & 471 & 15920 & 268 & 24,2 & 27,0 & - & 163 & 3989 \\
\hline 100 & 235 & 28,0 & 4,5 & 41,9 & - & 532 & 22291 & 118 & 26,0 & 33,8 & - & 137 & 4380 \\
\hline 120 & 167 & 28,6 & 4,5 & 50,8 & 一 & 595 & 30226 & 68 & 27,2 & 41,3 & 一 & 134 & 5283 \\
\hline 140 & 125 & 29,4 & 4,5 & 59,8 & - & 623 & 37255 & 42 & 28,8 & 53,8 & - & 141 & 7130 \\
\hline 160 & 95 & 29,8 & 4,5 & 68,8 & 91 & 640 & 40069 & 30 & 29,8 & 68,8 & 91 & 177 & 10638 \\
\hline \multirow[t]{2}{*}{180} & \multirow[t]{2}{*}{76} & \multirow[t]{2}{*}{30,0} & \multirow[t]{2}{*}{4,5} & \multirow[t]{2}{*}{77,8} & \multirow[t]{2}{*}{82} & \multirow[t]{2}{*}{640} & \multirow[t]{2}{*}{40829} & 19 & \multirow[t]{2}{*}{30,0} & \multirow[t]{2}{*}{77,8} & \multirow[t]{2}{*}{82} & 151 & \multirow[t]{2}{*}{9632} \\
\hline & & & & & & & & 8216 & & & & 1256 & \\
\hline
\end{tabular}

Für bieje unb bie folgenden äberfichten finb bie Retben nid)t ausigeglidben, fonbern gegeben, 
einer ber ältejten, ein 180 jäbriger 3 ud enbeftant, währent ber 21 jäbrigen $\mathfrak{B e r}$. jüngunggbauer auf bie volle burchfchnittliche Berboppelung ber Ringbreite. EEbenfo weift ber Geite 42, 43 al\& Beifpiel für bie Inthaltsberechnung verwendete, in biejem Falle von Sugeno auf licht erwachjene Fichtenort, bei etwa balber Gtammzahl

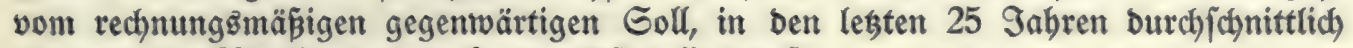
bie Doppelte Ringbreite beg Sochwalbjhluffes auf.

2lud) bie geringere Bobengüte icheint alв Sinberungsigrunb nicht zu gelten, benn nach allem, was fich) bier aus zahlreichen Slnterfuchungen ableiten läpt, baben bie geringeren Etanborte bei vorfichtiger Bebanblung am prompteften geantwortet.

In allen Fällen macht fich baz vermebrte Didfenwach stum nur fo lange gelteno,

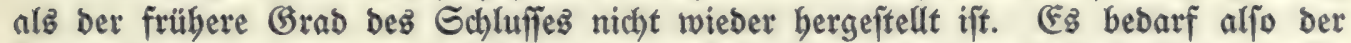

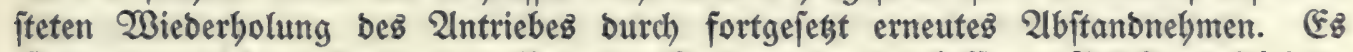
ift vorzugreifen, ebe bie zu pflegenden Gtämme an ber befferen Etärfeentwicfelung gebinbert werben fönten.

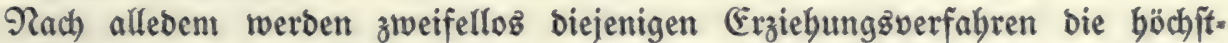

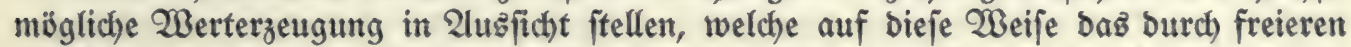

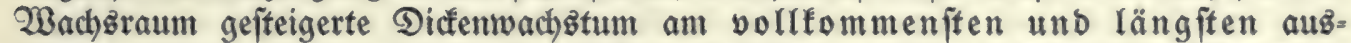
nugen, fofern babei minbeftenz gleicher Solzertrag uno auzreichenbe 2liftreinbeit getwabrt bleiben.

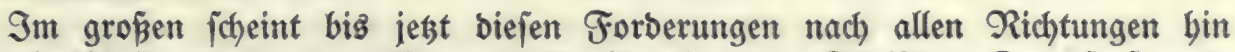

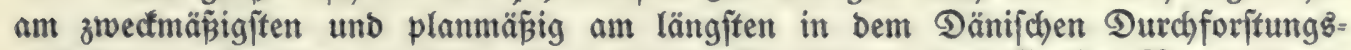
verfabren entiprochen zu fein. Bon feinem Begrüner, bem Grafen Reventlow, waren bie leitenden (Grunbzüge bereitż im 21nfange bes vorigen Jahrbunbertz nieber= gelegt, nachbem von ihm veranlap̧te vergleichende Slnterjuchungen über bie 3utwachs:

\section{auf gutem Boben, nadi Gram.}

\begin{tabular}{|c|c|c|c|c|c|c|c|c|c|c|c|c|}
\hline \multicolumn{2}{|c|}{$\begin{array}{l}\text { (Befamtertrag im } \\
\text { Bertuerbätnis }\end{array}$} & \multicolumn{4}{|c|}{ In Solz } & \multicolumn{6}{|c|}{ Sm $\mathfrak{B}$ ertverbältnt } & \multirow{3}{*}{ 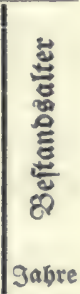 } \\
\hline $\mathrm{S}$ a $\mathrm{D}$ & $\mathrm{V}+\mathrm{S}$ a $\mathrm{D}$ & Vlz & $\mathrm{Vdz}$ & $\mathrm{Glz}$ & Gdz & Vlz & $\mathrm{Vdz}$ & $\mathrm{Glz}$ & Gdz & Gwz & $\begin{array}{l}\text { Davon } \\
\text { werben } \\
\text { fliipig }\end{array}$ & \\
\hline \multicolumn{2}{|c|}{ einbelten } & \multicolumn{4}{|c|}{ Geftmeter } & \multicolumn{4}{|c|}{ werteinbetien } & \multicolumn{2}{|c|}{ Drozente } & \\
\hline 145 & 1124 & 10,7 & 5,9 & 16,7 & 7,3 & 125 & 43 & 153 & 49 & 15,6 & 2,9 & 23 \\
\hline 1521 & 5854 & 7,0 & 6,6 & 15,3 & 10,9 & 222 & 103 & 321 & 139 & 7,5 & 2,3 & 42 \\
\hline 4371 & 13905 & 5,3 & 6,2 & 13,5 & 11,9 & 291 & 154 & 450 & 224 & 4,7 & 1,7 & 62 \\
\hline 8360 & 24280 & 4,3 & 5,7 & 11,9 & 12,0 & 340 & 194 & 546 & 296 & 3,4 & 1,3 & 82 \\
\hline 12740 & 35031 & 3,6 & 5,3 & 10,7 & 11,9 & 374 & 223 & 614 & 350 & 2,8 & 1,1 & 100 \\
\hline 18023 & 48249 & 3,0 & 5,0 & 9,6 & 11,5 & 407 & 252 & 661 & 402 & 2,2 & 0,8 & 120 \\
\hline 25153 & 62408 & 1,4 & 4,5 & 8,6 & 11,1 & 352 & 266 & 708 & 446 & 1,9 & 1,0 & 140 \\
\hline 35791 & 75860 & 0,9 & 4,0 & 9,7 & 10,9 & 142 & 250 & 673 & 474 & 1,7 & 1,3 & 160 \\
\hline 45423 & 86752 & 0,0 & 3,6 & 7,6 & 10,5 & 38 & 227 & 545 & 482 & 1,3 & 1,2 & 180 \\
\hline
\end{tabular}

wie fie bie 3ufammenitellung unb Berecbnung unmittelbar bieten. 
leiftungen im lichteren unb bichten Gtanbe im Deutichen 2 uthengebiet an ber 2 ejer

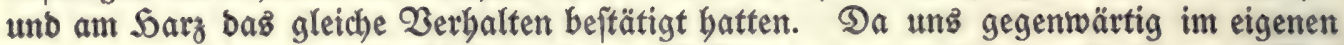
Lanbe von gleich ober äbnlich bebandelten Beftänden in außreichender $3 a b l$ zuverläjifige

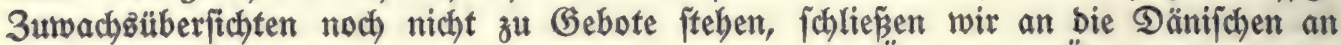

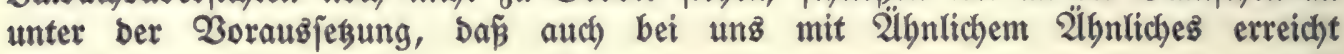
werben mǘpte.

Der Rern bę Dänijchen Berfabrenz rubt in fnappíter Fafinng uno Begrenzung in bem Sag:

Smmer bann einen Gtamm entnehmen, wenn er einen ober gar mebrere am Gdaft, befonbers binfidbtich ber Alitreingeit wertwoller geartete Radbarn an bem zu erbaltenden unb weiter auszubilbenden Teil ibrer Rrone banbgreiflid fääbigt ober beengt.")

Für bie grunbjägliche Gchonung bez Slnterftanbes ift etwa feit 1845 namentlich Ģröber (Webellaborg) eingetreten.

In bie Augen fpringt ohne weiteres trog bes unter ftänbiger 2 Binbwirtung geringeren Söbenwuch fez ber höhere Gefamtertrag an Solz, ber noch erheblich

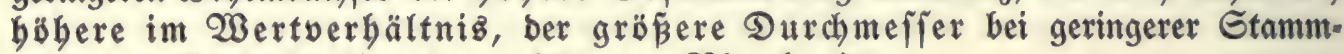
zabl, bas (błeidbleiben ber mittleren Ringbreite.

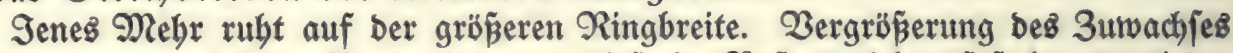
ift bie 2 irfung vermebrter 3 lattarbeit und bieje im Bejtandzleben fajt immer wieber bie Folge erweiterten 2 achşraumę. Die mäß̈ige, Den oberen Rronenraum treffende Ernveiterung erweift fich als bie wirffamite. (Enfflich beeinträchtigt wiro bas Bebeihen nur burch jolche Nachbarn, weldhe ben oberen Rronenraum fitreitig machen, während bas Beberrichte faum noch wejentlich fdaden, fonbern im Gegenteil vielfach nubbringend wirten fann.

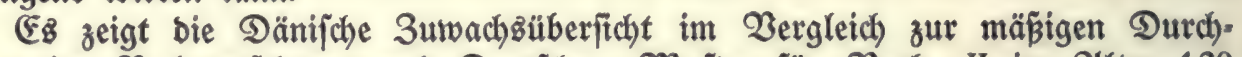
forítung im Beberridbten nach Deutichem Mujter für Buche II im 2llter 120 eine Eteigerung

a) in $\mathfrak{S o l l}_{\mathrm{z}}$ auf bas . . . . . . . . 1,37 factie,

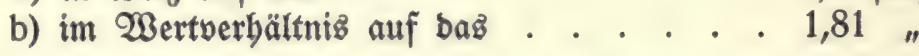

währenb bie Anwenbung ber "ftarfen" Durchforitung im Beberrichten ober vom Gdhwachen her ez nur biz zu einer Steigerung bringt:

a) in Solz auf baz . . . . . . . . . . 1,006 fache,

b) im $\mathfrak{B e r t w e r b a ̈ l t n i s ~ a น f ~ D a ̊ s ~ . ~ . ~ . ~ . ~ . ~ 1 , 0 1 6 ~ " ~}$

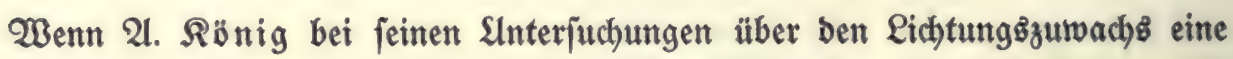
thappe $\frac{3}{2}$ fachung fand, to feben wir bier als Enbergebnis in Dem beiberjeitigen Gtärfeverbältni $\frac{50,8}{31,8}$ jogar noch etwå̊ mebr.

*) Die im Sinne jener Brunbzäge gehaltene Bramtwalber 21nleitung zur 2luð̇zeichnung ber Durdforftungen im Serríd)enden tann Durd bie Berlagsbudbandlung zum Preife von 30 Pf. bezogen werben. 


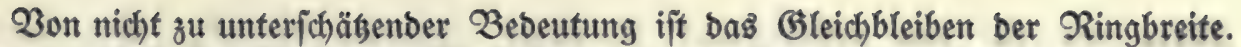
शach bem mehrfach bejprochenen (Einflup̈, weld)e bie Stärfe und Gtärtezunabme auf

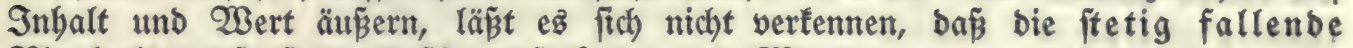

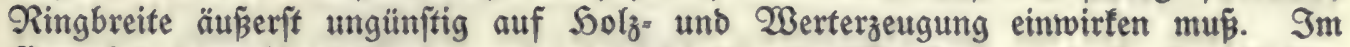
Gegenjas bazu bietet bie bauerno gleidbbleibende Ringbreite, wie fie jomobl bier für Buche als nach "Mlündener Sefte" X für (Eiche als tatfächlich erreicht bei ber Durchforffung im Sorrichenden vorfiegt, baz benfbar Günjtigite, fofern bie ftetig fteigende nicht weiter in Frage fommt. 2luch bier ift auf um po vollfommeneren Ërfolg zu rechnen, je allmäblicher bie Sïbergänge bei Der Rronenumlichtung geíchaffen

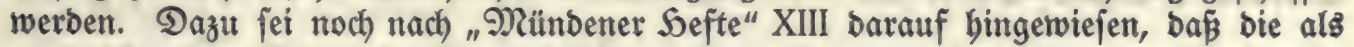
rertmebrenber Faltor in Betracht tommende "Feinbeit" bes Solzes weniger auf Edhmalringigfeit alz auf (Gleichmäp̄igleit ber Ringbreiten berubt. Bei Fiche tann

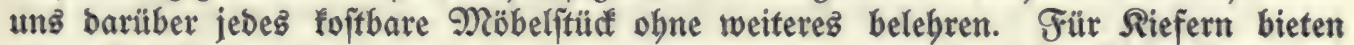

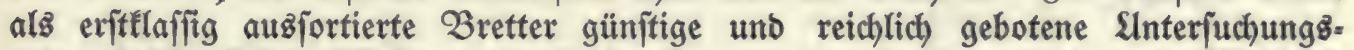

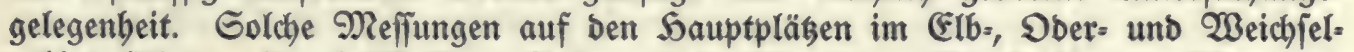
gebiet fübrten für befttlaffige Riefern beछ Ojtenz zu Ringbreiten zrwijchen ben Grenzen von 1 biz $3 \mathrm{~mm}$, immer aber möglichif gleichmäp̈ig entweber fdhmaler ober breiter, wäbreno Mattbes für ben 2 Bejten, zwar nicht an fortierten beftelafifgen Brettern, aber an ben "anerfannt guten" Riefern bei Bamberg Sabrringbreiten von 3 bis $5 \mathrm{~mm}$ gefunben hat.

EEs fann feinem 3weifel unterliegen, bá̉ wir mit gleicter ober ähnlicher Behanblung ber Beftänbe aud) bei uns minbejtens zu fehr ähnlichen Ěrgebniffen

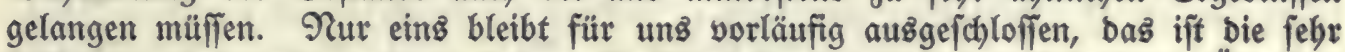
frübzeitig einjeğende unb in furzen 3wijchenräumen nach ber Dänifhen s̈lberficht wieberfebrenbe Durchforftung, weldhe fijon jehr früb eine Áberlegenbeit in ber

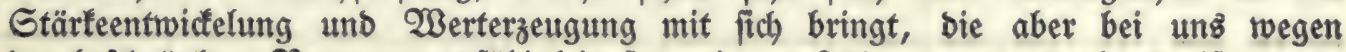

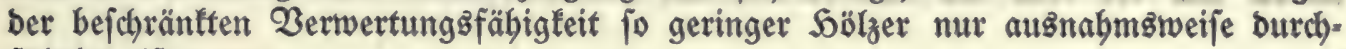
fübrbar ift.

Die bem Dänifchen Beifpiel aแรื ber Wirflichfeit möglichjit nad)gebilbeten Ṡberfichten 6 biz 10 bringen bie zablenmäpige Probe auf bas Bejagte. Dabei ifit gered)net mit einer $\frac{3}{2}$ fachung unb vergleid) ghweife mit einer $\frac{5}{4}$ fachung ber Ringbreite, um bamit bie ungefäbren, in ben Bereich beż tatjäd)lich (Erreichten fallenben (Brenz. werte feftzulegen. Nach Den bişerigen (Ermittelungen if bie $\frac{5}{4}$ fache $\mathfrak{Z}$ erftärfung Der Ringbreite ber Betrag, welcher alß Durchjchnitt für bie Bejamtheit ber feit 18 Jabren in Bramwald burchweg nad) äbnlichen und gleichen (Brunb. fätzen behanbelten Durchforftungen ericheint, robei Riefer unb Fichte fid ein wenig günjtiger als Buche geftellt haben. Das alles für eine 3eit bes \{́bergangez mit vorfichtiger uno allmäblicher Sinüberleitung in Den neuen 3uftanb. Ob unb inwieweit für ben Befamtburchjochnitt mebr erreichbar ift, muß bie 3ufunft lebren.

Die Ṡberfichten fegen gleid) bleibenbe Ringbreiten vorats, wie fie wenigften bis zum 2llter 120 burch bie Dänifchen Ërgebniffe bejtätigt finb. Gollte barüber binaus bie gleiche Söbe nidbt baltbar fein, fo wirb ein Sinfen boch böchfenz in bem 
Maßje wie für ben gejchloffenen Sochwald eintreten tönten. Die bavon zu erwartende Birtung läp̈t fich auz bem Zerlauf ber Rurben auf ben entiprechenden Wertzumachabilbern berleiten.

纟ีber bas bei ber Berechnung eingejhlagene Zerfahren jei furz folgenbes angefübrt:

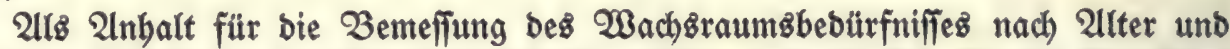
erreichbarer Stärfe hat bie Wachbraumbzahl gebient, wie fie fich für bie Deutichen

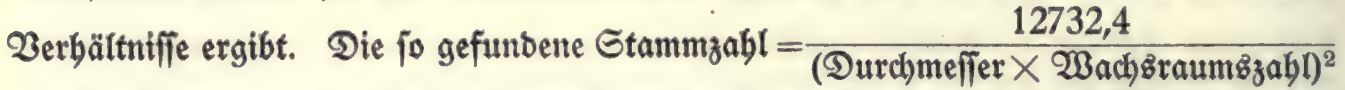
gibt bie Obergrenze für ben vollen Gdhlup. Da biejer aber, um bie Wirfung nidjt zu beeinträchtigen, nie wieber ganz erreidyt werben barf, bat eine weitere Soerabję̧ung Der Gtammzahl nach ber auż bem Dänif́chen Beifpiel entnommenen Stala auf $0,98,0,90,0,87$ uff. ftattgefunben.

Weiter ift Dann aus ber 21ngabe ber Inbaltżtafeln für ben Einzelf́tamm uno Gtammzabl ber Borrat abgeleitet.

Für bie Borerträge ift gerechnet bas eine $\mathfrak{M a l}$ mit ben Inbalten, wie fie fỉch nach ber bem Dänifhen Beifpiel entnommenen Slala für Söbe uno Stärte bez

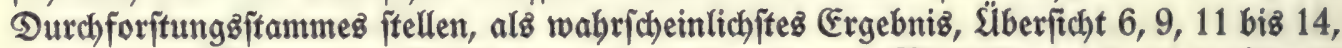
baz anbere Mal unter Finjęung beż entipprechenden Mittelítammes vom Soupt-

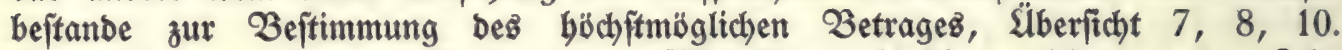
2uch bei bem eriteren Fall ij zu bem Mittelítamm binüber geleitet um ben 3eit= punft, wo bie Gtärle erreicht wiro, biz zu weld)er Der (Einheitß̈wert wie ber Durch= mefler fteigt, weil von ba ab ber Sieb auf bie "Diden" mit Recht in ben 20 orber grund tritt.

\{̈berfid)t 6. Bucbe II mit $\frac{3}{2}$ facher Ringbreite, äbnlid

\begin{tabular}{|c|c|c|c|c|c|c|c|c|c|c|c|c|c|}
\hline \multirow{4}{*}{ 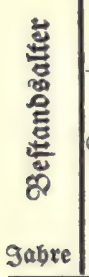 } & \multicolumn{7}{|c|}{$S \in a u p t b e f t a n b$} & \multicolumn{6}{|c|}{ Entnommen } \\
\hline & \multirow{3}{*}{$\begin{array}{c}\text { Stamm: } \\
\text { zabl } \\
\text { Etid }\end{array}$} & \multirow{3}{*}{$\begin{array}{c}\begin{array}{c}\text { 2ritter. } \\
\text { böbe } \\
\mathrm{m}\end{array} \\
\end{array}$} & \multirow{3}{*}{ 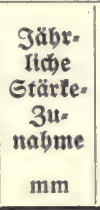 } & \multirow{3}{*}{$\begin{array}{c}\text { gRitt" } \\
\text { lere } \\
\text { Gtärfe } \\
\text { in } \\
\text { Bruft. } \\
\text { böbe } \\
\mathrm{cm}\end{array}$} & \multirow[t]{3}{*}{$\begin{array}{c}\text { Ein: } \\
\text { beitsos } \\
\text { wert } \\
\text { făllt von } \\
100 \text { auf }\end{array}$} & \multirow{3}{*}{$\begin{array}{c}\text { Borrat } \\
\mathrm{fm}\end{array}$} & \multirow{3}{*}{ 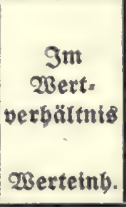 } & \multirow{3}{*}{$\begin{array}{c}\text { Stamm: } \\
\text { zabl } \\
\text { Gtült }\end{array}$} & \multirow{3}{*}{$\begin{array}{c}\text { gmittel } \\
\text { bäbe } \\
\text { m }\end{array}$} & \multirow{3}{*}{$\begin{array}{c}\text { gritt: } \\
\text { Yere } \\
\text { Stärte } \\
\text { in } \\
\text { Orwutt- } \\
\text { bube } \\
\mathrm{cm} \\
\end{array}$} & \multirow[t]{3}{*}{$\begin{array}{c}\text { Ein: } \\
\text { beits. } \\
\text { wert } \\
\text { fădut von } \\
100 \text { auf }\end{array}$} & \multirow[t]{2}{*}{\begin{tabular}{|c|}
$\begin{array}{c}\text { gor: } \\
\text { ertrag }\end{array}$ \\
fiti fe \\
\end{tabular}} & \multirow[t]{2}{*}{$\frac{\begin{array}{c}9 \mathrm{~m} \\
\text { wert- } \\
\text { verbältnis }\end{array}}{20 \text { gabre }}$} \\
\hline & & & & & & & & & & & & & \\
\hline & & & & & & & & & & & & fm & $\mathscr{B} \in \times t$ \\
\hline 40 & 2175 & 11,9 & 4,2 & 11,2 & - & 161 & 1803 & 3645 & 10,1 & 8,6 & - & 58 & 409 \\
\hline 60 & 981 & 18,1 & 4,2 & 19,6 & - & 313 & 6135 & 1194 & 16,7 & 15,5 & - & 126 & 1644 \\
\hline 80 & 512 & 23,2 & 4,2 & 28,0 & - & 424 & 11872 & 469 & 21,6 & 22,4 & - & 160 & 3188 \\
\hline 100 & 315 & 27,0 & 4,2 & 36,4 & - & 515 & 18746 & 197 & 25,1 & 29,5 & - & 146 & 3885 \\
\hline 120 & 216 & 29,6 & 4,2 & 44,8 & - & 592 & 26522 & 99 & 28,1 & 36,7 & - & 136 & 4598 \\
\hline 140 & 157 & 31,4 & 4,2 & 53,2 & - & 651 & 34633 & 59 & 30,5 & 47,9 & - & 151 & 6582 \\
\hline 160 & 120 & 32,8 & 4,2 & 61,6 & 98 & 703 & 42439 & 37 & 32,5 & 59,5 & - & 164 & 9014 \\
\hline \multirow[t]{2}{*}{180} & \multirow[t]{2}{*}{93} & \multirow[t]{2}{*}{34,0} & \multirow[t]{2}{*}{4,2} & \multirow[t]{2}{*}{70,0} & \multirow[t]{2}{*}{90} & \multirow[t]{2}{*}{734} & \multirow[t]{2}{*}{46242} & 27 & \multirow[t]{2}{*}{33,7} & \multirow[t]{2}{*}{67,9} & \multirow[t]{2}{*}{92} & 176 & \multirow[t]{2}{*}{10803} \\
\hline & & & & & & & & 5727 & & & & 1117 & \\
\hline
\end{tabular}


Die Slala lautet:

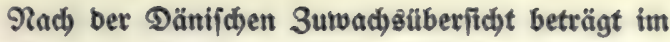

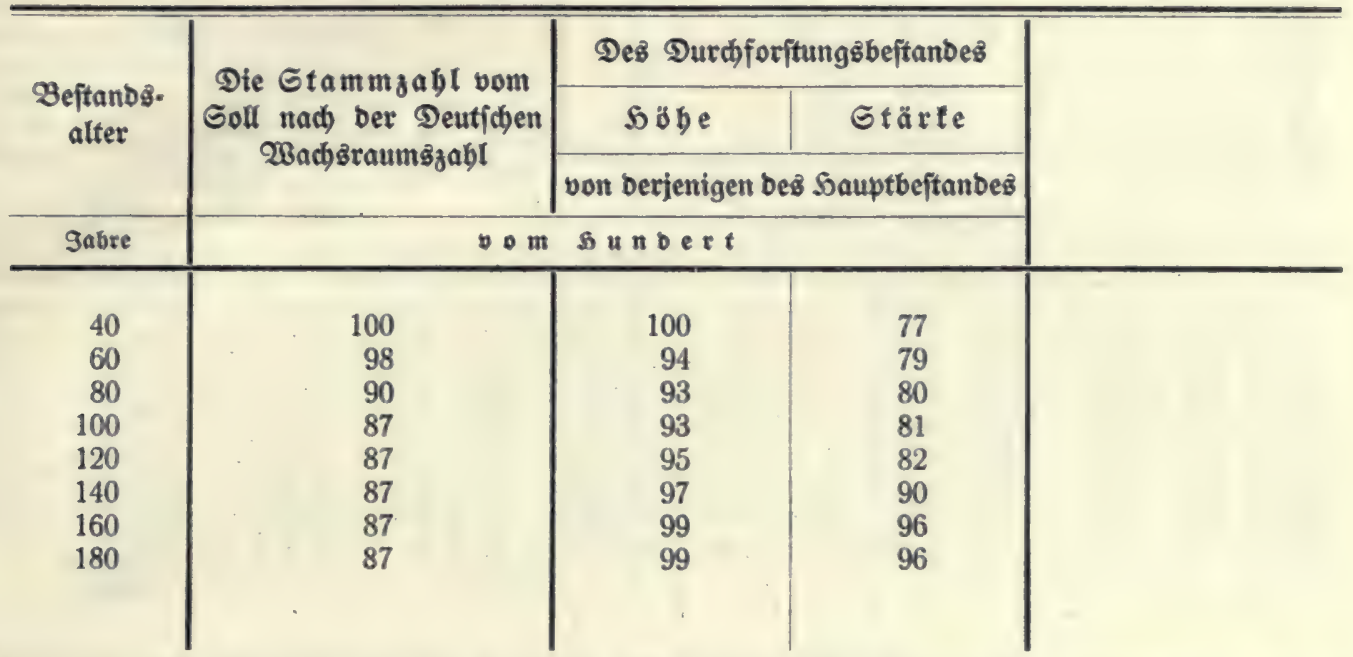

Die Bucbung ber für fünfiäbrige 3eiträume berechneten Borerträge if́ in

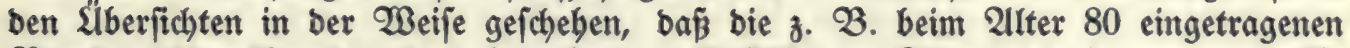
Beträge als wäbrend bez vorbergebenben fünfiäbrigen 3eitraums eingegangen, aljo in ber Regel im 2llter von 75 entfallen, anzujeben finb.

Danach ergeben bie Berechnungen:

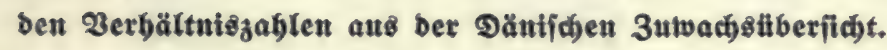

\begin{tabular}{|c|c|c|c|c|c|c|c|c|c|c|c|c|}
\hline \multicolumn{2}{|c|}{$\begin{array}{l}\text { Gefamtertrag im } \\
\text { Bertverbälnis }\end{array}$} & \multicolumn{4}{|c|}{ In $\mathfrak{S o l}$} & \multicolumn{6}{|c|}{ Im Wertberbältnibี } & \multirow{3}{*}{ 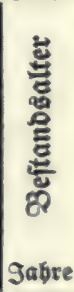 } \\
\hline$S_{\underline{\underline{a}}} \mathrm{D}$ & $V+S a$ & $\mathrm{Vlz}$ & $\mathrm{Vdz}$ & Gilz & Gdz & Vlz & $\mathrm{Vdz}$ & Glz & Gdz & Gwz & $\begin{array}{l}\text { Davon } \\
\text { werben } \\
\text { fuîtg }\end{array}$ & \\
\hline \multicolumn{2}{|c|}{ einbeiten } & \multicolumn{4}{|c|}{ Geftmeter } & \multicolumn{4}{|c|}{ zertetnbeiten } & \multicolumn{2}{|c|}{ prozente } & \\
\hline 409 & 2212 & 9,0 & 4,0 & 13,0 & 5,5 & 149 & 45 & 204 & 55 & 11,3 & 3,1 & 40 \\
\hline 2053 & 8188 & 7,0 & 5,2 & 13,8 & 8,3 & 254 & 102 & 359 & 137 & 5,8 & 1,7 & 60 \\
\hline 5241 & 17113 & 5,2 & 5,3 & 12,4 & 9,6 & 297 & 148 & 481 & 214 & 4,0 & 1,6 & 80 \\
\hline 9126 & 27872 & 4,8 & 5,2 & 11,8 & 10,1 & 381 & 188 & 588 & 279 & 3,1 & 1,1 & 100 \\
\hline 13724 & 40246 & 4,4 & 4,9 & 10,6 & 10,2 & 437 & 221 & 664 & 335 & 2,5 & 0,9 & 120 \\
\hline 20306 & 54939 & 3,6 & 4,7 & 10,8 & 10,2 & 457 & 247 & 802 & 392 & 2,3 & 1,0 & 140 \\
\hline 29320 & 71759 & 2,6 & 4,4 & 10,8 & 10,3 & 322 & 266 & 762 & 448 & 1,8 & 1,0 & 160 \\
\hline 40123 & 86365 & 1,7 & 4,1 & 10,0 & 10,3 & 153 & 257 & 703 & 480 & 1,5 & 1,2 & 180 \\
\hline
\end{tabular}




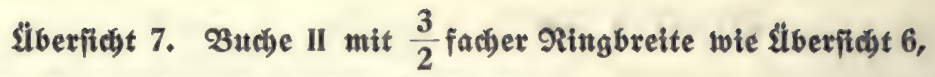

\begin{tabular}{|c|c|c|c|c|c|c|c|c|c|c|c|c|c|}
\hline \multirow{3}{*}{ 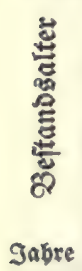 } & \multicolumn{7}{|c|}{ sauptbeftand } & \multicolumn{6}{|c|}{ Entnommen } \\
\hline & \multirow{2}{*}{$\begin{array}{l}\text { Gtamm: } \\
\text { zabl } \\
\text { Gtild }\end{array}$} & \multirow{2}{*}{$\begin{array}{c}\text { 2rittel- } \\
\text { babe } \\
\text { m }\end{array}$} & \multirow[t]{2}{*}{$\begin{array}{c}\text { 9äbr= } \\
\text { Itde } \\
\text { Stärte: } \\
3 \text { us= } \\
\text { nabme } \\
\text { mm }\end{array}$} & \multirow[t]{2}{*}{$\begin{array}{c}\text { פRitt: } \\
\text { Iere } \\
\text { Gtarte } \\
\text { in } \\
\text { Brufts } \\
\text { Boge } \\
\mathrm{cm}\end{array}$} & \multirow[t]{2}{*}{$\begin{array}{c}\text { Ein: } \\
\text { betta. } \\
\text { wert } \\
\text { făkt von } \\
100 \text { auf }\end{array}$} & \multirow{2}{*}{$\begin{array}{c}\text { Borrat } \\
\mathrm{fm}\end{array}$} & \multirow{2}{*}{$\begin{array}{c}9 m \\
\text { wert" } \\
\text { verbältnts } \\
\text { שerteinb. }\end{array}$} & \multirow{2}{*}{$\begin{array}{c}\text { Etamm } \\
\text { zabl } \\
\text { Stuid }\end{array}$} & \multirow{2}{*}{$\begin{array}{c}\text { 2itter. } \\
\text { babe } \\
\mathrm{m}\end{array}$} & \multirow[t]{2}{*}{$\begin{array}{c}\text { פRitt- } \\
\text { lere } \\
\text { Gtärte } \\
\text { in } \\
\text { Oruft: } \\
\text { Gube } \\
\mathrm{cm}\end{array}$} & \multirow[t]{2}{*}{$\begin{array}{c}\text { Ein: } \\
\text { beit\&: } \\
\text { wert } \\
\text { fălut von } \\
100 \text { auf }\end{array}$} & \multirow[t]{2}{*}{$\begin{array}{c}\begin{array}{c}\text { 3or. } \\
\text { ertrag }\end{array} \\
\text { filix te } \\
\text { fin } \\
\end{array}$} & $\frac{\begin{array}{c}9 \mathrm{~m} \\
\text { 2Bert. } \\
\text { verbăltuts }\end{array}}{20 \text { gabre }}$ \\
\hline & & & & & & & & & & & & & Bert \\
\hline 40 & 2175 & 11,9 & 4,2 & 11,2 & - & 161 & 1803 & 3645 & 10,1 & 9,1 & - & 68 & 480 \\
\hline 60 & 981 & 18,1 & 4,2 & 19,6 & - & 313 & 6135 & 1194 & 16,7 & 17,5 & - & 155 & 2244 \\
\hline 80 & 512 & 23,2 & 4,2 & 28,0 & - & 424 & 11872 & 469 & 22,0 & 25,9 & - & 214 & 4895 \\
\hline 100 & 315 & 27,0 & 4,2 & 36,4 & - & 515 & 18746 & 197 & 26,2 & 34,3 & - & 207 & 6422 \\
\hline 120 & 216 & 29,6 & 4,2 & 44,8 & - & 592 & 26522 & 99 & 29,0 & 42,7 & - & 196 & 7742 \\
\hline 140 & 157 & 31,4 & 4,2 & 53,2 & - & 651 & 34633 & 59 & 31,0 & 51,1 & - & 187 & 8941 \\
\hline 160 & 120 & 32,8 & 4,2 & 61,6 & 98 & 703 & 42439 & 37 & 32,5 & 59,5 & - & 174 & 9771 \\
\hline \multirow[t]{2}{*}{180} & \multirow[t]{2}{*}{93} & \multirow[t]{2}{*}{34,0} & \multirow[t]{2}{*}{4,2} & \multirow[t]{2}{*}{70,9} & \multirow[t]{2}{*}{90} & \multirow[t]{2}{*}{734} & \multirow[t]{2}{*}{46242} & 27 & \multirow[t]{2}{*}{33,7} & \multirow[t]{2}{*}{67,9} & \multirow[t]{2}{*}{92} & 176 & \multirow[t]{2}{*}{10813} \\
\hline & & & & & & & & 5727 & & & & 1377 & \\
\hline
\end{tabular}

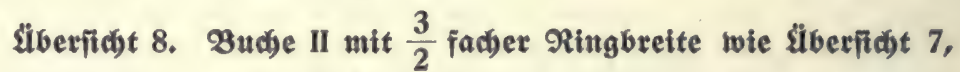

\begin{tabular}{r|r|r|r|r|l|r|r|r|r|r|r|r|r}
40 & 2175 & 11,9 & 4,2 & 11,2 & - & 161 & 1803 & 3645 & 10,1 & 9,1 & - & 68 & 480 \\
60 & 981 & 18,1 & 4,2 & 19,6 & - & 313 & 6135 & 1194 & 16,7 & 17,5 & - & 155 & 2244 \\
80 & 483 & 23,2 & 4,2 & 28,0 & - & 400 & 11200 & 498 & 22,0 & 25,9 & - & 233 & 5424 \\
100 & 245 & 27,0 & 4,2 & 36,4 & - & 400 & 14560 & 238 & 26,2 & 34,3 & - & 250 & 7746 \\
120 & 146 & 29,6 & 4,2 & 44,8 & - & 400 & 17920 & 99 & 29,0 & 42,7 & - & 194 & 7644 \\
140 & 96 & 31,4 & 4,2 & 53,2 & - & 400 & 21280 & 50 & 31,0 & 51,1 & - & 160 & 7651 \\
160 & 68 & 32,8 & 4,2 & 61,6 & 98 & 400 & 24147 & 28 & 32,5 & 59,5 & - & 131 & 7373 \\
180 & 51 & 34,0 & 4,2 & 70,0 & 90 & 400 & 25200 & 17 & 33,7 & 67,9 & 92 & $\frac{110}{6757}$ & 6757
\end{tabular}

צ̈berfitht 8 zeigt, wie Tehrentnahmen ben Ěrfolg f̧mälern, fobald fie liber

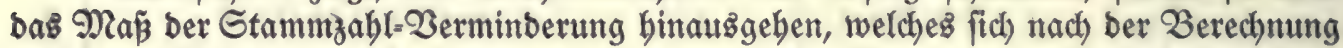

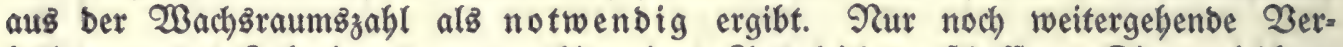

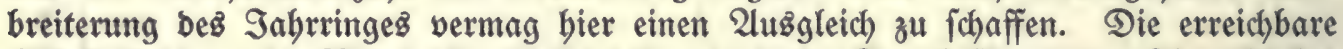
Gtärfezunahme, bie Ringbreite, bleibt baber in lester Pinie befítimment. Shre richtige Feftlegung bilbete fichon für Reventlow und Seebach ben Edhlüffel bes Ganzen. Sie ift zugleid) bas wanbelbarfte (Glieb ber Rechmung, während bie übrigen int

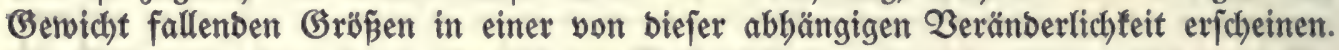
Die Ringbreite fann burch bie 21rt ber Beftanbsbehandlung in einem nicht zu unter-

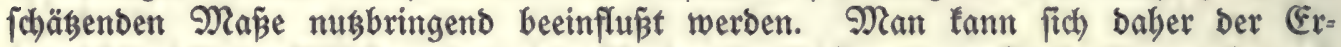

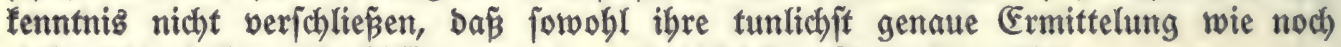
mehr ibre zielbewußste Pflege zu ben einträglichjten Llufgaben zäblt.

3um 2 ergleid) mit ben siberfithten 1 biz 3 folgen noch mit SAnteriftellung einer $\frac{3}{2}$ fachung ber Ringbreite bie S̈berfïhten 11 biz 14 für bie III. Bobentlaffe. Dabei

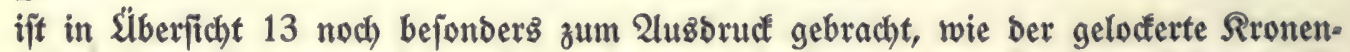

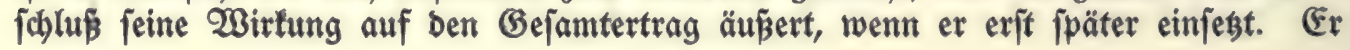


jebó im 2orertrag auf ben פRittelitamm begogen.

\begin{tabular}{|c|c|c|c|c|c|c|c|c|c|c|c|c|}
\hline \multicolumn{2}{|c|}{$\begin{array}{l}\text { Befamtertrag im } \\
\text { खertverbältnis }\end{array}$} & \multicolumn{4}{|c|}{$\mathfrak{I n S o l z}$} & \multicolumn{6}{|c|}{$9 m \mathfrak{B}$ ertuerbăltnis } & \multirow{3}{*}{ 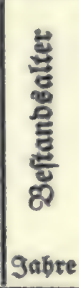 } \\
\hline $\mathrm{S} \underset{\underline{a}}{\underline{D}} \mathrm{D}$ & $V+S \stackrel{a}{=} D$ & Vlz & $\mathrm{Vdz}$ & Giz & Gdz & Vlz & Vdz & Glz & $\mathrm{Gdz}$ & Gwz & $\begin{array}{l}\text { Davon } \\
\text { werben } \\
\text { fruing }\end{array}$ & \\
\hline \multicolumn{2}{|c|}{ etabetten } & \multicolumn{4}{|c|}{ Geftucter } & \multicolumn{4}{|c|}{ 2Bertetubetcen } & \multicolumn{2}{|c|}{ Prozente } & \\
\hline 480 & 2283 & 9,0 & 4,0 & 13,4 & 5,7 & 149 & 45 & 189 & 57 & 10,5 & 2,2 & 40 \\
\hline 2724 & 8859 & 7,0 & 5,2 & 15,8 & 9,1 & 254 & 102 & 408 & 148 & 6,7 & 2,5 & 60 \\
\hline 7619 & 19491 & 5,2 & 5,3 & 16,0 & 10,8 & 297 & 148 & 592 & 244 & 5,0 & 2,5 & 80 \\
\hline 14041 & 32787 & 4,8 & 5,2 & 14,6 & 11,6 & 381 & 188 & 717 & 328 & 3,9 & 1,8 & 100 \\
\hline 21783 & 48305 & 4,4 & 4,9 & 13,2 & 11,9 & 437 & 221 & 812 & 403 & 3,1 & 1,4 & 120 \\
\hline 30724 & 65357 & 3,6 & 4,7 & 11,8 & 12,0 & 457 & 247 & 876 & 467 & 2,5 & 1,2 & 140 \\
\hline 40495 & 82934 & 2,6 & 4,4 & 11,0 & 11,9 & 322 & 266 & 777 & 518 & 1,8 & 1,1 & 160 \\
\hline 51308 & 97550 & 1,7 & 4,1 & 10,0 & 11,7 & 153 & 257 & 703 & 542 & 1,5 & 1,2 & 180 \\
\hline
\end{tabular}

2orrat 400 fm nid)t tiberforeitenb, alsbann ber gejamte 3 utwad) genubt.

\begin{tabular}{|c|c|c|c|c|c|c|c|c|c|c|c|c|}
\hline 480 & 2283 & 9,0 & 4,0 & 13,4 & 5,7 & 149 & 45 & 189 & 57 & 10,5 & 2,2 & 40 \\
\hline 2724 & 8859 & 7,0 & 5,2 & 15,8 & 9,1 & 254 & 102 & 408 & 148 & 6,7 & 2,5 & 0 \\
\hline 8148 & 19348 & 0,0 & 5,0 & 15,0 & 10,7 & 168 & 140 & 557 & 242 & 5,0 & 3,5 & 80 \\
\hline 15894 & 30454 & 0,0 & 4,0 & 11,2 & 11,1 & 168 & 146 & 552 & 305 & 3,1 & 2,6 & 100 \\
\hline 23538 & 41458 & 0,0 & 3,3 & 8,8 & 10,8 & 168 & 149 & 544 & 345 & 3,0 & 2,1 & 12 \\
\hline 31189 & 52469 & 0,0 & 2,9 & 7,6 & 10,4 & 168 & 152 & 556 & 375 & 2,6 & 1,8 & 14 \\
\hline 38562 & 62709 & 0,0 & 2,5 & 6,4 & 9,9 & 69 & 151 & 450 & 392 & 1,9 & 1,6 & 160 \\
\hline 4531 & 70519 & 0,0 & 2,2 & 4,4 & 7,2 & 43 & 140 & 317 & 392 & 1,3 & 1,1 & 18 \\
\hline
\end{tabular}

tann mur bann zum vollen Exfolg fübren, wenn er nod) möglid)it lange augęgenust wirb. Te ppäter man bamit anfangen tann, Dber je geringer bas Dicf́enwachątum an fich ift, ober je weniger feine Sebung gelingt (Ślberficht 9 unb 10), befto länger uno biz in um fo b̆b̆erez allter muß mit ber Rronenumlichtung fortgefabren werben, wenn man ben bächjtmöglichen (Durchfdhnitt Der (Bejamtwerterzeugung erreichen will.

Wir fönnen aljo mit Silfe ber Durd)forjtung im Serrichenden mindeftens bie befīere - gröpere und einträglichere -, wabrjheinlich aber bie befte 2lrbeit er: reichen, und zwar für febr lange Dauer, mit bem Enbziele wirflicher Startholz= Erziebung.

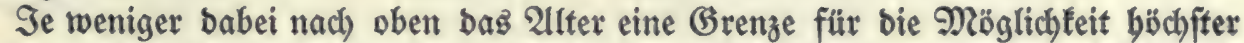

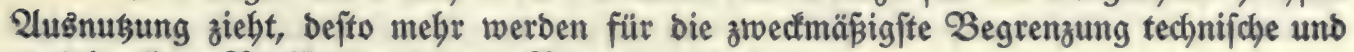
walbbauliche Rüdfichten in ben 2 orbergrunb treten.

3ugleich feien bier noch einige tweitere Wirfungen furg berïbrt, bie in forjtlichen Rreijen allerlei Bebentlichleiten wadhgerufen baben.

(Daş ift zunächft bie Befürchtung, es werbe bei gelodertem Sdhlup zu viel

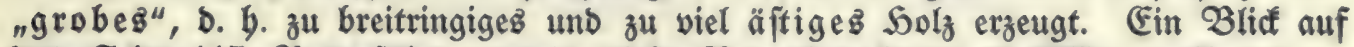
bå Geite 115 2lugigefübrte mad)t biefe Bebenten leidgt binfällig, weil bie zu 
Sibericht 9. Budbe II mit $\frac{5}{4}$ facher

\begin{tabular}{|c|c|c|c|c|c|c|c|c|c|c|c|c|c|}
\hline \multirow{4}{*}{ 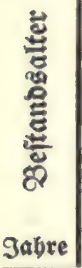 } & \multicolumn{7}{|c|}{$\mathfrak{S} a \mathfrak{a} p$ tbeft $\mathfrak{a} \| b$} & \multicolumn{6}{|c|}{ Entnommen } \\
\hline & \multirow{3}{*}{$\begin{array}{l}\text { Stamm } \\
\text { zabl } \\
\text { Stild }\end{array}$} & \multirow{3}{*}{$\begin{array}{c}\text { MRittel } \\
\text { göbe } \\
\text { m }\end{array}$} & \multirow{3}{*}{$\begin{array}{c}\text { 9äbr. } \\
\text { fiøe } \\
\text { Stärte- } \\
3 u= \\
\text { nabme } \\
\text { mm }\end{array}$} & \multirow{3}{*}{$\begin{array}{c}\text { gDitt- } \\
\text { Iere } \\
\text { Stärfe } \\
\text { in } \\
\text { gruft= } \\
\text { bbbe } \\
\mathrm{cm}\end{array}$} & \multirow[t]{3}{*}{$\begin{array}{c}\text { Eein: } \\
\text { betts: } \\
\text { wert } \\
\text { fällt von } \\
100 \text { auf }\end{array}$} & \multirow{3}{*}{$\begin{array}{c}\text { Borrat } \\
\mathrm{fm}\end{array}$} & \multirow{3}{*}{$\begin{array}{c}9 \mathfrak{y} \\
\text { 2Bert- } \\
\text { verbältuts } \\
\text { Werteinb. }\end{array}$} & \multirow{3}{*}{$\begin{array}{c}\text { Stamm } \\
\text { zabl } \\
\text { Stuid }\end{array}$} & \multirow{3}{*}{$\begin{array}{c}\text { 2Nittel= } \\
\text { böbe } \\
\text { m }\end{array}$} & \multirow{3}{*}{$\begin{array}{c}\text { 2Ritt: } \\
\text { Iere } \\
\text { Stärte } \\
\text { in } \\
\text { gruit: } \\
\text { bobe } \\
\mathrm{cm}\end{array}$} & \multirow[t]{3}{*}{$\begin{array}{c}\text { Ein: } \\
\text { beits. } \\
\text { wert } \\
\text { fălut yon } \\
100 \text { auf }\end{array}$} & \multirow{2}{*}{\begin{tabular}{|c|}
$\begin{array}{c}\text { 3or. } \\
\text { extrag }\end{array}$ \\
fir te \\
\end{tabular}} & \multirow[t]{2}{*}{$\frac{\begin{array}{c}9 \mathrm{~m} \\
\text { 28ert- } \\
\text { verbăttnts }\end{array}}{20 \text { gabre }}$} \\
\hline & & & & & & & & & & & & & \\
\hline & & & & & & & & & & & & $\mathrm{fm}$ & $\mathscr{B} \mathrm{ert}$ \\
\hline 40 & 2623 & 11,9 & 3,5 & 10,2 & - & 160 & 1632 & 3197 & 10,1 & 7,9 & - & 43 & 282 \\
\hline 60 & 1273 & 18,1 & 3,5 & 17,2 & - & 308 & 5298 & 1350 & 16,7 & 13,6 & - & 112 & 1300 \\
\hline 80 & 685 & 23,2 & 3,5 & 24,2 & - & 416 & 10067 & 588 & 21,6 & 19,4 & - & 151 & 2616 \\
\hline 100 & 428 & 27,0 & 3,5 & 31,2 & - & 506 & 15787 & 257 & 25,1 & 25,3 & - & 137 & 3125 \\
\hline 120 & 297 & 29,6 & 3,5 & 38,2 & - & 583 & 22271 & 131 & 28,1 & 31,3 & - & 130 & 3760 \\
\hline 140 & 217 & 31,4 & 3,5 & 45,2 & - & 640 & 28928 & 80 & 30,5 & 38,9 & - & 135 & 4846 \\
\hline 160 & 167 & 32,8 & 3,5 & 52,2 & - & 692 & 36122 & 50 & 32,5 & 47,0 & - & 139 & 6096 \\
\hline \multirow[t]{2}{*}{180} & \multirow[t]{2}{*}{130} & \multirow[t]{2}{*}{34,0} & \multirow[t]{2}{*}{3,5} & \multirow[t]{2}{*}{59,2} & \multirow[t]{2}{*}{-} & \multirow[t]{2}{*}{724} & \multirow[t]{2}{*}{42861} & 37 & \multirow[t]{2}{*}{33,7} & \multirow[t]{2}{*}{55,7} & \multirow[t]{2}{*}{-} & 156 & \multirow[t]{2}{*}{8177} \\
\hline & & & & & & & & 5690 & & & & 1003 & \\
\hline
\end{tabular}

\{̈beritat 10. Buthe II mit $\frac{5}{4}$ fadder

\begin{tabular}{r|r|r|r|r|r|r|r|r|r|r|r|r|r}
40 & 2623 & 11,9 & 3,5 & 10,2 & - & 160 & 1632 & 3197 & 10,1 & 8,4 & - & 52 & 361 \\
60 & 1273 & 18,1 & 3,5 & 17,2 & - & 308 & 5298 & 1350 & 16,7 & 15,4 & - & 141 & 1841 \\
80 & 685 & 23,2 & 3,5 & 24,2 & - & 416 & 10067 & 588 & 22,0 & 22,4 & - & 203 & 4049 \\
100 & 428 & 27,0 & 3,5 & 31,2 & - & 506 & 15787 & 257 & 26,2 & 29,4 & - & 202 & 5401 \\
120 & 297 & 29,6 & 3,5 & 38,2 & - & 583 & 22271 & 131 & 29,0 & 36,4 & - & 186 & 6288 \\
140 & 217 & 31,4 & 3,5 & 45,2 & - & 640 & 28928 & 80 & 31,0 & 43,4 & - & 182 & 7402 \\
160 & 167 & 32,8 & 3,5 & 52,2 & - & 692 & 36122 & 50 & 32,5 & 50,4 & - & 167 & 7967 \\
180 & 130 & 34,0 & 3,5 & 59,2 & - & 724 & 42861 & 37 & 33,7 & 57,4 & - & 132 & 9424 \\
& & & & & & & & 5690 & & & & $\mathbf{1 2 6 5}$ &
\end{tabular}

ertwartenben Steigerungen aus bem $R$ ahmen bes (Guten nicht berausitreten uno mit

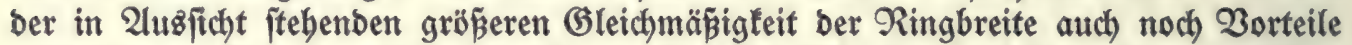

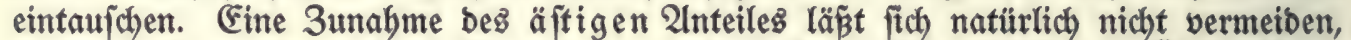

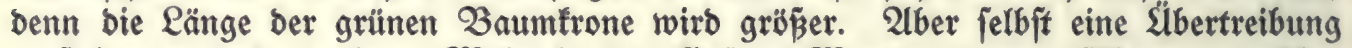
muß immer noch zu einem $\mathfrak{M e h r}$ in ber Bejamt= 2 erterzeugung fübren gegenüber Der EErhaltung bes vollen oberen Gdhlupjptanbes, wie folgenbes einfache 3ahlenbeifpiel

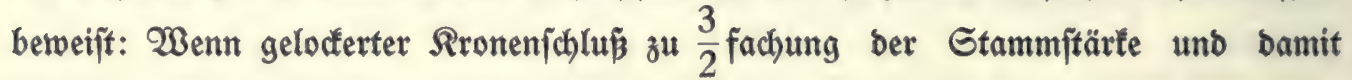

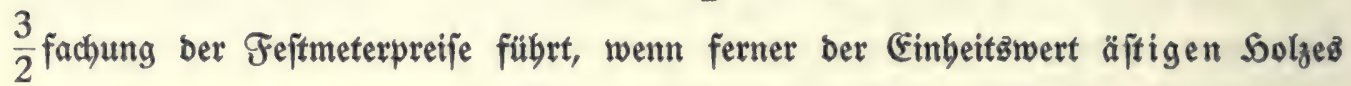

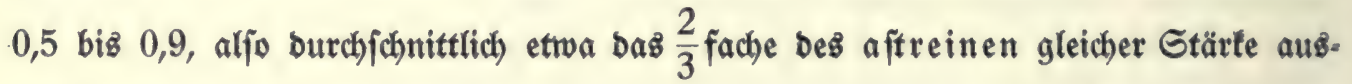
madyt unb nur unter bejonbers ungünjtigen Berbältniffen auf bas $\frac{1}{2}$ fache fintt, fo fann jenes Berfabren bei gleidjem Borrat audh bann noch Feinen Schaben an ber 
Ringbreite, fonit twie Eีberfitbt 6.

\begin{tabular}{|c|c|c|c|c|c|c|c|c|c|c|c|c|}
\hline \multicolumn{2}{|c|}{$\begin{array}{l}\text { (Befamtertrag im } \\
\text { Bertverbältnis }\end{array}$} & \multicolumn{4}{|c|}{ In Sold } & \multicolumn{6}{|c|}{ Sm Wertberbättnis } & \multirow{3}{*}{ 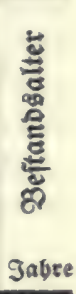 } \\
\hline Sa $\mathrm{a}$ & $\mathrm{V}+\mathrm{S} \underset{\mathrm{a}}{\underline{\mathrm{D}}}$ & $\mathrm{Vlz}$ & $\mathrm{Vdz}$ & $\mathrm{Glz}$ & Gdz & Vlz & $\mathrm{Vdz}$ & $\mathrm{Glz}$ & $\mathrm{Gdz}$ & Gwz & $\begin{array}{l}\text { Davon } \\
\text { werben } \\
\text { fatilg }\end{array}$ & \\
\hline \multicolumn{2}{|c|}{ einbelten } & \multicolumn{4}{|c|}{ Gefitueter } & \multicolumn{4}{|c|}{ wertetnbelten } & \multicolumn{2}{|c|}{ D sosente } & \\
\hline 282 & 1914 & 8,6 & 4,0 & 12,0 & 5,1 & 130 & 41 & 157 & 48 & 9,6 & 1,7 & 40 \\
\hline 1582 & 6880 & 7,2 & 5,1 & 13,6 & 7,7 & 222 & 88 & 309 & 115 & 5,8 & 1,5 & 60 \\
\hline 4198 & 14265 & 4,6 & 5,2 & 12,8 & 9,0 & 253 & 126 & 412 & 178 & 4,1 & 1,6 & 80 \\
\hline 7323 & 23110 & 4,4 & 5,1 & 11,2 & 9,5 & 311 & 158 & 453 & 231 & 2,9 & 0,9 & 100 \\
\hline 11083 & 33354 & 4,2 & 4,9 & 10,6 & 9,6 & 363 & 186 & 563 & 278 & 2,5 & 0,9 & 120 \\
\hline 15929 & 44857 & 4,2 & 4,6 & 10,0 & 9,6 & 413 & 207 & 638 & 320 & 2,2 & 0,8 & 140 \\
\hline 22025 & 58147 & 3,0 & 4,3 & 9,6 & 9,6 & 400 & 226 & 710 & 363 & 2,0 & 0,9 & 160 \\
\hline 30202 & 73063 & 1,6 & 4,0 & 9,4 & 9,6 & 353 & 238 & 787 & $\begin{array}{c}406 \\
1\end{array}$ & 1,8 & 1,0 & 180 \\
\hline
\end{tabular}

\section{Ringbreite, jonjt wie Iีberitcht 7.}

\begin{tabular}{r|r||r|r|r|r|r|r|r|r|r|r|r}
361 & 1993 & 8,6 & 4,0 & 12,6 & 5,3 & 130 & 41 & 163 & $\mathbf{5 0}$ & 10,0 & 2,0 & 40 \\
2202 & 7500 & 7,2 & 5,1 & 15,6 & $\mathbf{8 , 4}$ & 222 & 88 & 351 & $\mathbf{1 2 5}$ & 6,6 & 2,4 & 60 \\
6291 & 16318 & 4,6 & $\mathbf{5 , 2}$ & 15,8 & 10,2 & 253 & 126 & 504 & $\mathbf{2 0 4}$ & 5,0 & 2,5 & 80 \\
11652 & 27439 & 4,4 & 5,1 & 14,2 & 11,0 & 311 & 158 & 601 & $\mathbf{2 7 4}$ & 3,8 & 1,8 & 100 \\
17940 & 40211 & 4,2 & 4,9 & 13,2 & 11,4 & 363 & 186 & 690 & $\mathbf{3 3 5}$ & 3,1 & 1,5 & 120 \\
25342 & 54270 & 4,2 & 4,6 & 11,8 & $\mathbf{1 1 , 5}$ & 413 & 207 & 742 & $\mathbf{3 8 8}$ & 2,6 & 1,1 & 140 \\
33309 & 69431 & 3,0 & 4,3 & 10,6 & $\mathbf{1 1 , 4}$ & 400 & 226 & 783 & $\mathbf{4 3 4}$ & 2,2 & 1,1 & 160 \\
42733 & 85594 & 1,6 & 4,0 & 10,0 & 11,1 & 353 & 238 & 835 & $\mathbf{4 7 6}$ & $\mathbf{1 , 9}$ & 1,1 & 180 \\
& & & & & & & $\downarrow$ & & $\downarrow$ & & &
\end{tabular}

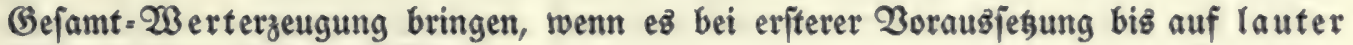
äftiges Solz fommen follte,

$$
\text { benn noch immer ift auch bier } \frac{3}{2} \cdot \frac{2}{3}=1 \text {. }
$$

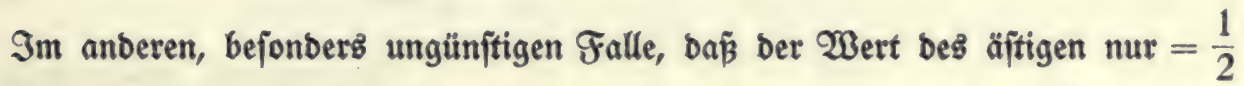

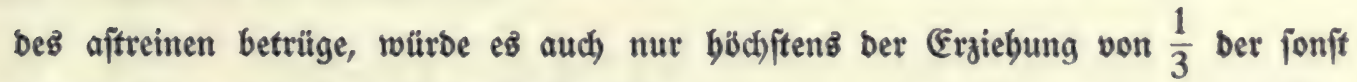
erreichten affreinen Gdhaftmaffe bedürfen,

$$
\text { Dent } \frac{1}{3} \cdot \frac{3}{2}+\frac{2}{3} \cdot \frac{1}{2} \cdot \frac{3}{2}=1 \text {. }
$$

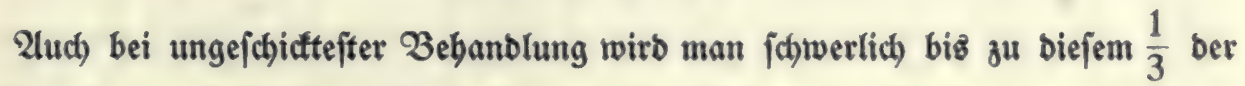

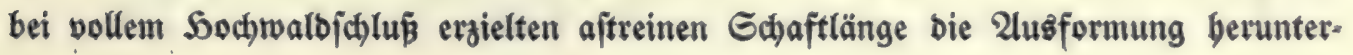




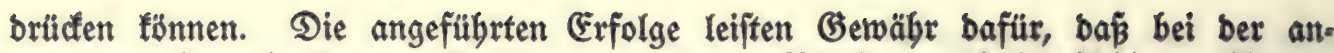

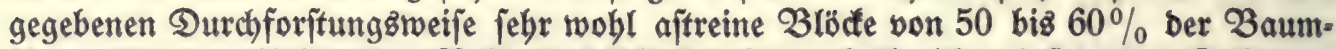

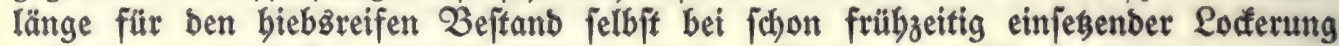
Dez vberen Echluffę heraużzarbeiten fino. Dies namentlich bann, wenn man Den Unterftand, bejonders von bichter jhattenben 2 rten in ausireichender Menge uno

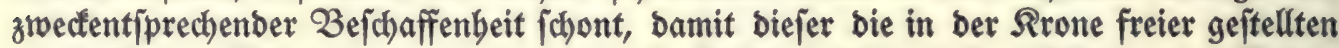
wertbolleren Stämme von unten berauf aftrein machen unb erbalten, ben Boben fchüben unb pflegen bilft.

EEbenjowenig ftebt eine Steigerung ber bem $æ a l b e$ brohenben (5efabren von foldhen $\mathfrak{D u r d b}$ forjtungen im Serrjchenben bei allmählicher Sintiberleitung unb verftändiger Sandhabung zu befürd)ten. EEz werben in Sauptbeftanbe fräftigere

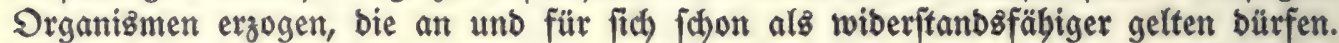
Was infonderbeit ben Sturm anlangt, fo wirft er mur jebr aug̉nahmsineije in einem einzigen 2 Inprall vernichtenb. Gewöbnlich fpricht auch bier febr wejentlid ber Faftor

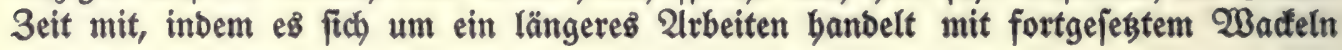

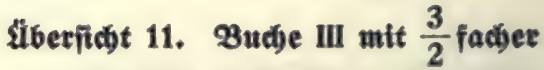

\begin{tabular}{|c|c|c|c|c|c|c|c|c|c|c|c|c|c|}
\hline \multirow{3}{*}{ 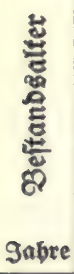 } & \multicolumn{7}{|c|}{$S a u p t b e f t a n b$} & \multicolumn{6}{|c|}{ Entnommen } \\
\hline & \multirow{2}{*}{$\begin{array}{l}\text { Gtamm } \\
\text { zabl } \\
\text { Gtild }\end{array}$} & \multirow{2}{*}{$\begin{array}{c}\text { शrittel- } \\
\text { bibe } \\
\text { m }\end{array}$} & \multirow{2}{*}{$\begin{array}{c}\text { 9ăbr- } \\
\text { latbe } \\
\text { Gtärte. } \\
3 u \\
\text { nabmte } \\
\text { mm }\end{array}$} & \multirow{2}{*}{$\begin{array}{c}\text { 2ritt- } \\
\text { rere } \\
\text { Etăte } \\
\text { in } \\
\text { Bruft: } \\
\text { bobbe } \\
\mathrm{cm}\end{array}$} & \multirow[t]{2}{*}{$\begin{array}{c}\text { Ein: } \\
\text { beition. } \\
\text { wert } \\
\text { füut von } \\
100 \text { auf }\end{array}$} & \multirow[t]{2}{*}{ Bortat } & \multirow{2}{*}{$\begin{array}{c}\text { Sm } \\
\text { Wert. } \\
\text { verbäItnts } \\
\text { Werteinb. }\end{array}$} & \multirow{2}{*}{$\begin{array}{l}\text { Stammt } \\
\text { sabr } \\
\text { Gtilat }\end{array}$} & \multirow{2}{*}{$\begin{array}{c}\text { gattel. } \\
\text { bobe } \\
\text { m }\end{array}$} & \multirow{2}{*}{$\begin{array}{c}\text { Dritt- } \\
\text { rere } \\
\text { Stäte } \\
\text { in } \\
\text { Bruft- } \\
\text { bobbe } \\
\mathrm{cm}\end{array}$} & \multirow[t]{2}{*}{$\begin{array}{l}\text { Cin- } \\
\text { betts. } \\
\text { wert } \\
\text { fâfl von } \\
100 \text { auf }\end{array}$} & $\begin{array}{c}\begin{array}{c}\text { Bor: } \\
\text { extrag }\end{array} \\
\text { fiir ie }\end{array}$ & $\begin{array}{c}\begin{array}{c}9 m \\
\text { æBert. } \\
\text { verbätuis }\end{array} \\
20 \text { gabre }\end{array}$ \\
\hline & & & & & & & & & & & & $\mathrm{fm}$ & खe: \\
\hline 40 & 3055 & 10, & 3,4 & 8 & - & 122 & 1074 & 2055 & 8,6 & 6 & - & 30 & 177 \\
\hline 60 & 1417 & 15,8 & 3,4 & 15,7 & - & 258 & 4051 & 1638 & 14 & 12 & - & 88 & 929 \\
\hline 80 & 700 & 20,4 & 3,45 & 22,6 & - & 330 & 7458 & 717 & 19,0 & 18,1 & - & 136 & 2161 \\
\hline 100 & 420 & 24,0 & 3,45 & 29,5 & - & 399 & 11771 & 280 & 22,3 & 23,9 & - & 120 & 2586 \\
\hline 120 & 286 & 26,5 & 3,4 & 36,4 & - & 460 & 16744 & 134 & 25 & 29 & - & 10 & 2993 \\
\hline 140 & 207 & 28,2 & 3,45 & 43,3 & - & 506 & 21910 & 79 & 27,4 & 37, & - & 112 & 3857 \\
\hline 160 & 156 & 29,8 & 3,45 & 50,2 & - & 546 & 27409 & 51 & 29,4 & 45,2 & - & 119 & 5012 \\
\hline \multirow[t]{2}{*}{180} & \multirow[t]{2}{*}{120} & \multirow[t]{2}{*}{31,0} & \multirow[t]{2}{*}{3,45} & \multirow[t]{2}{*}{57,1} & \multirow{2}{*}{ - } & \multirow[t]{2}{*}{570} & \multirow[t]{2}{*}{32547} & 36 & \multirow[t]{2}{*}{30,7} & \multirow[t]{2}{*}{53,7} & \multirow{2}{*}{ - } & 129 & \multirow{2}{*}{6514} \\
\hline & & & & & & & & 4990 & & & & 843 & \\
\hline
\end{tabular}

G̈betifht 12. Riefer III mit $\frac{3}{2}$ fadget

\begin{tabular}{r|r|r|r|r|l|l|r|r|r|r|r|r|r}
40 & 1969 & 12,0 & 4,0 & 13,6 & - & 203 & 2761 & 4531 & 10,7 & 10,5 & - & 115 & 921 \\
60 & 883 & 15,9 & 4,0 & 21,6 & - & 284 & 6134 & 1086 & 15,0 & 17,1 & - & 132 & 1920 \\
80 & 458 & 19,1 & 4,0 & 29,6 & - & 321 & 9502 & 425 & 17,8 & 23,7 & - & 131 & 2763 \\
100 & 291 & 21,9 & 4,0 & 37,6 & - & 369 & 13874 & 167 & 20,4 & 31,2 & - & 106 & 2990 \\
120 & 203 & 24,1 & 4,0 & 45,6 & - & 409 & 18650 & $\mathbf{8 8}$ & 22,9 & 41,5 & - & 111 & 4193 \\
140 & 147 & 25,8 & 4,0 & 53,6 & 96 & 434 & 22332 & 56 & 25,0 & 51,6 & 98 & 126 & 6036 \\
160 & 111 & 27,3 & 4,0 & 61,6 & 88 & 452 & 24502 & 36 & 27,0 & 59,6 & 90 & 119 & 6256 \\
180 & 87 & 28,4 & 4,0 & 69,6 & 80 & 461 & 25669 & 24 & 28,2 & 67,6 & 82 & 117 & 6155 \\
& & & & & & & & $\mathbf{6 4 1 3}$ & & & & $\mathbf{9 5 7}$ &
\end{tabular}


unb Rütteln, äbnlich wie beim Locfern eineछิ Pfablez von Renjchenbanb. Dem

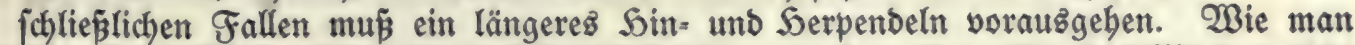

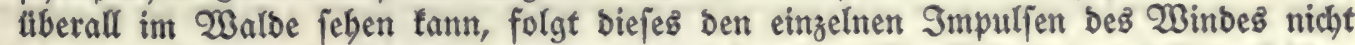

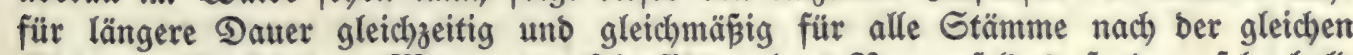
Richtung, äbnlich Dem $230 g e n$ Der Oberfläd)e einez̉ Roggenfelbeš, fonbern febr balb Durcheinanber, entiprecheno Der verjchiebenen Penbellänge ber einzelnen Etämme, alfo un fo ungleichmäpiger, je verfchiebener bie Söbe ift. Diefe fo unb fo oft im gegen= teiligen, einanber hemmenden Sinne fich äupernde WBirtung aนf baร ineinander verichlungene und verwachfene 23 urzelgetwebe und ben 2 urzelteller fann nicht ofne Einfluß bleiben auf bie Gtandfeftigleit ber Bejtände. Sebenfalls lebrt ber $23 a l b$ an vielen Beifpielen, baßj im $23 a d)$ rraum beengte, uniform gleich lange Gruppen ber Gefabr leidjter erliegen als bie mit Bielgeftaltigfeit in Der Söbenabftufung. Lebtere zeigen in böherem Grabe bie Eidherung in fich felbit. Erliegt bier bennoch ber vor.

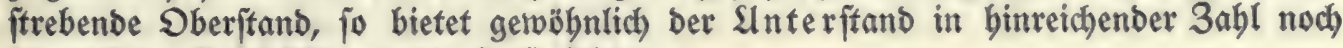
braucbbare Erjatzitämme, bie jonj feblen.

Ringbreite, fonf wie Îlberît 6.

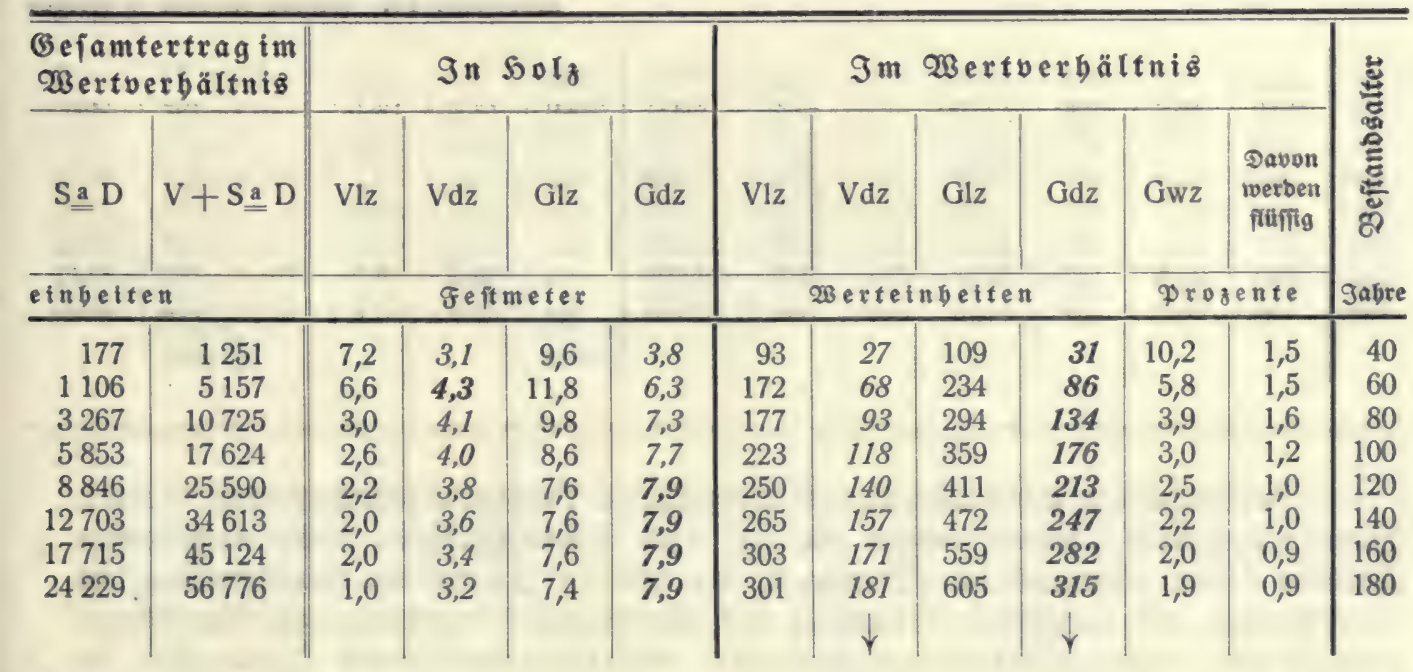

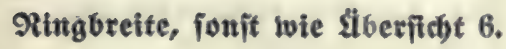

\begin{tabular}{|c|c|c|c|c|c|c|c|c|c|c|c|}
\hline 921 & 3682 & 5,0 & 5,1 & 10,6 & 8,0 & 135 & 69 & 192 & 92 & 7,0 & 2,1 \\
\hline 2841 & 8975 & 3,4 & 4,7 & 10,0 & 8,9 & 175 & 102 & 284 & 150 & 4,6 & 1,8 \\
\hline 5604 & 15106 & 1,0 & 4,0 & 7,6 & 8,7 & 154 & 119 & 306 & 189 & 3,2 & 1,6 \\
\hline 8594 & 22468 & 2,0 & 3,7 & 6,8 & 8,5 & 219 & 139 & 394 & 225 & 2,9 & 1,3 \\
\hline 12787 & 31437 & 1,2 & 3,4 & 6,8 & 8,4 & 216 & 155 & 465 & 262 & 2,5 & 1,3 \\
\hline 18823 & 41155 & 0,8 & 3,1 & 7,0 & 8,3 & 118 & 160 & 441 & 294 & 2,0 & 1,5 \\
\hline 25079 & 49581 & 0,6 & 2,8 & 6,6 & 8,1 & 84 & 153 & 405 & 310 & 1,7 & 1,3 \\
\hline 31234 & 56903 & 0,8 & 2,6 & 6,6 & 7,9 & 51 & 143 & 328 & 316 & 1,3 & 1,1 \\
\hline
\end{tabular}




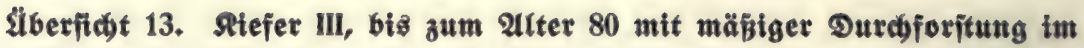

\begin{tabular}{|c|c|c|c|c|c|c|c|c|c|c|c|c|c|}
\hline \multirow{3}{*}{ 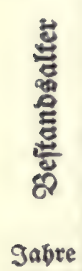 } & \multicolumn{7}{|c|}{ So a u p t beftanb } & \multicolumn{6}{|c|}{ Entnommen } \\
\hline & \multirow{2}{*}{\begin{tabular}{|c|} 
Stamm: \\
zabl \\
Gttid
\end{tabular}} & \multirow{2}{*}{$\begin{array}{c}\text { פritter- } \\
\text { bobe } \\
\text { m }\end{array}$} & \multirow{2}{*}{ 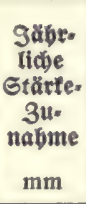 } & \multirow{2}{*}{$\begin{array}{c}\text { Ditit- } \\
\text { lere } \\
\text { Starkte } \\
\text { tn } \\
\text { Bruft- } \\
\text { bobe } \\
\mathrm{cm}\end{array}$} & \multirow[t]{2}{*}{$\begin{array}{l}\text { Cin: } \\
\text { bett } 8= \\
\text { wert } \\
\text { fülut bon } \\
100 \text { ouf }\end{array}$} & \multirow{2}{*}{$\begin{array}{l}\text { 20rrat } \\
\mathrm{fm}\end{array}$} & \multirow{2}{*}{$\begin{array}{c}9 m \\
\text { wert. } \\
\text { verbältnis } \\
\text { Werteing. }\end{array}$} & \multirow{2}{*}{$\left|\begin{array}{c}\text { Etamm: } \\
\text { zabt } \\
\text { Stidi }\end{array}\right|$} & \multirow{2}{*}{$\mid \begin{array}{c}\text { DRittel- } \\
\text { bibe } \\
\mathrm{m}\end{array}$} & \multirow{2}{*}{$\begin{array}{c}\text { शritt- } \\
\text { lere } \\
\text { Stärfe } \\
\text { in } \\
\text { gruft. } \\
\text { böbe } \\
\mathrm{cm}\end{array}$} & \multirow[t]{2}{*}{$\begin{array}{l}\text { Cetn. } \\
\text { beits: } \\
\text { wert } \\
\text { fâtut von } \\
100 \text { auf }\end{array}$} & \multirow{2}{*}{\begin{tabular}{|c|}
$\begin{array}{c}\text { Bor: } \\
\text { ertrag }\end{array}$ \\
fitr ie \\
\end{tabular}} & $\begin{array}{c}\text { 9m } \\
\text { 2Bert. } \\
\text { verbätnts } \\
20 \text { gabre }\end{array}$ \\
\hline & & & & & & & & & & & & & $23 \mathrm{e}$ \\
\hline 40 & 3070 & 12,0 & 2,7 & 10,9 & - & 211 & 2300 & 3430 & 8,2 & 7,5 & - & 52 & 329 \\
\hline 60 & 1490 & 15,9 & 3,0 & 16,8 & 一 & 292 & 4906 & 1580 & 12,3 & 11,2 & - & 70 & 693 \\
\hline 80 & 870 & 19,1 & 2,8 & 22,8 & - & 354 & 8071 & 620 & 14,2 & 15,4 & - & 65 & 895 \\
\hline 100 & 526 & 21,9 & 3,6 & 30,0 & - & 416 & 12480 & 344 & 18,0 & 23,4 & - & 99 & 2043 \\
\hline 120 & 336 & 24,1 & 4,0 & 38,0 & - & 469 & 17822 & 190 & 21,7 & 32 & - & 132 & 3867 \\
\hline 140 & 229 & 25,8 & 4,0 & 46,0 & - & 496 & 22816 & 107 & 24,3 & 42,8 & - & 151 & 5909 \\
\hline 160 & 166 & 27,3 & 4,0 & 54,0 & 96 & 521 & 27009 & 63 & 27,0 & 52,0 & 98 & 154 & 7455 \\
\hline \multirow[t]{2}{*}{180} & \multirow[t]{2}{*}{126} & \multirow[t]{2}{*}{28,4} & \multirow[t]{2}{*}{4,0} & \multirow[t]{2}{*}{62,0} & \multirow[t]{2}{*}{88} & \multirow[t]{2}{*}{540} & \multirow[t]{2}{*}{29462} & 40 & \multirow[t]{2}{*}{28,2} & \multirow[t]{2}{*}{60,0} & \multirow[t]{2}{*}{90} & 142 & \multirow[t]{2}{*}{7519} \\
\hline & & & & & & & & 6374 & & & & 865 & \\
\hline
\end{tabular}

İberîtcht 14. Fidhte III mit $\frac{3}{2}$ fadher

\begin{tabular}{|c|c|c|c|c|c|c|c|c|c|c|c|c|}
\hline \begin{tabular}{l|l}
40 & 4158
\end{tabular} & 9,2 & 3,9 & 10,0 & - & 237 & 2370 & 4092 & 7,5 & 7,7 & - & 71 & 492 \\
\hline 1618 & 15,9 & 3,9 & 17,8 & - & 413 & 7351 & 2540 & 14,4 & 14,1 & - & 194 & 2257 \\
\hline 809 & 20,7 & 3,9 & 25,6 & - & 515 & 13184 & 809 & 19,7 & 21,8 & - & 230 & 4293 \\
\hline 500 & 23,9 & 3,9 & 33,4 & 97 & 596 & 19309 & 309 & 23,2 & 31,1 & 99 & 228 & 6238 \\
\hline 348 & 25,8 & 3,9 & 41,2 & 88 & 626 & 22696 & 152 & 25,4 & 39,3 & 91 & 207 & 7044 \\
\hline 257 & 27,4 & 3,9 & 49,0 & 72 & 667 & 23532 & 91 & 27,0 & 47,1 & 76 & 188 & 6789 \\
\hline 194 & 28,9 & 3,9 & 56,8 & 63 & 693 & 24798 & 63 & 28,6 & 54,9 & 65 & 182 & 6441 \\
\hline 180 & \multirow[t]{2}{*}{30,2} & \multirow[t]{2}{*}{3,9} & \multirow[t]{2}{*}{64,6} & \multirow[t]{2}{*}{55} & \multirow[t]{2}{*}{708} & \multirow[t]{2}{*}{25155} & 44 & \multirow[t]{2}{*}{29,9} & \multirow[t]{2}{*}{62,7} & \multirow[t]{2}{*}{57} & 174 & \multirow[t]{2}{*}{6230} \\
\hline 150 & & & & & & & 8100 & & & & 1474 & \\
\hline
\end{tabular}

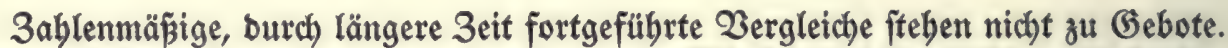
Einen ungefäbren 2lnbalt mögen bie auf bas Wirtichaftgjabr 1905 entfallenden Berlujte bieten cinerjeitz im $\mathfrak{B r a m w a l}$, wo jeit 18 Sabren bie Durchforffung im

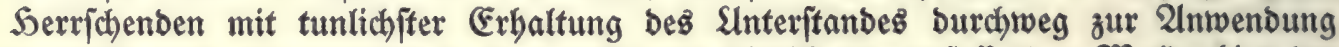
gebracht wirb, anbererjeits in bem mebr alg 18000 ha umfaffenden 2 albgebiet ber benad)barten Reviere mit jonjt jebr ähnlichen Berbältniffen, wo aber nid)t ober nur Gin und wieber auf jene 2 art burchforftet ift. Danach bat im Durdsichnitt pro Seftar ber Brammalb burch Gturm verloren in $\mathfrak{B}$ ude etwa ein 2 rittel, in Fichte etwa bie Sälfte an Feitmeterzahl von ben bortigen Einbǚen. Daz fpricht, wenn eళ̊ auch nicht unbebingt beweift, feineß̊falls zu ungunften eines berart gelocterten oberen Rronenichlufeв.

Nicht anberz liegt bie Gache beim $G_{\text {dhn }}$ eebruct. Sier fpringen bie Borzüge fortgefegter berartiger 2lużmujterungen ohne weiteres in bie 2 lugen, weil ę̧ fich um

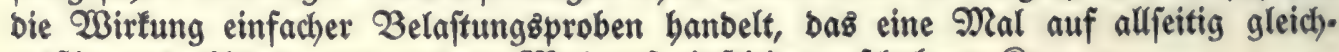
måpig ausgebilbete, bas anbere $\mathfrak{M a l}_{\text {auf }}$ einjeitig verjchobene Rronen. 
Belgerridten, von ba ab im Serridgenben mit $\frac{3}{2}$ fadjer Ringbreite wie Silberfint 6 .

\begin{tabular}{|c|c|c|c|c|c|c|c|c|c|c|c|c|}
\hline \multicolumn{2}{|c|}{$\begin{array}{l}\text { Gefamtertrag im } \\
\text { wertverbätnis }\end{array}$} & \multicolumn{4}{|c|}{$9 n \mathfrak{S O l z}$} & \multicolumn{6}{|c|}{ Im 2Bertuerbätnis } & \multirow{3}{*}{ 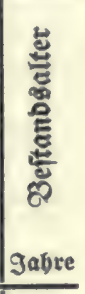 } \\
\hline $\mathrm{S} \underset{\mathrm{a}}{\mathbf{D}} \mathrm{D}$ & $\mathrm{V}+\mathrm{S} \stackrel{\mathrm{a}}{=} \mathrm{D}$ & $\mathrm{Vlz}$ & $\mathrm{Vdz}$ & $\mathrm{Glz}$ & $\mathrm{Gdz}$ & $\mathrm{Vlz}$ & $\mathrm{Vd} z$ & $\mathrm{Glz}$ & $\mathrm{Gdz}$ & Gwz & $\begin{array}{c}\text { werben } \\
\text { friflitg }\end{array}$ & \\
\hline \multicolumn{2}{|c|}{ cinbetten } & \multicolumn{4}{|c|}{ Geft meter } & \multicolumn{4}{|c|}{ wertetubetten } & \multicolumn{2}{|c|}{ Drozente } & \\
\hline 329 & 2629 & 5,0 & 5,3 & 8,0 & 6,6 & 107 & 58 & 129 & 66 & 5,6 & 1,0 & 40 \\
\hline 1022 & 5928 & 3,6 & 4,9 & 7,4 & 6,9 & 143 & 82 & 185 & 99 & 3,8 & 0,9 & 0 \\
\hline 1917 & 9988 & 2,8 & 4,4 & 5,6 & 6,8 & 159 & 101 & 202 & 125 & 2,5 & 0,5 & 80 \\
\hline 3960 & 16440 & 3,2 & 4,2 & 8,2 & 7,0 & 250 & 125 & 377 & 164 & 3,0 & 1,0 & 100 \\
\hline 7827 & 25649 & 2,0 & 3,9 & 8,6 & 7,4 & 256 & 149 & 479 & 214 & 2,7 & 1,3 & 120 \\
\hline 13736 & 36552 & 1,5 & 3,5 & 9,1 & 7,6 & 261 & 163 & 582 & 261 & 2,6 & 1,4 & 140 \\
\hline 21191 & 48200 & 1,0 & 3,3 & 8,7 & 7,8 & 146 & 169 & 535 & 301 & 2,0 & 1,4 & 160 \\
\hline 28710 & 58172 & 0,9 & 3,0 & 8,0 & 7,8 & 113 & 164 & 483 & 323 & 1,6 & 1,3 & 180 \\
\hline
\end{tabular}

Ringbreite, fonfit wie S̈berfid)t 6.

\begin{tabular}{r|r|r|r|r|r|r|r|r|r|r|r|r|}
492 & 2862 & 7,4 & 5,9 & 14,8 & 7,7 & 150 & 59 & 207 & $\mathbf{7 2}$ & $\mathbf{8 , 7}$ & 2,4 & 40 \\
2749 & 10100 & 9,4 & $\mathbf{6 , 9}$ & 19,0 & 11,3 & 295 & 123 & $\mathbf{4 3 4}$ & $\mathbf{1 6 8}$ & 5,9 & 1,9 & 60 \\
7042 & 20226 & 5,0 & 6,4 & 16,5 & 12,6 & 309 & 165 & 544 & $\mathbf{2 5 3}$ & 4,1 & 1,8 & 80 \\
13280 & 32589 & 4,3 & 6,0 & 15,7 & $\mathbf{1 3 , 2}$ & 300 & $\mathbf{1 9 3}$ & 632 & $\mathbf{3 2 6}$ & 3,3 & 1,7 & 100 \\
20324 & 43020 & 2,4 & 5,2 & 12,8 & 13,0 & 181 & 189 & 536 & $\mathbf{3 5 9}$ & 2,4 & 1,6 & 120 \\
27113 & 50645 & 2,2 & 4,8 & 11,6 & 12,8 & 44 & 168 & 346 & 362 & 1,5 & 1,3 & 140 \\
33554 & 58352 & 1,9 & 4,3 & 11,0 & 12,5 & 81 & 155 & 383 & $\mathbf{3 6 5}$ & 1,5 & 1,2 & 160 \\
39784 & 64939 & 0,8 & 3,9 & 9,5 & 12,1 & 15 & 140 & 306 & $\mathbf{3 6 1}$ & 1,2 & 1,2 & 180 \\
& & & & & & & & & & & &
\end{tabular}

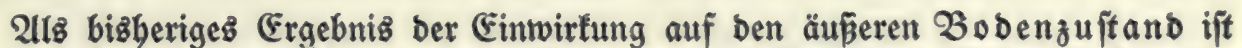
allerorten erfennbar eine 2lnberung zum Befferen. In Buche unb (Fidhe: 3 uammenfallen ber bohen, unzerjegten Raubbecfe, zunehmende Durchmürbung ber oberen Boben: fichic)t, 2usbreitung ber Mulfflora, bejonberzె Gauerflee, Walbmeifter, Bingelfraut; in Fichte unb Riefer: Sidbjegen Der rohen Rabelbecfe, 2luftreten von Mloofen, Gauertlec, Garnfraut.

3ur Frage ber $\mathfrak{B}$ ieberfebr ber Durdbforftungen fei bemert, baj fowohl bie

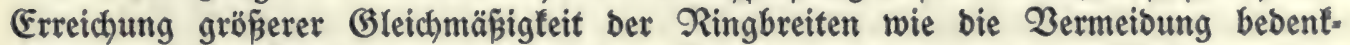
licher, zu jäher Eingriffe für bäufigere Wieberholungen jprechen. Will man ben einzelnen Eingriff in Den Grenzen von 10 bis $20 \%$ Der jeweiligen Etammzabl halten,

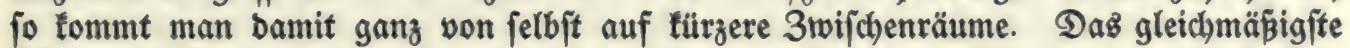

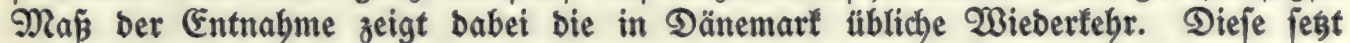
biż etwa zum 2llter 100 bie 2(nzahl ber 3wijchenjabre gleich) Der 3iffer beż entprechenden Sabrzebnts, burdjforjtet aljo in ben $30 \mathrm{er}$ Sabren alle 3 in ben $40 \mathrm{er}$ alle 4 , in ben 50 er Sabren alle 5 Sabre uff. uno febrt erjt vom 100. aufwärts alle 
10 Sabre wieber. Nacbjtebent if die prozentuefle Gtammzablverminderung für biefe, powie für bie 5 and 10 jäbrige Wieberfehr miteinander in 2 ergleich geftellt.

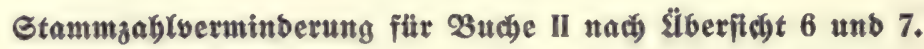

\begin{tabular}{|c|c|c|c|c|c|c|c|}
\hline \multirow{2}{*}{$\begin{array}{c}\text { Beftanosalter } \\
\text { gabre } \\
\end{array}$} & \multirow{2}{*}{$\begin{array}{c}\text { Gtammzabl } \\
\text { Gttid }\end{array}$} & \multicolumn{6}{|c|}{$\begin{array}{c}\text { 3u entnebmen bei } \text { Wieberfebr ber } \\
\text { (Durd)foritung nach }\end{array}$} \\
\hline & & Sabren & $\%$ & Sabren & $\%$ & Sabren & $\%$ \\
\hline 30 & 3814 & 3 & 13 & 5 & 22 & 10 & 43 \\
\hline 40 & 2175 & 4 & 14 & 5 & 18 & 10 & 35 \\
\hline 50 & 1412 & 5 & 16 & 5 & 16 & 10 & 31 \\
\hline 60 & 981 & 6 & 17 & 5 & 14 & 10 & 28 \\
\hline 70 & 706 & 7 & 19 & 5 & 14 & 10 & 27 \\
\hline 80 & 512 & 8 & 19 & 5 & 12 & 10 & 24 \\
\hline 90 & 392 & 9 & 18 & 5 & 10 & 10 & 20 \\
\hline 100 & 315 & 10 & 18 & 5 & 9 & 10 & 18 \\
\hline 110 & 259 & 10 & 17 & 5 & 9 & 10 & 17 \\
\hline 120 & 216 & 10 & 15 & 5 & 8 & 10 & 15 \\
\hline 130 & 183 & 10 & 14 & 5 & 7 & 10 & 14 \\
\hline 140 & 157 & 10 & 13 & 5 & 7 & 10 & 13 \\
\hline
\end{tabular}

Enticheibet man fich für gleichbleibende 3wijchenzeiten, fo wirtbe Demnach biz zum 80. ober 100. Sabre bie Wiebertebr alle 5 Sabre ben $\mathfrak{B}$ orzug verbienen.

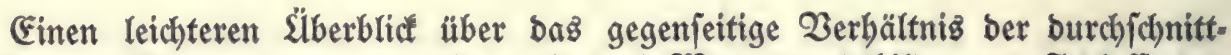

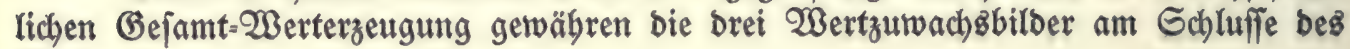
Bucheร..

Der fürzeren 3ujammmenfaffung und einfacheren Begenüberftellung ber Ëno. ergebniffe bienen bie šlberfichten 15 bis 17.

Ėz lann nicht in Der 2lbitht liegen, aus ben wenigen bier entwickelten Beifpielen weitergehenbe und ins einzelne fübrende Echlüiffe zu ziehen. (Ës genüge, ben einfachen, aber auf Tatjächlichem rubenden 3ablentreis fo weit gejchloffen zu feben,

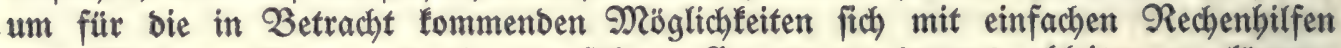
bem Wabren näbern uno bie ungefähren Grenzwerte baraus ableiten zu tönnen. Sie erjoseinen auch in biejen allgemeinen SImriffen beutlid) genug, um Daraus bie Richtung bez weiter einzujhlagenben 2 egez erfennen zu fönnen.

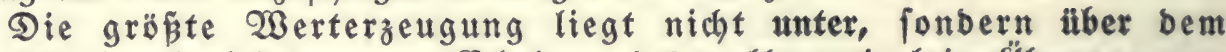
Alter 120, fowobl bei bauernber Ërbaltung bes vollen wie beim s̈bergang zum gelocierten Rronenjolum.

Man hat bie Wabl, ob man über bas 2lter 120 binaus bie ßerterzeugung Der lesten brei Epalten ausmuken ober bafür nach 2abwirtichaftung und nette Roften erforbernber Beftandşbegrïnbung von vorn anfangen unb fich für bie gleiche $3 e i t$ mit bem Erträgnis ber zwei vorberften Spalten begnîgen will in bem Bewuptéein, ba= mit beffer feinem prozentuellen Bebürfniz Rechnung getragen zu baben.

Nan hat bie $23 a h l, ~ o b$ man ber 2 eizheit legten Echlü juchen will in ber

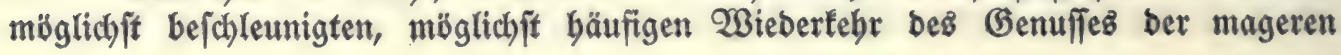




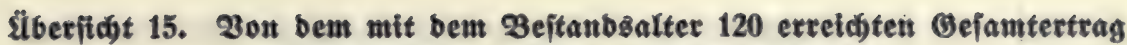
an Derbigolz + Reifig im 2 Bertvergältnis

\begin{tabular}{|c|c|c|c|c|c|c|c|c|}
\hline \multirow{3}{*}{ werben ergeugt } & \multicolumn{8}{|c|}{ in ber 2ltergtlañe } \\
\hline & $\left|\begin{array}{c}\mathrm{b} i \mathrm{~B} \\
40\end{array}\right|$ & $\begin{array}{l}41 \\
\text { biz } \\
60\end{array}$ & $\left|\begin{array}{c|}61 \\
\text { bią } \\
80\end{array}\right|$ & \begin{tabular}{|l|}
81 \\
bis \\
100
\end{tabular} & \begin{tabular}{|l|}
101 \\
$\mathbf{b i g}$ \\
120
\end{tabular} & $\left|\begin{array}{l}121 \\
\text { biB } \\
140\end{array}\right|$ & $\mid \begin{array}{l}141 \\
\text { bis } \\
160\end{array}$ & \begin{tabular}{|l}
161 \\
bit \\
180
\end{tabular} \\
\hline & \multicolumn{8}{|c|}{ 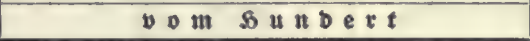 } \\
\hline
\end{tabular}

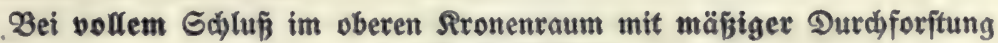
im Beberrid)ten.

\begin{tabular}{|c|c|c|c|c|c|c|c|c|c|c|c|}
\hline & & nad & šberficht & 7 & 17 & 24 & 26 & 26 & & 24 & 21 \\
\hline . I & entipt & n & " & 6 & 18 & 23 & 26 & 27 & 27 & 24 & 4 \\
\hline & Extra & 。 & " & 16 & 20 & 24 & 22 & 18 & 19 & 18 & \\
\hline & & " & $"$ & 10 & 19 & & 24 & & & & \\
\hline
\end{tabular}

Bei geloctertem Gdilu im oberen Sironenraum und Durdforfitung in serrictienben.

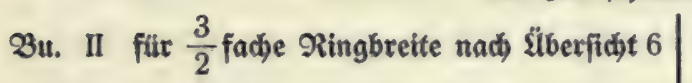

" $\frac{3}{2}$

\begin{tabular}{|c|c|c|}
6 & 5 & 15 \\
7 & 5 & 14 \\
8 & 5 & 16 \\
9 & 6 & 15 \\
10 & 4 & 14 \\
\hline & 5 & 15
\end{tabular}

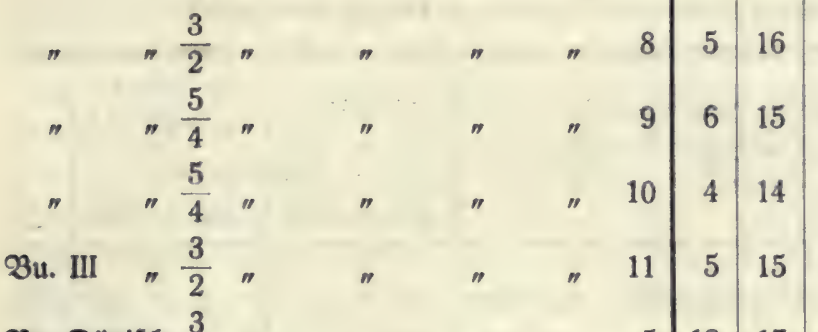

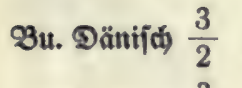

Sic. III für $\frac{3}{2}$

" $\frac{2}{2}+\frac{3}{2}$ fadje "

Fi. III " $\frac{3}{2}$ fadie

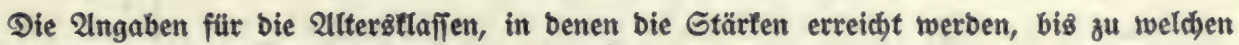
bie Cinlleitŝwerte wie bie Durd)mefler f́teigen, find fetter gebrudt.

zrvei borberften Epalten mit ben unvermeiblic) binzutretenben Rulturauggaben ober in

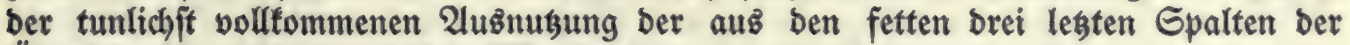
S̈berfid)t 15 winfenden boben Werterzeugung, aljo ob man bie vielgenannten guten Legebübner vor ober nach Errjchöpfung ihrez golbenen Eierfegens jahlachten will.

2lbtreiben uno Rablbauen Der Brotberbiener vor ber 3eit fino febr bebent= liche Sinternebmungen. Pan bleibe fid) ber vollen Berantwortlichleit bewuṕt uno vergefie nie, wie leicht und rajch alte, aufgejparte Borräte fidh aufbrauchen lafjen,

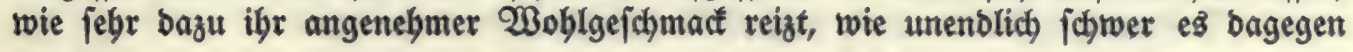




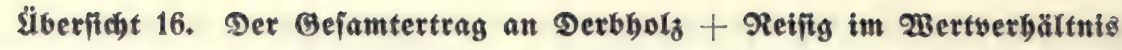

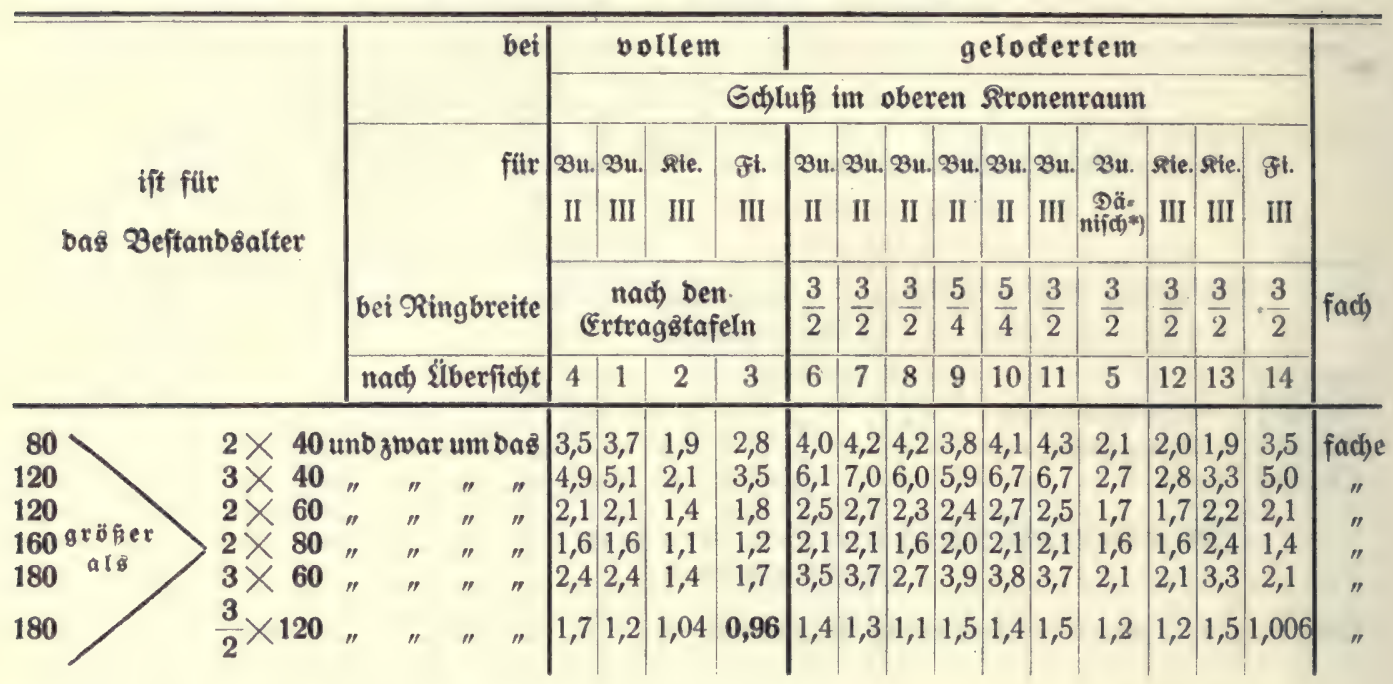

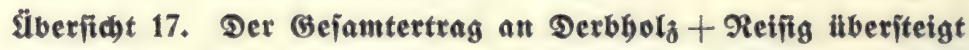

bei geloctertem oberen Rronenjळhluß̃ Denjenigen Des

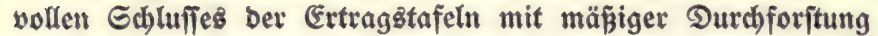
nach) Ślberficht $1,2,3,4$ bei

ஒื. II für $\frac{3}{2}$ facbe Ringbreite nad) Überfitht 6 um ১aв

\begin{tabular}{|c|c|c|c|c|}
\hline \multicolumn{2}{|c|}{ in $\mathrm{Solz}$} & \multicolumn{2}{|c|}{$\begin{array}{l}\text { im } 2 \text { ert- } \\
\text { verhätnis }\end{array}$} & \\
\hline \multicolumn{4}{|c|}{ im Beftandģalter } & \\
\hline 120 & 180 & 120 & 180 & \\
\hline 1,2 & 1,4 & 1,5 & 1,9 & fadbe \\
\hline 1,4 & 1,6 & 1,8 & 2,1 & $"$ \\
\hline 1,3 & 1,3 & 1,6 & 1,5 & " \\
\hline 1,2 & 1,3 & 1,3 & 1,6 & $n$ \\
\hline 1,4 & 1,5 & 1,5 & 1,9 & " \\
\hline 1,2 & 1,3 & 1,5 & 1,9 & $"$ \\
\hline 1,4 & 1,4 & 1,8 & 1,9 & $"$ \\
\hline 1,4 & 1,7 & 1,9 & 2,2 & $n$ \\
\hline 1,3 & 1,6 & 1,5 & 2,3 & $"$ \\
\hline 1,4 & 1,6 & 1,6 & 1,6 & $\Rightarrow$ \\
\hline
\end{tabular}

Fi. III

จu. III

$$
\text { " } \frac{3}{2}
$$

Bu. Dänij๘") " $\frac{3}{2}$ "

Rie. III

$$
\begin{aligned}
& \text { " } \frac{3}{2} " \\
& =\frac{2}{2}+\frac{3}{2} \text { fache } " \\
& =\frac{3}{2} \text { facte }
\end{aligned}
$$

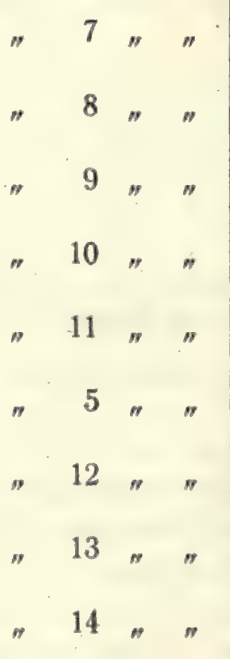

") Berglidjen mit 3 u. II bei mäpiger Durchforftung im Beberridten. 
roirb, unb welches Berzid)teళ eв bebarf, fie ba allmählich wieber nachzuzieben, wo

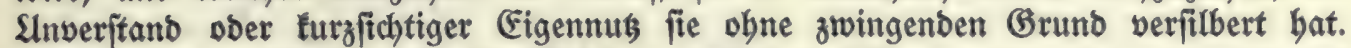
Went Borausficht unb Borfid)t voranteben jollen, wirb es unabweizbarez

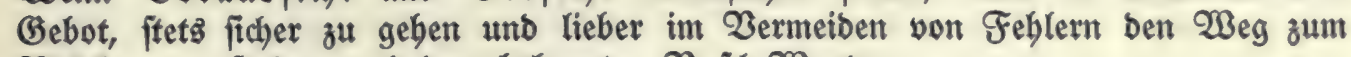
Richtigen zu juchen nach Dem befannten $\mathfrak{B} u$ jh-Worte:

\section{(DaB Gute - biejer Gab fiebt feft -

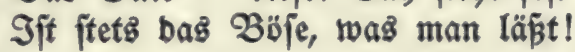

2uch bie vielgepriejente Prozentwirtid)aft vermag in ber $23 i t f(i c h$ teit nicht

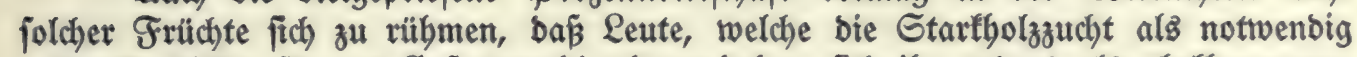

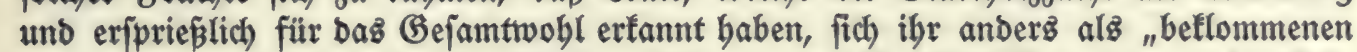
Serzenz" in bie 21 rme werfen umo untrügliche Eprache ber Tatjachen. Slberall, wo man fich über bas blöe Liebäugeln binaus zu weit mit ber Prozentwirtichaft eingelaffen hat, Gaben bie wertwollen 2lltbeftänbe bie 3eche bafür bezablen müiffen. 2luch als Gegengenid)t gegen angeblich "ỉbertrieben bobe" Slmtriebe bedürfen wir ihrer nicht. Denn wo find bei ung noch bie überalten, "faulen" Beftänbe zu finben, weldhe, wenn man

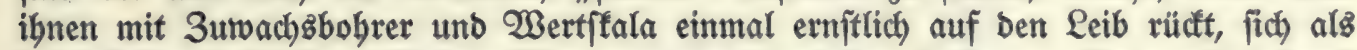

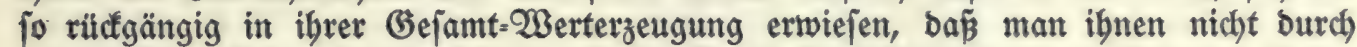
angemefiene Bebandlung rieber auf bie Etrümpfe helfen fonnte. Ober wo ift ber

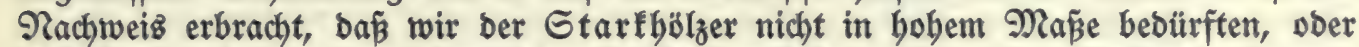

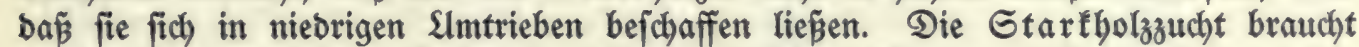

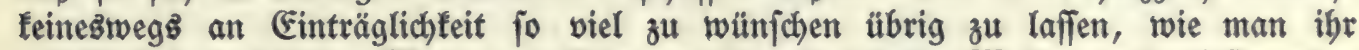
getwöbnlich nachfagt. Pag ber Privatmann mit feinem 2 albe nach biejen ober jenen Grunbjäßzen verfabren, wie er will. Staatsforfiten bürfen nicht Gegenitanb rein faufmännifcher SAnternebmungen werben. Gollen fie ber Bebarfabefriebigung bez Lanbes im reichjiten Naßje gerecht werben, fo wirb bie Starkbolzzucht eine ifrer widhtigften 2lufgaben bleiben müfien. SAno fie fann bies, obne bafür bie vermeintlich fo bohen Opfer zu erforbern.

Golange Starḱgolzzucht als nötig unb nüblich fíd erweift, bie Prozent= wirtjhafft aber als ibre Gegnerin gelten mun, wirb man gut baran tun, von ber Prozentroirtichaft wenigitens in ben Staatsforiten fern zu bleiben, olgne jeboch ba eine beffere Berzinjung zu unterfchäßsen ober gar von ber Sanb zu weijen, two fie

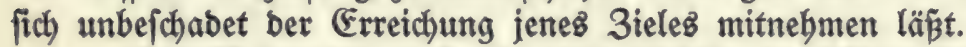

Gtarkholzzucht verfpricht bie böchfte burchjohnittliche (Gefamt=2Bertleiftung pro Flächeneinbeit. Durch fortgejeste (Gemährung eines ber erreichbaren Gtärfe-

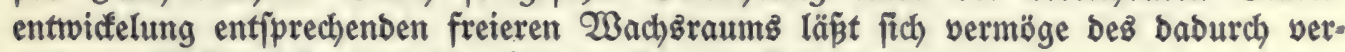
mehrten Dicfentwach)ztums Das 3iel in fürzerer 3eit erreichen.

Der gelocferte obere Rronenjchlué geifattet eine erbeblich bägere Nubbarmachung als bie bauternbe E゙rhaltung Deż vollen, uno zwar biz über bie Etärle binauछ̄, biz zu welcher bie Einbeitżwerte fteigen wie bie (Durchmefier.

CEs gilt, für bas bier nur in allgemeinen Slmrifien und nach ben ungefäbren Grenzwerten Berfolgte weitere unb genauere Slnterlagen zu gewinnen. Die vom

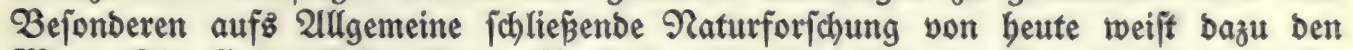
Weg. Shr (5runopfeiler ift ber $\mathfrak{B} e r j u c h$. Gie bält biejentge Theorie für bie befte,

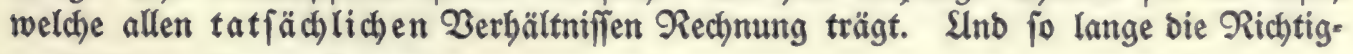


feit ibrer Berjucbe nidbt burd) Tatjachen wiberlegt if́, weift fie alle nur auf Frwägungen gegrïnbeten (Eintoänbe zurüă. Gie füblt fich nid)t gebunben burch ben

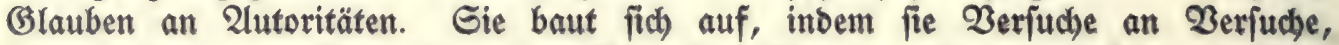
Beobachtungen an Beobachtungen reibt. Sie läßjt nur gelten, was̊ fich nach Sat: fächlichem meffen, berechnen und folgerid)tig entwideln läpt, einerlei, ob es fich mit bem bişher allgemein Geglaubten bectit ober ihm zuwiberläuft.

Die in Daz Grope gebenden Gpefulationen über baż Problem haben vielen

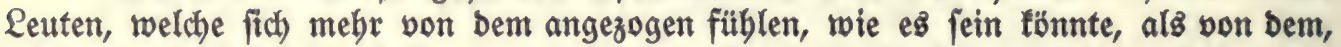
wie zu verrichten. 2lber wir bebürfen ibrer in erfter Linie und baju eines ungetrübten

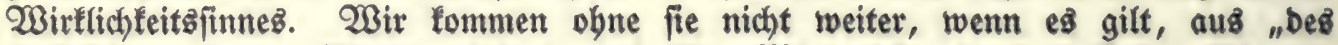

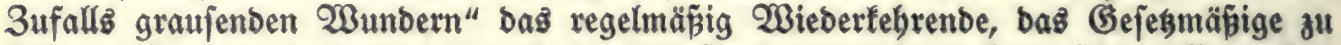
finben. (ç mag bequemer ober boch mindejtens angenebmer fein, feinen (Bebantenapparat pielen zu lafien, zmectbienlicher jobwerlich. Wie leicht verleitet bie Gotteg: gabe Phantafie gerabe an folchen Gebieten bazu, baj Gunbert Sabre vor ibm fino

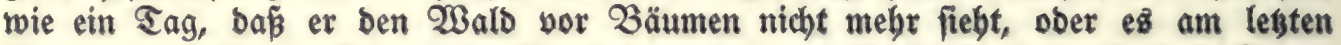

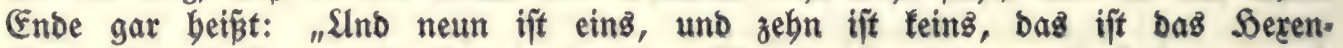

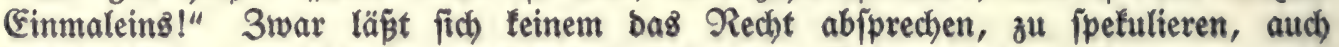

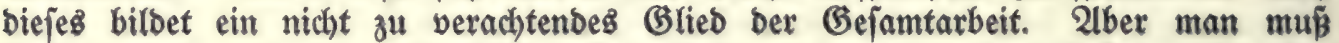
forbern, baj auch bie geiftreichiften Sypothejen immer nur Soypotbejen, nicht aber Q̈̈jungen bez Problems genannt werben. Wer Soypothejen aufitellt, mü fie zu beweifen fuchen und zeigen, Dap feine 21njd)autung beffer ben Satfachen entfpricht

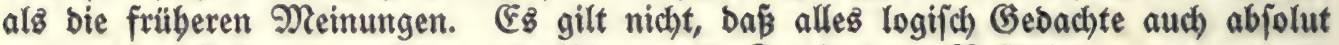

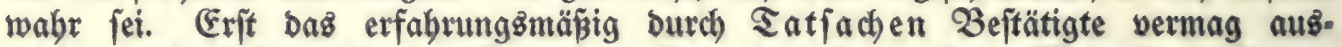
reichend fejte Pfeiler für Den Bedanfenaufbau abzugeben. Seber 2 Beiterbau erforbert immer wieber ein Nebr und ein Befferes folcher tatfächlichen Grundlagen. Gie allein leiften Gewähr für ben wabren Fortichritt. 
$-131-$

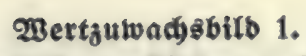

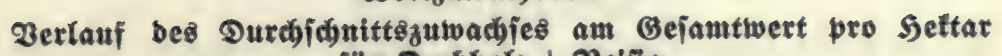
fiir Derbbolz + Retpis

von $\mathfrak{B}$ ude II. Bobenflaffe nach Dem $\mathfrak{B e r t v e r b a ̈ l t n i s , ~}$

bei vollem uno gelodertem Ghluß im oberen Rronentaum.

Die Rrelfe bezeid)nen auf Den Bilbern bie allterştufen, in benen bie Gtärte erreidht wirb, bis zu weldher bie Cinbeitswerte fiteigen wie bie Durdbmefier.

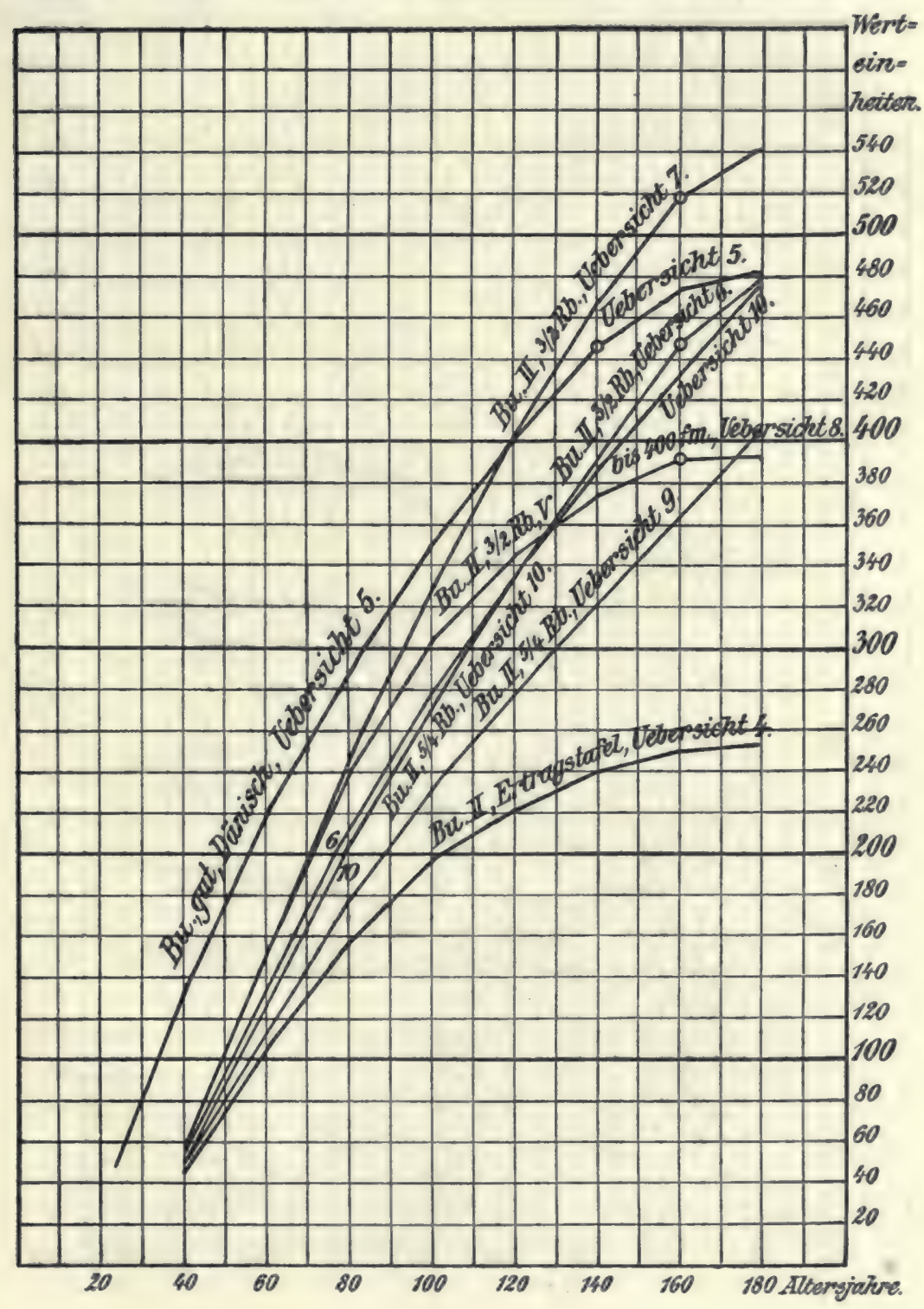

$9^{*}$ 
ஐertzutwachobtlo 2.

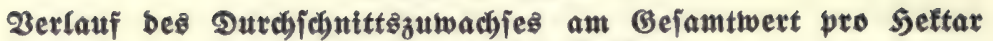
für Derbbols + Reiftg

auf III. Bobentlaffe von $\mathfrak{B} u$ d)e, Riefer unb gid te nad, bem 2 sertberbältnis, bei volfem uno gelodertem Gdhlü im oberen sronenraum.

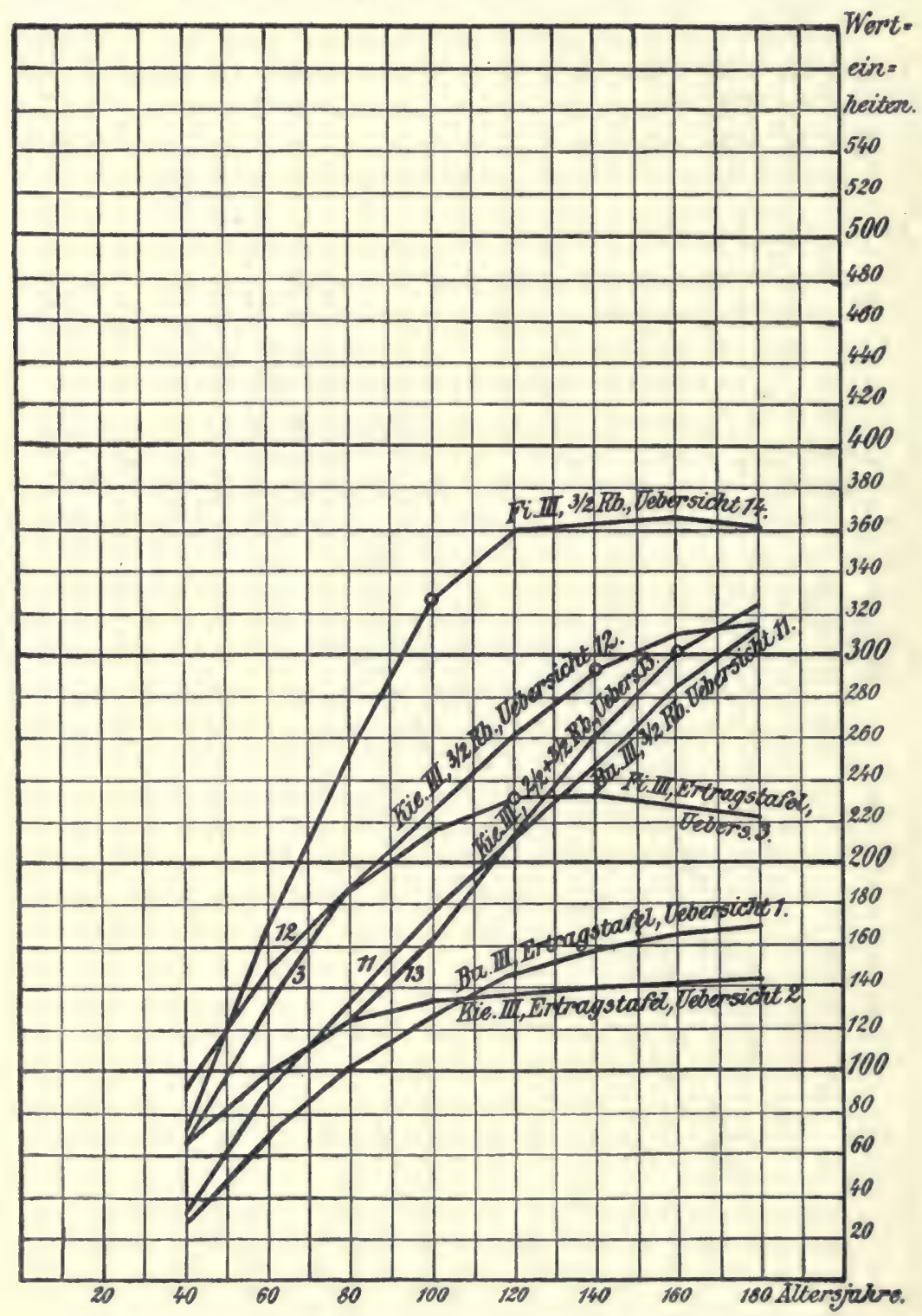


ஐBertzuwadj)bitb 3.

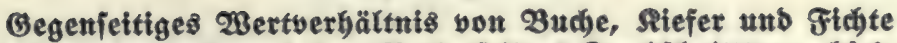

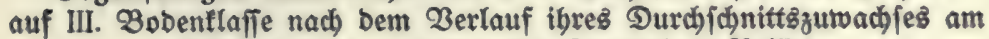
Bejamtwert pro Seltar fuir Derbholg + Reifig,

bei vollent unb gelodertem Gd)lǘ im oberen Rronentaum, in De a r nach ber gegenwärtigen Preizlage an ber Obertwejer.

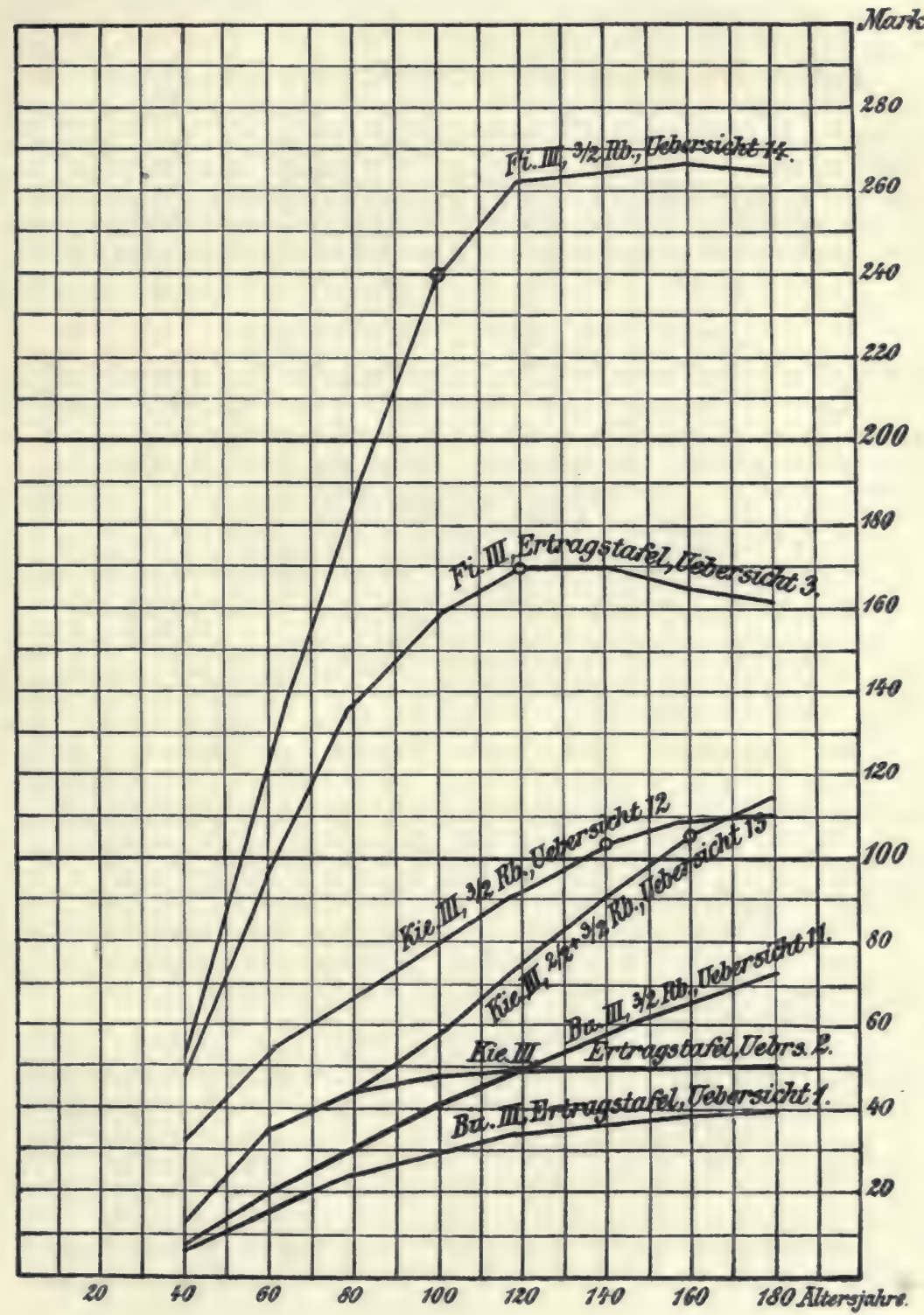





\section{Neumann, \\ Verlagsbuchbandlung 'für Candwirtschaft, Fischerei, Gartenbau, Forst. und Jagdwesen, \\ Neudamm.}

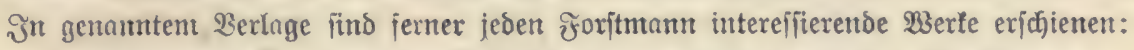

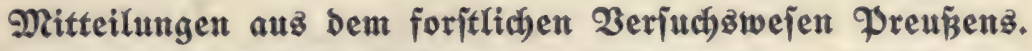

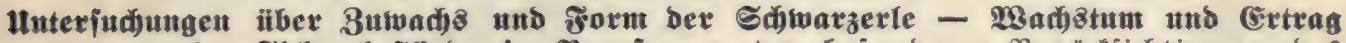

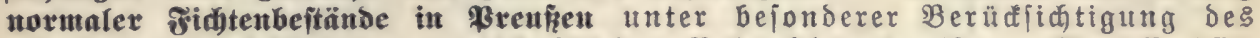
Einfluffes berfdiedener rirtidfaftlider Behandlungsmeifen. SBon Brofeffor Dr. 5diwappad, (5bersmalde. \$reis geheitet 3 Mif., gebunden 3 Mif. 50 Br.

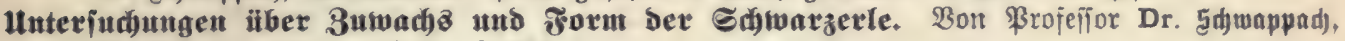
(5bersmalbe. \$reis geheftet 1 Mit.

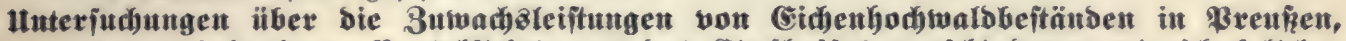

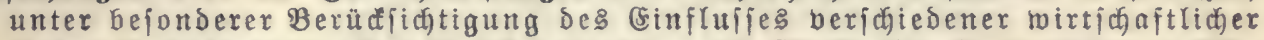

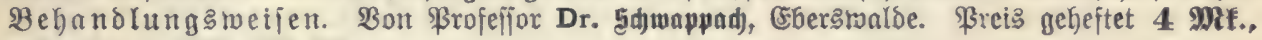
gefunden 4 Mrf. 50 Mf.

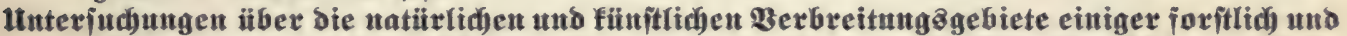
prianzengeographif widitigen golzarten in Norbs uno Mrittelocutidiand. Eriter Ieil: Die sorigontalverbreitung ber Riefer (Pinus gilvestris L.). Mit einer

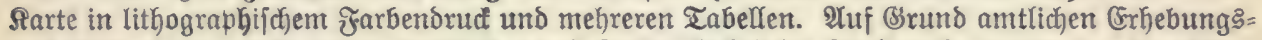

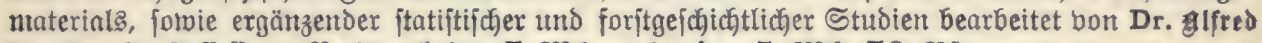
Bengler, Foritafiefior. \$reis geheftet 5 Mif., gebunden 5 MZf. 50 Bł.

\section{Empfeblenswerte forjtiche $\mathfrak{B e r f e . ~}$}

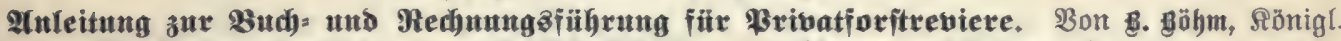
Dberföriter. Freis fartoniert 2 Mgf. 50 gif. Die hierzu gehörigen, fowie eine groß̈e Bahl jonjt überall eingeführter foritlider $\mathfrak{B} u$ d führungsformulare, zirfa 60 an

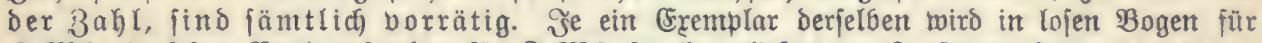
6 Mif., in feiten Bano gebunden für 9 Mif. franfo geliefert, an Foritbertwaltungen aud) zur

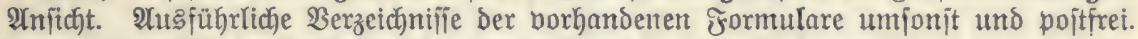

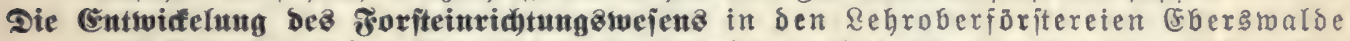

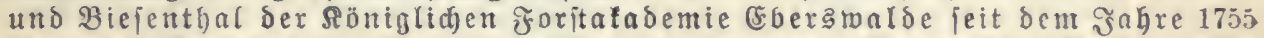
bis zur Begentrart. Bon Joritafiefior Dr. Borgmann, Ebersmalde. streis geheftet

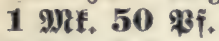

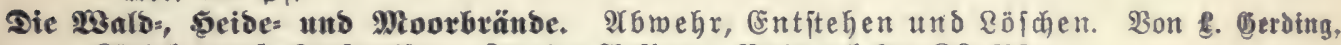

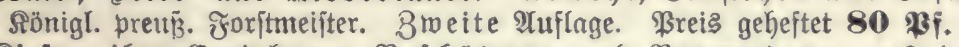

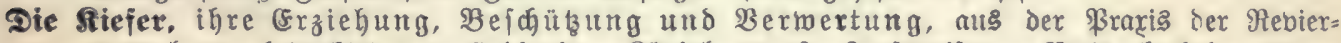
berwaltung betradjtet bon Godberien, Rönigh. pretis. đoritmeifter. Sreis hochelegant ge= bunben 6 Mif.

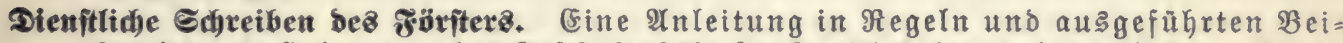

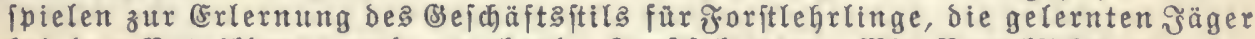
bet ben Bataillonen und angehende Forftefretäre. Drit Berüdfichtigung Der Minifterial= Exlaffe bom 20. Mai und 19. Juni 1896, bearbeitet und herauggegeben bon

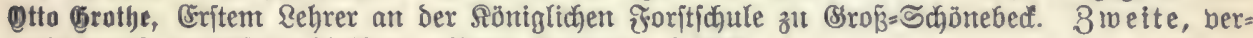

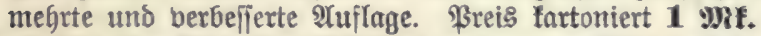

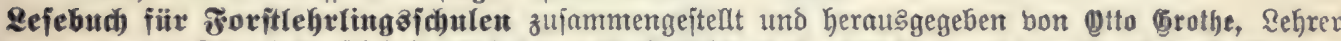

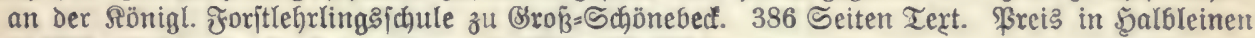
2 Mif., Beidentausgabe in Reinen 2 Mif. 50 :r.

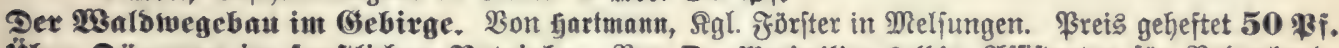

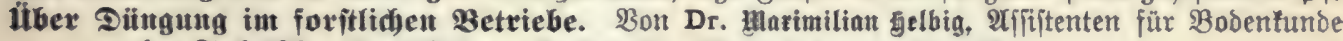

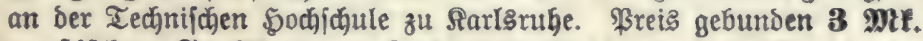

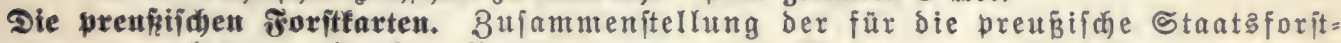
berwaltung geltenden Bejtimmungen über anfertigung, 2Ufbebahrung und Berjendung, fomie fortführung ber forftfarten. Wit zehn farbigen, lithographifden Doppeltafeln und einem Anbang über die Daritellung ber Ribellementsprofile und die Fubrung ber Sandriffe zu den Bermeffungsmanualen. Bon C. German, Sỏnigl. Dberförtter. Breis fein gebunden 6 Mat. 
Zabclfen zun Beitimuen ber widtigiten \$olzgetoüd) Des beutfaen cinigen ausländifacen angebauten (Sehölzen nach Brättern und Anolpen,

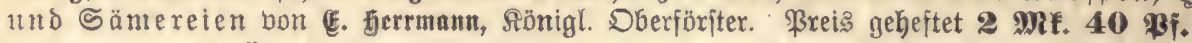

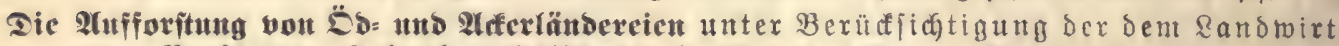

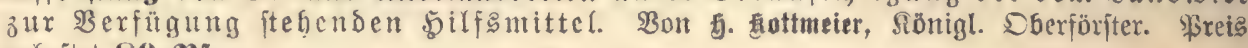
geheftet 80 Ri.

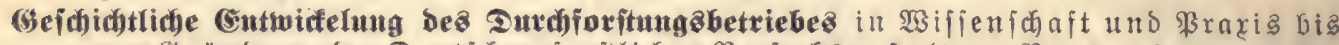

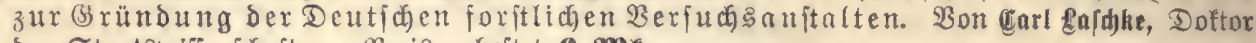
ber Stratsmiffenichaften. Breis geheftet 6 Mif.

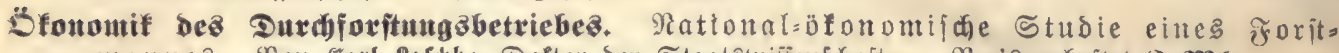

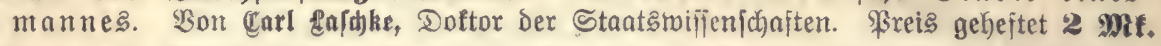

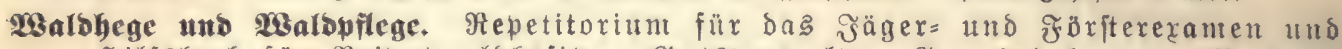

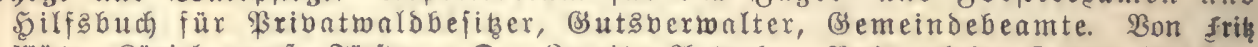

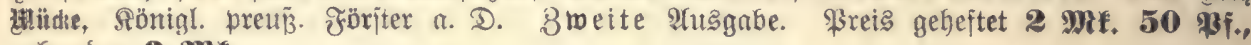
gebunden 3 Mif.

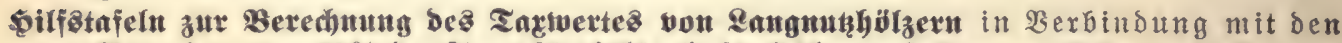

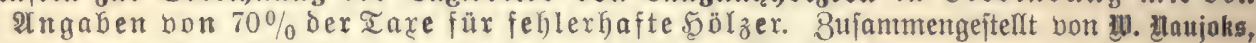

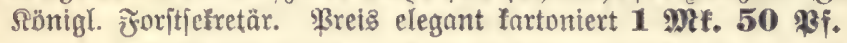

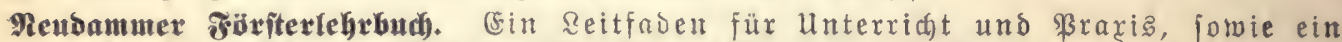

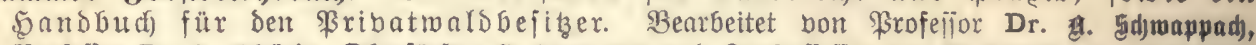

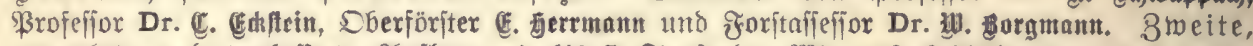
berntebrte unb berbefferte $\mathfrak{A}$ uffage, 4. big 7. Taufend. Mit 192 Abbilbungen und cinent

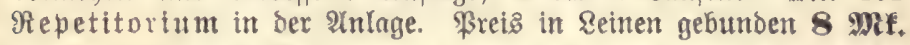

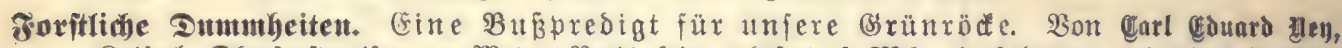
Ratferl. Dberforitmeifer zu Metz. Treis fein gefeftet 4 Mef., hochelegant gebunden 5 Mif.

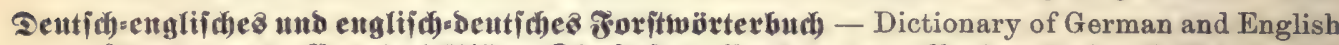

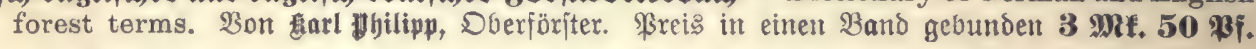

Foritlidbe Runbidau. Jahresüberficht über bie gefamte foritlid)e Biteratur Deutfdi)= Inude, Biterreid)

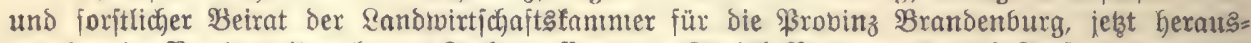

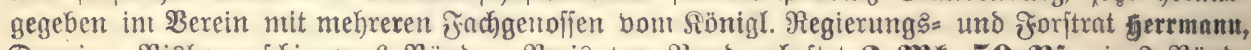
Danzig. Biaher erfohienen 6 Bände. Freis pro Band geheftet 2 Mgf. 50 Pf., je 2 Bände

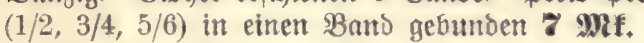

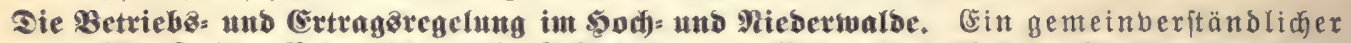

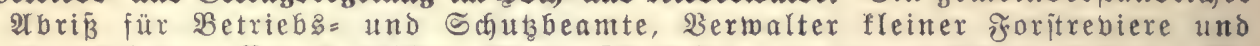

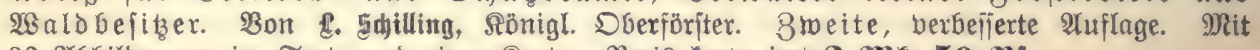

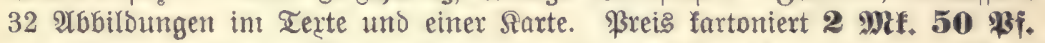

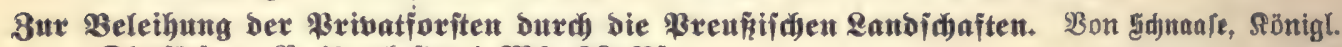

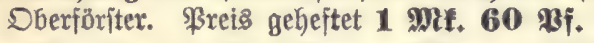

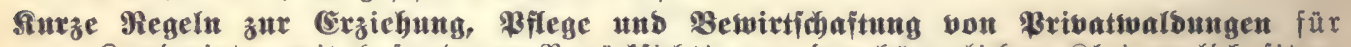
Sandwirte, mit bejonderer Berüfithtigung ber bäuerlichen Rleinmalobefiber. Bon kil. 5noenf, Rönigl. baber. Jroritwart. \$reis geheftet 1 Mrf.

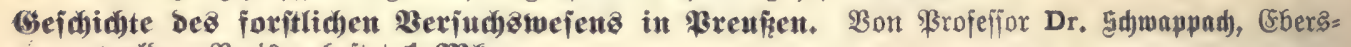
malse. \$reis gefeftet 1 Mif.

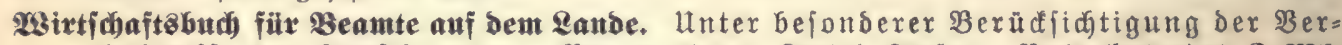

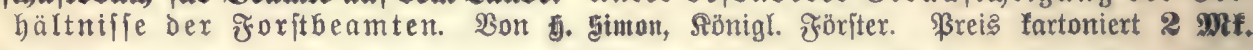

Die Ralbrente uns ibve nadbaltige Crhöhung. Bon Guttav Wagener, foritrat in ßenf. \$reis geheftet 10 Mit., fein gebunden 12 Mif.

Ratidlägc für ben 2ubau von :aub= unb Rabelbolz unter Berücfichtigung Dex Boden:

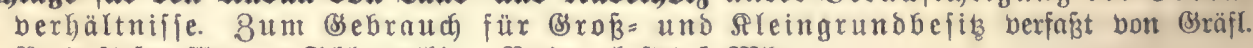

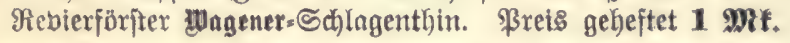




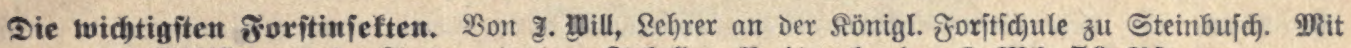

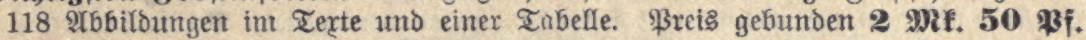

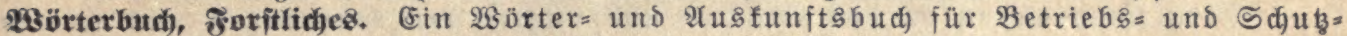

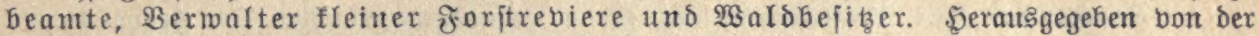

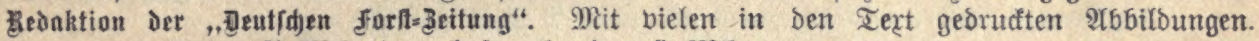
\$reis fein geheftet $\mathbf{5}$ MRt., bauerbaft gebunben 6 Mlf.

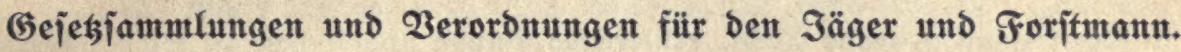

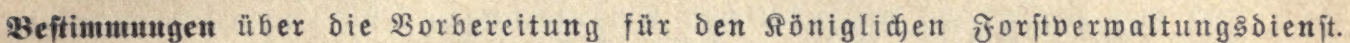
Som 25. Jamuar 1903. Skreis gebeftet 40 \$i.

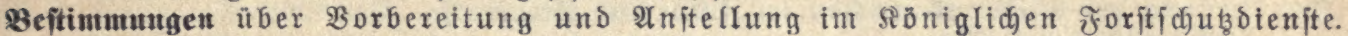
Bom 1. Dftober 1905. \$reis geheftet 60 \$í.

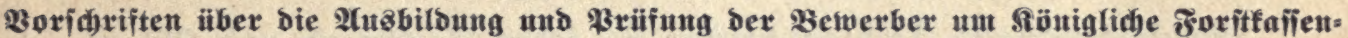
Rentanten-Stellen. Bont 12. Jebrutar 1904. Freis gehejtet 20 \$干.

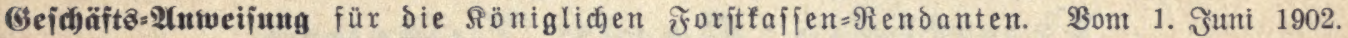
'Breis gebeftet 2 gif. 50 \$f.

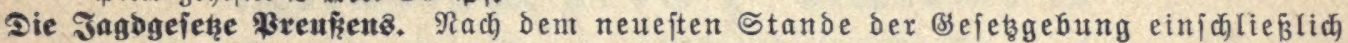

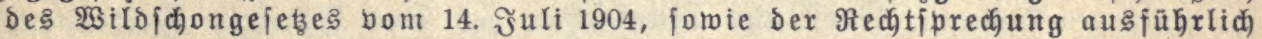

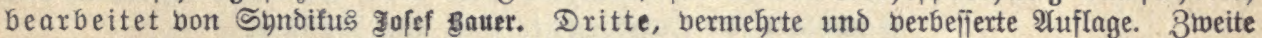

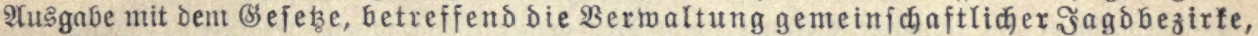

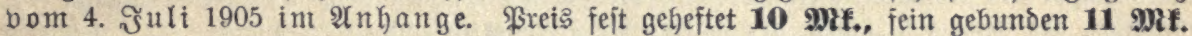

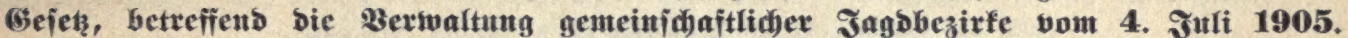

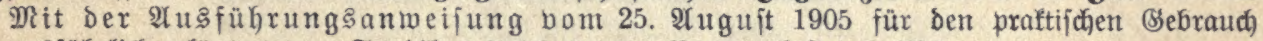

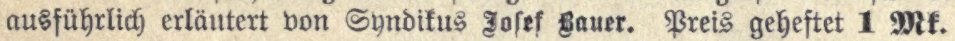

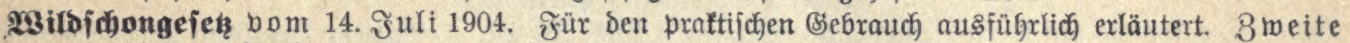

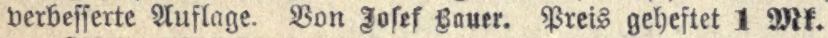

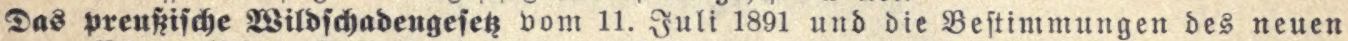

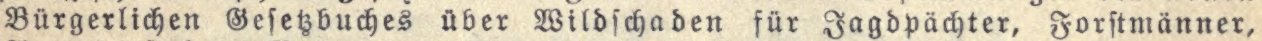

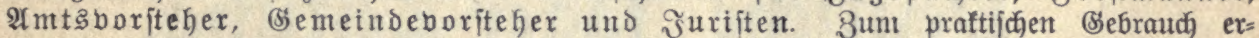

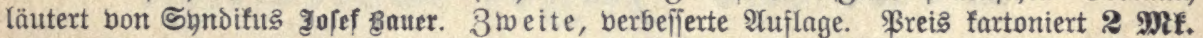

(5ejeh, betreffent ben Froxitbiebitahl, vom 15. April 1878. 8weite 2Urflage. Mit (5x=

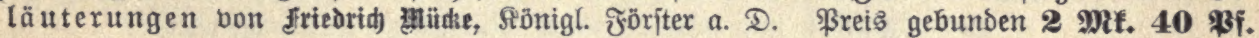

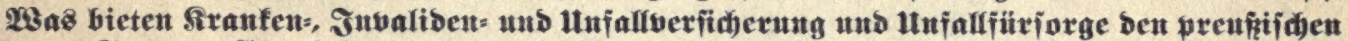

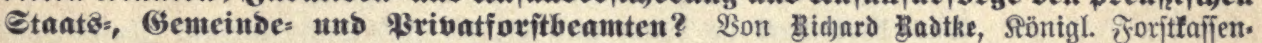
rendant. \$reis fartoniert 1 MR. 80 Bf.

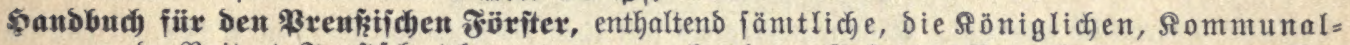

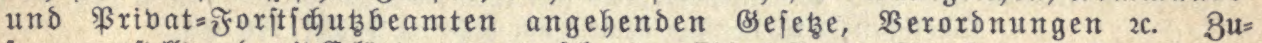

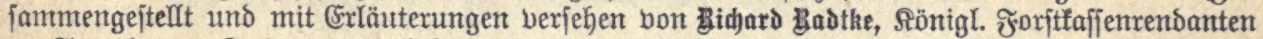

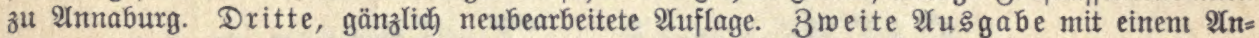
hang, enthaltend: Reue Beftimmungen über die Dienftländereinubung mit den Boridriften über bie $\mathfrak{A}$ แeinanberjezung bei Dienjtübergaben bom 11. 3. 1901,

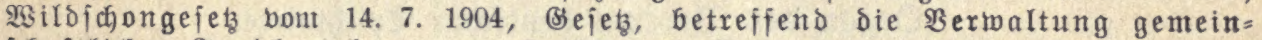
fdaftlicber §agbbezirfe, bom 4. 7. 1905 uno Bejtimmungen über 20 orbereitung

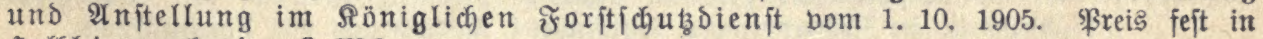
Salbleinen gebunben 6 Mrf.

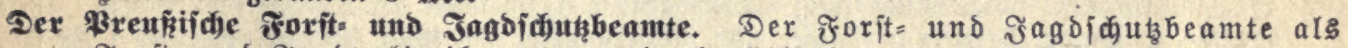

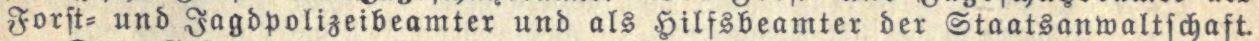

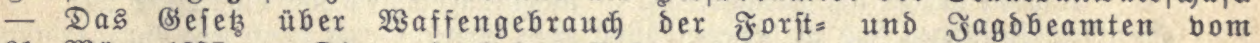
31. März 1837. - Die gefetzlidben Beftimmungen über bie Beftrafung ber

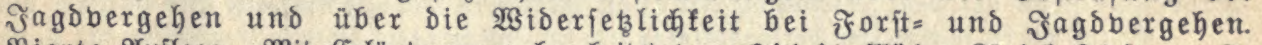

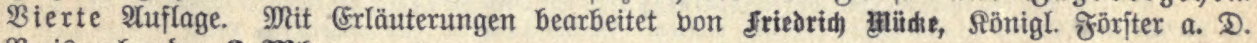
ßreis gebunden $\mathbf{3}$ Mtf. 


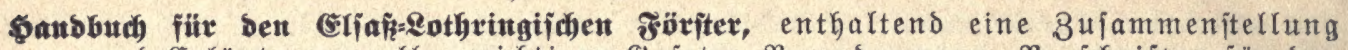
und Erläuterung aller michtigen bejez̧e, Serorbnungen, Borjchriften für den Foritidubbeamten in ben Staats= und ungeteilten Waldungen und in Den

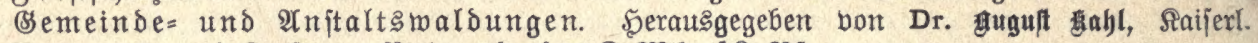

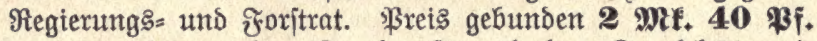

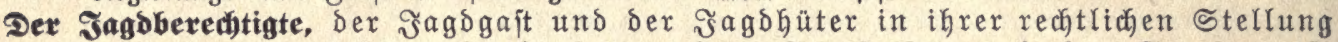

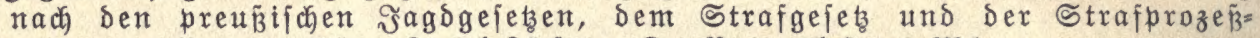

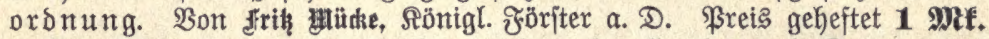

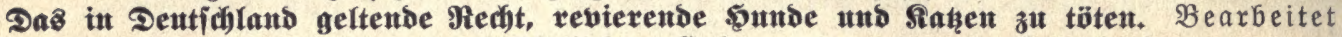
und mit zablreiden aubführlichen (srläuterungen und entichetoungen ber

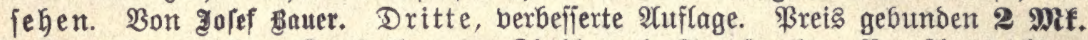

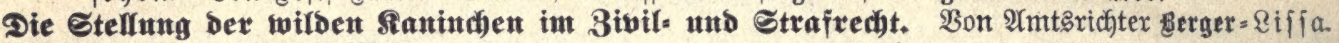
\$reis gebunten 3 Mif.

Empfehlenswerte Fachzeitichriften fïr jeden Forjtmann und Säger:

\section{Deutlohe forlt-Zeitung.}

Mit Den Beilagen: Forjtliche Rutbichau uno Dez Föriterz Feierabende.

Fachblatt fïr Foritbeamte uno 2 albbeiner.

Hmtliches Organ des Brandversicherungsvereins Preussischer Forstbeamten, des Uereins Rönigl. Preussischer Forstbeamten, des Vereins Waldheil, des Vereins für Privatforstbeamte Deutschlands, des Forstwaisenvereins und des Vereins Ferzoglich Sachsen=Meiningischer Forstwarte.

Şerausgegeben unter Mitwirfung herborragender froritmänner.

(Exidfeint wöctentlich Sonntage.

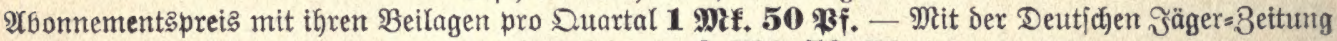
gemeinjant bezogen 3 Mif. 50 \$ץ.

\section{Deutlche Jäger-Zeitung.}

Organ für Sagd, Gdhieß̄wejen, Fił Seraugsgegeben und rebigiert unter Mitwirfung herborragender

Seiomänner, \$utbefenner und Raturforjcher.

Mit ben Beilagen: Das Dåz Secfele. Bereins:-3eitung *

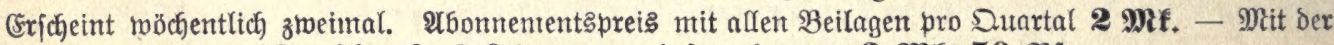
Deutichen frorjt=8eitung gemeinjam bezogen $\mathbf{3}$ Mif. 50 タ̧.

\section{fílcherei - Zeitung.}

\section{Drgan Deళ Zereinz Deutjaher Seichwirte.}

Wochenschrift für die Interessen der gesamten deutschen Fischerei, Fischzucht und (eichwirtschaft, des Fisch)andels, der Fisd)verwertung, Sportfischerei, Zierfischzucht und Hquarienkunde.

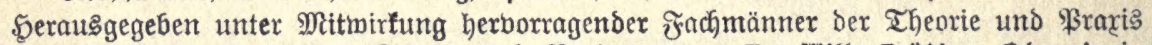

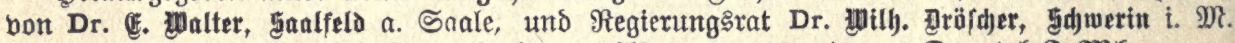

(Ericheint mödjentlicf Sonnabends. - 216onnententspreis pro Duturtal $\mathbf{2}$ Mif.

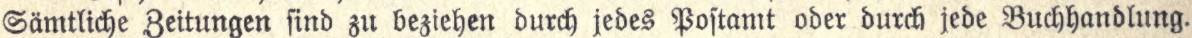

Probenummern ber brei 3 eitungen mit alfen $\mathbf{B e i l a g e n ~ w e r b e n ~ u m i o n i t ~ u n b ~ p o i t f r e i ~ g e l i e f e r t . ~}$

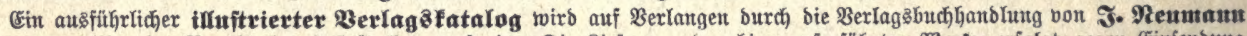

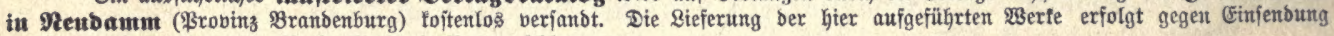
bes Betrages franto, unter 9achnabme mit \$ortozuichlag. 


\section{LIBRARY}

\section{UNIVERSITY OF TORONTO}

SD

553

$\mathrm{M} 43$

1906
Michaelis

Die Betriebsregulierung in den Preussischen

Staatsforsten

Biomed

PLEASE DO NOT REMOVE

CARDS OR SLIPS FROM THIS POCKET

UNIVERSITY OF TORONTO LIBRARY 
